\title{
The Potential for Clustering of the Maritime Transport Sector in the Greater Dublin Region
}

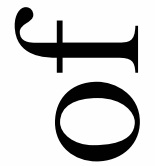

(1) ob

(1)

Fra

$\square$

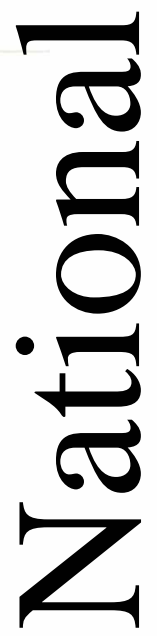

\section{NORAR SMURHI HBRAR \\ NATONAL COLLEGE \\ OSPRELAND}

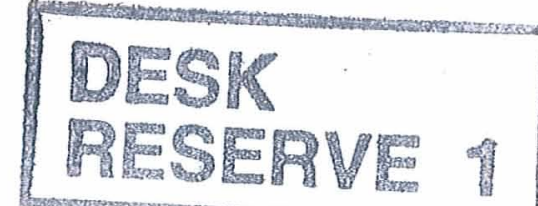

Valerie Brett BSc (Hons), MSc

Supervisor: Prof. Michael Roe BA (Hons), MSc, PhD

National College of Ireland

Submitted to the Higher Education and Training Awards Council, October, 2007 
This project (Grant-Aid Agreement No. PHD/IMDO/04) is carried out with the support of the Marine Institute and the Marine RTDI Measure, Productive Sector Operational Programme, National Development Plan 2000 - 2006.

YOUR PLAN - YOUR FUTURE
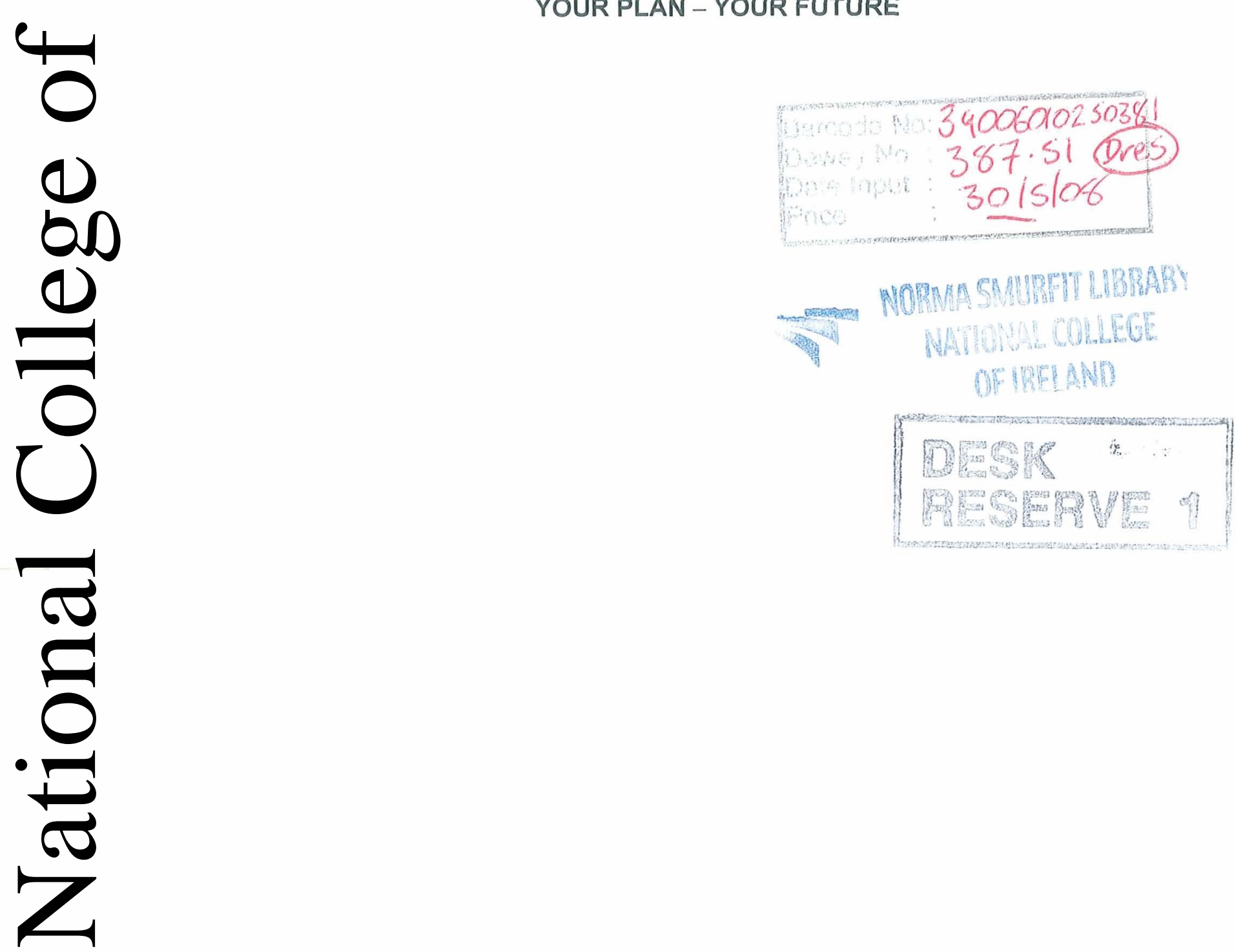
I Valerie Brett, declare that this thesis is submitted by me in partial fulfilment of the requirement for the degree of Doctor of Philosophy, is entirely my own work except where otherwise accredited. It has not at any time either whole or in part been submitted for any other educational award.

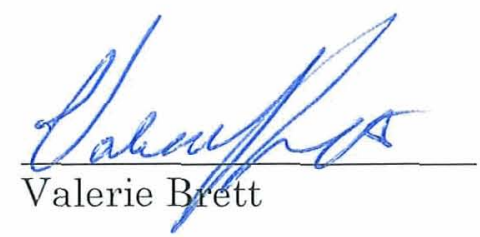

We have passed the knowledge, skill and competence of the candidate Valerie Brett by way of viva voce examination using the thesis, submitted in partial fulfillment of the requirements of the degree of Doctor of Philosophy, as evidence, and find that it meets with the standard determined by the Higher Education and Training Awards Council. We recommend that the degree be awarded.

Examiners' Signature [Internal]

Examiners' Signature [External] 


\section{Acknowledgements}

The first person I would like to thank and acknowledge is my supervisor Prof. Michael Roe. Thank you for your years of supervision, guidance and encouragement. I don't believe I could have accomplished or survived this process without your support along the way. Thank you for being you and being there. After years of supervision and consistently correcting my grammar and spelling I believe at this point Michael we are friends.

I would like to thank the Marine Institute, the NDP and everyone at the IMDO for their support and the opportunity to undertake this $\mathrm{PhD}$.

Very special thanks to my friend Victoria who I have only one thing to say; "one day Victoria, one day .................."

I would like to thank Ann Fogarty for all her visits and chats; they kept me happy and sometimes even alive. If it were not for you Ann, I would have no idea what I would do with my life.

To Sinead Hennessey and Ann Power for being my friends. It is precious.

To Orla, looking forward to the next couple of months with you is perhaps the only thing that kept me going over the last few months. I am glad and grateful we are going together.

A special thanks to Frank Flynn, who probably has no idea why, but I do, and that's enough. Cheers Frank!

A special thanks to the researchers Teresa Hurley, David Joyce and Michael Coleman. A special thanks to Sabine Moebs for all your help and formatting skills.

I would like to thank everyone at NCI who helped along the way but especially Nicola Carroll, Eamon Jordan, Brendan MacPartlin, the library staff, IT and finance.

I would like to thank Mark for spending the last three years having no idea what I have been doing. Lots of love.

Thanks to the Killers for Mr. Brightside, the Twang for Either Way, and the 10 minute version of Dire Straits Romeo and Juliet on YouTube.

To my Mum and Dad and all my friends and family, kind regards to you all

$\operatorname{xxxx}$

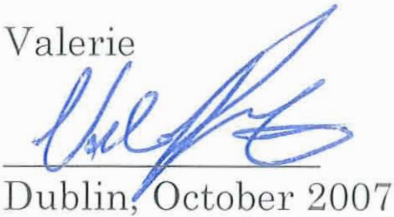




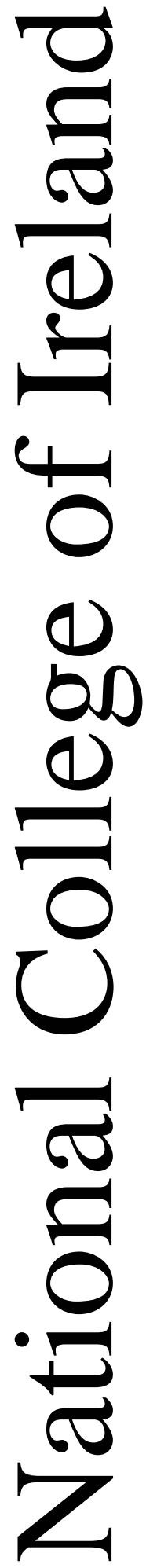

"Truth is a matter of the imagination. The soundest fact may fail or prevail in the style of its telling: like that singular organic jewel of our seas, which grows brighter as one woman wears it and, worn by another, dulls and goes to dust. Facts are no more solid, coherent, round, and real than pearls are."

(LeGuin, 1969) 


\begin{abstract}
A cluster of industry is an economic occurrence that provides a particular industry with a distinct, and sometimes global, competitive advantage. A cluster infers a level of critical mass in terms of firms, industry players, employment, active business relationships, innovation, knowledge development and an economic contribution to a domestic economy. Maritime clusters are industries that are usually located at, or were originally centred on, the trading activities of a port. Some of the world's major maritime clusters include the clusters of Rotterdam, Singapore and London.

Ireland is an island nation on the periphery of Europe and therefore requires the facilities to accommodate the trade of commodities. The country's principle port lies in the Greater Dublin Region (GDR) and therefore there is some level of maritime transport activity. Also, the critical mass of maritime and maritime transport related firms lies in the GDR. Therefore, it is known that there is some level of maritime transport clustering. In the context of the requirement of an island for transport facilities, and the concept that there are far more smaller potential maritime clusters like Dublin than there are major maritime clusters like Rotterdam - "what is the potential for the clustering of the maritime transport sector in the greater Dublin region?"

Governments or policy makers wishing to create a cluster, or to enhance the clustering potential of an industry: will attempt to mimic the behaviour of major successful clusters. Clusters are complex systems. Basically, all clusters are different: therefore, an economic formula devised from the observation of any successful cluster will not guarantee success. However this does not imply that a smaller cluster can not improve its clustering potential in some way. The current research was facilitated by experts from GDR maritime transport industry, through the application of the Delphi Method. A consensus on key clustering-enhancing characteristics, derived from four economic theories that conceptualize clustering and competitive advantage provided the framework for the current research. The consensus
\end{abstract}


achieved will help build knowledge and understanding of potential clustering of the maritime transport sector in the GDR.

Keywords: Maritime, Clusters, Ports, Economic Development, City, Delphi.

Title: The Potential for Clustering of the Maritime Transport Sector in the Greater Dublin Region

Author: Valerie Brett
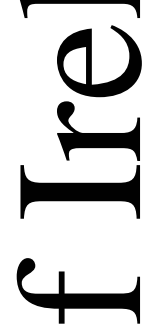

$\longrightarrow$

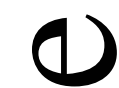

on

(1)

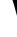

$r$

$\longrightarrow$

厂

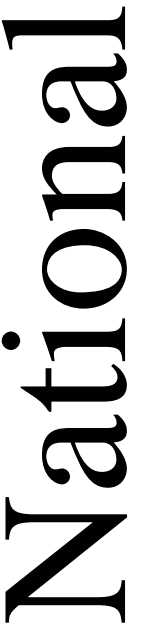


Table of Contents

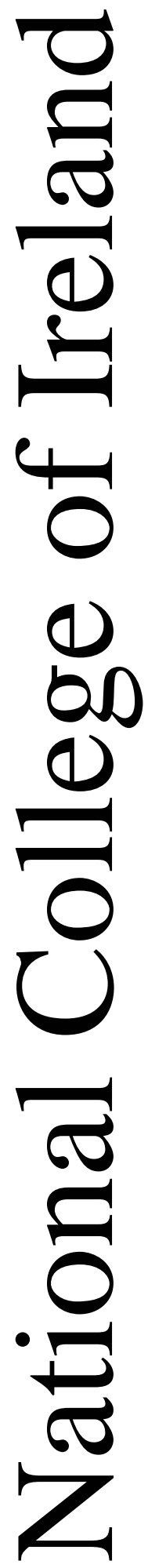

Chapter 1. Introduction................................................................................................ 1

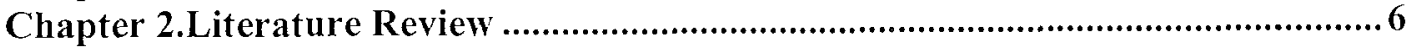

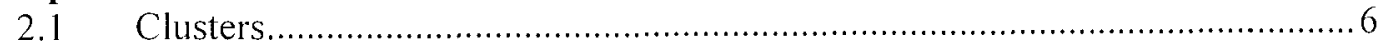

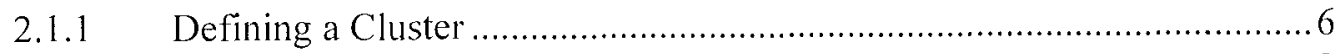

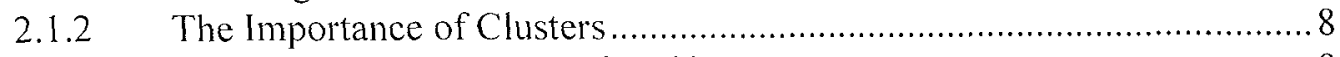

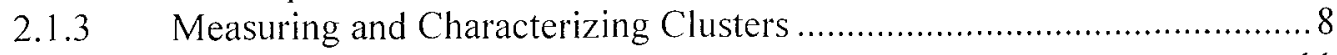

2.1.4 Proximity and Skills .................................................................... 11

2.1.5 Innovation, Co-ordination, Co-operation and Competition ................... 13

2.1.6 Clusters and Policies ..................................................................... 15

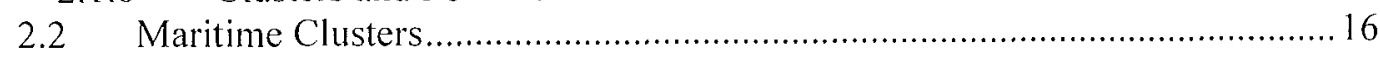

2.2.1 London Maritime Service Cluster .................................................... 17

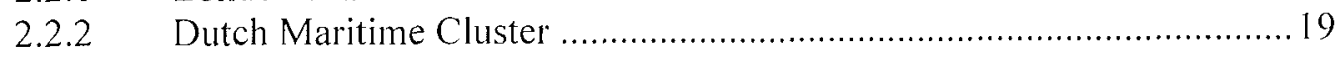

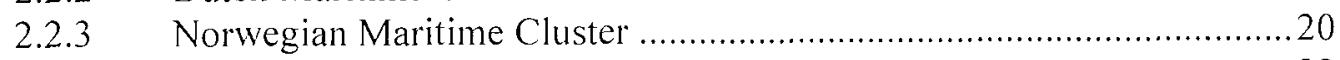

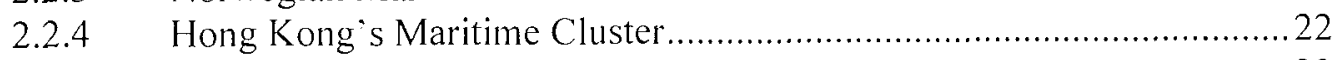

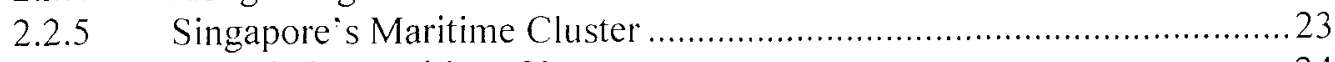

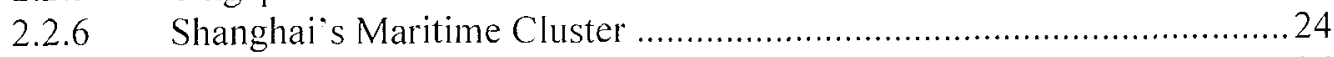

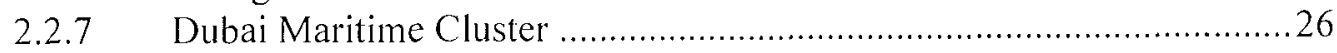

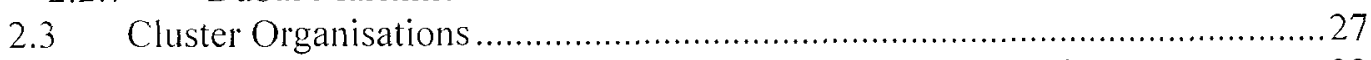

2.4 Clusters and Maritime Policy within a European Framework ….....................32

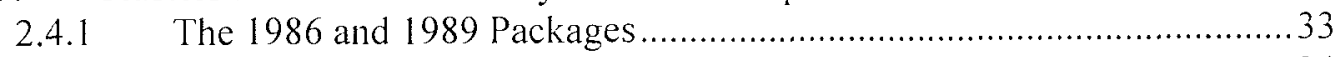

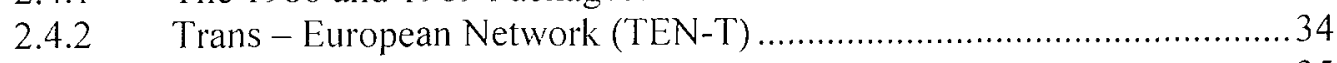

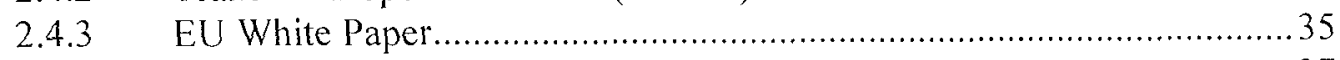

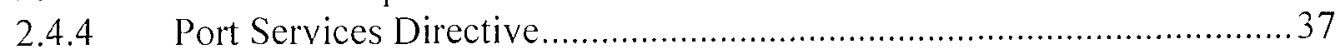

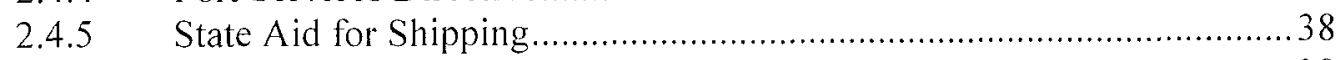

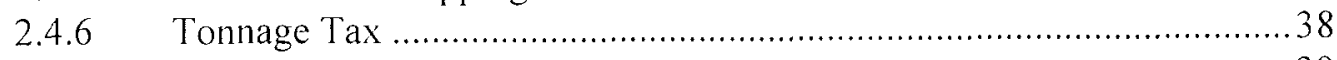

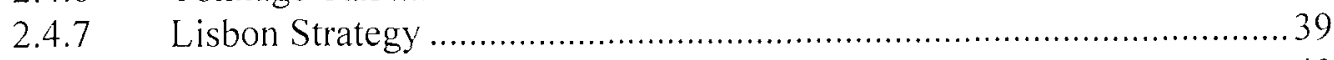

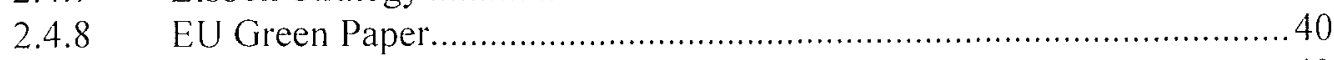

2.5 Ireland, Maritime Industry, Clusters and Policies.................................... 43

Chapter 3.Cluster Structure Cluster Governance ...................................................55

3.1 Agglomeration Economics / New Economic Geography …..........................50

3.1.1 Labour Supply ......................................................................... 5

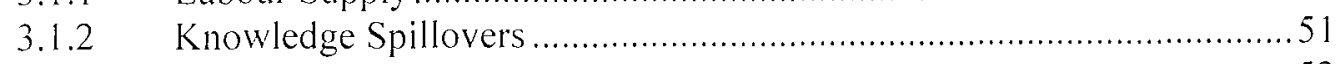

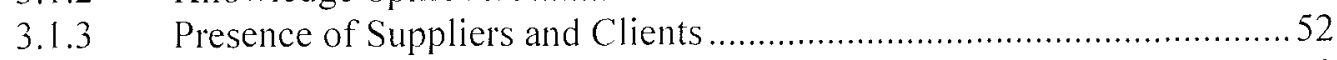

3.2 Competitiveness Theory - Porter's Diamond Model ...................................5 53

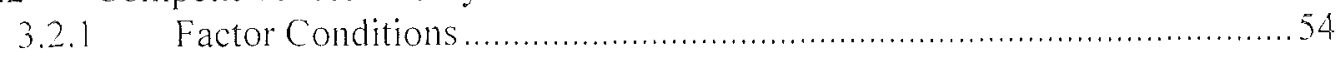

3.2.2 Demand Conditions.............................................................. 54

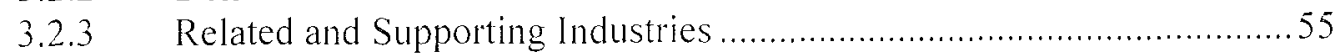

3.2.4 Firm Strategy, Structure and Rivalry .................................................55

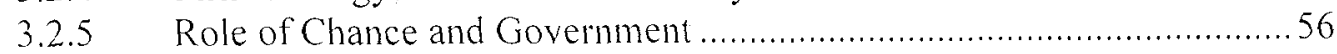

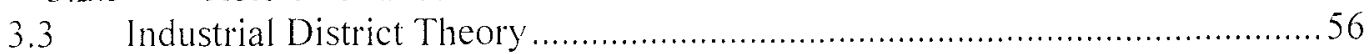

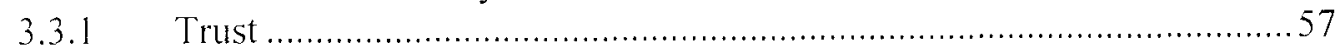

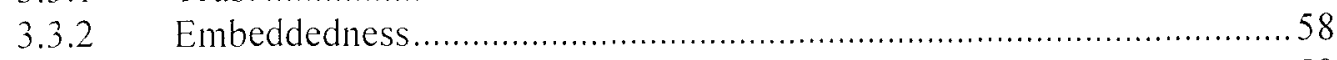

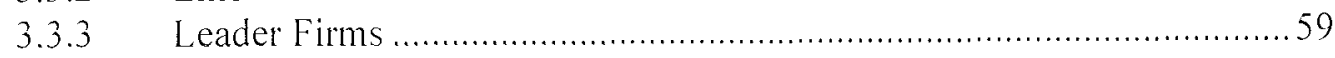

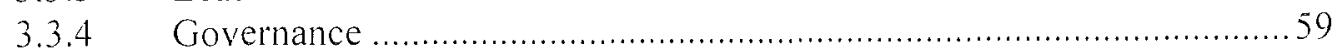

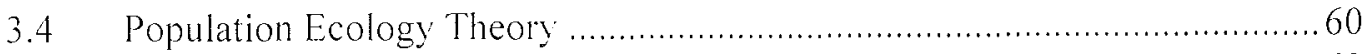

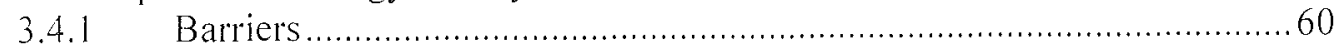

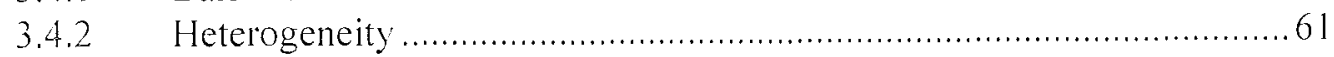

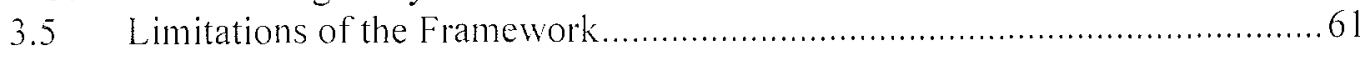


Chapter 4.Cluster Mapping and Sectors …...............................................................6.6. 64

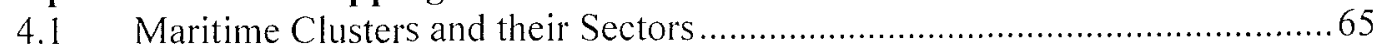

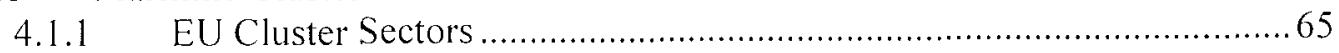

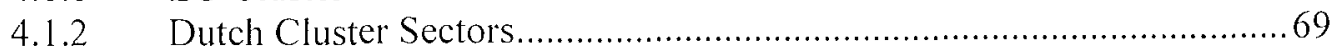

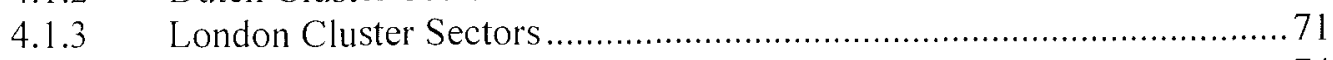

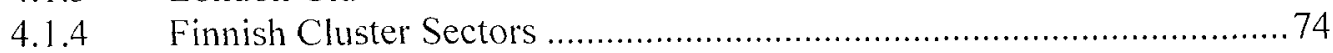

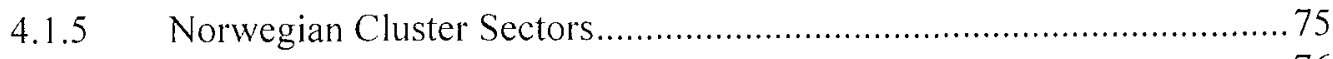

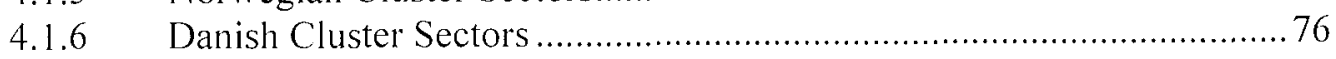

4.1.7 Hong Kong Cluster Sectors........................................................... 77

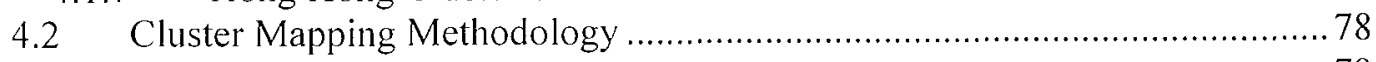

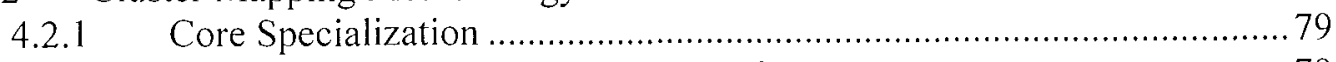

4.2.2 Greater Dublin Region (GDR) Boundary .......................................... 79

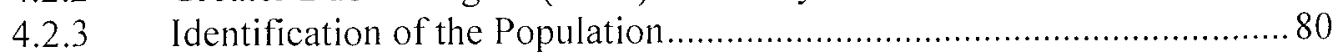

4.2.4 Identification of the Relevant Sectors ............................................... 81

Chapter 5.Methodology Selection and Discussion ...................................................8 84

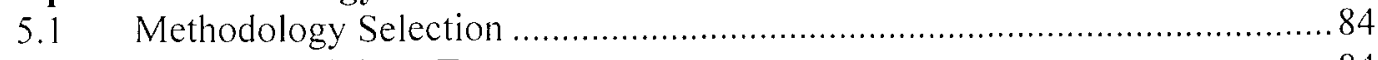

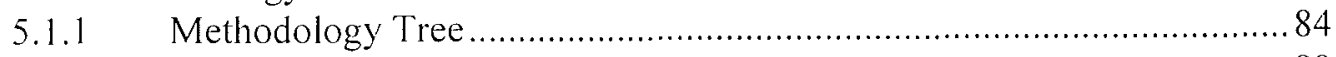

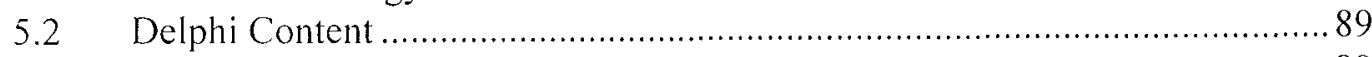

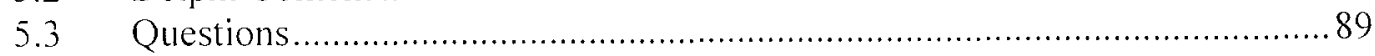

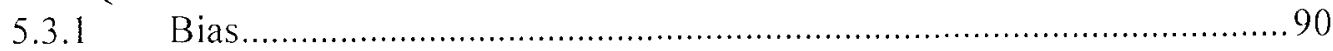

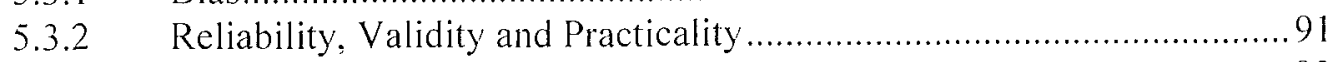

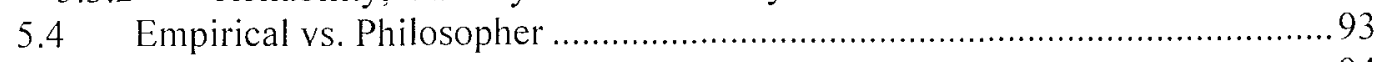

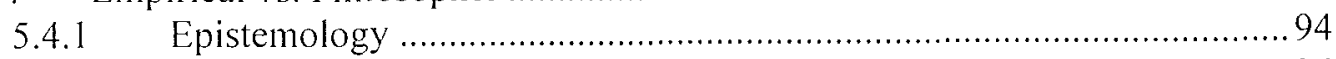

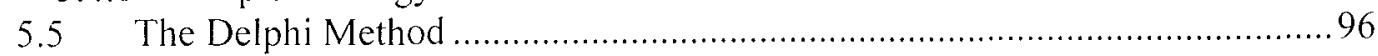

5.5.1 Definition of the Delphi Method ......................................................... 98

5.5.2 The Objectives of the Delphi Method ................................................... 98

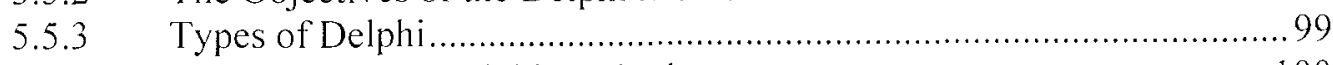

$5.6 \quad$ Characteristics of the Delphi Method ….............................................. 100

5.6.1 Expert Panel .............................................................................. 100

5.6.2 Control Opinion Feedback ........................................................ 102

5.6.3 Anonymity of Panel Member's ...................................................... 104

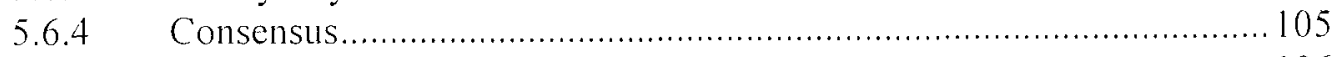

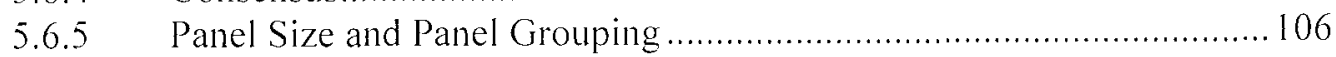

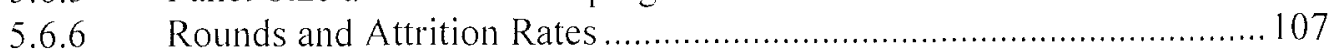

5.7 The Effectiveness, Reliability and Validity of Delphi .............................. 108

5.7.1 Justification for using the Delphi Method...................................... 111

5.7.2 Comparing Delphi with other Methods ........................................ 112

Chapter 6.GDR Maritime Transport Delphi....................................................... 115

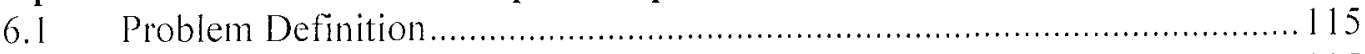

6.1.1 Framework for Questions......................................................... 115

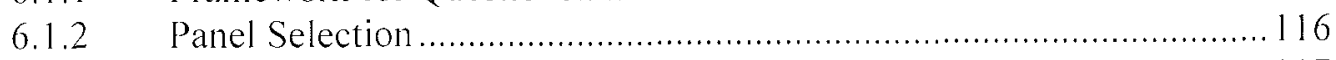

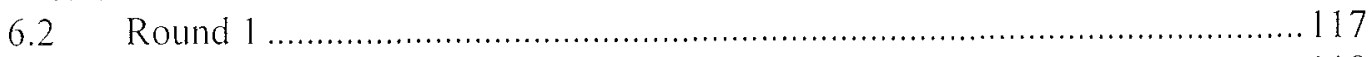

6.2.1 Development of Delphi Round 1 Questionnaire .............................. 118

6.2.2 Breakdown of Delphi Round I Questionnaire ............................... 120

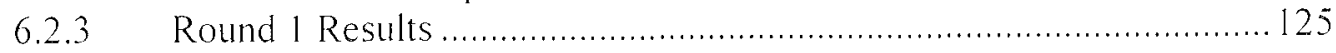

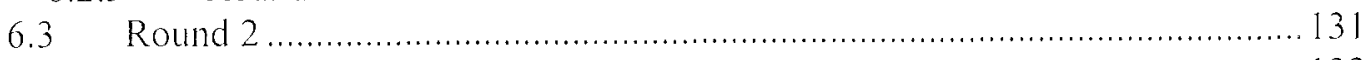

6.3.1 Development of Round 2 Questionnaire ...................................... 132

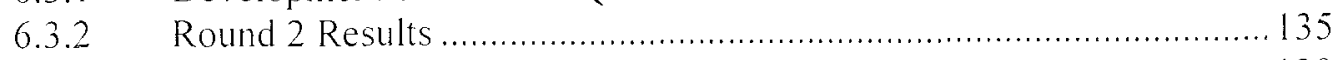

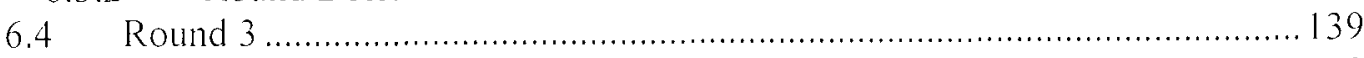

6.4.1 Development of Round 3 Questionnaire ................................... 139 


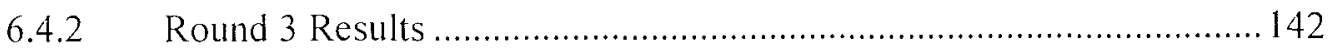

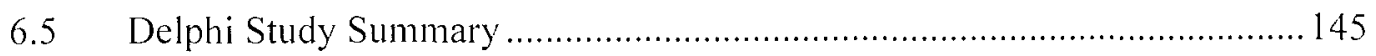

Chapter 7.GDR Maritime Transport Delphi Results ..............................................147

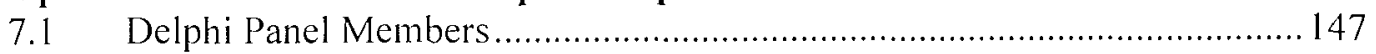

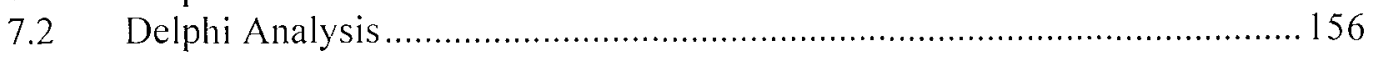

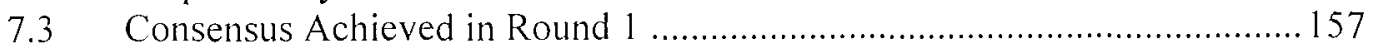

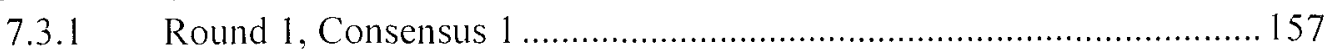

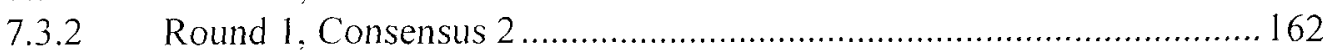

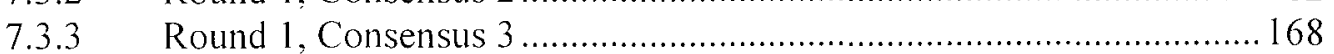

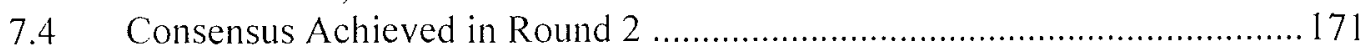

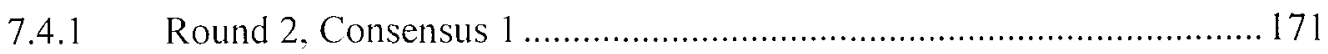

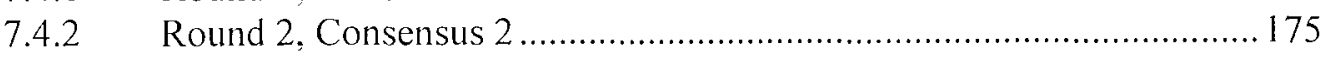

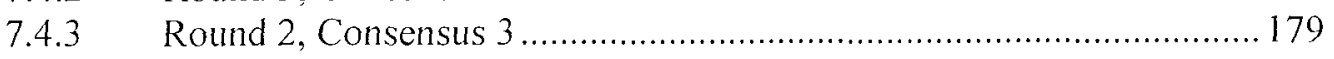

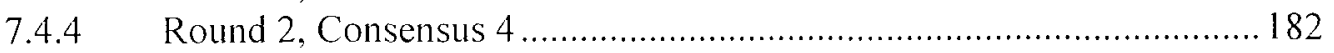

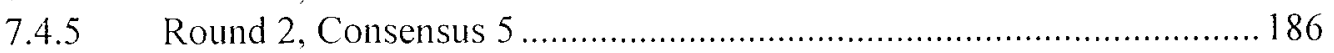

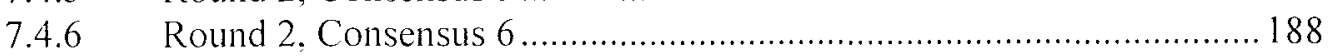

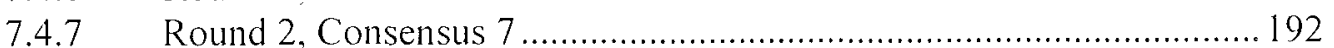

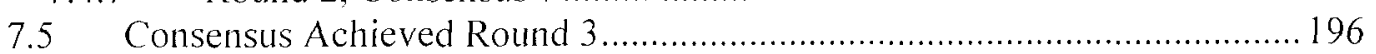

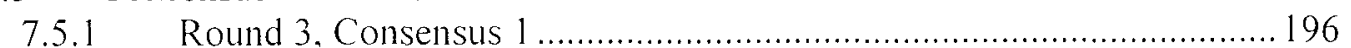

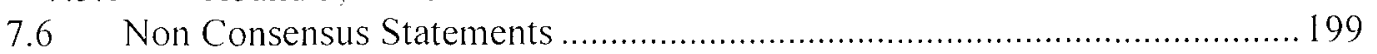

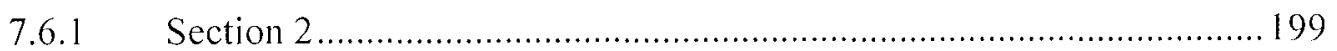

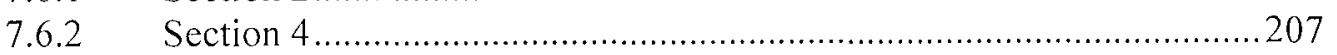

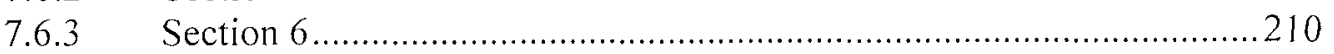

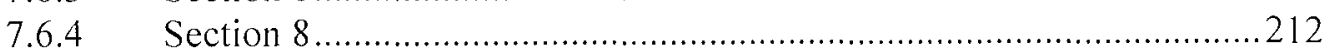

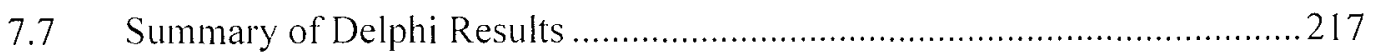

7.7.1 Analysis of Delphi Consensus per Section ......................................218

7.7.2 Concluding Remarks ...................................................................2 219

Chapter 8. ... A Maritime Cluster or a Consequence of Co-location of Capital City and Principle Port? ...................................................................................................228

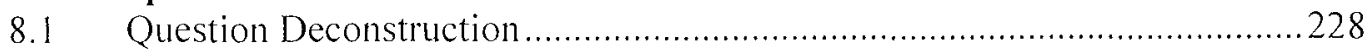

8.2 The Difference between a Seaport and a Maritime Transport Cluster...........229

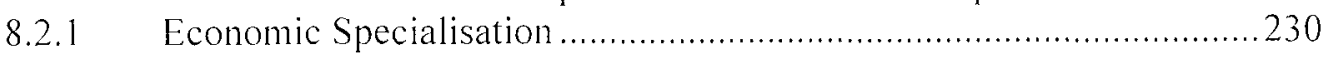

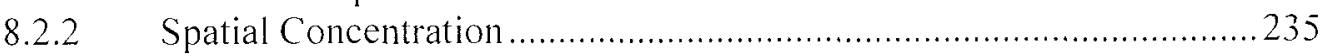

8.2.3 Mutually Related Firms..............................................................2239

8.3 The Evidence/Argument for and against that the GDR Maritime Transport

Sector as a Maritime Transport Cluster. ............................................................2.24

8.3.1 The Argument for the GDR as a Maritime Transport Cluster .............242

8.3.2 The Argument against the GDR as a Maritime Transport Cluster....... 246

8.4 The GDR Maritime Sector as a Port Cluster with Capital City Supporting

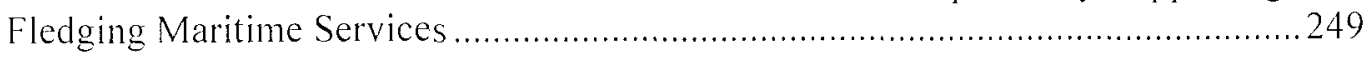

8.4.1 The Importance of Cities and Dublin City .......................................2 249

8.4.2 The Role of the Port in the Making of Major Cities and Clusters .......251

8.4.3 The Relationship between Cities, Ports and Maritime Clusters...........254

8.4.4 Importance of Understanding Port. City and Cluster.........................254

Chapter 9.Conclusions .....................................................................................257

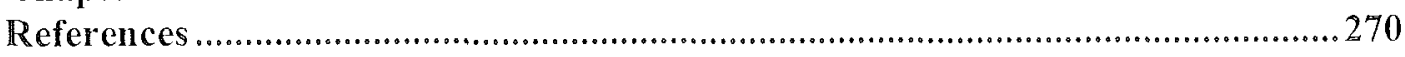

\section{Appendices}

Appendix 1: Dublin Port and Drogheda Port Statistics.............................2295

Appendix 2: Bremore Deepwater Port Development...............................2297 
Appendix 3: NACE Classification..........................................298

Appendix 4: Round I Appreciation Letter.......................................300

Appendix 5: Delphi Round I Questionnaire..................................... 301

Appendix 6: Delphi Panel Member Information Document........................ 312

Appendix 7: Delphi Round 2 Questionnaire.................................... 314

Appendix 8: Delphi Round 3 Questionnaire...................................328

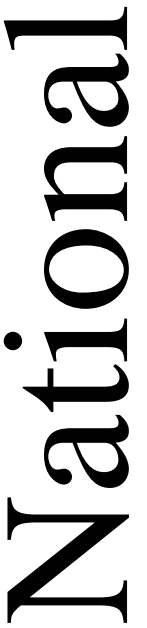


List of Figures

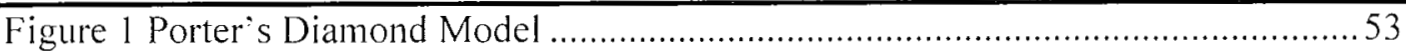

Figure 2 Tentative Classification of the Maritime Economy …......................................6 68

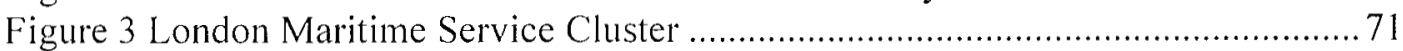

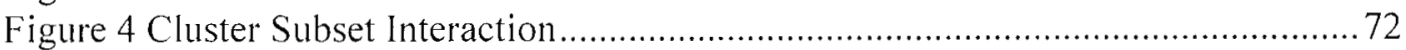

Figure 5 Shipbuilding Cluster Relationship with Sub-Sectors ...................................75

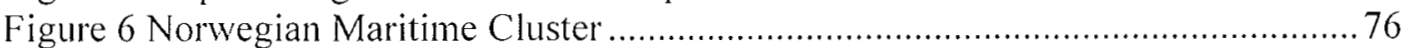

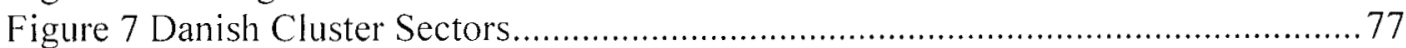

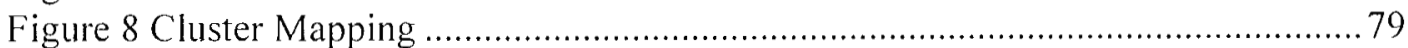

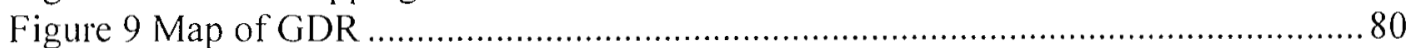

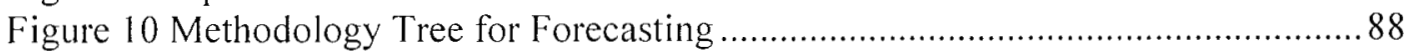

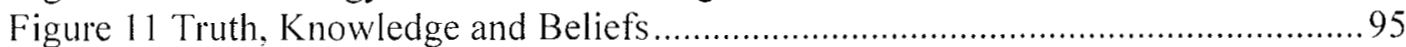

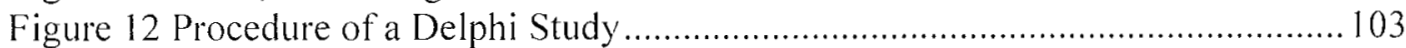

Figure 13 Delphi Model Development Round 1 ...................................................... 119

Figure 14 Delphi Model Development Round 2 ................................................... 134

Figure 15 Delphi Model Development Round 3 ................................................... 141

Figure 16 Interrelationship in the Dublin Maritime Cluster ......................................2234 
List of Tables

Table 1 Capacity Shortfalls Identified for 2014 as per 2004 Updated Assessment of Commercial Seaport Capacity

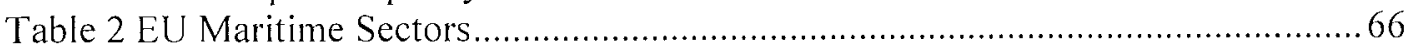

Table 3 Dutch Maritime Cluster Sectors........................................................................ 70

Table 4 London Maritime Service Cluster Sectors ........................................................ 71

Table 5 Sea Vision Description of UK Maritime Sectors ...............................................73

Table 6 Hong Kong Maritime Cluster Illustration of Sectors and Activities ................. 78

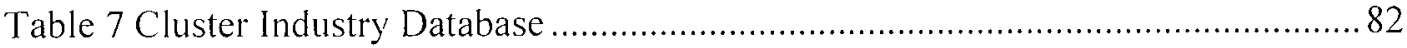

Table 8 Taxonomy of Delphi Inquiry Designs ........................................................ 100

Table 9 Frequency of Delphi Studies Published over the Period from 1995 to 2004 ... 110

Table 10 Comparison of Delphi with Traditional Surveys ..........................................113

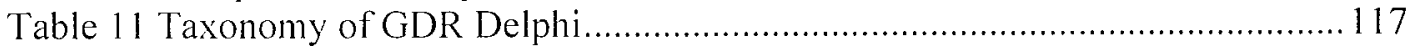

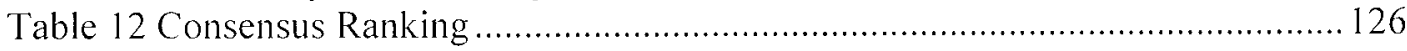

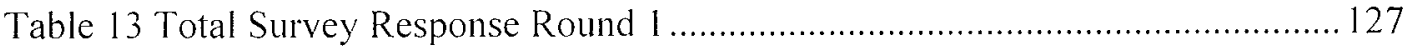

Table 14 Delphi Round 1 Graph Display Results .................................................... 128

Table 15 Total Response Survey Round 2 ........................................................ 135

Table 16 Delphi Round 2 Graph Display Result .................................................. 136

Table 17 Total Response Survey Round 3 ........................................................... 142

Table 18 Delphi Round 3 Graph Display Result ................................................ 143

Table 19 Delphi Panel Member Representation per Round per Industry Sector .......... 148

Table 20 Delphi Panel Members Sector Representation In Terms of Work Experience

Table 21 Delphi Candidates Current Positions of Employment ............................... 151

Table 22 Industry Organisation Membership ...................................................... 152

Table 23 Low. Medium and High Ranking in Round 1, 2 and $3 \ldots \ldots \ldots \ldots \ldots \ldots \ldots \ldots \ldots \ldots \ldots . . . \ldots \ldots$

Table 24 Further Research Questions Derived from the Opinions Returned in the GDR

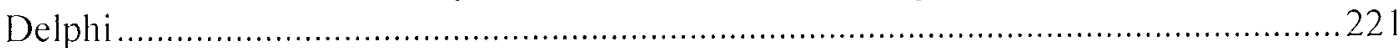

Table 25 Estimated Value of Trade Handled by State Commercial Seaports $(€)$........2235

Table 26 Population in Province. County or City .....................................................250

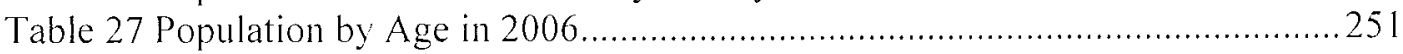


Abbreviations

Analytic Hierarchy Process (AHP)

Chartered Institute of Transport \& Logistics (CITL)

Conference of Peripheral Maritime Regions (CPRM)

Community Support Framework (CSF)

Department of Communications, Natural Resource and the Marine (DCNRM)

Dubai Maritime City (DMC)

Dutch Maritime Network Foundation (DMNF)

European Commission (EC)

European Free Trade Associations (EFTA)

European Register of Shipping (EUROS)

European Union (EU)

Foreign Direct Investment (FDI)

Greater Dublin Region (GDR)

Gross Domestic Product (GDP)

Gross National Product (GNP)

International Association of Classification Societies (IACS)

Information, Communications and Technology (ICT)

Industrial Development Authority (IDA)

Institute of Chartered Shipbrokers (ICS)

International Financial Service Centre (IFSC)

International Labour Organisation (ILO)

International Maritime Organisation (IMO)

International Monetary Fund (IMF)

International Transport Workers Federation (ITF)

Irish Continental Group (ICG)

Irish Maritime Development Office (IMDO)

Maritime Cluster Fund (MCF)

Multi-Attribute Utility Theory (MAUT

Multinational Enterprises (MNEs)

Maritime Industries Forum (MIF)

Maritime Industry Council (MIC)

National Development Plan (NDP)

National Institute for Transport and Logistics (NI'TL)

National Reform Programme (NRP)

National Spatial Strategy (NSS)

Norwegian International Ship Register (NISR)

Norwegian Maritime Exporter's Association (NME)

Norwegian Shipowners Association (NSA)

Organisation for Economic Co-Operation and Development (OCED)

Port Development Council (PDC)

Pilot Actions for Combined Transport (PACT)

Research and Development (R\&D)

Singapore Maritime Foundation (SMF)

Strengths, Weakness, Opportunities, Threats (SWOT)

Trans- European Network (TEN-T)

United Arab Emeritus (UAE) 
United Nations Conference on the Law of the Sea (UNCLOS)

United Nations Conference for Trade and Development (UNCTAD)

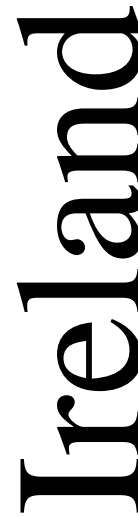

C

0

(1)

of

(1)

r

8

U

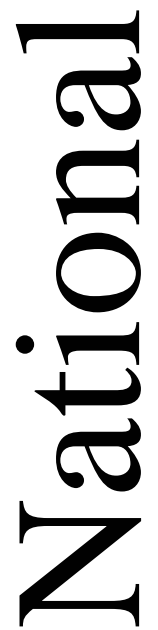




\section{PhD Executive Summary: The Potential for Clustering of the Maritime Transport Sector in the Greater Dublin Region.}

\section{Background}

A cluster of industry is an economic occurrence that provides a particular industry with a distinct sometimes global competitive advantage. Successful clusters are seen as avenues for regional and national growth. Maritime clusters are industries that are usually located at, or originally centred on, the trading activities of a port. Some of the world's major maritime clusters include the clusters of Rotterdam, Singapore and London. Island nations like Ireland require out of necessity transport activities to facilitate the trade of commodities. However, due to Ireland's peripheral location and its lack of transhipment port status, the maritime transport sector in the greater Dublin region (GDR) is not a world-renowned maritime transport cluster. However due to the requirement of transportation facilities, and despite the small nature of the cluster and its international competitors, it is unreasonable to perceive that the GDR maritime transport sector cannot improve its clustering potential.

Aims of the research

By examining the potential clustering of the GDR maritime transport sector, the main aims and objectives of the research are:

- To establish by consensus if the GDR maritime transport sector is a maritime transport cluster.

- To develop guidance for the development of the GDR maritime transport cluster.

- To develop a level of understanding on the capability of the GDR maritime transport sector to improve its clustering potential.

- The taking of established theories to see how useful they are to provide a structure for explorative analysis.

- The development of an effective and explorative research process.

The key research questions are:

- What is the potential for the clustering of the GDR maritime transport sector? 
- Is the GDR a maritime transport cluster or is it the result of basic firm agglomeration?

Method

The nature of the research is explorative and it investigates the potential clustering of the GDR maritime transport sector. Therefore, for the purpose of data collection, the Delphi Method was applied. The Delphi Method is a technique to utilise and obtain an agreement or consensus on a number of statements, opinions or views. The method caters for the utilisation of experts from the GDR maritime transport industry; as who is more suitable to provide opinion on the GDR maritime transport sector than appropriate experts active within the industry? As the research question is based on clusters, the Delphi panel was constructed with experts from all of the maritime transport sectors functioning within the GDR maritime transport sector.

Clusters of industry are complex systems and there is no one economic theory or model that can be applied to an individual cluster to evaluate or measure its full effect. de Langen (2003) devised a framework for cluster analysis based on four of the main schools of thought on industrial clustering and competitive advantage. The core clustering features devised from economic theories help provide a framework to aid in the design of the Delphi questionnaire, as it allows for the analysis of a cluster from a checklist perspective; a type of cluster strength, weakness, opportunities and threats (SWOT) analysis based on characteristics that can potentially improve industrial clustering.

\section{Sample}

For each question the Delphi panel were required to select either an "agree". "disagree" or "unable to comment" response. The Delphi panel were also instructed that they must provide an explanation for their answer. For example, the first question in the Delphi asked the panel if they consider the greater Dublin region maritime transport sector as a maritime transport cluster. Of the total 37 returned responses, 29 agreed, 7 disagreed and 1 was 
unable to comment. The importance of the first question in Round 1 of the GDR Delphi is to ascertain if the Delphi candidates consider that they are operating within a maritime transport cluster. The opinions or explanations provided by the panel members in support of their answers were constructed into threads of opinion, which were used to discuss and further validate the final consensus results of the Delphi.

\section{Findings}

The Delphi consisted of 17 questions of which 11 reached a final level of consensus agreement. Consensus was achieved in questions based on: economic theory regarding the level of trust; the heterogeneity of the sector; levels of internal and external competition; cluster knowledge and access to cluster knowledge; the labour supply; proximity to the cluster and benefits thereof; the cluster's ability for future potential; and a consensus on the GDR maritime transport sector as a maritime transport cluster.

\section{Conclusion}

The research identified with a reasonable level of consensus agreement that the GDR maritime sector is a maritime transport cluster and that it has potential for further industry clustering. The opinions, provided in response to the Delphi questions, devised a further 19 research questions to help examine and build understanding of the sector and its clustering potential. From the Delphi, the panel highlighted that, in their opinion, although they consider the GDR a maritime transport cluster, it could also be the consequence of major port facility and the capital city being one and the same. The sector may physically appear to be a small cluster, but the perceived cluster could be the consequence of distorted demographics in terms of population and industry players. The GDR is Ireland's biggest market and therefore there is an imbalance in terms of population and market demographics. The country's principle port facility is located in the GDR and therefore the critical mass of maritime transport firms are located in the GDR, in order to be at the point where business delivers. The GDR cluster is predominately based on firms that have a direct relationship with 
the port, and this raises the concept of the clustering relationships of the maritime transport sector in the GDR. Is there a difference between a seaport cluster and a maritime transport cluster, and to what extent does the capital city support fledging maritime service clustering? The research concludes by identifying the importance of the temporal dimensions of clusters, in that clusters of industry evolve, grow and decline and are affected by movements in international markets and clusters of industry are in constant movement as opposed to a fixed economic state. Therefore, in the context of the GDR, further examination of the maritime transport cluster and any policy intervention must take into consideration temporal dimensions. This may require a modification of perspective, to take into account other policy approaches that may facilitate the role of the capital city in future potential clustering, such as urban branding, city evolution, and knowledge management for example.

\section{Implications for further research}

As discussed, a further 19 questions were devised for further research on the GDR maritime transport clustering potential. The implication for the research is that many governments and policy makers will attempt to enhance industry clustering by mimicking major successful clusters. Such an approach will not always produce the results desired, as clusters of industry are fundamentally different. In the context of maritime clusters, and specifically for island nations that require maritime transport activities, the research approach outlined can be useful to aid in the understanding of the potential clustering of maritime industries, especially smaller maritime clusters. Resources and knowledge should be focused on such industries, as they are fundamentally required for the economy. In terms of maritime clusters, there are far more potential clusters like Dublin than there are major maritime clusters like Rotterdam, and therefore. in light of the potential failure of mimic polices, such potential clusters should be approached from a different perspective. 


\section{Chapter 1.Introduction}

This is a story of time. The only consistency in time is that it is in a constant state of process. Comparing a cluster to time might appear strange. However, in the analogy of time and clustering as a process displays the complicity of an industrial cluster as an economic concept and that it's continual clustering and economic evolution further adds to its complex nature. Clusters as an area of research is popular because of the importance of the economic concept of clusters of industry to companies, firms and organisations that co-exist and function within an economic and geographic boundary. The re-popularisation of research in clusters is perhaps driven by the perceived importance of clusters not only to businesses but also to governments, policy makers, academics, institutions and the general region in which a cluster is located. Historically, and prior to contemporary understandings of clusters of industry, the drive in research was to understand why some countries were rich and why some were poor, and why some countries have a distinct international competitive advantage in a particular industry, which affords them global market dominance. Successful clusters can be seen as avenues for regional economic intensification which can reflect a nation's national growth potential, and can represent a key contribution to the development of a knowledge-based economy. Therefore, clusters as an economic consequence will continue to hold relevance.

The literature on clusters provides descriptions and characterizations of what constitutes a cluster; however despite examples of definitions and explanations, there is still a need to address what exactly constitutes a cluster in an individual research question on a specific cluster. Is there a requirement level that must be reached or maintained before an industry supported by a region can designate itself as a cluster? Basically. is there a standard size and density for the average cluster? What are the other factor's that can contribute to the cluster's formation and on-going success? One such factor is the effect, if any, of established business relationships or 
levels of cluster dynamism. Clusters are not exclusively about size and the number of business units present. In any case, size does not guarantee an internationally competitive advantage, although in the first instance, critical mass of business units can have a positive effect on clustering due to the agglomeration of firms in a specific region. In examining clusters, literature has a tendency to concentrate on the success stories of major clusters. If a nation wants to build/develop a major successful cluster, then the logic is to copy what other major successful clusters do. However, from a different perspective, it could be argued that there are far more small-sized clusters in the world than major international successful clusters with a distinct competitive advantage. Cluster literature and theory tend to provide research and understanding on how to mimic successful clusters. However, not all industries and nations can have an internationally successful cluster. Therefore, "what is a cluster" can mean different things to different nations, and with clusters, very little is certain, although what is certain is that clusters are complicated. To date, a framework cannot be devised that can effectively and efficiently analyse a cluster and all its potential effects. Clusters of industry are fundamentally not exactly the same. However, a review of the literature available on clusters does provide a building-block of knowledge and understanding on the concepts of industrial clustering.

Ireland is an island nation located on the periphery of Europe. The country's principal port and the critical mass of maritime and related firms lie in the Greater Dublin Region (GDR). The research question specifically investigates the "potential clustering of the maritime transport sector in the greater Dublin region". The relevance and importance of the research question to the maritime sector in Ireland and, specifically the Dublin region, is that Ireland is an island nation, and therefore requires the commercial activities that facilitate the transportation of commodities. Therefore there is some level of maritime transport activity. Due to the geographical requirement for the transportation of goods, and the fact that within the GDR lies the country's principle port and the critical mass of 
maritime firms, it is known that there is some level of clustering in the GDR maritime transport sector. While it appears, in a physical context, that there is some clustering or basic firm agglomeration and, although the GDR maritime transport sector is not a world-renowned maritime cluster, the maritime transport industry is of necessity to the island and the economy of Ireland. Within the context of necessity and the development of knowledge on clusters and the clustering of industry, what is the potential for the maritime transport sector in the GDR to potentially improve its clustering ability? What is the potential to enhance the industry economically for the individual industry players? What is the perception of the cluster internationally? Many governments and supranational governmental bodies concentrate resources on the clustering of industries, as it is seen as having potential benefits to a wide spectrum of players both economically and socially. However, it is logical to concentrate such efforts on an industry that must function (as in the case of Ireland as an island, a maritime transport industry) as opposed to directing such efforts into a industry that is not a necessity, such as a biotechnology cluster which may inherently fail to cluster. Other industries may have a greater economic return in the short to medium term. However, it is also recognised that clusters can fail, and that world markets are demanding and can alter economically, and that what may be a successful technology cluster today could be in a very different economic state in ten or fifteen years time.

Consequently an objective of the rescarch is to identify and establish if the GDR maritime transport sector is a maritime cluster. Although a potential cluster like Dublin - while small - may show visible signs of clustering and appear to physically look like a cluster, it has still not been classified or proven as a maritime transport cluster. International perception would not class it as a cluster because the natural thought process is to compare the Dublin maritime cluster to major successful international maritime clusters. There is an obvious difference between the two cluster concepts, but comparing a larger cluster to a smaller potential cluster does not automatically infer that the smaller cluster is not in fact a cluster or that it 
lacks an ability to develop stronger clustering forces. Clusters have economic relationships that fuel and enhance competitive advantage, and a cluster is more that just the benefits in economies of scale in terms of colocation and co-proximity. However, it is important to establish if the GDR is a cluster or just a consequence of basic firm agglomeration, which may appear to display clustering characteristics despite a prospective lack of cluster dynamism. A subsequent objective of the research is to develop, through the research process, an understanding of the potential clustering of the sector in order to help devise or begin to formulate a process that can aid in the guidance of developing the clustering potential specifically and directly attributable to the maritime transport sector in the GDR. It can be argued that some major world-renowned clusters are perhaps occurrences that are contrary to the economic norm because they hold such distinct and formidable competitive advantage. However, the knowledge gained in understanding the workings of such clusters from theories of industrial clustering and competitive advantage can also help in developing the clustering potential of smaller clusters. However there is a tendency for governments and cluster organisations to develop guidelines that attempt to mimic the behaviour of such successful clusters. A mimic approach is unrealistic because the industry attempting to improve clustering is perhaps void of the specific characteristics that made the major successful cluster successful in the first place. Smaller potential clusters of industry need to be approached from a different perspective. or altered and adapted to meet the specific situation and economic occurrence being observed. Understanding major cluster success stories provides a substantial source of knowledge and an indication of what can be achieved and also what can fail.

The nature of the research is explorative in that it investigates potential clustering which indicates a capacity or ability to improve, grounded by the constant movement of economic clustering. An objective of the research is to gather data, which leads to the question, from where will the data come? The terminology in the word 'cluster' indicates that a cluster of industry is delimited by a level of economic and geographic boundary, and within that 
boundary are the business units that economically act. An industry cluster has a core economic specialisation, and the cluster constitutes all business, firms and organisations in co-proximity and mutually related to the cluster's economic specialisation. For maritime transport, there are a variety of possible sectors, such as shipping, agency, insurance, law and ports although a maritime cluster does not have to have representation from all possible maritime transport sectors in order to be perceived as a maritime cluster. In terms of the actors in the GDR maritime transport sector: they are a source of knowledge which can be utilised to extract data, which can help to aid in developing an understanding of the potential clustering of the GDR maritime transport sector. Due to the complexity of industrial clustering, and the explorative nature of the research, it is important that the research develops an effective research process. The objective of the research is qualitative, as the explorative nature of the research and the concept of clusters dictate, to a certain extent, the involvement of players from the GDR maritime transport sector as a source of knowledge to aid in the collection of data.

By examining the potential clustering of the GDR maritime transport sector the objectives of the research is to establish by consensus if the GDR maritime transport sector is a maritime transport cluster. Develop guidance for the development of the GDR maritime transport sector and develop further a level of understanding on the capability of the GDR maritime transport sector to improve its clustering potential. The core objective of such research questions has its relevance in the point of policy intervention. in that if policies or strategies devised from cluster theory are implemented to improve industry clustering, on a sector of industry that may appear physically to look like cluster, but is void of specific clustering characteristics and clustering behaviour due to its formation based on features of firm agglomeration - such policies will inevitably fail. 


\section{Chapter 2.Literature Review}

The fundamental components of the current research are based on two key areas, first generic clusters and cluster theory and second, clustering with respect to the maritime transport industry. Cluster theory is applied with respect to the research area of maritime transport and therefore it is necessary to undertake a literature review on cluster theory and research concerning maritime transport. The following literature review will include relevant work on clusters and clustering and areas of maritime transport, maritime clusters, and maritime policies. However core theories in relation to clustering are discussed in Chapter 3 and will not be discussed further in this chapter.

\subsection{Clusters}

A cluster is primarily an economic concept and it is the central activity that denotes the cluster genre, i.e. maritime transport cluster, biotechnology cluster. The area of cluster research is well-documented and has been developed considerably over the years and the following literature review will look at some of the research and ongoing work produced.

\subsubsection{Defining a Cluster}

Fundamentally a cluster is an agglomeration which yields as "internationally recognisable competitive advantage" (Porter, 1990) in a particular sector of industry and regional clustering is common in virtually all advanced economies and a growing trend in developing conomies (Enright, 2003). Examples of such international competitive success include the financial service cluster in London, the high tech cluster in the Silicon Valley, the Napa Valley wine-producing cluster in California, and the software outsourcing cluster in Bangalore. In order to understand what exactly a cluster is, a natural course of direction is to examine current and contemporary definitions on clusters. However due to the amount of literature available on the clustering process and the inherent complicated nature of clusters, it is difficult to provide one definition that can 
incorporate all the possibilities and effects of clustering and deliver a sufficient understanding of the economic consequence of spatial industrial clustering. Baptista (2003) describes a cluster as;

"A strong collection of firms usually concentrated in the same geographical area. These agglomerations are typically linked to the presence of an infrastructure of related and supporting industries and the proximity of a strong science base: universities and research centers which act as sources of technological knowledge"

Definitions on clusters and the process of industry clustering tend to take the form of a problematic definition (Roberts, 2005) in that they instruct us to the way clusters should be. To describe a cluster is perhaps a more attainable concept than attempting to define a cluster, as terminology can be a more productive reasoning for explaining what a cluster is when compared to one (or many) standardized definitions. Dayasindhu (2002) using cluster terminology describes a cluster as:

"Suppliers, producer's, customer's, labour markets and training institutions, financial intermediaries, professional and industrial associations, university departments, schools, regulatory institutions and bodies of law and government"

Enright (2003) also addresses the concept of defining a cluster as a consequence of terminology and discusses eleven key factors of terminology to help examine and define an individual cluster. The factors include the geographic scope of a cluster, cluster density and breadth, the active base of a cluster which refers to the number of, and nature of the activities in the region. The strength of the competitive position, the stage of cluster development (i.e. the life cycle), the level of technological activities and innovative capacity and finally the ownership structure of the cluster, which can either be foreign owned or locally owned or a combination of both. The attempt to define a cluster highlights its complex nature. To summarise, a cluster incorporates many different variations but the concept of clusters centres on the belief that they can help to foster greater regional innovation and development, spread and create new knowledge supported by regional innovation and produce while benefiting from economies of scale in many economic factors (Brown, 2000). 


\subsubsection{The Importance of Clusters}

The importance of clusters is immense and the sheer volume of literature provides a good illustration of the level of interest in the subject and the range of issues that are addressed in research on clusters. On a basic examination, clusters benefit individual business units and economies and a domestic cluster is key to driving economic growth in an individual region (Porter, 1990). The proximity of "linked firms" creates benefits such as economies of scale in expertise, labour, products, innovation, skills and attributes such as knowledge creation and information flows (Morosini, 2002). Cluster's are therefore vital to firms, however due to their impact on an individual region and a country's economy, clusters are also important to government, policymakers, local and regional development authorities supported by academics, consultants and research and development (R\&D) institutions. The interest in clusters can be described as an economic fashion that rises and falls through the years (Karlsen, 2005) as the cluster based policy approach and the use of core key terminology by governments such as the "knowledge economy" come and go. The globalisation of economies has compelled governments and academics to examine and understand why some countries have this natural competitive advantage in a particular industry and why others do not. Developing economies and governments see clustering of industries as a means to progression in terms of economic stability, employment and knowledge creation and the raising of living standards and prospects of the indigenous population. For developed and developing economies in terms of clusters and clustering there are two key questions that centre on the clustering concept; first if I have an international competitive cluster in a particular industry, how do I keep it and second, if I don't have an international competitive advantage in a particular industry, how can I get one?

\subsubsection{Measuring and Characterizing Clusters}

The drive of governments, academics and policy makers through R\&D associated with clusters requires a need to understand how well an 
individual cluster is performing or could potentially perform. It is important to have some tool or mechanism of cluster measurement despite the complicated nature of the matter being observed. De Langen (2003) discusses various cluster measurement tools such as the average profitability indicator, cluster productivity indicator, cluster share of exports indicator and the cluster outward (and inward) foreign direct investment indicator. De Langen (2003) also discusses the inappropriateness of some of the indicators as they fail to incorporate measurement of all possible cluster complexities such as social behaviours and the effects of what people do (Benneworth, 2002) as a possible influence on the clustering process. It is discussed by Benneworth (2002) in citing Dosi (1987) that although there is no one key indicator or tool for cluster measurement, there is also no one complete model in which to analyse a cluster due to the inherent failure of available economic models to take into consideration the complete possible effects of industrial clustering. The absence of one cluster economic model which can fit all clusters, or the optimum tool of measurement for a cluster which can quantify all the possibilities with respect to both hard and soft economics is an unfortunate characteristic of the nature of research on clusters. However there is also a plausible reason for this in that clusters of industries are not the same. If a model or theory were developed to analyse a textile cluster in India it could not be utilised to analyse a technology cluster in Italy. There are just too many possible variations and differences between individual clusters and the effects of their surrounding environment. An illustration of this is the taking of cluster polices from a successful cluster and applying the policy to a less favoured region which has the absence of core features of the successful cluster, which made it successful in the first place. Therefore successful clusters should perhaps be looked at as an exceptional rather than a general economic occurrence (Benneworth, 2002). However any cluster measurement should take both a quantitative and qualitative approach providing both statistical resources and input from industry and cluster practitioners where available. Measurement is important for understanding a cluster in its present state 
and how policies and strategies can be implemented to fuel cluster development or resolve any weakness in a cluster. From a policy implementation aspect the measure of a cluster should analyse the appropriateness, effectiveness and efficiency of any intervention implemented (Ecotec Research \& Consulting, Undated).

Clusters have been examined in many ways in order to try and develop sufficient knowledge to understand the concept of clusters and how they function. A cluster can have a life cycle which is divided into four key stages. First the embryonic stage, which is a cluster in an early stage of growth, second, the established stage which is a cluster that is considered to have the potential for further growth, third the mature stage which is a cluster which could find it difficult to secure further potential growth patterns in the future and finally the declining stage of a cluster (Ecotec Research \& Consulting, Undated). A cluster can also be examined though four key dimensions as described by Ecotec Research \& Consulting (Undated) as (1) network and partnerships, (2) the level of social effect of a cluster, (3) the level of innovation and $R \& D$ capacity of a cluster in order to create new knowledge and maintain itself through the established stage and (4) the supply and quality of skills within the cluster and the supportive economy with respect to the level of employment and firm statistics. The life cycle of a cluster can also be looked at similarly through what Enright (2003) discuses as the activity level of a cluster which concentrates on five core areas. First the "working cluster" which has knowledge. firms. suppliers. expertise and the right forces present to fuel clustering, second the "latent cluster" which provides a critical mass of firms to support the cluster and illustrates the benefits of clustering, but there is however a distinct lack of information flows, cooperation and general social interaction. The "potential cluster" has the forces present to be a success but it needs encouragement to strengthen the forces, "policy driven clusters" are focused by government support to try and build and fuel a cluster and are driven by political issues or other requirements such as job creation (e.g. E.U Lisbon Agenda), and finally "wishfully thinking clusters" which are policy driven by the lack of 
critical mass of firms and business units, examples of such would be many of the government driven (although some successful) biotechnology clusters. The features of clustering such as the life cycle and the four dimensions approach are useful tools to aid in the developing of understanding of an individual cluster. Just as in the difficulty of finding one definition to encompasses all cluster features in order to provide a true reflective definition of a cluster that can illustrate all possible affects, finding a tool for cluster measurement is just as difficult a task. Brown (2000) in citing Feser (1998) discuss that there is no unified all composing cluster theory but just a range of theories, ideas and views that strive to understand the logic that is a cluster and a clustering process.

\subsubsection{Proximity and Skills}

Clusters have some level of geographic boundary and firms within that boundary have a certain degree of proximity to each other, within which lies certain benefits of clustering or economies of scale. The concentration of industries in regional areas or industrial districts has been discussed by many scholars (Marshal, 1890, Krugman, 1991) giving attention to the benefits such as the economies of scale in labour and labour expertise, customers, suppliers and economies associated with shared infrastructure, natural resources, reduced transport and transaction costs (Enright, 2003). Proximity is related to geography and the localized construction of clusters and cluster theory in economic geography (discussed in more detail in Chapter 3) which strives to understand why some geographical locations are more successful and competitive than other regions and why clustering forces dominate and create a stickiness to a specific geographical region (Zander, 2004). This force of stickiness appears non transferable to other regions which in turn reinforces the strength of a region despite the development of communication over the decades which has lead to the apparent so called "death of distance" due to increases in sophisticated communications and the emancipation of globalisation (Cairncross, 1995). Proximity is also relevant for information flows as it is argued by Zander (2004) that flows of information and flows of cluster knowledge are localized 
to the cluster and may be denied to newcomers forming a cluster barrier of entry. Cluster knowledge and the lack of willingness to trust and share cluster knowledge can both be a barrier to entry and a barrier to exit. In the discussion of proximity, literature does not appear to provide as much documentation in respect to possible negative affects of proximity on firm localisation such as the poaching of good staff, the imitation of new knowledge and technology which can diffuse quickly through a cluster and the diseconomies of agglomeration such as congestion and high land rents. Looking at the potential disadvantages of proximity lead Morosini (2002) to raise the question, "how can actors of a cluster reach the right medium of advantages and disadvantages of firm proximity"? It could be difficult for a cluster or more specifically a cluster organisation, government, local council or individual firm to strike that balance between the positive and negatives of industrial proximity.

Clusters attract firms and business units to a region. The attraction of firms inevitably attracts labour to that region and also supports the employment of persons within an area. The availability and specialisation of skills and knowledge of labour present in a cluster is a recognised agglomeration effect (Krugman, 1995, 1991) which can be a strong exit barrier which can help keep firms sticky to the cluster and its region (refer to Chapter 3 for examples). The skill level is important to a cluster and it can be a fundamental core aspect of a cluster's ongoing success as skill level within a cluster is linked to the quality of the labour and the knowledge of the labour supply (Enright, 2003). Strong cluster's are a source of labour which can also act as a brain drain to the cluster as the employment, skill and knowledge available for the individual can be an attractive prospect in terms of developing an individual career. The subsequent emerging labour fresh out of university is also attracted to industry clusters due to the mass of potential employment and the personal benefits for them to learn their profession from the best in the world. Government cluster polices such as in the case of the technology industry utilise clusters as a means to attract labour to an area that may require an economic boost or to support a 
depopulated area or a government objective to balance a country's industry in terms of spatial consideration.

\subsubsection{Innovation, Co-ordination, Co-operation and Competition}

Innovation like the term clusters is difficult to define because it is described in different ways and represents different things to different people. Gordon and McCann (2005) argue that innovation is different from pure invention and that innovation is the commercial success of a product rather than the invention of that product. Not only is defining innovation intricate but identifying the source of innovation is also demanding as innovations are changes, developments, improvements, and the development of new knowledge in a technological framework of a firm (Gordon and McCann, 2005). Innovation in clusters is driven by the need to create a constant new supply of knowledge as innovation can be the tool that can help prevent a cluster from progressing into decline. Baptista (2001) argues that any region that falls behind in the technology stages either through production of, or the implementation of new technology will start to lag behind and face possible industrial decline. Baptista (2001) also argues that the development and subsequent diffusion of new technologies may occur faster in industrial geographical areas which cater for and help develop a strong foundation and source of cluster knowledge. Fritsch's (2003) argument is supportive of a widely accepted hypothesis that innovation is linked to areas where industries localise as a result of positive forces of agglomeration conomics in contrast to areas of low density. Therefore an area of firm density is more likely to succeed in fostering innovation, and that the distribution of innovation is linked to the geography of clusters and the essence of localisation of industry knowledge (Gordon and McCann, 2005) as the cluster characteristics supports new and improving innovation. Enright (2003) discusses that the importance of innovation for clusters is driven by the direction of local pressure. which is then acted upon by local government and councils and therefore the growth and development of local clusters are linked to the capabilities and the drive of performance of local government. Dayasindhu (2002) in citing Nonaka (1991) discusses that the environment 
in which the cluster works and the fact that customer demands constantly change over time and within the constant movement of global marketplaces firms and a cluster must be flexible. That flexibility is sourced in the innovation and growth of new knowledge and is important for the consistent and on going development of a cluster and linked to its ongoing success (Enright, 2003).

From Morosini's (2002) perspective derived from a literature review of cluster research, both knowledge integration and the level of competition are crucial factors that facilitate economic performance. Morosini (2002) argues that from the current literature an hypothesis can be formed which states;

"The higher the degree of knowledge integration between member firms, and the higher the global scope of competition of member firms, the higher the economic performance of industrial cluster."

Individual firms within a cluster compete with one other and to some degree firms within a cluster co-ordinate and co-operate within local and global markets. Strong domestic competition helps firms succeed in international markets and Porter (1998) discusses that if the domestic market is not highly demanding and competitive, firms do not need to act in a dynamic manner and therefore are unlikely to have success in international demanding markets. Therefore a good level of indigenous competition between firms in the same region can have a positive effect for the overall cluster in both national and international markets. However obstructive behaviour and disxuptive competition can also lead to a negative effect fostering mistrust between players and protectionist behaviour. Ideally for the optimum result a balance is required between good healthy levels of competition and a good level of co-operation between firms. This ideal level of firm behaviour has lead to a new descriptive term called co-competition. The level and affect of co-competition is reflective in the process of cluster innovation and competition between local firms to fuel innovation and that that drive can be more powerful than the effects of foreign competition (Porter, 1990). This can also be supportive of the agglomeration effect of knowledge spillovers. It is perhaps easier to focus on competing neighbours 
as the access to the level of knowledge and "rumour" of what they are doing is more attainable due to the co-proximity.

\subsubsection{Clusters and Policies}

As discussed there has been a considerable interest in clusters and an increasing interest in cluster literature supported by growth in the area of policy and governance literature relating to clusters. The ultimate aim of such cluster polices is to encourage a cluster to be created, to grow a cluster and perhaps more vital, policies to secure a cluster's position and strength in international markets. Policies for clusters can be seen all over the world along with policies from some of the world's biggest institutions such as the OCED, EU, World Bank and UNCTAD (Enright, 2003). Cluster policies have also become increasingly prevalent in European Structural Funds and Benneworth (2002) argues that it is a likely trend that will continue as Europe adjusts to future enlargement. There is diversity in the approach to cluster policies as westernised countries and economies will concentrate the drive of cluster policies from a local level i.e. local government and councils. Cluster initiatives in smaller less developed countries will drive the initiative from a national government level (Enright, 2003), in a top down approach as opposed to a bottom up approach. Enright (2003) discusses the results of a survey of government polices in which none appeared to have any or even a moderate impact on the cluster. However from a review of literature it is accepted that clusters can aid in the development and successful competitive performance of regional economies (Leibovitz, 2004). Individual regions supported locally or nationally will strive to develop a world renowned cluster; however many regions in differing countries are trying to successfully cluster the same sector of industry such as in areas of biotechnology and telecommunications. Some of those policies will undoubtedly fail as not all regions who want a world leading cluster in telecommunications will have success in producing and sustaining such a cluster (Enright, 2003). Governments or agencies with a goal to implement a cluster strategy would be better concentrating upon what is naturally present such as raw materials, a specialised workforce or the advantage of a 
strategic location. Benneworth (2002) argues that Porter's Five Forces model is popular with policy makers as it is a simpler task in one sense to concentrate on the advantages of the competitive advantage as opposed to having to generate ideas for new industry activities for future growth.

While literature considers clusters that are a success there are also clusters that fail. Cluster failure is not a subject as heavily researched as in the literature depicting successful clusters. The failure of clusters can appear as a natural process when examined within the context of the cluster life cycle, however certain clusters do manage to prolong their success and maintain economic importance. This capability to evolve is fundamental to the ability of the cluster and the individual firms to adapt to changes in the market and behave in a manner of constant flexibility that lends them the capability to evolve and survive. Enright (2003) however provides insight into possible mechanisms that enhance clusters towards the failure stage of the lifecycle; perhaps the most interesting of the possible failure mechanism is when a cluster suffers a loss of dynamism through ossification. A cluster suffers such a loss when the forces that encouraged the grow th of the cluster in the first place prevent firms from reacting to stimulus from outside the cluster and the international market place (Enright, 2003). The cluster becomes rigid and unable to move with inflexibility and the firms within the cluster become muted to world markets. There are many examples of cluster polices from a variety of approaches, governments, organisations and world institutions and the literature review will examine in Section 2.4 European policies that either directly or indirectly effect clustering of industry.

\subsection{Maritime Clusters}

A maritime cluster conjures up an image of some of the important and most successful clusters of maritime transport activities located in regions such as London, Rotterdam and Singapore. It is vital for any maritime cluster regardless of its size or importance to have an awareness of other internationally competing clusters. The range and possible examples of maritime transport clusters is extensive due to the varying size and 
economic impact of maritime industries, however the following literature review will look at the major maritime clusters dominating Europe and Asia.

\subsubsection{London Maritime Service Cluster}

The City of London has established itself as an international maritime service centre and the city holds a substantial financial core of the maritime shipping loan portfolio, which in 2002 held 18\% of the world order book (IFSCL, 2003). The London cluster in 2003 employed 14,200 personnel in the service sector which helped to contribute in 2002 some £1.092 million to the UK balance of payments ${ }^{1}$. The core specialization is mainly attributed to ship broking, insurance, commercial banks, legal services, ship classification and R\&D (IFSCL, 2003). London has a supportive legal framework in the development of Admiralty law and there is a significant presence of overseas shipowners in the London cluster (Maritime London, 2006).

The London based organisation Maritime London discusses that the reasons for London's success to date is due to a number of key factors supported by the city's maritime tradition and history. London, and the maritime London that is present today was built on the back of growth in trade during the 19 th century which led to a concentration of shipowners and merchants which provided a key critical mass and current clustering effect of independent service providers. The maritime industry that we see in the UK today developed from the early strengths of the UK merchant fleet and shipbuilding industry until their subsequent decline in 19\%0's (Brownrigg. 2006). The decline of the hard elements of the UK maritime industries such as shipbuilding, the merchant fleet ${ }^{2}$ and the numbers of British seafarers 3 could arguably have lead towards the identification of and importance of related maritime transport service sectors and the maritime competitive

\footnotetext{
${ }^{1}$ However Sea Vision UK defined the UK cluster (not specifically London) for the year 19992000 with a turnover of $£ 37$ billion ( $€ 55$ billion), which was greater than aerospace and agriculture combined, 250.000 direct jobs and a similar number employed indirectly.

2 The UK owned fleet fell from a peak of 50 million deadweight tonnes in 1975 to 7 million deadweight tonnes by 1999 (Brownrigg. Dawe. Mann and Weston, 2001).

${ }^{3}$ Between the years 1980-1999 the number of UK officers and rating fell by $75 \%$ and $59 \%$ respectively (Brownrigg. Dawe. Mann and Weston. 2001).
} 
advantage held by the City of London (Brownrigg, et al, 2001). However the decline in British seafarers is argued by Gardner (et al, 2001) as having a negative effect on the future of the London maritime cluster while Selkou and Roe (2002) argue that the UK tonnage tax regime which implemented a compulsory cadet training requirement to replenish the stock of British seafarers is nothing more than a subsidy to the UK maritime industry and a contradiction to the EU single market and free competition policy founded in the Treaty of Rome. The decline of the hard elements of the UK maritime transport industry could be applied to most European maritime industries in light of the increasing effects of globalisation, the decline of European registries due to "flagging out" and the increase in competitiveness of Asian economies and growth in Asian maritime clusters such as Hong Kong, Singapore and Shanghai.

Because of London's strong global position, the Corporation of London commissioned Fishers Associates to write a report for "A Call For" Action" in order to understand and evaluate the London cluster, and therefore protect for the future what the corporation calls their "natural asset" (Fishers Associates, 2004). There are over 1,750 companies or organizations that participate within the London maritime service cluster (Fishers Associates, 2004) and London maintains a strong hold in many areas of the cluster as its strength lies in its depth, breath, mix and weight of combined financial, legal and knowledge based services. The cluster is also supported by the position that London maintains due to its presence as an international banking centre, its prominence, confidence and longstanding maritime tradition. London is also the residence of important maritime organizations such as the Baltic Exchange, the International Maritime Organization (IMO), The International Transport Workers Federation (ITF), and the International Association of Classification Societies (IACS) along with a sizeable range of support and intermediate services. The Fisher's Consultants report brings attention to the fact that if the City of London wishes to maintain its "natural maritime asset" into and right through the $21^{\text {st }}$ century it requires the city to act now. The report highlighted that $98 \%$ 
of industry actors that were surveyed concluded that London is the maritime service stronghold. However 59\% acknowledged that it would lose its prominent position within the next 10 to 20 years (Fishers Associates, 2004). The report concludes that their needs to be distinct encouragement from local and national government for the public and private services of the cluster to work better together for the benefit of the whole cluster.

\subsubsection{Dutch Maritime Cluster}

A 1994 paper commissioned by the Ministry of Transport, Public Works and Water Management entitled "The Future of the Dutch Shipping Sector" was the facilitator for the shift in objectives on the Dutch maritime cluster (Janssens, 2006). The report moved the emphasis away from purely maintaining a Dutch flagged fleet to one considering the importance of a national shipping policy to facilitate the potential of the "added value" and "employment" benefits of increasing general maritime transport activities (Janssens, 2006). The Dutch cluster is supported by The Dutch Maritime Network Foundation (DMNF) which is an independent foundation that was established in 1997 and is one of the first maritime proactive cluster initiatives to be established (Dickery, 1997). One of the first tasks of the DMNF was to establish the economic importance of the maritime sector and to establish and define the relevant maritime sectors into eleven key segments (Lloyds List, 2000). The Dutch cluster success is founded on the strength of the eleven sectors and the fact that the cluster is complete with representation from the majority of possible maritime cluster sectors with key strengths in shipping, dredging, yacht building and maritime services (Janssen, 2006). In 1997 the turnover of the cluster was $\mathrm{C} 17.8$ billion which rose to $\mathrm{E} 21.4$ billion in 2002 and provided a total added value of $2.9 \%$ of the Dutch Gross National Product (GNP) (Janssen, 2006). The Netherlands is also a world leader in certain niche areas such as heavy lift and transport, towage and salvage, geological survey and model testing. However, a key strength of the cluster is the proximity of the units contributing to the Dutch cluster as there are some 11,500 maritime companies in a $100 \mathrm{~km}$ 
radius which provides a base for the enhancement of relationships and the ongoing development of new cluster knowledge (Janssen, 2005).

The city of Rotterdam hosts one of Europe's largest commercial ports, which is strategically located in the northwest of the European continent and located at a pivotal point for fierce port competition along the Atlantic Arc trading area (Nautical Enterprise Centre, 2001). Rotterdam is one of Europe's deepest ports and thus can facilitate some of the world's largest ships (Port of Rotterdam, 2004). The port is situated at an advantaged location resting near some of Europe's most important inland waterway connections that enables the Dutch maritime cluster and the Port of Rotterdam to service an extensive hinterland. The Dutch cluster also hosts the Erasmus University which is located in Rotterdam and is active in many areas of transport research through the university's school for economics, transport, infrastructure and logistics. Recent work by de Langen (2003), (2004), (2005) on the area of seaport clusters, governance and the importance of the port activities to the cluster's identity has strengthened the importance of the role of the port within a cluster region.

\subsubsection{Norwegian Maritime Cluster}

Norway is a nation with a strong maritime history and tradition and today the country is strong in ship-owning, ship management, ship broking, ship finance, and marine insurance as well as hosting one of the most leading and important classification societies for the shipping world in Det Norske Vertias. In 198' Norway introduced the Norwegian International Ship Register (NISR), which helped to create a more level playing field for Norwegian ship owners, which at one point helped to secure the expansion of the Norwegian merchant fleet from 24 million dwt to 55 million dwt during the period from 1986 to 1991. Today however the register has stabilized to an estimated figure of 750 registered ships (Wijnolst, et al, 2003). Norway's strength of numbers in the shipowning sector of the maritime industry has help to provide the country with a strong maritime cluster and is a key feature for future cluster growth (Fisher's, 2004). 
Due to the topography of the country the idea that a cluster is confined to just one region or area of the country, is in the case of Norway not strictly true. The main maritime region of Norway is Oslo and other concentrations of maritime industries are located in Vestfold, Buskerud and Telemark, Aust and Vest-Agder, Rogaland region, Hordaland, Sogan and Fjordane region and Møre og Romsdal. Oslo and the southern region of Rogaland have seen the highest rate of growth due to the effect of the country's oil industry. Oslo specializes in maritime knowledge, which includes law, brokering, classification, insurance and information and technology. The northern region of Rogaland concentrates on offshore related activities in relation to the petroleum sector. The Møre region fundamentally consists of concentrations of ship design and shipbuilding, while the north of the country concentrates on sea fishing (Wijnolst, et al, 2003).

The Norwegian cluster is home to two major finance players, DNB which is the largest bank in Norway and the Nordic Bank Nordea which is a leader in the arrangement of syndicated loans (Kristian, 2005). Kristian (2005) argues that the strength of the cluster lies in the well founded cooperation and synergy that exists between all the players in Norway's maritime cluster. However concern has been raised over the fiscal arrangements in Norway with the head of the NSA claiming that Norwegian companies have been moving abroad due to the country's negative tax regime and this is having a negative effect on the country's cluster (Fairplay, 2005, A). Operators in Norway ideally want to obtain a tonnage tax regime in line with the rest of Europe which is seen as crucial for further development of Norwegian maritime industries (Fairplay, 2005, B). Norway also has a number of leader firms such as Wallenius Wilhelmsen, the world's largest transporters of cars, Teekay Navion Shuttle Tankers, the leading operator of shuttle tankers, SeaDiin one of the largest drilling company's and Farstad is a leading offshore supply company.

Norway is also proactive on the issue of developing the cluster and the Norwegian Maritime Exporters Association (NME) was established in 1995 in order to preserve Norway's position within the international shipping 
community. The NME promotes the co-operation and co-ordination of all maritime industries in Norway and it helps members to identify new possible markets and areas for future growth. Norway's maritime industry has had the benefit of a number of organizations that aid the support and development of the industry for all players such as The Norwegian Shipowners Association (NSA) founded in 1909 which represents the interest of shipping and offshore related sectors, the Norwegian Shipbrokers Association, the Maritime Forum of Norway whose objective is to secure the needs of the maritime community onto the country's political agenda as its aim is to assure and continue Norway as a leading maritime service cluster for the $21^{\text {st }}$ century.

\subsubsection{Hong Kong's Maritime Cluster}

Hong Kong is one of the world's most important maritime centres and has the advantage of having one of the world's major deepwater container ports which acts as a transhipment and logistics hub for the Asia-Pacific Region. In June 2003 the Maritime Industry Council (MIC), whose aim is to develop maritime industries in Hong Kong, was reformed after the recommendation from the report "Study To Strengthen Hong Kong's Role as an International Maritime Centre". in order to concentrate on enhancing the competitiveness and attractiveness of the Hong Kong cluster (Maunsell Consultants, 20035). The MIC is a high level advisory body that consists of private sector representatives and government officials in order to direct, inform and advise the government on the best strategic solutions to develop the Hong Kong cluster (Wallis, 2003, A). The Hong Kong government has been called to look towards its European competitor (Rotterdam) for inspiration regarding the changes the Dutch made to their own maritime cluster with regards to closer operation, image, flexible manning policy and suitable and incentive tax regime (Wallis, 2003, B). The report also highlights the pressure Hong Kong is facing as it recognizes the fact that governments such as the UK. Netherlands and Norway have responded to the industry by

\footnotetext{
A report that was produced in association with Erasmus University Centre for Contract Research and Business Support.
} 
helping to forge initiatives for cluster development, and Singapore and Shanghai have actively taken steps towards attracting more maritime industry actors to their respective regions. The report also discusses a forward governance approach with co-operation between Hong Kong, Singapore and Shanghai in order to promote an Asian maritime cluster secured by each nation's individual maritime excellence, a proposed Asian one stop cluster shop. According to the United Nations Conference for Trade and Development (UNCTAD) report into the Review of Maritime Transport (2004), Asia is the fastest growing area for maritime development, as the region holds the world's top three container ports supported by critical mass in terms of port activities, ship operators and owners which can help to fuel Asian maritime cluster development. Hong Kong's advantage in support of its prominent port activities is that it also has a well-developed maritime service sector and sizeable financial services with the added advantage of the English language and English common law (Fisher Associates, 2004).

\subsubsection{Singapore's Maritime Cluster}

Singapore is one of the most thriving maritime clusters in Asia and the port of Singapore is strategically located as a gateway to the east as the port acts as a major transshipment hub for the Asian region. The Singapore cluster activities include shipping, shipbuilding along with support services such as ship management, legal services and an established ship register. Singapore's cluster and port are under a constant competitive threat from nearby countries of Thailand and Malaysia. Singapore has had to take forceful action in order to maintain its cluster and the port's premier position from the overall strong growing threat of the fast growing Asian market and other ports in the region such as Malaysia's Port Klang. In 2002 the Maritime and Port Authority of Singapore formulated a Maritime Cluster Fund (MCF), which established an $\$ \$ 50 \mathrm{~m}$ budget to enhance and help deliver manpower development along with the local transport infrastructure and value added services such as ship management, brokering, chartering, finance and legal services for the cluster's player's (MPAS, 2002). A Maritime Technology Cluster Development Roadmap has 
also been developed which has highlighted some main areas which require further R\&D namely (a) building up maritime R\&D capabilities, (b) development of the technology component of the maritime industry and (c) develop the various technology sectors of the maritime transport technology cluster which is a fast growing maritime sector (Singapore Maritime Portal, 2002). The development of maritime education is also important as the MCF has helped to organize and fund degree courses in the area of maritime transport in order to strengthen their expertise, research ability and general qualified labor pool. The Singapore cluster is built on port activities but it also has considerable support from government which has termed its cluster strategy as "London plus" (Smith, 2004). The Singapore government has provided a range of support for the cluster including $\mathrm{S} \$ 20 \mathrm{~m}$ (US $\$ 11.6 \mathrm{~m}$ ) to upgrade IT facilities for SME's, $\$ 100 \mathrm{~m}$ for research and development in marine technology and $\$ 80 \mathrm{~m}$ for a maritime cluster fund, and $\$ \$ 50 \mathrm{~m}$ which has been noted for manpower training and development (Smith, 2004).

\subsubsection{Shanghai's Maritime Cluster}

Shanghai has benefited from the general growth in Asian economies along with advantages of a mass export market and low labor costs. In the concept of developing cluster's Shanghai is a relatively young model and has a long way to go to develop but the cluster has considerable future potential aided in its geographic location and port abilities. Shanghai already hosts a large financial sector that is experiencing a consistent line of growth and the city also holds one of the world's leading maritime universities and nautical training facilities (Smith, 2004). In the clusters discussed so far all but one (London) is centered on a major port and as the port of Shanghai and the Asian region develops, Shanghai will undoubtedly grow in maritime importance and maritime clustering strength.

\subsubsection{German Maritime Cluster}

The German maritime cluster is another European stronghold for maritime activities. Like most European nations to date Germany introduced the tonnage tax regime in 1999 (Selkou and Roe, 2004) which helped lead to the 
doubling of the German total deadweight fleet and the re-flagging of 135 vessels (Adamowitsch, 2006). Currently the German merchant fleet consists of approximately 2,800 ships exceeding a GRT of over 52 million, of which half of those vessels is less than for years old (Adamowitsch, 2006). Leading maritime sectors in Germany include the shipbuilding industry which had a turnover of $€ 6.1$ billion in 2005 and the shipping industry which in 2005 had a turnover of $€ 15$ billion (Adamowitsch, 2006). Germany's approach to cluster co-ordination is a government lead objective which is an individual approach when compared to its European counterparts that lead by an organization cluster initiative approach. Germany's state secretary and coordinator of maritime affaires considers that the government lead approach is a more successful concept as the co-ordination of any maritime cluster is complex due to the variety of sectors involved (Adamowitsch, 2006).

Hamburg is an important competing maritime cluster based in the Northern Europe and Atlantic Arc region. Hamburg has a number of maritime services based in the cluster but the port and ship owning are perhaps its core cluster activities. The finance and shipping sector has been boosted by Germany's KG tax efficient ship financing arrangements which is credited with adding a substantial number of ships onto the German ship register. Fisher's Associates (2004) reported that Germany is engaged in cluster: research and supported at both a national and regional level. The Ministry of Transport has recently called for a study to investigate the German cluster and its maritime achievements and subscquent importance to the overall economy, however the report is not expected until the end of 2007(Adamowitsch, 2006). Germany's National Maritime Conference has developed to become the leading platform for the debate of German maritime concerns and concentrates on the political and economic issues concerning the cluster's development. A Maritime co-coordinator was appointed from the Federal Ministry of Economics and Technology to develop maritime strategy within all maritime sectors across the whole country (Fisher Associates, 2004). Education and R\&D is also being forged ahead with the opening of the Hamburg School of Logistics in 2003 as a 
public-private partnership between the Hamburg University of Technology and the Kuehne Foundation of Schindellegi in Switzerland (Hamburg School of Logistics, 2003).

\subsubsection{Dubai Maritime Cluster}

The Dubai maritime cluster has taken a one stop shop concept for its maritime cluster by aiming to provide the complete maritime city i.e. the Dubai Maritime City (DMC). The DMC claims it will provide the first ever purpose built maritime cluster driven by the needs of the maritime community both locally in Dubai and internationally to have a dedicated hub and maritime community which will be a global focal point in which to conduct maritime business (Dubai Maritime City, 2006). The DMC project so far has reclaimed from the sea an area of over 2.16 million square hectares for the location of the maritime city, two new ship lifts were built with capacity of 3,000 and 6,000 tons respectively and contracts were awarded for the construction of breakwaters and a quay wall. DMC is home to DP World which came about due to the merger of Dubai Ports Authority and DPI Terminals, Dubai Dry-docks is an established leading shipyard which employs over 5,400 skilled employees and claims that almost every major management company has utilised their facilities and expertise at some point in their business operations (Dubai Maritime City, 2006). In January 2006 the United Arab Emeritus (UAE) established its own Ship Owners Association as a vehicle of communication and a forum for companies registered and licensed in the UAE to act as a platform for action and communication with government, and to drive and develop the DMC. DMC claims that Dubai's maritime reputation is based on a long maritime tradition and experience in a wide range of maritime sectors which enables DMC to propose the one stop cluster shop approach for international maritime industries

There are many clusters of maritime industries around the globe which provide an array of maritime services and vary in terms of size, services and economic importance. Clusters of industry in general come in all shapes and 
sizes and maritime transport clusters are no exception. There are different maritime clusters in terms of economic competitiveness as some clusters are considered to hold global competitive advantages. However there are also smaller clusters of maritime industries which are still of great importance for domestic economies. In terms of maritime industries, maritime clusters operate in a global international business and the discussion above provides an example of some of the world's maritime clusters and their approach towards the clustering of their maritime industries.

In reviewing other maritime clusters in Europe and Asia raises the concept of a typology of maritime clusters, in that there are different types of and classes of cluster. For example, a maritime industry can start as a type A maritime cluster with basic maritime services and then grow through to a type $\mathrm{B}$ and $\mathrm{C}$ etc, and finally reaching a status similar to that of major maritime clusters like London, Rotterdam and Singapore. Literature on clusters from an economic perspective display that not all clusters of industry are the same and a model or formula based on observations of major successful clusters cannot be devised and repeated in another region and industry gaining the same international competitive advantage. To summarise the literature review, and with specific reference to maritime clusters, they fundamentally are not the same. Maritime clusters vary in size but more importantly they vary in the concentration of there services. Certain maritime clusters are predominately serviced based, some have a greater concentration on logistics and finally some clusters are more port focused. Therefore it is reasonable to argue that within the context of maritime cluster's there are three main clusters types, namely; service based clusters, logistics based clusters and port focused clusters.

\subsection{Cluster Organisations}

Clusters of industry can develop naturally owing to a strategic location or the supply of a local resource. However cluster's can also benefit from a more organised approach from policies implemented or benefit from a structured organisation with the objective of understanding the clustering of the 
industry and improve competitiveness. In recent year's many cluster initiatives and programmes to fuel competitiveness have been established either from government lead initiatives or from private organisations with an underlying objective to secure ongoing cluster competitiveness and long term survival. Understanding and knowledge can be gained by examining such organisations and the following discussion will explore a few examples of such organisations and their objectives. The discussion below is not exhaustive in terms of cluster organisations but provides an insight into such organisations.

In terms of Ireland the Irish Maritime Development Office (IMDO) is Ireland's first national dedicated office for the promotion and development of Ireland's shipping and maritime services sector. The IMDO is an office of the Marine Institute which is a state agency dedicated to researching and developing Ireland's marine resources (IMDO, 2006). The IMDO's statutory mandate is to promote the growth and development of Irish shipping and related maritime services sector with core aims to:

- To promote and assist the development of Ireland as an international competitive location for shipping and shipping services.

- To capitalise on Ireland's opportunity to capture a share of the large expansion envisaged for global shipping and its services sectors.

- To promote Ireland as an international centre for ship registration.

- To develop and implement a strategic framework for the shipping industry and its ancillary services sector.

The IMDO is not simply a cluster organisation with rigid cluster objectives but it is a government office established to promote and develop a sector of industry. Many governments have similar organisations for different industries or for industry in general and even though its core objective is not clustering it still has an important role to play with the development of competitiveness of maritime and related maritime transport activities. The IMDO suggests to the maritime industry that the government consider's the industry of importance and of economic relevance to the country. This is 
further endorsed by the island nation status of Ireland and the benefit of a specific government office dedicated to Irish marine and maritime industries.

The Singapore Maritime Foundation (SMF) launched in March 2004 is a private sector led organisation whose aim is to promote the different sectors of Singapore's maritime industry with the relevant government agencies and promote the Singapore maritime cluster (SMF, 2007). The mandate behind the SMF can be described as a forum for communication and knowledge, a catalyst to stimulate co-operation and cluster development and finally to partner both the government and the private sector to promote the Singapore cluster. SMF co-ordinates communication and support of the Singapore cluster by a number of programmes, initiatives, international events, conferences, education and seminar series, exhibitions, industry working and discussion groups while encouraging industry participation in international maritime events.

The Maritime London (2006) organisation's core constitution is to encourage the ongoing success of the London maritime cluster. It has three main aims;

1. To maintain and enhance London's position as a world premier maritime city.

2. Promote all the maritime interests in London, working if necessary with other bodies and organisations.

3. To encourage inward location of foreign maritime interests.

The member list for the London Maritime organisation covers a wide spectrum and provides representation from all key sectors within the London maritime cluster. The executive committee of the organisation also provides representation from the entire London clustex including; Admiralty Solicitors Group, Baltic Exchange, Chamber of Shipping, HSBC, Lloyds Register, Moore Stephens, NUMAST, Salvage Association, Association of Average Adjusters, Royal Bank of Scotland and Seatrade to name a few (Maritime London, 2006). While Maritime London specifically concentrates of the region of London, Sea Vision UK is a national campaign to raise 
awareness of the sea and the importance of the maritime transport sector to the whole UK (Sea Vision UK, 2006). Sea Vision's main objectives are to increase the public's general awareness of the importance of the sector and especially to raise that awareness among the younger population. Its three core messages are;

1. Our seas are vital to trade, energy, defence, leisure and the environment.

2. The UK maritime sector makes a major contribution to our economy and quality of life.

3. Our maritime industries are modern and high-tech and offer excellent career opportunities.

Fundamentally Sea Vision aims to provide a "blue print" (Sea Vision, 2006) for maritime sector cooperation across the whole of the UK as the organisation does not just concentrate on core maritime transport activities but also takes into consideration all users of the sea including recreational. Another UK organisation is Mersey Maritime which is based in Liverpool and is an organization with a pure business initiative developed by the maritime industry located in the Merseyside area of the UK. The aim of the organization is to build on past success and to consolidate and import business for future maritime industries in the Merseyside area which currently facilitates 1000 business units which employs 2,6000 personnel, with a turnover of $£ 2.5$ billion per annum (Mersey Maritime, 2007). The Mersey Maritime objective. direction and rision is to develop industry towards a status of a world class cluster of maritime businesses.

From a European perspective there are many examples of cluster organisations and initiatives from within the EU both regionally and nationally. The Maritime Industries Forum (MIF) was created in 1992 but was re-launched with a fresh face in June 2000, and the MIF's main objective is to address topics of common interest to industry sectors with a view to enhancing their competitiveness. The forum consists of representatives from the European Industry Associations, representatives of the EU Member States and the European Free Trade Associations (EFTA). 
the Commission, the Parliament and Regional bodies, together with affiliated organisations and observers (MIF, 2007). The main objectives of the forum are to create communication between maritime sectors, provide a voice for maritime industries in political debate, maintain and promote competitive European maritime clusters and to keep the European parliament advised on development and key problem areas for the sectors growth and competitiveness. A broader European based organisation is The Maritime Development Centre of Europe which is a cross sectoral interest organization based in Copenhagen and its members are from Denmark and Sweden and include; shipowners and operators, shipyards, port authorities, R\&D, national authorities, trade and interest groups, service and consultancy, finance and insurance companies (Maritime Development Centre of Europe, 2007). One of the most recognised maritime cluster organisations is The Dutch Maritime Network Foundation (DMNF) which is perhaps the first specific maritime cluster driven organisation. The DMNF is an independent foundation whose role and objective is to reinforce and promote the Dutch maritime cluster (DMNF, 2005). One of the early tasks completed by the organisation was to research and analyse the Dutch maritime cluster and identify its key sector components. The organisation identified eleven key sectors in which to concentrate their efforts of promotion and cohesion. A more recent established European cluster organisation is the CMF which was officially established on January $1^{\text {:t }}$ 2006. The organisations objective is to promote both at home and aboard the French maritime activities (ENMC Newsletter, 2006). The new organisation has gained the support of many French maritime practitioners including maritime companies, professional federations and maritime associations through their commitment of $€ 50,000$ annually to the running of the organisation (Spurrier, 2006). The organisation will not take the traditional route of defining. measuring and evaluation the French cluster and its maritime activities but provide a forum of communication and lobbying of national and European government 
There are other organisations that take a purely regional approach and initiatives that are co-ordinated from a national and supranational level; however in the wider concept of clusters there are organisations such as Sea and Water (2007) in the UK which promote water as a commercial and environmental sustainable mode of transport for freight. This shift of traffic from road to the sea or waterways is reflective of EU policy and the White Paper: A Time to Decide 2010 in terms of the European perspective of the benefits of using shipping and inland shipping for the movement of freight. While not a direct cluster initiative it can be argued that any promotion to increase shipping freight will have benefits for maritime industries. Another organisation is The Society of Maritime Industry's who's aim is to promote and support companies which build, refit and modernise warships, and supply equipment and services for all types of commercial and naval platforms, ports and terminal infrastructure and maritime security, offshore oil \& gas, and marine science and technology (Society of Maritime Industries, 2007).

The discussion provides a brief insight into a variety of cluster organizations and cluster type programmes run by either government or private body interests. Such organisations and programmes can be seen all over the world and in terms of Europe at a regional, national and a supranational level. The focus of such programmes can be general in terms of competitiveness for a region or country or more specific addressing the needs of a particular industry.

\subsection{Clusters and Maritime Policy within a European Framework}

It is important within a European framework that clusters are provided with the relevant support, funding and policy as the sea is a fundamental asset to European economies. Within the maritime policy hierarchy the United Nations Convention on the Law of the Sea (UNCLOS) facilitates a global maritime policy which within the EU member states are party to. However with regard to regulation of European maritime industries there are two main areas, first the safety, manning and environmental 
regulations regarding merchant shipping which are laid down by the International Maritime Organisation (IMO). The second aspect of EU maritime regulation is with regard to polices to develop and protect maritime industries and communities. The following section discusses the European legislative framework with respect to EU regulations and policies that enhance the maritime transport sectors in Europe. Some of the policies discussed are direct maritime policies and some are more general industry policies, however the aim is to improve, enhance and develop a contemporary situation and therefore the policies discussed have relevance, although they may not appear to be direct maritime clustering policies. The discussion is not an exhaustive assessment of European maritime policies but an introduction to some of the past and current polices that have helped to shape the competitiveness of European maritime industries.

\subsubsection{The 1986 and 1989 Packages}

For a considerable part of the European Union life span there were no maritime policies (Paixao and Marlow, 2001) as Europe considered the issue an individual member state concern. Greece, Spain and Portugal joined the EU in 1986 which in doing so raised the importance and relevance of maritime issues within a European context. The increase in maritime awareness induced what is the so called the 1986 "First Package", which is four regulations concerned with the liner shipping market (Selkou and Roe, 2004). The four regulations were;

"Council Regulation (EEC). No.1055/86 which applies the principle of freedom to provide services to maritime transport between member states and between member states and third countries.

в Council Regulation (EEC), No.4056/86 laying down detailed rules for the application of Article 85 and 86 of the Treaty to maritime transport.

a Council Regulation (EEC), No.4057/86 related to unfair pricing practices in maritime transport.

в Council Regulation (EEC), No.4058/86 concerning co-ordinated action to safeguard free access to cargoes in ocean trade. 
The core purpose of the directives was to implement legislation to immobilize restrictive practices in liner shipping and to secure for European communities a legislative vehicle to combat unfair competition from other countries (Brooks and Button, 1992, Urrutia, 2006). In 1989 the "Positive Measures Package" was introduced which proposed measures for a common shipping policy. The core objective of the positive measures package was to introduce a European Register of Shipping (EUROS) to address the decline in competitiveness of community shipping fleets, to prevent "flagging out", the growing decline of EU seafarers and to create an effective port state control regime (Selkou and Roe, 2004). However EUROS was unpopular within the industry and due to European manning requirements membership within the registry would place community shipowners at a competitive disadvantage and the proposal was later withdrawn by the Commission.

\subsubsection{Trans - European Network (TEN-T)}

The Trans- European Network (TEN-T) was established in July of 1996 by the European Parliament and Council adopted under Decision $N^{\circ}$ 1692/96/EC to develop a trans-European transport network (TEN-T) for greater cohesion of road, railways, inland waterways, airports, seaports, inland ports and traffic management systems (European Commission, 2006). The drive behind the $\mathrm{TEN}^{-\mathrm{T}}$ project parallels the foundation of Europe as a single market place in terms of the development of national networks and physical infrastructure and the access to them. The objective of TEN-T is to encourage economic and social cohesion with the establishment of a trans-European transport network as a foundation for ongoing European competitiveness. The EU has highlighted that sufficient progress is not being made in terms of the original objectives of TEN-T. The original investments for the trans-European network for the period of 19961997 inclusive was C38 billion, the estimated financial resources required for completion by 2010 could amount to $\mathrm{C} 400$ billion. In 2003 the commission proposed a review of the TEN-T's to take into consideration changes in previously expected traffic flows in terms of continued growth in 
world trade and in light of the expansion of the EU over the last few years and to take into consideration any future members of the European Union.

\subsubsection{EU White Paper}

The EU White Paper: European Transport Policy for 2010: Time to Decide was produced in 2001 with the aim of "harmonisation and liberalisation" for European transport and to turn "intermodality into a reality". The paper had four key objective sections;

- Shifting the balance between modes of transport.

- Eliminating bottle necks.

- Placing users at the heart of transport policy.

- Managing the globalisation of transport policy.

However for maritime transport the most important section related to the shifting of balance between the modes of transport as the EU pledged to encourage and support the importance of short sea shipping. The paper identified short sea shipping and inland waterway transportation as a means to cope with increasing congestion as the two modes remained greatly underused within Europe (European Commission, 2001). The paper also addressed the importance of intermodality for developing a competitive alternative to road transport with sufficient capacity to compete viably with road transport, supported by the community's "Marco Polo" programme which aids initiatives inline with promoting motorways of the sea (European Commission. 2001). From the publication of the EU White Paper and looking forward to 2002, the EU stressed that the basis of its maritime policy for the future should concentrate of the following areas (Selkou and Roe, 2004);

- Enhancing the competitiveness of EU shipping.

- Continuing to open up the markets for ports and shipping as a cost effective alternative to long distance road haulage.

"Strengthen control of all vessels in EU waters. 
- Develop short sea shipping and improved connection of ports to inland transport - the sustainable development of motorways of the sea.

- Enhance the status and attractiveness of maritime professionals to retain European know how.

- Increase transparency and attractiveness and the monitoring of the implementation of European maritime policies.

It is also noted in the White Paper that the Commission proposed development of the "Motorways of the Sea" as a competitive alternative to road transport and a parallel policy to the "TENT-T" project. The core objectives of the Motorways of the Sea plan reflects those in the White Paper and the "TENT-T" project, which is to reduce road congestion through a modal shift and through application of the Motorways of the Sea projects which condenses that modal shift on to core sea based logistical routes. Four main corridors were identified, Motorway of the Baltic Sea, Motorway of the sea of South-East Europe, Motorway of the Sea of South West Europe and Motorway of the Sea of Western Europe which includes Portugal, Spain, via the Atlantic Arc to the North and the Irish Sea (European Council and European Parliament, 2004). The EU "Motorways of the Sea" project is expected to run until 2020 and therefore analysis of the effect of the programme is premature (Psaraftis, 2005).

\subsubsection{Marco Polo}

The Marco Polo programme superseded the PACT (Pilot Actions for Combined Transport) programme to support the objective to shift 12 billion ton-kilometres a year from road to non-road modes (Psaraftis, 2005). The Marco Polo funding was less than first expected. The first call in 2003 had funding of $€ 15$ million, of which 13 projects were retained out of 92 proposals. The second call was held in 2004 which had a budget of $€ 400$ million for 2007-2013 (Psaraftis, 2005) which has significantly expanded the programme and will include actions in support of EU policy for Motorways of the Sea and the modal shift outlined in the White Paper. Marco Polo will facilitate through projects a model shift in all segments of the freight 
market as the programme intends to support commercial actions which is a distinctive approach from programmes such as Trans-European Networks which provides support through R\&D. The commission has estimated that for every $€ 1$ provided by Marco Polo funding will generate at least $€ 6$ in social and environmental benefits (European Commission, 2007).

\subsubsection{Port Services Directive}

The EU Port Services Directive has been a sensitive and controversial piece of EU maritime policy that failed twice in its attempt to be part of European legalisation. The significance of the port services directive comes from the objective of the $\mathrm{EU}$ to reduce road congestion and promote motorways of the sea via the EU Commissions aim to improve market access to port services. The commission proposed a legal framework of "opening up" the maritime sectors of stevedoring, berthing and piloting to the forces of competition (European Commission, 2004). The defeat of the directive on market access for port services is viewed as a victory for the competition and efficiency of European ports (Psaraftis, 2005) as many in the industry considered that the EU directive should concentrate on competition between ports rather than their market access (Stares, 2005, A). EU Commissioner Loyola de Palacio in launching the directive said it would provide an "injection of dynamism" to the import export industry while in contrast it is already argued that Europe's port industry is already highly dynamic, efficient and competitive (Stares, 2005, B) and in January 2006 the second EU Port Services Directive failed in its attempt to deregulate the quaysides. Farrell (2001) argues that while a basic set of rules for Community ports would be useful to ensure and aid intra-European port competition maintains a level playing field the Directive fails to provide transparency and consistency as member states are permitted and have varying rules regarding individual ports. The directive also fails to provide any inclination of how the Commission would determine if an individual ports practice is in line with European objectives in terms of the Port Services Directive. Between 1994 and 2000 over 1,000 directives and regulations have been put forward but 
only three have ever been defeated (one being the port directive)(Stares, 2006).

\subsubsection{State Aid for Shipping}

LeaderSHIP 2015 is an EU lead initiative in support of the European shipbuilding and ship repair industry in response to the ever increasing competitive pressure the sector faces from Asian economies. LeaderSHIP's aim is centred on one direct aspect of cluster theory which is the power gained in the creation of new knowledge. The shipbuilding industry has suffered from a lack of global rules as there is a tendency for states to support the sector because of certain benefits such as high employment. European shipyards cannot compete with its subsidised low cost competitors in Asia; however the European yards can be at the forefront of new technologies and leaders of innovation with respect to shipbuilding, technology and design. Due to the competitive pressure on the sector it has encouraged concentration on the knowledge aspects of the shipbuilding industry such as specialisation in the production of sophisticated vessels (European Commission Green Paper, 2006) or what could be termed a strive to maintain the lifespan of the sector though an approach of "competitiveness through excellence".

\subsubsection{Tonnage Tax}

The implementation of a tonnage tax regime within Europe is a successful example of cohesion in European shipping policy. Tonnage tax allows a category of shipping companies to choose between traditional corporation tax, or a tax on the basis of the number and size of ships the company operates. During the 70's and 80's European countries suffered a decline of their flagged fleets and the Commissions 1997 State Aid Guidelines proposed measures to secure the survival and competitiveness of European flagged shipping (Selkou and Roe, 2004). The Commission 1997 State Aid report highlighted the competitive threat towards EU shipping from outside the EU as the Treaty of Rome regulations forced EU countries to behave in a competitive, harmonised and liberalised manner. The implementation of a 
tonnage tax regime was one such measure proposed by the EU outlined in the 1996 paper Towards a New Maritime Strategy to help provide supportive measures to the shipping industry in light of continued commercial pressure of operating within the EU and the European single market. While tonnage tax allows tax breaks within European countries not all tonnage tax regimes are identical, some regimes have different levels of commitment as many require an "opt in" of a minimum of 10 years. Some regimes are "flag blind", and some provide seafarers with deductions in tax (Selkou and Roe, 2004). The UK version has a cadet training requirement and for every 15 members of staff onboard there must be one cadet in training, which was implemented as a response to the decline in the uptake of UK Seafarers. Brownrigg (et al, 2001) argues that the City of London has a comparative advantage in terms of a maritime service cluster and that the cluster requires ex-British seafarers to enter that cluster for specific labour purposes to maintain that distinct competitive advantage and the loss of British seafarers (Leggate, 2004, Gardner, et al, 2001, Goss, 1993,) will inevitably have a negative impact of the London maritime service cluster. The benefit of the training aspect of the UK tonnage tax has been disputed with the Ratings Union RMT demanding an employment link with the training feature of the UK regime (Osler, 2006).

\subsubsection{Lisbon Strategy}

The Lisbon Strategy, Lisbon Agenda or Lisbon Process is an action development plan developed for the European Union set forth by the European Council in Lisbon on March 2000. The Lisbon Strategy is reflective of key characteristics of cluster theory with core objectives of the strategy founded on the concentration of knowledge based economy aspects for a single European market and to transform Europe into the biggest knowledge based economy by 2010 through applications of innovation and knowledge based approaches (EurActiv, 2004). In the current strategy, the Lisbon Strategy has five key goals which combined and achieved would increase the Gross Domestic Product (GDP) of the EU from 12\% to 23\% and 
increase employment to about 11\% (Gelauff and Lejour, 2006). The five targets are as follows;

- Internal market for services.

- Reduction of administrative burden.

- Goals on improving human capital.

- $3 \%$ target on research and development expenditure.

- $70 \%$ target on the employment rate.

The Lisbon strategy had to be re-launched due to disappointing results as it was clear that the targets for the strategy were not going to be accomplished by the deadline of 2010. The European Commission President Barroso described the stagnation of the Lisbon Strategy in 2005;

"Lisbon has been blown off coun'se by a combination of economic conditions. international uncertainty. slow progress in the member states and a gradual loss of political focus" (Europa, 2006)

The realignment of the Lisbon Strategy was to create a concentrated focus on job growth and to strengthen working relationships and partnerships between the Commission and member states. The reduction in the goals of the Lisbon Strategy is to enable a political focus on two of the core Lisbon objectives, which are an employment rate of $70 \%$ and a $R \& D$ investment of 3\% of GDP by 2010 (Europa, 2006). Member states have prepared a National Reform Programme (NRP) covering the relevant policy subject to the previous stated goals for their individual country.

\subsubsection{EU Green Paper}

On 7 June 2006, the European Commission (EC) adopted a Green Paper on Maritime Policy for the European Union entitled "Towards a Future Maritime Policy for the Union: a European Iision for the Oceans and Seas". The Green Paper has emerged from a year long consulting process with stakeholders to identify gaps between sea related sector policies and to raise debate on the future of maritime Europe. Part of that consultation stage was conducted through the Mare Forum and the DMNF in the European Maritime Policy Conference in Brussels in November 2005. The proceedings from the conference have helped to illustrate the diversification of interests 
concerned with European policy on oceans and seas. The European Commission Green Paper (2006) highlights what is felt across the industry that citizens of Europe are unaware of the importance of Europe's seas and oceans and the potential that they hold for individual nations. It is estimated that between $3-5 \%$ of Europe's gross domestic product is created by marine based industries and services, however this figure does not include the value added by raw materials such as oil, gas and fish (European Commission Green Paper, 2006). The importance of maritime activities to Europe can be visualized from certain statistics such as the fact that Europe remains the maritime superpower in the world owning $40 \%$ of the world fleet, orders $40 \%$ of new buildings, has a turnover in shipbuilding that exceeds that of Korea, Japan and China, handles 25\% of world seaborne trade through its ports, is the number one in yacht building, dredging, inland shipping, offshore services and has leading research classification societies and research institutions as a well as navies (Adamowitsch, 2006, European Commission Green Paper, 2006). The implementation of high level governance of maritime industries is important especially with regard to building cohesion for current cluster initiatives available at a local, national, regional and European level (European Commission Green Paper, 2006). The core objectives of the paper are;

* Retaining Europe's leadership in sustainable maritime development.

- Maximising quality of life in coastal regions.

"Providing the tools to manage our relations with the oceans.

- Maritime governance.

a Reclaiming Europe's maritime heritage and reaffirming Europe's maritime identity.

The current Green Paper suggests the formation of an annual conference on best practice for European maritime governance and to bring together representatives from all laver's of government and the relevant stakeholders for discussion, evaluation and future policy development in European maritime affairs and industries. 
The EU enterprise and industry (2004) commissioned the Policy Research Corporation to carry out a study of the impact of the maritime industries in Europe, the purpose of which was to provide basic economic and statistical data on the $15 \mathrm{EU}$ nations (at that time) and Norway. The EU15 report highlights the concern with respect to the methodology prescribed by member states to gather information on indigenous maritime clusters and therefore the facts and figures detailed in report are "best estimates". The issue of cohesion of data concerning maritime industries was again recently addressed again by Janssens (2006) with regard to how the Eurostat statistical systems could be harmonised to evaluate all current 27 member state's maritime industries at a consistent level and in light of the future policy through Europe's Green Paper on European maritime industries. The EU15 paper also discusses the possibility of a classification system (such as NACE) with regard to maritime industries which would help the process of analysing maritime sectors, as of the ten maritime sectors identified in the paper over half were not covered by EU member state statistics.

The role of the European Union in terms of maritime policy has developed considerable since the original first measures package of 1986 and 1989. Europe hosts $70,000 \mathrm{~km}$ of coastline along two oceans and four seas and EU maritime regions account for some 40\% of GDP (Commission of European Communities, 2007). As of October 2007 the European Commission presented its Blue Book which is a vision for the integration of maritime policy for the Furopean Union (Commission of Furopean Communities. 2007) which specifically addresses maritime clusters. The Commission intends to take a review of the situation regarding $\mathrm{EU}$ maritime clusters with the objective to first understand and amalgamate maritime industries, maritime cluster's and maritime policies and to ultimately identify the key driver's and characteristics of successful European maritime clusters. The maritime agenda in terms of an EU focus increasingly grows in importance and relevance and will have a more concentrated role in enhancing for the future EU maritime industries. 


\subsection{Ireland, Maritime Industry, Clusters and Policies}

The European Union is heavily dependent on maritime transport and Ireland as an EU member is an island nation located on the periphery of Europe. Ireland experienced a period of rapid growth during the 1990's which resulted in the Irish economy being dubbed the "Celtic Tiger". In a short period of time Ireland went from being the poor man of Europe to becoming one of Europe's wealthiest and fastest growing economies. The Celtic Tiger's growth was fuelled by high domestic demand as private consumption exploded due to noticeable gains in individual incomes and general wealth along with consistent and strong sustainable investment (IDA, 2006). The reasons for such rapid drive and growth of the Irish economy is debated as a consequence of many factors such low corporation tax, EU funding, decades of investment in education, a young labour force and free market capitalism.

In terms of other clusters of industry in Ireland, O'Malley and Egeraat (2000) discuss a software, music, and dairy cluster with respect to Porter's five forces on competitive advantage. Clustering related to the industries of chemicals and pharmaceutical plants are cited to be primarily located in the Cork region of the country (Gleeson, et al, 2005). However, perhaps the most recognisable cluster in Ireland is the International Financial Service Centre (IFSC) cluster located in Dublin city which was developed by the Irish government in 1987 in response to rapid growth in the finance sector and was a success in both developing a cluster of industry and a process of urban renewal (IDA, 2007, A). In 2001 the IFSC employed an estimated 8,500 personnel and the cluster held many of the world's leading financial institutions, law firms, accountancy and taxation advisor's (Williams and Shiels, 2002). Ireland's Information, Communications and Technology (ICT) cluster is a key economic sector to the Irish economy. The critical mass and headquarters of firms are based in Dublin although ICT firms are also located in Belfast, Cork, Galway and Limerick. Green (2000) argues that according to Organisation for Economic Co-operation and Development 
(OCED) Ireland has one of the highest concentrations of information and communication technology activity and employment of all OCED countries. In 2001 nearly 8000 companies employed 14,000 personnel, generating C1.4bn in revenue (Origin, 2002) despite the economic downturn of 2000 and 2001 which had a negative effect on the global software market. The software market also has strong links with research and development and further funding and investment is vital to the future of the software industry and maintaining Ireland's software cluster. Ireland has many university based research campuses supporting the creation of new knowledge and labour supply for the ICT cluster.

In 1949 the Industrial Development Authority (IDA) was formed as part of the Department of Industry and Commerce to support and facilitate export driven business in Ireland. Currently the IDA has three sub-organisations; Foras which concentrates on policy for trade, enterprise, science, technology and innovation, IDA Ireland which concentrates on the promotion of foreign direct investment (FDI) into Ireland and finally Enterprise Ireland which works with Irish industry and partnerships. Currently and post Celtic Tiger boom one of the main objective strategies of the IDA is to develop and promote Ireland as a knowledge based economy which is an increasing trend in well developed economies in light of the onslaught of globalisation and the increase in relocation of manufacturing to Asia. Ireland has been successfully in attracting FDI and the IDA has actively supported this in helping to entice and ensure the location of hitech industries in Ireland such as Dell, IBM and Hewlett Packard (Gleeson, et al, 2005).

As highlighted in the discussion on policies within a European framework, while there may be pure direct cluster policies there are also initiatives, organisations and policies that may also positively affect an individual industry and its clustering potential and therefore within that context are relevant for any discussion on cluster's and developing industry. Similar in context to the European TENT-T, the Irish government developed a National Spatial Strategy (NSS) which is a 20 year plan to devise and design a better balance of social, economic and physical development for the 
country of Ireland and one of the key concepts of the strategy is to develop the potential for critical mass, gateways, hubs, complementary roles and linkages (NSS, 2002). The driving force behind the strategy is to strengthen and restructure the Irish economy in reflection of the accelerated change seen through the 1990's. Ireland has also invested heavily in the country through the National Development Plan (NDP) supported by the EU Community Support Framework (CSF). The first NDP which ran from 2000 to 2006 invested $\mathrm{C} 57$ billion of public, private and EU funds into numerous projects supporting a wide range of programmes concentrating on education, transport, health, rural development and local development (NDP, 2007). The current NDP will run from 2007-2013 which builds on the previous investments through implementing a budget of $\mathrm{E} 185$ billion concentrating on programmes for sustainable growth, greater social inclusion and balancing regional development. Specifically for transport, the Irish government in 2005 launched their Transport 21 programme for investment in transport for the period $2006-2015$ with an estimated budget of C34.4 billion (Transport 21, 2006).

In light of all the positive effects of the Celtic Tiger, there is criticism in terms of the lack of reforms with regard to the transport sectors and the slow breakdown in transport government monopolies and the construction of new roads and motorways to cope with increasing commuter pressure. As already discussed in terms of a cluster or maritime objective organisation Ireland has the IMDO which was established to promote, develop and support maritime industries in Ireland. In terms of maritime policy the IMDO was instrumental in helping to establish a tonnage tax regime in Ireland in February 2001. Similar to Europe overall, Ireland witnessed a decline in its flagged fleet from 80 registered vessels in 1981 to 42 in 2001 (Selkou and Roe, 2004). Prior to the introduction of the tax the Irish government were faced with considerable pressure from firms such as the Irish Continental Group (ICG) who threatened to re-flag to the UK registry along with Arklow Shipping who threatened to re-flag 27 vessels to the 
Netherlands registry. The fiscal disadvantage of the tax regime prior to the introduction of the Irish tonnage tax was described by the chairman of ICG;

"We will not be able to continue to fly the Irish flag indefinitely if our tax regime is more onerous that that of our competitors who are free to trade into Irish ports while enjoying the benefits of other $E U$ countries tonnage tax regimes" (Lloyds List, 2001)

Due to Ireland's low corporation tax (12.5\%) Ireland can provide one of Europe's most competitive tonnage tax regimes. Under the Irish tonnage tax regime a shipowner will only pay a fraction of the tax that would normally be required as the tax is calculated by applying a fixed speculative profit based on the size of a vessel and then applying the standard corporation tax (i.e. 12.5\%). Due to Ireland's low corporation tax this makes Ireland's tonnage tax regime one of the most competitive in Europe (IMDO, 2003). Tanker and dry cargo operator d'Amico is an example of one company which has recently moved its head office to Ireland and according to the company manager the attraction of Ireland is its $12.5 \%$ corporation tax rate, and its stable political and economic environment (Frank, 2004). Ireland's tonnage tax regime is just one component of overall tax and fiscal benefits provided by the Irish government. The Irish government continually strives to create an exceptional tax environment and has a commitment to place Ireland on a competitive field so it has compatibility with other jurisdictions offering transparency and clarity. Some of the world's major companies have located in Ireland including; Johnson \& Johnson, Coca Cola, Citibank, GE Capital and Ireland has also been highly successful attracting FDI into the country supported by a network of tax treaty's with some of the world's major trading nations such as the US, Canada, Japan and Korea (IMDO, 2003).

The IMDO also made an attempt to update and modernise the Irish ship register in conjunction with support from the IDA to promote Ireland as an international centre for ship management and related maritime business (MacSweeney, 2003, A). In late 2003 and in light of Ireland's new tonnage tax regime, concern was raised that the Irish registry was in danger of becoming a flag of convenience as eight ships registered on the Irish registry 
were over 20 years old (MacSweeney, 2003, B) and the level of the resources to inspect ships was also raised.

In terms of maritime transport Irish ports facilitate $99 \%$ of the volume of Ireland's foreign trade (Port Policy Statement, 2005) and as an island nation Ireland's ports are vital to the economic infrastructure. Irish commercial ports are regulated through the Harbours Act $1996-2000^{7}$ and through the state via the DCNRM (Department of Communications, Natural Resource and the Marine) who acts as the single and only shareholder (High Level Review, 2004). The government policy towards the port sector is that the Republic's ports should operate commercially without exchequer support to provide sufficient capacity to secure the future needs of the economy (Ports Policy Statement, 2005). Specifically within the GDR, these are the ports of Dublin and Drogheda (Appendix 1: Dublin Port and Drogheda Port Statistics). Dublin is the largest port in Ireland which handles nearly 30 million tonnes of freight in all modes of which almost two thirds are imports (Oram, 2006). Currently there is concern about future capacity constraints at Dublin port and Ireland's ports in general given the potential negative effects it could have on port congestion as the growth trend in traffic volumes through Irish ports increases. In the port policy statement it was highlighted that the future anticipated shortfall capacity in Ireland will be over 12.2 million tonnes over the next 10 year's (Port Policy Statement, 2005). However in examining projections from the entire port sector in Ireland there appears sufficient capacity and EU funding up to 2000 which has helped facilitate port capacity leaving ports sufficient to cope with the short to medium demand. However some of the capacity is located in geographical sites in which demand for that space may never materialise and therefore the future capacity restraints are a considerable problem for Irish ports and the government. However Irish ports and in particular Dublin Port; in order to deal with the predicted shortfall in capacity have

\footnotetext{
In 2003 the estimated value of imports and exports through the Republic's ports was 6130 illion. compared to airports which were between C7-C10 billion (Port Policy Statement. 2005).

Port companies under the Harbour Act 1996-2000 are responsible for the management. direction. control and development of the ports as a commercial state company. (High Level Review. 2004).
} 
taken steps to increase capacity through more efficient use of the land space currently at there disposal (ICG,2007).

Capacity Shortfalls Identified for 2014 as per 2004 Updated Assessment of Commercial Seaport Capacity ${ }^{5}$

Table 1

Capacity Shortfalls Identified for 2014 as per 2004 Updated Assessment of Commercial Seaport Capacity

\begin{tabular}{|l|l|l|l|}
\hline Port & Bulk Solids & Bulk Liquid & Unit Load \\
\hline Drogheda & 130 & 80 & 720 \\
\hline Dublin & - & 1,380 & 2,930 \\
\hline Total & 130 & 1,460 & 3,650 \\
\hline
\end{tabular}

(Source: Port Policy Statement, 2005)

The Drogheda port company has proposed a solution to the capacity and congestion problem as the port currently has plans to relocate north of Drogheda to Bremore in order to construct a new port to deal with future capacity constraints and to provide a competitive service for the future growth potential of the port (Drogheda Port Company, 2006). Bremore is suitably located along the Dublin/Belfast infrastructure and economic corridor (Appendix 2: Bremore Deepwater Port Development) and holds attributes in its deepwater location, low residential density, good intermodal access and the strategic North/South location (Mangan, 2004). The Bremore Port would operate as a 24-hour facility and Phase 1 of the project would cater for 5 million tonnes of commercial freight. However at the end of Phase 3 of the development the port will have a capacity of up to 20 million tonnes. The Irish government has just recently approved the establishment of the joint venture between Drogheda Port Company and Castle Market Holdings which will allow for progression to the next stage which will concentrate on formulating the port design and planning prior to a public consultation process (Drogheda Port Company, 2006).

One of the most current controversial issues in the maritime transport sector in Ireland is the proposed Bremore development. General public opinion appears misguided, in that there is a perception that the argument

\footnotetext{
"Figures shown represent metric tonnes ('000tonnes). and do not indicate unit load as either Ro-Ro or Lo-Lo. and do not display further breakdown of cargo e.g. semi bulk or timber etc.
} 
is based around Dublin Port relocating to the Bremore site. Such misguided opinion has been put forward by the Progressive Democrats (PD's) political party before the 2007 general election and by Dublin City Council and their study into moving Dublin port and developing a "new city" at the current Dublin port location (Progressive Democrats, 2006). However the reality is that Drogheda Port is planning a new port development which would be in direct competition with Dublin port. A number of European cities have moved port activities outside the main city centre such as the Danish and Swedish cities of Copenhagen and Malmo respectively and Melbourne is also currently redeveloping and creating a mini waterfront city. Due to state ownership of the port and the soaring land values it could be argued that the state has a duty to examine if the land acquired for Dublin Port operations is being utilized to its full potential. Dublin Port consists of 650 acres valued at $€ 15 \mathrm{~m}$ an acre (Coleman, 2005) and is a prime city centre real-estate location that could be utilized for redevelopment for offices and business that could provide an economic stimulus for the city similar to the development of the IFSC in the early 1980's. Such a redevelopment would afford revenue for the exchequer. However opposing arguments question that such a move could make the $€ 770 \mathrm{~m}$ port tunnel development somewhat redundant. However it is also reasonable to argue that if the Dublin Port area were redeveloped and rezoned the port tunnel would provide the necessary physical infrastructure to support increase activity in terms of residence and business transport in and out of the city centre. This is even more important when taken in the context of the slow investment in Ireland's physical infrastructure and the overwhelming consensus of the limitations of the country's physical transport network.

The next chapter will examine specifically four of the main economic theories associated with clusters and the reasons for the clustering of industries in specific locations. 


\section{Chapter 3.Cluster Structure Cluster Governance}

As discussed in the previous chapter there is a considerable amount of literature on clusters, clustering and cluster theory which continues to be supplemented with contemporary work. Research helps to provide a means of comprehension in terms of an application for cluster measurement. To analyse and understand a cluster, even if it's just a snapshot of a cluster at a specific point in time, requires some sort of unit of analysis, measurement or qualitative understanding. De Langen (2003) devised a framework for cluster analysis based on four of the main schools of thought on cluster theory. The combination of the four main schools in de Langen's Cluster Structure Cluster Governance Framework allows for the analysis of a cluster from a checklist perspective, a type of cluster strength, weakness, opportunities and threats (SWOT) analysis. The following chapter will discuss the four main economic schools that make up the cluster structure cluster governance framework.

\subsection{Agglomeration Economics / New Economic Geography}

The spatial equilibrium theory or "new economic geography" is focused on the area of agglomeration economics which investigates the clustering of industry in certain locations and examines the benefits of increasing returns and the advantage firms obtain by being within a reasonable proximity to each other. The new economic geography concept or agglomeration economics which discusses extcrnalities that lead to industry localization. attributed by Marshall (1890), identifies three main agglomeration economies which are; the presence of a labour pool, presence of customers and suppliers, and knowledge spillovers. Therefore the agglomeration economy forces promote the clustering of industries in certain locations. Thus if the previous three forces dominate a cluster should have a good prospect of developing. There are also diseconomies associated with agglomeration economics which are high land rents and congestion which reverse the agglomeration power of the clustering force and drive down pricing power and keeps cities at a reasonable size. The economies of scale 
achieved by spatial concentration are a major influence on the establishment of clustering and a key concept of industrial location theory (Fujita, et al, 2001).

\subsubsection{Labour Supply}

The concentration of industries in a certain area or industrial district will attract a labour supply due to the co-location presence of firms with similar labour demands. The pooling of labour to an area allows for and can create a specialization and efficiency of a labour market or a brain drain to a region while reinforcing the localisation effect. Skilled labour can be attracted due to employment prospects and job mobility while for firms the cost of sourcing labour and firing labour is relatively cheap (de Langen, 2003). The clustering of labour is also related to knowledge as clusters can evolve to benefit from year's of industry knowledge and expertise. The City of London has a great maritime tradition and a financial and legal tradition as it is an important maritime financial and legal cluster. Enright (2003) discuses the prominence of the Carrara (Italy) stone cluster which evolved from the concentration of exporting indigenous marble to a labour pool so specialized it compensated for the cost of having stone imported, to be cut by Carrara stone cutters, and then re-exported. The US motion picture industry based in Los Angeles benefits from a labour pool so varied it allows producers to select a unique workforce and range of specialise skills from actors to graphics to writers for each individual movie (Enright, 2003).

\subsubsection{Knowledge Spillovers}

The force of knowledge and extent of knowledge spillovers stems from Mar'shall's (1890) notion of the "industrial atmosphere" as an economic resource that is "in the air". In terms of knowledge Bathelt (et al, 2004) discuses two types of knowledge which are tacit knowledge, which is local and codified knowledge, which is global. The benefit of tacit knowledge is in terms of economic spatial concentration and firm proximity in which repeated face to face meetings enhance the prospect and forms of information exchange (Bathelt, et al, 2004) and combined with codified 
knowledge can help create a valuable cluster resource. Knowledge is to some extent invisible and therefore it is difficult to measure its impact or value (Jaffe, et al, 1993, Audretsch, 2003). The mutual beneficial knowledge created due to close proximity helps to reduce transaction costs and facilitate knowledge development which in turn caters for the promotion of innovation and encourages knowledge spillovers (Karlsen, 2005). Knowledge and the pursuit of cluster knowledge and the management of that knowledge are the determinants of a particular industry or sector that can lead and drive an individual cluster towards global competitiveness (Dayasindhu, 2002) especially when competing cluster knowledge is growing in concentration. Knowledge is perhaps the most important feature and a fundamental resource for modern economies and hence the use of the term "knowledge economies" (Conçalves, 2006) or the ambition of nation to become a knowledge based economy. This is especially prevalent due to the onslaught of globalisation and the shift in production and manufacturing from western economies to Asia which further intensifies the value and production of new knowledge (Audretsch, 2003).

\subsubsection{Presence of Suppliers and Clients}

Agglomeration economics in terms of externalities has two core sections. First the concept of location externalities which are the derived benefits for firms in the same or similar cluster of industry within spatial proximity. The second is the urbanization externality which is referred to as the benefit of firms in many different industries within spatial proximity (Baptista, 2003). A cluster is subjected to a core economic specialisation and therefore firms, businesses and organisations located in the cluster are mutually related firms linked to the cluster's core economic specialisation. The presence of a good mix and weight of suppliers and clients in the context of a similar cluster of industry can incur lower transaction costs for firms and greater access to specialised outputs such as business services, personnel, training and trouble shooting (Porter. 1998, Enright, 2003). The supplier's potential to behave in an opportunistic manner is reduced due to the higher transparency of local relationships and the potential negative business 
effect of mistrustful behaviour. Locating in a cluster with a greater presence of customers enable firms to be at the point of business and allows for greater recognition of potential new market opportunities with reduced market risk due to a greater supply of customers.

The three forces of agglomeration economics outlined above encourage spatial concentration. However land scarcity and congestion are factors that disperse the clustering forces. Within a cluster there is a desire to be located within the cluster which creates an issue of land scarcity and congestion which can drive up the price of the cluster location. High land prices and increasing congestion can reflect negatively on the attractiveness of the choice of location of one cluster over another.

\subsection{Competitiveness Theory - Porter's Diamond Model}

Perhaps the most well know of all the major economic theories is Michael E. Porter's Diamond Model which was developed from his 1990 book The Competitive Advantages of Nations. Porter's Diamond theory is based on a need to understand,

"Why do firms based in particular' nations achicve international success in distinct segments and industries"? (Porter, 1990)

According to Porter the competitive advantage of industry is reflected in the diamond model (Figure 1). Porter illustrates that it is firms and not nations that compete in international markets and the presence of competing clusters is a key dynamic factor to nation competitiveness (Jasimuddin. 2001).

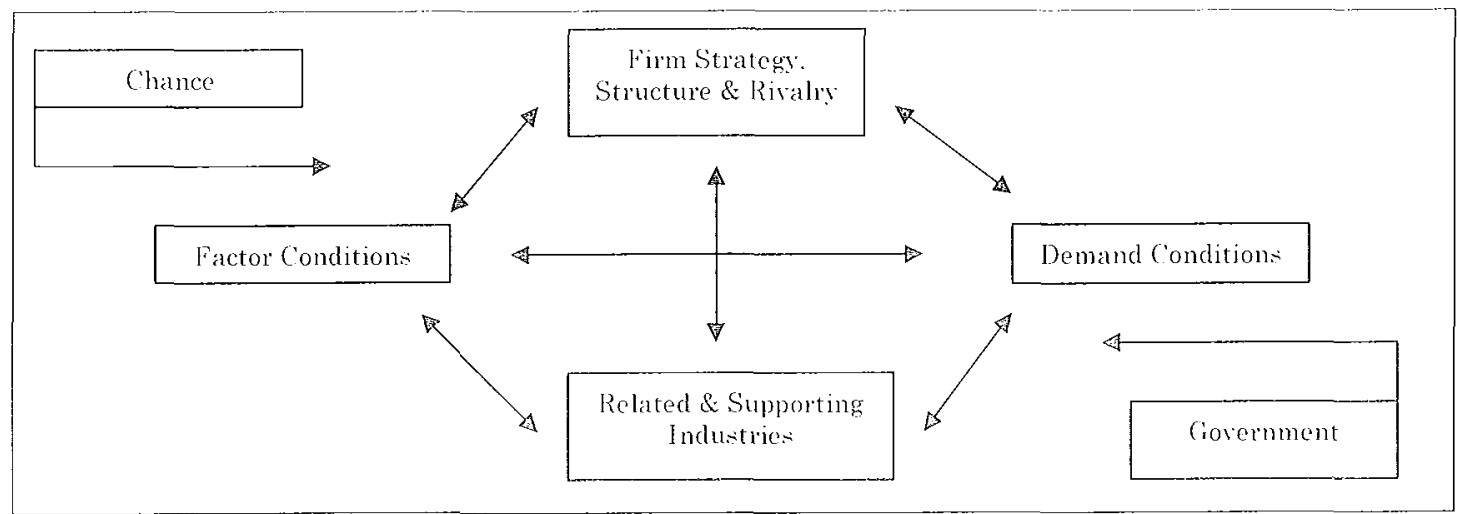

Figure 1 Porter's Diamond Model (Source: Porter. 1990, p. 72) 
Nations succeed in clusters of industry rather than isolated islands of industry and it is the mix and weight of those clusters that are the root of a nation's comparative advantage and a reflection of the state of an individual economy (Porter, 1990). The determinants of competitive advantage within the diamond model are domestic factor conditions, domestic demand conditions, the presence of related and supporting industries and firm strategy, structure and rivalry. Porter (1990) also identified two subsequent factors, the influence of government and the role of chance events.

\subsubsection{Factor Conditions}

Factor conditions or factors of production are perhaps the obvious features of economic resource such as infrastructure, land, capital, labour and availability of resources (Jasimuddin, 2001). Such key factors are created by advanced sophisticated economies and are not inherited features of production. Porter (1991) argues that the most important aspects of production include specialized heavy investment as a local resource or a pool of labour, but they do not necessarily provide a competitive advantage in knowledge intensive industries. To encourage competitive advantage a factor condition must be highly specialized and meet the industry's particular needs, as such types of factor conditions are much harder for foreign companies to imitate and thus nations whose industries are proficient at factor creation tend to succeed. Disadvantages can also help cluster competitive dynamism because when firms face similar disadrantages they are driven towards innoration to protect their competitive position and thus the disadvantage can become the advantage (Porter, 1991).

\subsubsection{Demand Conditions}

The demand factor is necessary as Porter (1990) argues that a good home market will instigate good conditions for competing abroad. The application of good home demand encourages indigenous firms to interpret and respond with faster and greater efficiency to demanding markets despite the effects of globalisation on world markets (Porter, 1991). If a firm has a good 
understanding and appreciation of a constantly adapting and demanding home market then firms will have a more precise view of what international buyers and markets require. An example of demand conditions is if a competitive industry is a sophisticated and demanding customer (for the products of its suppliers), it helps to generate domestic demand conditions which drive to maintain a competitive advantage among supply industries (O'Malley, et al, 2000). Demand conditions force companies to innovate, develop and lead the way forward in challenging the tough problems brought on by demanding world markets and their customers in order for firms to remain successful and retain competitiveness in an increasing market of globalisation.

\subsubsection{Related and Supporting Industries}

This factor deals with the presence of local suppliers and related industries as the closeness between related and supporting industries helps to facilitate the exchange of information and fosters local co-ordination and innovation between firms. Competitive suppliers also help to create advantages that will filter downstream through the cluster and increase competitiveness, the mix, weight and embeddedness of the related and supporting industries. A strong mix can help provide strength to a cluster and apply a resistance to external shock. Porter (1990) also introduced the concept of related industries that can be correlated due to their similar needs or similar requirements of factor conditions such as a labour supply. The need for such labour and the close proximity of firms can help lead to and strengthen the labour pool for all firms associated within the cluster (O'Malley, et al, 2000). The concepts of related industries in Porter's work helps to illustrate how firms within industries complement each other within a cluster of industry.

\subsubsection{Firm Strategy, Structure and Rivalry}

Firm strategy, structure and rivalry are the conditions that preside over the environment of companies and how they are formed, organised and managed and the quality of domestic rivalry (Porter, 1991). The presence of 
internal competition is an important factor for cluster nourishment and a strong competitive indigenous environment helps firms within the cluster to behave in a more dynamic way. The rivalry in the domestic market place helps firms succeed in international markets. Porter (1990) argues if firms within a cluster do not have to fight through constant innovation to maintain their customer base and market share it is therefore unlikely they will perform dynamically in international markets, and in doing so weaken the indigenous cluster in the international arena.

\subsubsection{Role of Chance and Government}

Porter also discusses the role of chance and the role of government among the five mutually enforcing factors. Within a cluster and it's supporting five forces the whole group of industry benefits flow forward, backward and horizontally (Porter, 1990). Enright (2003) in discussing innovation highlights that literature suggests that face-to-face meetings, planned or unplanned, formal and informal are vital to the innovation process. Information and innovation flows throughout the cluster and rivalry spreads and encourages growth and innovation in the supporting and related firms. Government can influence a cluster by its visible support for the industry through regulations, laws, tax breaks and supportive polices such as funding for research and innovation.

Porter's key features of the diamond model are mutually enforcing and each defines a point of national competitive advantage classified within a system which is driven by factors of competitive advantage and excludes to some degree social influences on cluster development.

\subsection{Industrial District Theory}

The industrial district school or the "new regional science" concentrates on the analysis of local business units, leader firms and their behavior. The industrial district theory focuses on the level and application of trust (Cooke, 2002) within a cluster, embeddedness, social depth of firms, the importance of institutions and the role of governance. The theory argues that it is regional concentration that encourages further innovation and that 
chance meetings secure a higher level of trust which in turn benefits the whole cluster. Morosini (2002) incorporating the work of Marshall (1890) describes a cluster or industrial cluster as;

"An industrial cluster] is a socioeconomic entity characterized by a social community of people and a population of economic agents localized in close proximity in a specific geographic region. Within an industrial cluster, a significant part of both the social community and the economic agents work together in economically linked activities, sharing and nurturing a common stock of product, technology and organizational knowledge in order to generate superior products and services in the market place"

Karlsen (2005) argues that literature provides only a few reasons as to how an economy and the domestic culture interact and the effects of such interaction. Scholars have begun to reformulate their view and application of cluster research from the economic concentration of localized activities to a more sociological approach in that clusters really are social communities with efficiencies and abilities for knowledge creation and transfer (Morosini, 2002). The industrial district school of thought is moving increasingly towards the concept of learning economies, learning regions and innovation systems (Karlsen, 2005).

\subsubsection{Trust}

Economic sociologists will look at the relationship between firms and the relationship of trust. Trust is a feature of cluster theory, although the function and level of trust in a particular cluster can be a problematical attribute to measure or value. In the first instance, what is trust? Trust can be described or defined as.

"Firm belief in the reliability, truth of someone or something"

Or defined as,

"Acceptance of the truth of a statement without cvidence of investigation" (Oxford Dictionary, 2005)

Definitions or understandings of the meaning of trust do not convey the importance of this feature of cluster theory and its importance to any working cluster regardless of how immeasurable or quantifiable the level of trust in a cluster may be. Trust and its adversary mistrust are behaviors, 
feelings and in some cases an action (based on either trust or mistrust). Trust as a behavior helps to lower transactions costs and illustrates the relationship of firms in a cluster (Cooke, 2002). Lower transaction costs are described by Dayasindhu (2002) as the costs of an exchange relationship which includes the drafting and negotiating of contracts, dispute settlement and general exchange relationship and administration costs. Cooke (2002) argues that learning economies have the recognised trait of high trust levels and that trust, learning and knowledge can help to increase economic efficiencies due to low transaction costs and increased level of knowledge effects (Dijk and Sverrisson, 2003). Trust is a vital component for cluster success and a feature that may have eluded previous cluster scholars of its importance and possible positive effects (Cooke, 2002). Successful clusters, regions and industrial districts could not wholly attribute their success alone to the power of strong domestic markets and strong inter firm rivalry (Cooke, 2002).

\subsubsection{Embeddedness}

Embeddedness is a term used to describe the strength of relationships in a cluster as all possible economic models are affected by the actors economically "acting" within the cluster, and that "acting" is a reflection of the sociological make up of a region (Morosini, 2002). Embeddedness as a concept of sociology is also a subsequent feature of cluster theory that can help to determine global competitiveness (Dayasindhu, 2002). It can be argued that some of the benefits associated with clustering are conceived due to the nature of the social climate of the cluster in the forms of local culture, values and norms (Forsman and Solitander, 2003). Embeddedness like the role of trust in clusters is an illustration of social relations and the level or depth of embeddedness fosters trust and helps prevent firms and organizations from the behavior mode of opportunism and reduces the cost of knowledge transmission (Audretsch and Feldman, 2003). However an ideal level of embeddedness is a mid range or intermediate level as too much embeddedness can become too restrictive and fragment relationships within the cluster (Dayasindhu, 2002). Literature also gives an indication of the 
negative effects of too much embeddedness as clusters, in order to keep within the world market mode of constant innovation need to integrate repeatedly with external networks (Forsman and Solitander, 2003). Too much domestic and regional interaction and reliance could numb firms from the changes and movements of international markets which are essential for long term competitive success.

\subsubsection{Leader Firms}

Clusters have firms and firm variety can help enhance a cluster's potential performance. Firms within clusters that are leader firms are positioned and behave in a certain way due to their knowledge, market position and the ability they have to make investments that can create benefits for all firms within the cluster (de Langen, 2003). Leader firms can help to build a reputation of a cluster which can enhance the overall perception of a cluster and its competitive performance. Leader firms help to create and maintain high standards; improve the capability of knowledge transfer in a cluster and increase the internationalization of a cluster (Dutch Maritime Forum, 2004). There is no direct benefit in terms of the relationships between firm size and leader firm behaviour (de Langen, 2003); however a leader firm can have a substantial impact on other firms in the cluster (Nijdam and de Langen, 2003).

\subsubsection{Governance}

The feature of governance is perhaps visible to some degree in each of the theories discussed within this chapter and a feature present in regional and national clusters. Governance can take form at local, regional, national and supernational levels as European member states also have a multi-level governance framework (Cooke, 2002). EU governance issues have driven many policies for support and development of "less favored regions" and supporting frameworks and funding for driving innovation, knowledge and R\&D. Wang and Slack (2004) argue that governance is a collection of institutions, industry associations, local councils and government which address the social and economic issues of a country or more specifically a 
region. De Langen (2004) argues that analyzing governance leads to a greater understanding of the potential level of competition and performance of a region.

\subsection{Population Ecology Theory}

Population ecology is not a core cluster-based theory but research on clusters has discussed a cluster or referred to a cluster as a population, which includes all firms within the cluster and the related and associated firms and organizations (de Langen, 2003, Cooke, 2002). This area's main contribution to cluster theory is with respect to the level of entry and exit barxiers to the cluster and the amount of start-ups, failures and bankruptcies, the basic population dynamics of a cluster and the cause and effects of shifts of movements in a cluster population.

\subsubsection{Barriers}

The term cluster barriers are made with reference to the barriers faced upon entering or exiting a cluster. Ideally a cluster will want to have high exit barriers which amplify the level of a firm's stickiness to a cluster. There are many types of exit barriers a firm may experience such as immobility of assets including machinery, the stickiness of labour, specialised labour and specialised knowledge (de Langen, 2003). To exit a cluster may be a considerable expense despite a company's good balance sheet (Harrigan and Porter, 1991). The strength of exit barriers affords confidence in the long term success probability of the cluster and thus reduces the possibility of firms exiting the region which can help to secure jobs and encourages firms to make long term investments. Thus high exit barriers drive to increase the performance of a cluster. Cluster entry barriers take the form of social and cultural barriers and barriers to regional cluster knowledge. de Langen (2003) argues that such knowledge can be obtained by learning by doing or through interaction, but it can be a costly process as the flow of cluster knowledge to new entrants depends on the current existence of social and trust within the cluster and the willingness of the current cluster actors to encourage the flow of cluster knowledge to new entrants. 


\subsubsection{Heterogeneity}

The heterogeneity of a cluster is the mix and variety of related and supporting industries of a cluster and the variety of such business firms adds to the overall potential of a cluster's performance. A cluster and it's variety of firms and business units, have what can be described as a compilation of capabilities and possibilities such as the ability to learn, to innovate and to create and transfer knowledge, all of which are intrinsically linked to the social climate of a cluster. Proficient levels of cluster heterogeneity allow for greater opportunities for firm co-operation and innovation and afford a protection from external shocks and severe changes in world or local markets (de Langen, 2003). The opportunities of $\mathrm{co}^{-}$ operation driven by the cluster heterogeneity can help the diffusion of innovation across a cluster (Goswami and Karmeshu, 2004) which is similar to the diffusion of cluster knowledge. Firms which have international parent companies adds internationalisation to the cluster which helps to facilitate the information flow more efficiently within and through firms rather than across markets (de Langen, 2003).

\subsection{Limitations of the Framework}

Porter's competitiveness theory or diamond framework has received criticism over the years due to its inability to include individual cluster specifics (Dayasindhu, 2002), such as the study of small open peripheral economies and the exclusion of foreign multinational enterprises as having and facilitating a contribution to domestic competitive advantage (OMalley, et al, 2000). Within the Irish context in the investigation of three international competitive clusters (dairy, software and music), it was highlighted that Porter's strategy would be inappropriate because the clusters showed divergence from some of the core features of the diamond model. Ireland's small open economy means limited domestic demand. rivalry and supply and there is a significance presence of foreign direct investment in the Irish economy (Cooke, 2002). While new economic geography predominately looks at the forces of agglomeration and what 
hard structures help induce clustering in a region, and population ecology is based on the population dynamics of a region, however they both fail to take into consideration the effects and behavioural aspects of clusters of firms. Benneworth (2002) argues that academics have theorized clusters into two areas: first geographical clusters and second, the new economic geography which focuses on the "hard" features of clustering. Benneworth (2002) in citing Dosi (1987) criticizes this approach in models as weak because of the failure of the models to take into consideration the effects of what people do. The absence of one cluster model which can fit all clusters, or the optimum tool of measurement for a cluster which can quantify all the possibilities of a cluster, with respect to both hard and soft economics is an unfortunate inherent characteristic of the nature of research on clusters. An illustration of this is taking cluster polices from a successful cluster and applying the policy to a less favoured region, which has the absence of core features of the successful cluster, which made it successful in the first place. Such successful clusters should perhaps be looked at as exceptional rather than a general economic occurrence (Benneworth, 2002) as Dayasindhu (2002) argues that the analysis of clusters or a framework for cluster development should be investigated from a perspective of economics and cluster theory, sociology and knowledge management. It is perhaps within the recognised limitation of an individual theory to sufficiently analyse a cluster, its inherent complex nature, and the effects of both the hard and soft economics of cluster performance that piloted de Langen (2003) to devise the cluster structure cluster governance framework. However caution must be taken in applying the framework to any methodological research as the combination of four theories has the danger of losing the validity of an individual economic model. However the combination of the theories can be used as a process of initial research exploration or information data collection. de Langen (2003) used the framework to develop questions utilised for an interview process and case study approach to investigate the performance of seaport clusters in Durban, Rotterdam and the Lower Mississippi. 
Chapter 2 and Chapter 3 have provided a review of literature concerning clusters, cluster theory and relevant aspects of maritime transport and policy. The next chapter develops the research and specifically begins to investigate a maritime cluster in terms of individual maritime sectors and addresses specifically the process of sector identification for the GDR maritime transport sector.
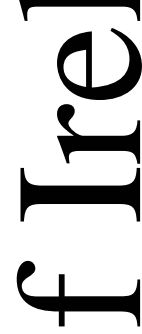

$\longrightarrow$

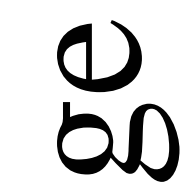

(1)

F

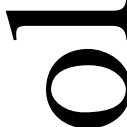

(

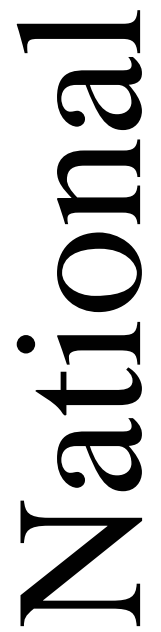




\section{Chapter 4.Cluster Mapping and Sectors}

The purpose of this chapter is to provide an illustration of the GDR maritime transport sector. It will provide an essential picture of what the GDR maritime transport sector looks like in terms of the concentration and diversity of firms within the sector. The chapter will also investigate how other maritime clusters have been divided into sectors and the various ways in which maritime clusters are defined. This chapter will provide a basic step by step approach on how to delimit a maritime transport sector for the purpose of analysis of a potential maritime cluster.

The literature has provided to some degree an illustration of the possible sectors that constitute a maritime transport cluster. Defining the sectors of a maritime transport cluster is a direct derivative of the services that are functioning within the cluster. The first stage in sector identification was to conduct a brain storm of the possible sectors supported by examples from individual cluster models such as London and Rotterdam. Some sectors are more clearly identifiable than others such as the port sector for example. Identifying sectors for a general maritime transport cluster model is not an arduous task; however the difficulty is in applying that process to an individual maritime transport cluster as individual businesses may operate in more than one sector i.e. freight forwarding and agency for example, and some companies may have sister companies and subsidiaries. Individual sector identification is perhaps a more difficult objective than may be first perceived and it can become an arduous task with the potential for individual firms to be incorrectly classified. While there are international classification standards (Appendix: 3 NACE Classification) they perhaps do not facilitate an appropriate description of an individual maritime transport sector. Governments commonly class marine activities (i.e. fish science, aquaculture, etc) and maritime activities (e.g. shipping and transport. etc) together and also class industry sectors together for the purpose of central statistics i.e. road transport, maritime transport and air transport. This however may be entirely suitable from a government perspective who may 
wish to evaluate transport as a whole but for a particular industry i.e. maritime transport, it may require a more disaggregated form of data for the purpose of precise analysis. A relevant maritime cluster classification would cater for transparency in sectors and sub sectors and aid in evaluation of the current impact of strategies and policies (Peeter and Webers, 2006).

\subsection{Maritime Clusters and their Sectors}

When investigating a maritime transport industry from a cluster perspective it is important to identify what sectors operate within the core specialisation of the cluster being researched. In dividing a cluster into individual sectors this can to a certain extent appear to be a reasonable task. However clusters of the same industry (i.e. as in the current case of maritime transport) do not evolve and are not built in exactly the same way. Different clusters will contain different sectors with greater importance, not all clusters will have all the possible sectors included in a maritime transport cluster, and individual clusters will leave out and include different sectors depending on their perspective. The following discussion will examine some of the more recognised international maritime clusters and their identified maritime transport sectors.

\subsubsection{EU Cluster Sectors}

The EC paper entitled the "Economic Impact of Maritime Industries in Europe" (2004) had a main objective of presenting an overview and evaluation of the data available concerning the past and the future impact of maritime industries in Europe. One of the key consequences of the paper was that the availability and quality of the data sourced for the paper lacked clarity and had mis-matched definitions and therefore was limited in supporting policy making recommendations. The EC paper (2004) on the clustering of the maritime transport industry within EU member states provides a breakdown of the industry into ten key sectors (shipping, shipbuilding, offshore supply, inland shipping, maritime works, seaports and related services, fishing, recreation, maritime services and maritime 
equipment) and eleven sub sectors (seagoing vessels, repair and conversion, naval ships, scrapping, cables and pipelines, dredging and other works, recreational vessels, recreational services, $R \& D \&$ education, classification and inspection and support services). The EC paper defines the ten sectors as shown in Table 2.

Table 2 EU Maritime Sectors

\begin{tabular}{|c|c|c|}
\hline No. & Sector & Description/ Definition \\
\hline 1. & Shipping & $\begin{array}{l}\text { Merchant shipping and ship management: Short sea } \\
\text { shipping: Chartering out: cruise and ferry services and } \\
\text { ocean towage. }\end{array}$ \\
\hline 2. & Shipbuilding & $\begin{array}{l}\text { With the subsection of seagoing vessels which includes } \\
\text { merchant ships, fishing boats, ocean going tugs, workboats, } \\
\text { supply ships. Repair and conversion of seagoing vessels, } \\
\text { navel ships including new building and repair. Inland } \\
\text { vessels including barge, harbour tugs, inland work boats, } \\
\text { supply ships, floating sections, dry docking and scrapping. }\end{array}$ \\
\hline 3. & Offshore supply & $\begin{array}{l}\text { Seismic research: construction, installation and conversion } \\
\text { of platforms. storage vessels and equipment: drilling: } \\
\text { offshore related transport, engineering, communication. } \\
\text { consultancy and other support. }\end{array}$ \\
\hline 4. & Inland shipping & $\begin{array}{l}\text { Inland shipping and ship management, chartering out, } \\
\text { inland cruises and ferries, harbour and river towage, } \\
\text { freighting. }\end{array}$ \\
\hline 5 . & Maritime works & $\begin{array}{l}\text { With the subsection of cables and pipclines which includes } \\
\text { nautical cables and pipelines for offshore work, } \\
\text { telecommunications etc. Dredging including river works, } \\
\text { construction of dykes, harbours and canals and support } \\
\text { vesscls. }\end{array}$ \\
\hline 6. & Seaports and related services & $\begin{array}{l}\text { Cargo handling, shipping related storage, agenes: maritime } \\
\text { logistics and expedition, port authorities and pilotage. }\end{array}$ \\
\hline 7. & Fishing & $\begin{array}{l}\text { Maritime fishing: professional inland fishing: Shellfish } \\
\text { production. }\end{array}$ \\
\hline 8. & Recreation & $\begin{array}{l}\text { With the subsection of recreational vessels including yacht } \\
\text { construction. sporting. sailing and rowing boats, canoes. } \\
\text { inflatable boats, repair and floating sections. Recreational } \\
\text { services including yacht chartering, marinas, inland racht } \\
\text { basins, supporting services concerning construction of and } \\
\text { trade of recreational vessels. Facht related training and } \\
\text { trade. }\end{array}$ \\
\hline 9. & Maritime services & $\begin{array}{l}\text { With the subsection of } R \& D \text { and education which includes } \\
\text { R\&D. consultancy. nautical training and cducation. } \\
\text { Classification and inspection including classification } \\
\text { societies. sampling and labourites. Support services } \\
\text { including bunkering. ship supply. rescue. diving, marine } \\
\text { insurance. financing. brolserage, law and medical services. } \\
\text { creving. maritime associations and maritime government } \\
\text { services. }\end{array}$ \\
\hline 10. & Maritime equipment & $\begin{array}{l}\text { Manufacturing and wholesale trade in maritime } \\
\text { equipment. }\end{array}$ \\
\hline
\end{tabular}

(Source: EU, 2004)

The EU perspective of a maritime transport industry and its relevant sectors has to take into consideration all possibilities from all member states and as such produces an extensive illustration of possible sectors. The EU 
perspective takes into consideration a far greater depth of potential for maritime industries when compared to an individual maritime cluster perspective of its own cluster. The EU model allows for the consideration of maritime transport sectors, their sub-sectors and potential sub-sub-sectors. The description of sectors can be argued as being very maritime focused which is reasonable considering it is based on EU maritime sectors, however the context of Table 2 in a greater perspective is maritime clusters and therefore lacks a focus on logistics through maritime transport. From a European perspective much more needs to be accomplished in order to develop a robust and reliable format of maritime transport sectors and cocoordinated and unified statistics. Despite the acknowledgement of the lack of validity of data for maritime transport sectors in the 2004 paper not much has improved as the current European Commission Green Paper Policy ${ }^{6}$ process again identifies the serious lack of data which hinders sufficient accountability of maritime sectors within Europe (Wijnolst, 2006).

The recent Europe of the Sea Project (2006) which is supported by 50 coastal regions and cities and co-ordinated by the CPMR (Conference of Peripheral Maritime Regions) has an objective to develop a database on European maritime activities and identify main indicators and data of the industry which the conference identifies as currently lacking (CRPM, 2006). CRPM discusses the sectors of Europe's maritime industries from the approach of a maritime economy as opposed to a maritime cluster highlighting its diverse nature within European economies. CRPM argues that the European maritime economy is both commercial and public service based and can be classified into primary maritime sector activities (fisheries, aquaculture, energy and aggregate mining), categories of manufacturing maritime industries (shipbuilding, port equipment submarine cables, etc) and varied commercial activities (ports, shipping, tourism, cruise, banking and insurance etc). While public services include education, training, defence,

\footnotetext{
${ }^{6}$ On 7 June 2006. the European Commission adopted a Green Paper on a Future Maritime Policy for the European Union. The Green paper has five key themes. First, the retention of European leadership in terms of sustainable maritime development. maximizing quality of life in coastal regions, provide tools to manage relations with the oceans, maritime governance and reclaiming Europe's maritime heritage and reaffirming Europe's maritime identity.
} 
R\&D, safety, coastal environment and protection and areas of marine science. The CPRM approach is in line with that of the EU Green Paper as it covers the complete spectrum of maritime and marine based activities. However it further discusses (Figure 2) the individual industries with respect to their dependence on the sea in terms of traditional, tangent and indirect activities.

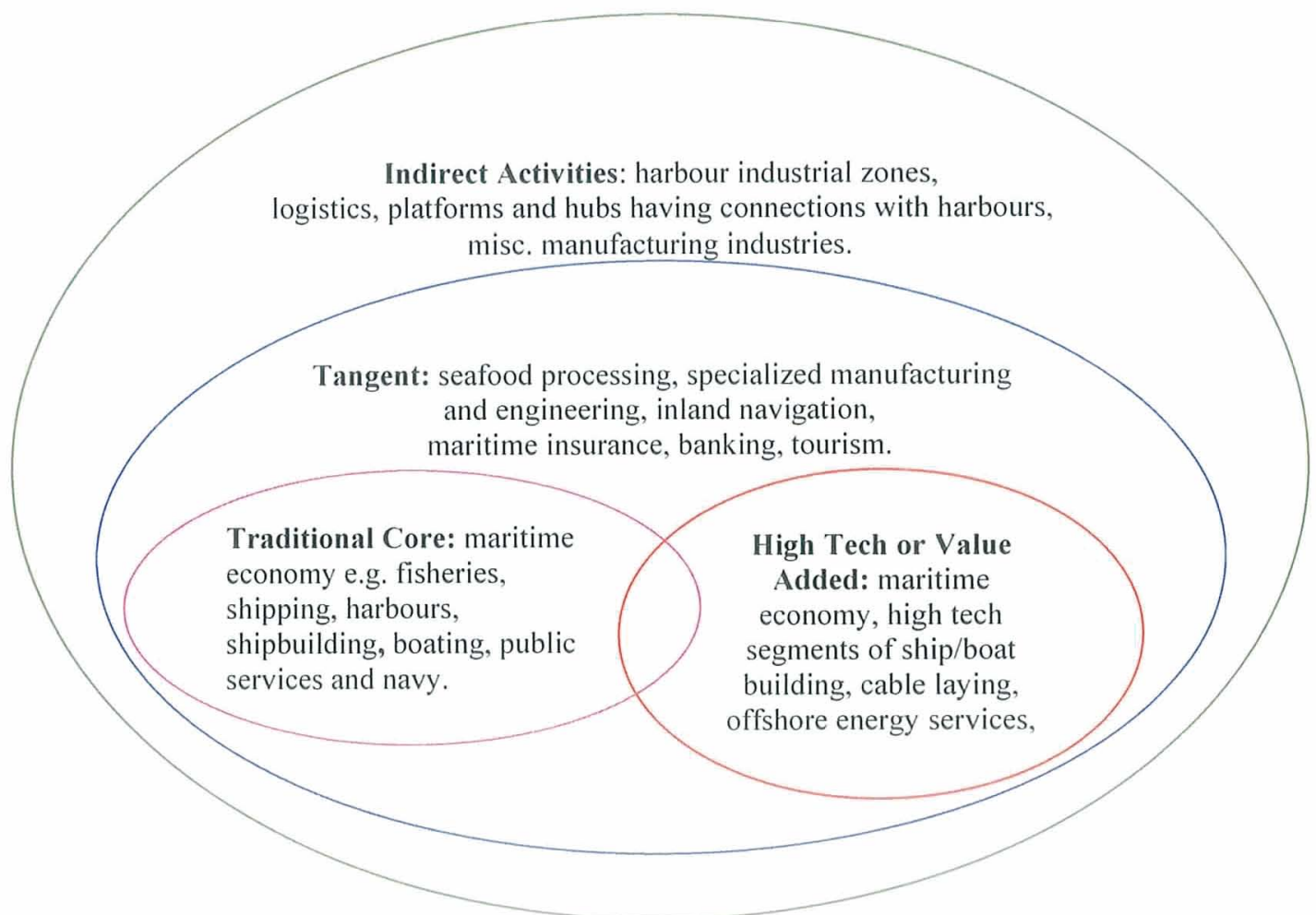

Figure 2 Tentative Classification of the Maritime Economy

(Source: CMRP, 2006)

The core maritime economy activities are strictly related to the marine environment and its resources, although CPRM does recognise the difficulty in any objective in terms of sector categorisation spanning a wide and potentially growing European community. There are traditional activities such as fisheries but also high tech and value added services such as offshore sectors. Tangential activities are determined to a greater extent by the market rather than strategic location and although there is a direct maritime link e.g. marine finance for example, they are not strictly defined and determined by maritime activities. Potential impact of the world economy, trade and trade growth can have a more direct effect on tangential 
activities as opposed to a marine environment and marine resources. Finally the indirect activities include suppliers and clients of the core and tangential aspects of maritime industries.

The discussion to date has looked at maritime transport sector division in terms of a European perspective. The following discussion will address how certain individual maritime clusters identify their maritime transport sectors. The selection of clusters represents both European and international maritime clusters; however the examples discussed below are not exhaustive or exclusive in terms of maritime clusters and industry sectors. The objective of the discussion is to provide a brief example of how different nations approach the concept of maritime industries and the identification and subsequent division of maritime transport sectors.

\subsubsection{Dutch Cluster Sectors}

It was established in reports commissioned by the Dutch Ministry that the Dutch maritime cluster was ill defined and lacked sufficient and appropriate statistical sectoral and cluster data (Janssens, 2006) for the purpose of understanding the potential of the cluster and for any future possible policy recommendations. In the first instance the Dutch cluster appeared to have the commonly found maritime transport cluster sectors of shipping, shipbuilding, dredging, inland shipping and port sectors. However consultation with the industry helped to identify the importance of sectors such as yacht building, fisheries, maritime services, the Royal Navy and equipment suppliers. The Dutch maritime cluster has identified eleven sectors relevant to the workings of the Dutch maritime cluster. 
Table 3 Dutch Maritime Cluster Sectors

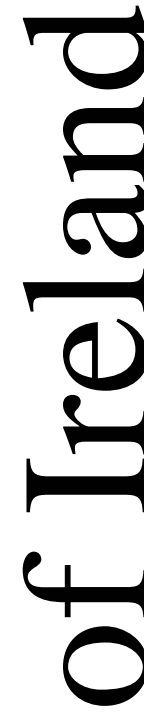

\begin{tabular}{|l|l|l|}
\hline No. & \multicolumn{1}{|c|}{ Sector } & \multicolumn{1}{|c|}{ Description/ Definition } \\
\hline 1. & Ports & Port related industry. \\
\hline 2. & Maritime services & Service industry. \\
\hline 3. & Shipbuilding & Metal handling. \\
\hline 4. & Marine Equipment & Metal work and machinery. \\
\hline 5. & Yachting & Recreation and tourism. \\
\hline 6. & Fishing & Fish producing and processing. \\
\hline 7. & Dredging & Construction. \\
\hline 8. & Offshore & Energy. \\
\hline 9. & Royal Navy & Defence. \\
\hline 10. & Inland shipping & Linked to no. 1 and no. 11. \\
\hline 11. & $\begin{array}{l}\text { Shipping: logistics and } \\
\text { transport }\end{array}$ & Logistics and transport. \\
\hline
\end{tabular}

(Source, Janssens, 2006)

The Dutch maritime cluster sectors are much more streamlined and specific to the activities of the cluster than the sectors and subsequent definitions described within the EU model. However the definitions of the sectors could be further clarified and be more precise. The sectors can also be subidentified in terms of those that are directly port related, of the eleven sectors; ports (1), inland shipping (10), shipping: logistics and transport (11), dredging (7) are primarily centered on the activities of the port. The next aspect of the cluster is with regard to shipbuilding (3) and marine equipment (4) as the Dutch maritime cluster also has a considerable shipbuilding sector as the Dutch produce a higher proportion of innovative ships when compared to the Europcan average (Fist Marine International, 2005). Ports are considered a good case for clustering and therefore help to attract and maintain a level of maritime services focused on and around port activities in terms of maritime services (2). The subsequent sections are defence (9), fishing (6), offshore (8) and yachting (5). The DMNF through the Maritime Cluster's Roundtable on the discussion of the future European Green Paper called for better statistical underpinning of the economic importance of European maritime clusters, i.e. the relationship between the sectors, direct and indirect added value and information on employment data (Janssens, 2006). 


\subsubsection{London Cluster Sectors}

The London maritime cluster was found by Fisher Associates (2004) to contain four main key sectors - shipping, industry associations, support services and intermediate services.

Table 4 London Maritime Service Cluster Sectors

\begin{tabular}{|c|c|c|}
\hline No. & Sector & Description/ Definition \\
\hline 1. & Shipping & $\begin{array}{l}\text { Which includes ship owners, charterers and cargo interests; ship } \\
\text { managers, shipbrokers and liner agencies. }\end{array}$ \\
\hline 2. & Industry Associations & Which includes both national and international associations. \\
\hline 3. & Regulators & $\begin{array}{l}\text { Which includes International Maritime Organisation and country } \\
\text { representatives, classification societies, flag state, Lloyd's } \\
\text { insurance market, Baltic Exchange and the UK government. }\end{array}$ \\
\hline 4. & Support Services & $\begin{array}{l}\text { Commercial consultants and researcher's, media firms/publishers } \\
\text { and conference organisers, information and communication } \\
\text { technology (ICT) services, manning and recruitment agencies, } \\
\text { maritime universities and colleges. }\end{array}$ \\
\hline 5. & Intermediate Services & $\begin{array}{l}\text { Which includes marine insurers (capital providers, insurance } \\
\text { companies, underwriters/managing agents), Lloyd's insurance } \\
\text { brokers, banker's and accountants. Technical consultants and } \\
\text { surveyors, legal advisors (lawyers, arbitrators and average } \\
\text { adjusters). }\end{array}$ \\
\hline
\end{tabular}

(Source: Fisher Associates, 2004)

As with the DMNF model of the Dutch cluster, the London cluster is a direct reflection of its activities. The London maritime cluster is also termed the London maritime service cluster as its strength is in the maritime support services the cluster provides and its strong legal and financial abilities supported by the strength of the City of London.

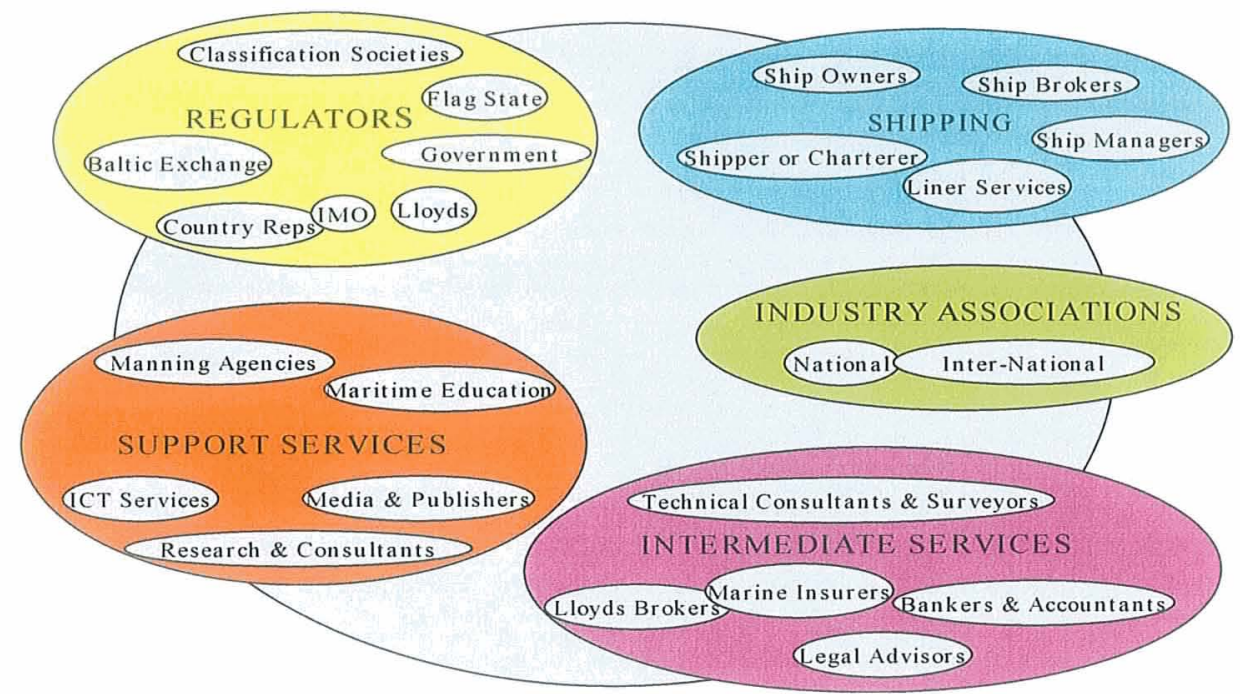

Figure 3 London Maritime Service Cluster (Source: Fisher Associates, 2004) 
As illustrated in the model (Figure 3) of the London maritime service cluster, each of the four key sectors has a number of sub-sectors or sectors included in the core. The London model is taken from a different perspective as a more consistent approach would be to highlight the importance of sectors such as banking, finance and law as opposed to having the services combined under the one heading of intermediate services. Such an illustration as depicted in Figure 3 is debatable in light of the importance of such services to the cluster's success. The model is suitable from a basic level in order to understand what services the London cluster has but it diffuses the relevance and importance of major contributing sectors such as maritime law and marine finance to the cluster and lacks the initial ability to understand the possible depth of the marine finance and legal subsectors. As the London maritime cluster is know as a maritime service cluster the Fisher report (2004) discusses the relevance of the maritime cluster's interaction with that of the City of London's financial cluster. While individual maritime transport sectors can have an underlying sub sector i.e. shipbuilding and metal works for example, maritime clusters also have cross relationships as illustrated in Figure 4 where the London maritime service cluster is a subset of the London financial cluster and the UK/London maritime cluster.
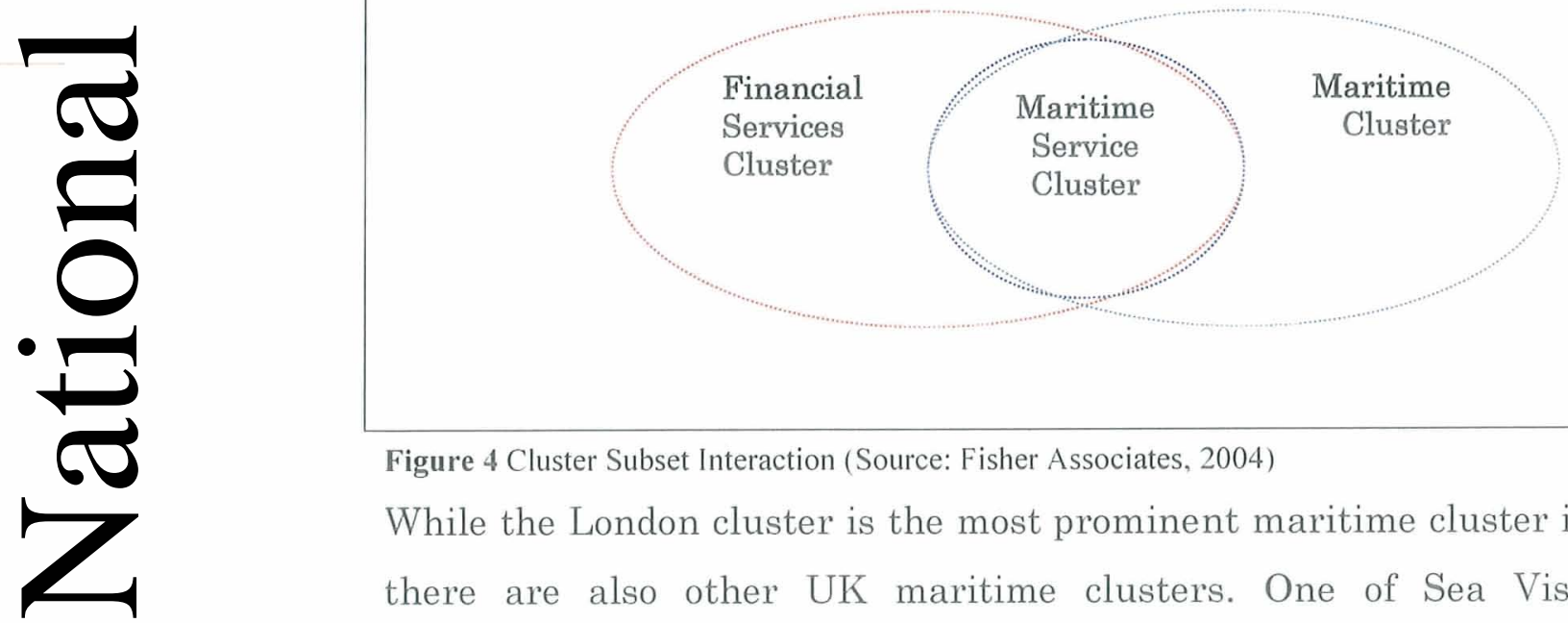

Figure 4 Cluster Subset Interaction (Source: Fisher Associates, 2004)

While the London cluster is the most prominent maritime cluster in the UK there are also other UK maritime clusters. One of Sea Vision UK's initiatives was to broadly define the UK maritime cluster but with respect to all activities related to the sea and not just a concentration on commercial 
activities (Sea Vision UK, 2007). The Sea Vision UK defined a total of 15 sectors for the maritime industry within the UK. The Sea Vision UK approach is similar to that of the European approach in that it takes a broad perspective of the cluster with the inclusion of recreational activities, technology, defence, research and development and fisheries.

Table 5 Sea Vision Description of UK Maritime Sectors

\begin{tabular}{|c|c|c|}
\hline No. & Sector & Description/ Definition \\
\hline 1. & Oil \& Gas & $\begin{array}{l}\text { Maritime services utilised in the exploration, development } \\
\text { and exploitation of offshore oil and gas fields. }\end{array}$ \\
\hline 2. & Shipping & $\begin{array}{l}\text { Shipping services utilised in the carriage of goods and } \\
\text { passengers and the chartering of vessels. }\end{array}$ \\
\hline 3. & Shipbuilding & $\begin{array}{l}\text { Construction and repair of commercial and naval ships and } \\
\text { other marine structures. }\end{array}$ \\
\hline 4. & Maritime Services & Maritime related business services provided by the "City". \\
\hline 5. & Ports & Loading, unloading and other handling of marine cargoes. \\
\hline 6. & Defence/Naval & $\begin{array}{l}\text { Military and civilian operations of the Royal Navy including } \\
\text { foreign ship sales. }\end{array}$ \\
\hline 7. & Leisure Marine & $\begin{array}{l}\text { All leisure activities including boat building and equipment } \\
\text { provision excluded above. }\end{array}$ \\
\hline 8. & Telecommunications & $\begin{array}{l}\text { The manufacture, surveying and laying of submarine } \\
\text { telecommunication cables. }\end{array}$ \\
\hline 9. & $\begin{array}{l}\text { Research \& } \\
\text { Development }\end{array}$ & $\begin{array}{l}\text { University, public sector and industry involved in maritime } \\
\text { R\&D. }\end{array}$ \\
\hline 10 . & New Technologies & $\begin{array}{l}\text { Include underwater unmanned vehicles, marine } \\
\text { biotechnology and marime software. }\end{array}$ \\
\hline 11. & Education \& Training & $\begin{array}{l}\text { Marine courses in the higher education sector and for } \\
\text { seafarer industry purposes. }\end{array}$ \\
\hline 12. & Ocean \& Survey & $\begin{array}{l}\text { Ocean surveys primarily for hydrographic and extractive } \\
\text { industry purposes. }\end{array}$ \\
\hline 13. & Safety \& Salvage & $\begin{array}{l}\text { Public and private sector activities related to maritime } \\
\text { safety and salvage. }\end{array}$ \\
\hline 14. & Mineral \& Aggregates & $\begin{array}{l}\text { Shipping services utilised in the off shore extraction of } \\
\text { minerals and aggregates (other than employment this is } \\
\text { covered in shipping above). }\end{array}$ \\
\hline 15. & Fisheries & Sea fishing and shellfish landing and fish falming activities. \\
\hline
\end{tabular}

The UK Sea Vision model comes from a different perspective to that of the London cluster. The Sea Vision approach like the EU approach takes all maritime activities into consideration and not just the importance of core commercial activities. The description in the UK model is more understandable than that of the EU attempt at sector description. However in the Sea Vision UK sector description the model recognises the importance of the City of London cluster, as the maritime services sector is described as maritime related business services provided by the City of London. 


\subsubsection{Finnish Cluster Sectors}

A technical review on the Finnish maritime cluster published in 2003 describes the term "maritime sector" as all the activities of a company related to seafaring, marine industries and port operations (Viitanen, et al, 2003). The Finish maritime cluster is divided into the following nine sectors;

1. Shipping companies.

2. Shipping companies and associated companies.

3. Ports.

4. Port operators and port related industry.

5. Interest groups and associations.

6. Public sector including administration, education, research and development.

7. Associated fields including, finance, insurance and classification.

8. Shipyards.

9. Shipyard subcontractors.

The Finnish approach to the division of the cluster into sectors is to represent mainly the core commercial shipping related activities while also affording importance to associations, the public sector, education, research and development. The three core sectors appear to be shipping companies, ports and shipyards, although the latter three also have sub sectors, namely shipping companies and associated companies, port operators and port related industry and shipyard sub-contractors. The approach is basic; however it does provide for the consideration that the sector's have depth and therefore a possible sub-sector and sub-sub-sector's. The concept of examining a cluster in terms of its depth and interrelationship with other possible clusters can help to provide an illustration of the potential ripple effect of an individual industry cluster. In terms of the shipbuilding cluster (refer to Figure 5), it could also incorporate the construction industry i.e. raw materials for example, an ICT cluster for ship design and technologies, an energy cluster for production of and optimising the use of energy on board and finally the environment which will in the future have an 
increasing effect on ship design through implementation of various regulations through the IMO.
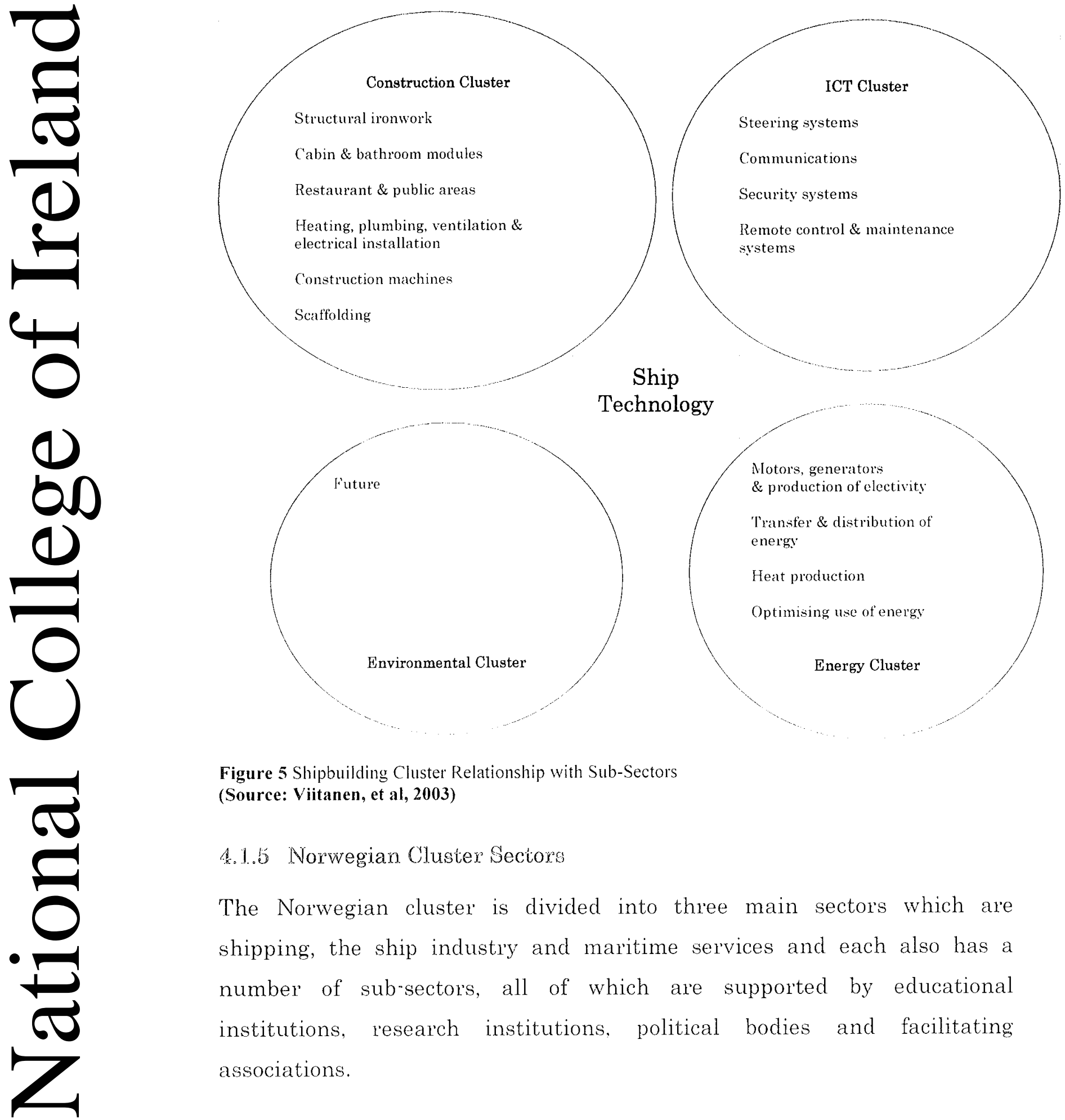

Figure 5 Shipbuilding Cluster Relationship with Sub-Sectors (Source: Viitanen, et al, 2003)

\subsubsection{Norwegian Cluster Sectors}

The Norwegian cluster is divided into three main sectors which are shipping, the ship industry and maritime services and each also has a number of subsectors, all of which are supported by educational institutions, research institutions, political bodies and facilitating associations. 

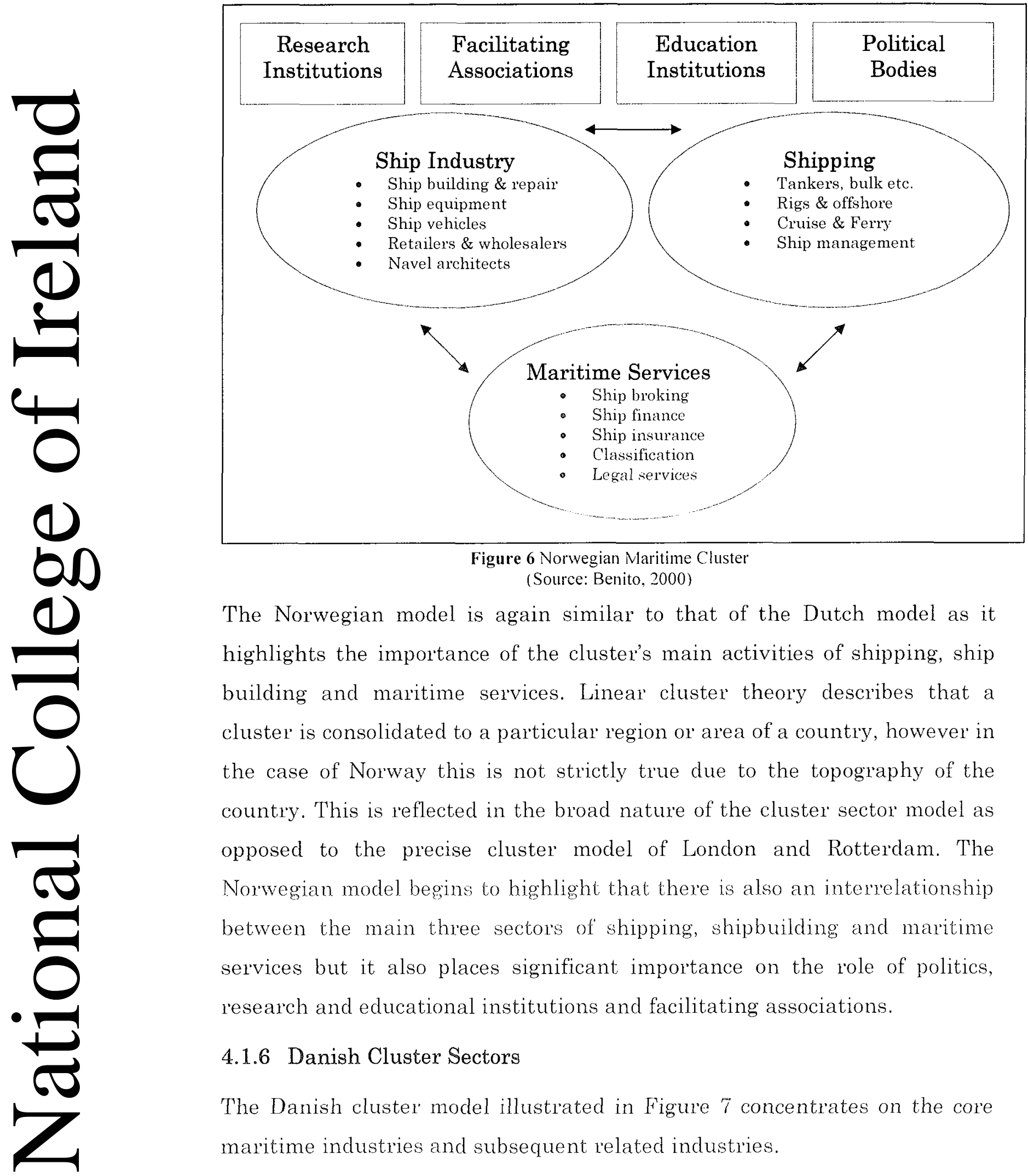

Figure 6 Norwegian Maritime Cluster

(Source: Benito, 2000)

The Norwegian model is again similar to that of the Dutch model as it highlights the importance of the cluster's main activities of shipping, ship building and maritime services. Linear cluster theory describes that a cluster is consolidated to a particular region or area of a country, however in the case of Norway this is not strictly true due to the topography of the country. This is reflected in the broad nature of the cluster sector model as opposed to the precise cluster model of London and Rotterdam. The Norwegian model begins to highlight that there is also an interrelationship between the main three sectors of shipping, shipbuilding and maritime services but it also places significant importance on the role of politics, research and educational institutions and facilitating associations.

\subsubsection{Danish Cluster Sectors}

The Danish cluster model illustrated in Figure 7 concentrates on the core maritime industries and subsequent related industries. 


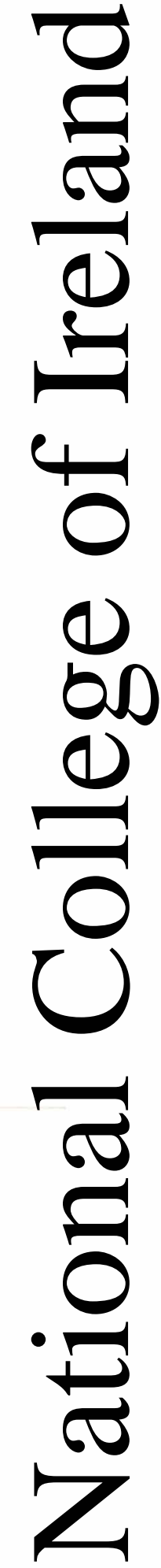

\section{Secondary} Industries

Suppliers

Subcontractors (inc. goods \& services)

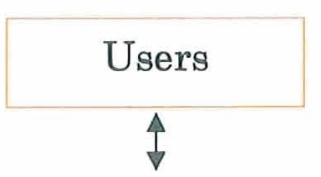

Core Industries

Shipping

Maritime services

Shipbuilding

Equipment industry

Offshore
Related Industries

The Danish Navy

Fishing industry

Leisure \& sport

\begin{tabular}{|l|}
\multicolumn{1}{|c|}{ Supporting Institutions } \\
Government authorities \\
International organisations \\
Business organisations \\
Education \\
Universities, research \& knowledge sharing \\
\end{tabular}

Figure 7 Danish Cluster Sectors

(Source: Bech, 2006)

The Danish model has also linked together a common user group in terms of cluster players such as transport purchasers and economies of scale in technologies and the labour supply for the cluster (Bech, 2006). The Danish cluster model allocates its principal commercial activities under the heading of core industries and separates out defence, fishing and recreation into the heading of related industries. Different clusters may hold more importance to the sectors of fishing and defence when compared to the Danish maritime cluster as Bech (2006) argues that the Dutch maritime cluster includes the core industries and the supporting industries and that related industries are present but not truly core maritime cluster industries.

\subsubsection{Hong Kong Cluster Sectors}

Hong Kong's maritime cluster traditionally would have been based on the commercial shipping activities of shipbuilding and repair, shipowners and operators, and port operations (Maunsell, 2003). The Hong Kong cluster is divided into twelve key sectors and unlike the London service cluster approach gives the areas of finance and law is own sector representation. 
Table 6 Hong Kong Maritime Cluster Illustration of Sectors and Activities

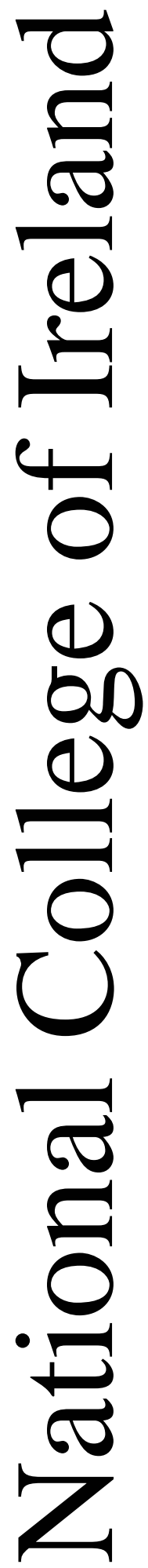

\begin{tabular}{|c|c|c|}
\hline No & Sector & Description \\
\hline 1. & Shipowner's & Shipowners and operators. \\
\hline 2. & Ship managers & $\begin{array}{l}\text { Ship managers, non-operating owners, professional } \\
\text { manpower, crewing. }\end{array}$ \\
\hline 3. & $\begin{array}{l}\text { Classification Societies } \\
\text { and Surveyor's }\end{array}$ & Classification Societies and surveyors. \\
\hline 4. & Marine insurance & Underwriters, P\&I cubs, brokers, average adjusters. \\
\hline 5. & Maritime Law & Lawyers, arbitrators. \\
\hline 6. & Ship Finance & Banks, financiers. \\
\hline 7. & Ship brokers & Sale \& purchase, chartering. \\
\hline 8. & $\begin{array}{l}\text { Local and International } \\
\text { Bodies and Associations }\end{array}$ & UN, Bilateral local and regional. \\
\hline 9. & Supporting Services & $\begin{array}{l}\text { Education and training, information services, auditing and } \\
\text { tax advisors, IT and communication services. }\end{array}$ \\
\hline 10. & Ship Registration & $\begin{array}{l}\text { HK ship registry, foreign registry, port authorities, port } \\
\text { state control. }\end{array}$ \\
\hline 11. & Marine Equipment & $\begin{array}{l}\text { Hull and load discharge equipment, engine/propulsion } \\
\text { equipment, maintenance and repair, bunkering, waste } \\
\text { disposal, safety equipment and electronics. }\end{array}$ \\
\hline 12. & $\begin{array}{l}\text { Ship agents incl. MNC } \\
\text { reps }\end{array}$ & \\
\hline
\end{tabular}

(Source: Maunsell, 2003)

However like the London maritime cluster which was built historically on the back of the success of the British merchant fleet and the city of London, the decline of the British fleet in the 1970's and increased competition from Asia lead to the concentration on maritime service activities such as law and finance in the Hong Kong cluster. The cluster has also seen a development in the so called "intellectual shipping activities" of finance, insurance, legal services, and arbitration. It is clear from the cluster descriptions provided that certain clusters are service focused, port focused, and logistics focused or some dual combination such as port/service focused or port/logistic focused.

\subsection{Cluster Mapping Methodology}

The first stage of analysis of a potential cluster ${ }^{\top}$ requires a few basic steps. Step one involves the identification of the core specialization of the potential cluster, as this is the primary or main business type of the cluster. Once the core specialization has been identified the potential cluster region requires identification i.e. the boundary of the cluster. The subsequent stage is to

\footnotetext{
The term "potential cluster" is used in the context that for some cluster research in the initial stage of exploration of the cluster may not readily assume that it is in fact a cluster.
} 
identify the businesses, firms, companies and organisations trading and operating within the defined boundary and to divide those business units into the relevant specific sectors of the cluster (de Langen, 2003). The approach above is a basic process of cluster delimiting for the purpose of initial explorative research on clusters.

\subsubsection{Core Specialization}

The core specialization of a potential cluster is its primary economic behaviour i.e. media, textiles, hi-tech etc. The core specialization of the potential cluster is based on the primary activity of the cluster present in a region due to a natural asset or some other factor attracting a concentration of industry to a specific region or location (de Langen, 2003). The core specialization for the current cluster analysis is maritime transport.

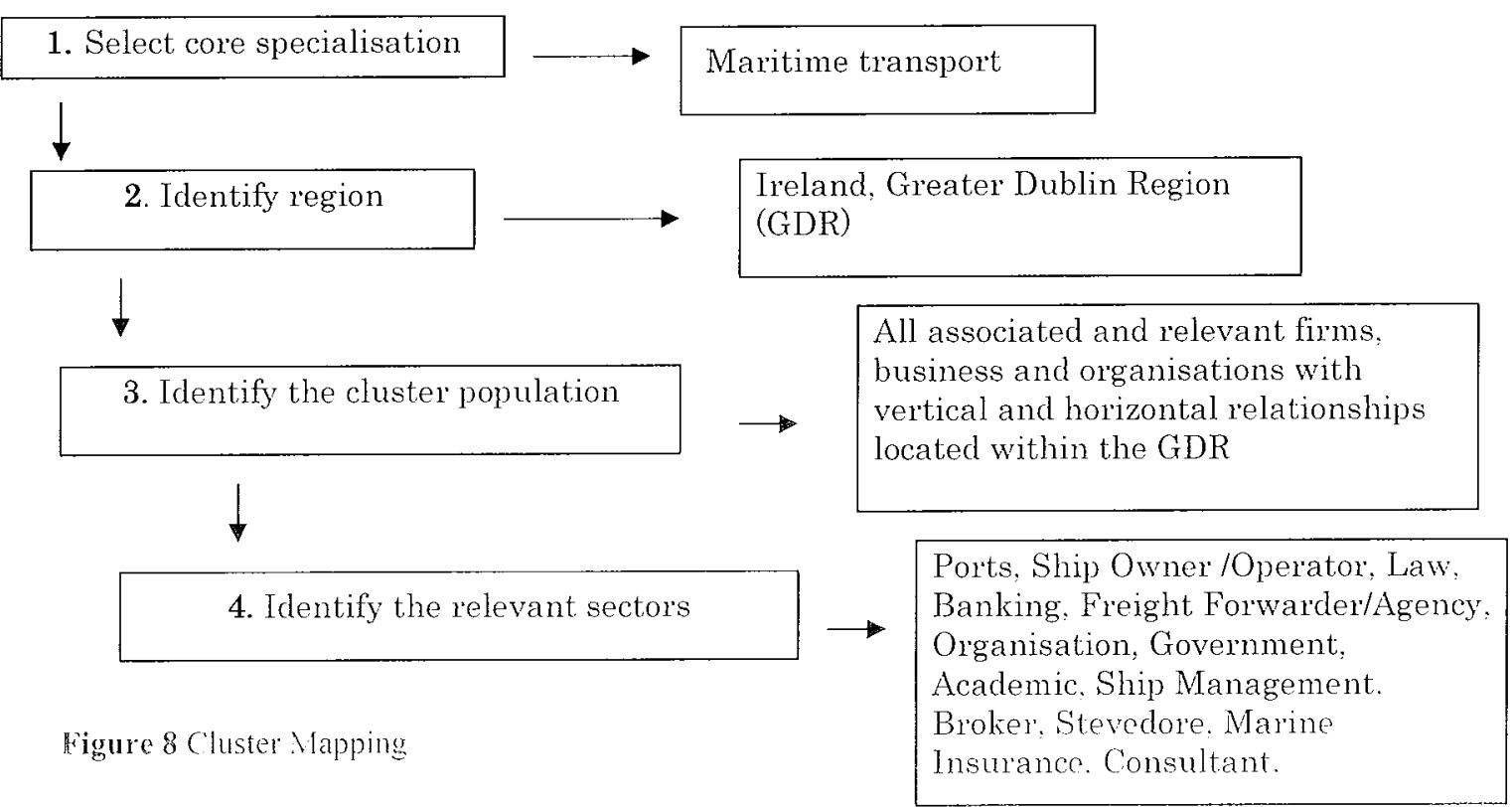

\subsubsection{Greater Dublin Region (GDR) Boundary}

The choice of a boundary for an individual cluster helps to confine its analysis and allows greater evaluation of the possible potential. However it is argued that clusters in one respect have no borders or natural boundaries (Saber 1996, de Langen, 2003) as firms and their level of business relationships and the application of links and linkages cross and supersede invented borders. However the construction of some sort of a boundary for 
the process of research on clusters does provide a control for the cluster and for the research. The implementation of a boundary helps to concentrate the current research on an area that includes the country's principle port, critical mass of industry players, the country's capital city and the location of the core financial and academic institutions. The boundary implemented for the research on the cluster of the maritime transport sector in Ireland concentrates the clustering effect within the Greater Dublin Region boundary which refers to the area including Dublin City and all the Counties of Dun Laoghaire/Rathdown, Fingal, Kildare, Meath, South Dublin and Wicklow (National Spatial Strategy, 2002, P11).

Figure 9 Map of GDR

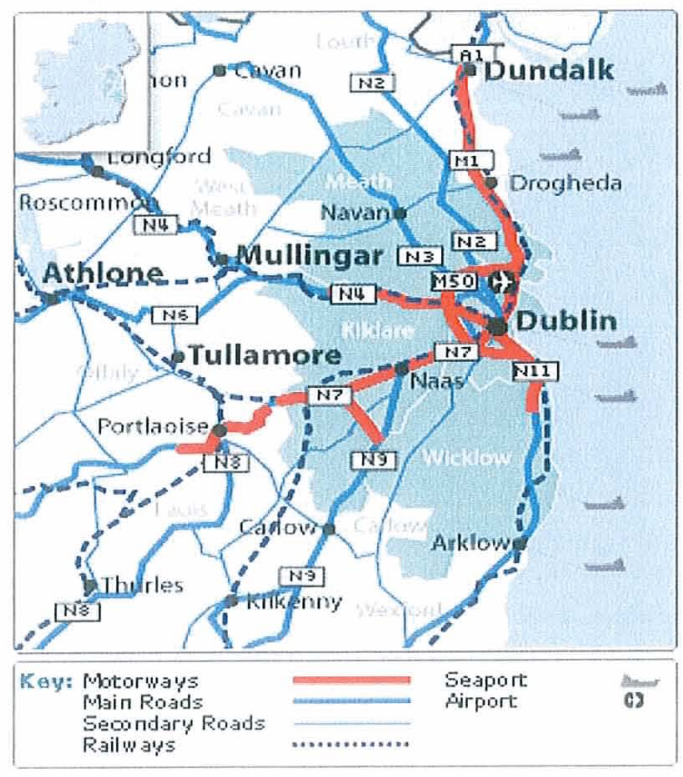

The purpose of the Irish government's National Spatial Strategy $2002-2020^{8}$ is a twenty year planning framework for Ireland with respect of the aim to achieve a more desired balance;

"[of] social, economic, and physical development and population growth between the regions" (NSS, 2002, p 10).

The report highlights the importance of the GDR to the economic competitiveness of the nation, and the objective of the government to use the success of the GDR post the effect of the Celtic Tiger as a benchmark for success in other regions.

\subsubsection{Identification of the Population}

The established boundary for the area of research caters for easier identification of the maritime transport related firms and organisations operating within the GDR. Therefore it is possible to count the number of firms within the region and divide the number of firms and organisations

\footnotetext{
${ }^{8}$ The National Spatial Strategy (NSS) is a coherent national planning framework for Ireland for the next 20 years.
} 
into categories, sectors, and if necessary sub-sectors, and thus provide a total population of the cluster's components. Therefore the next point of research is to investigate exactly what type of firm, business or organisation is included in the term and concept of maritime transport and into which sector each individual business unit should be categorised.

\subsubsection{Identification of the Relevant Sectors}

The first point of investigation of what exactly constitutes a maritime firm within a maritime cluster is based primarily on definitions of what is a cluster (refer to Chapter 2). The maritime transport sector can be considered an older industry when compared to more modern industries such as telecommunications and therefore identifying certain maritime transport sectors is more obvious. Also by examining how other maritime clusters define their sectors can provide a helpful insight into breaking a maritime cluster down into the most appropriate and relevant sectors. In order to devise a list of firms, business and organizations involved in the GDR maritime transport cluster, a database was compiled from an assortment of sources including the National Institute for Transport and Logistics (NITL) Irish Supply Chain Management Services Directory 2004/05, the Yellow Pages directory and general internet research all of which were supplemented and clarified from the IMDO interactive database. The cluster database intended to provide a comprehensive directory of all firms operating within the GDR maritime transport cluster, however over the period of research there is the possibility of new firms being established and firms exiting the market. There is also the make up of companies and the nature of a company and its subsidiaries and how that would affect the cluster database account. However due to the small nature of the sector in Ireland and more regionally Dublin, the author believes the margin of error in the cluster database with respect to the number: of firms in each maritime sector is minimal. In the case of the GDR cluster, some firms and their relevant sectors are easier to identify, such as the port sector for example. In certain instances as in case of the services of law, banking and consultants there are more firms present in the Dublin region than indicted in Table 7. 
However some may work in the maritime sector occasionally and therefore the representation in Table 7 strives to illustrate firms that operate sufficiently and commonly in the Irish maritime sector. The database of the Irish maritime firms operating within the greater Dublin Region comprised a list of a total of 250 units which include the ports, firms, business, industry organization and government bodies and agencies related to the GDR maritime transport sector. Table 7 shows the breakdown of the sectors and the number of companies per segment of the Irish maritime sector.

Table 7 Cluster Industry Database

\begin{tabular}{|l|r|}
\hline $\begin{array}{l}\text { Industry } \\
\text { Sector }\end{array}$ & $\begin{array}{c}\text { Number Of } \\
\text { Companies }\end{array}$ \\
\hline Freight Forwarders & 137 \\
\hline Ship/ Liner Agents & 37 \\
\hline Shipping /Operators/ Services & 25 \\
\hline Marine Insurance & 20 \\
\hline Industry Organisations & 11 \\
\hline Banking & 7 \\
\hline Government & 4 \\
\hline Port Companies & 3 \\
\hline Academic & 3 \\
\hline Legal & 2 \\
\hline Ship Management & 1 \\
\hline Total & 250 \\
\hline
\end{tabular}

(Source: Author's Own)

The initial way to approach an individual cluster in terms of an illustration of what sectors are present is to first look at the activities of the cluster. At this stage there is a maritime transport industry. However it can be unclear if the dominant position of the industry is based on a port cluster, a service cluster or perhaps a mix of both options. By first developing a list of player's within the industry helps provide an indication of what sectors may be present as opposed to identifying the sector first and then trying to mold firms into those identified sectors. This may not be a problem for the more obvious activities such as ports for example, but firms can operate in more than one sector depending on how the individual cluster sectors are laid out. Firms can also be subsidiaries of other companies and sister companies. The first important step is to identify who is there and what they do, and then devise the sector allocation. For the current research a list of the maritime 
transport firms and related activities were drawn up from various sources. Due to the nature of the research with respect to the cluster it is also important to identify relevant supportive activities such as industry organisations and government.

As seen in the various maritime clusters discussed above there are many ways to dissect a maritime cluster and its sectors. From a European perspective it is very important for understanding an individual cluster and being able to benchmark clusters against each other as a means of measuring performance. However it is clear from the models discussed above that such a task would require a high level of flexibility in order to cater for individual maritime cluster specific advantages e.g. the location of the IMO and similar important international maritime organisations is of great importance to the London cluster. It would not be appropriate for London to downplay the importance of the location of such organisations as key strengths to their cluster's competitive advantage. Such a level of flexibility to cater for all clusters is a difficult undertaking and reflective in the nature of clusters in that one model designed to evaluate a cluster in one region cannot be lifted and placed to evaluate a cluster in another region (although there are benefits in comparing clusters), and therefore the same concept applies to differing maritime clusters. When it comes to clustering there are too many possible variables. However it could also be argued that individual clusters are perhaps too quick to denote and identify the sectors involved in a specific cluster.

In the next chapter the process of methodology selection will be addressed in terms of the validity of the method chosen in the context of the research question, bias associated with research and potential limitations of the research method. The chapter will also discuss the research method selected concentrating on the key characteristics associated with the method, limitations of the method and examples of the method utilised for transport related research. 


\section{Chapter 5.Methodology Selection and Discussion}

The purpose of this chapter is to help understand the aim of the research question through the methodological process of data collection. The previous chapters discussed the aims and objectives of the research question, a review and discussion of maritime transport sectors supported by a literature review concentrating on clusters, maritime transport and more specifically four main economic theories surrounding the concept of clusters and clustering. The following text will discuss the validity of the methodology selection in terms of the objective of the research question, potential limitations and a discussion of the Delphi method.

\subsection{Methodology Selection}

The aims and objectives of the research have already been discussed and will not be repeated further within this chapter. However in summarizing the current objective of the research which is to understand the potential for the clustering of the maritime transport sector in the GDR provides the first course of direction in terms of methodology selection. Literature review on clusters and cluster theories and a general observation of a cluster indicates that it is a process of movement and economic evolution and therein lies the relevance of the term clustering. Currently there is no complete research approach to the GDR maritime transport sector which takes into consideration the potential sector as a maritime transport cluster. Furthermore in the objective of understanding the potential for clustering of the maritime transport sector leads to the question; where is the data and where will the data come from? The research is explorative in nature and lends towards the involvement of industry in terms of a process of data collection and further knowledge creation on the GDR maritime transport sector.

\subsubsection{Methodology Tree}

The methodology tree depicted in Figure 10 provides an effective framework in which to select the most appropriate method to conduct the research as 
the tree provides a step by step guide to the selection of a methodological process. The first point of discussion depicted on the methodology tree is the knowledge source which has two options; a knowledge source that provides either a statistical or judgmental source. For the current research the appropriate data format is a judgmental knowledge source as the research process is explorative in nature and takes into consideration the whole potential maritime clustering of the GDR as opposed to an individual specific sector. Also no substantial statistical data sources are available in terms of a complete GDR maritime cluster. However there is statistical data available in terms of cargo throughput, imports, exports, employment levels, and general government or related organisation central statistics. However the statistics that are available would be more functional once a general overall understanding and concept of the industry has been established or used to support any possible findings in the current research. As already discussed the judgement/opinion knowledge source comes from representatives of the GDR maritime transport industry, as who is more appropriate to provide opinions on the industry than the industry itself? The next link in the methodology tree provides either an unstructured or structured path. The unstructured link provides for where information is used in an informal manner. However in a structured format the research is formal and adheres to proven methods of analysis supported by documentation of the procedures conducted. It is important that the methodology carried out is substantial and supportive of rigorous research applications and research validity. The research requires the utilization of opinion from industry experts and therefore a research method which caters for a process of feedback would be appropriate as it would provide a platform for expert judgement opinion and matches the objectives of consensus or the attainment of general agreement. Therefore the methodology tree leads to the choice of either Prediction Markets or Delphi as research method. The objective of the research question as already discussed is explorative and strives to understand the maritime transport sector's potential clustering and therefore the Delphi Method would be a 
suitable methodological approach. For the purpose of clarification Figure 10 displays research methods for forecasting. The Delphi method was originally a methodological tool for forecasting however the method has evolved away from forecasting towards objectives of consensus or general agreement (Okoli and Pawlowski, 2004).

In the concept of methodological selection the discussion must also review other research methods that may have been applied and why such methods were rejected. The Delphi method is a type of questionnaire and therefore reasons as to why the traditional method of questionnaire was rejected was that such questionnaires have a low response rate and the candidates usually only answer the questions once, as opposed to the Delphi method which has the benefit of feedback and repetitive rounds. Traditional questionnaires require a sample population which would not be suitable in the current research question as the maritime industry in Ireland is small and the research required informed and experienced expert opinion as opposed to any individual with an opinion on the potential clustering of the maritime transport sector in the GDR.

The Delphi method as a technique has been described as a tool for forecasting, consensus and decision making and there are similar research tools that can also be applied such as Analytic Hierarchy Process (AHP) Multi-Attribute Utility Theory (MAUT) or Structural Equation Modelling (SEM). AHP is a structured technique used to help individuals deal with complex decisions. AHP uses mathematics and human psychology to provide a framework and structure to a problem which is approached from a hierarchy and simpler sub-problems approach. AHP converts the hierarchy evaluations to numerical values and a priority can be derived from each element of the hierarchy, and as such this capability distinguishes AHP from other decision making techniques. Another technique within the area of multi criteria decision making is the (MAUT). SEM is a type of network decision tree that enable a path to decision making form a starting point to an end point with each branching offering an alternative course of action. MAUT is methodological tool to aid in decision making and the concept of 
the method is that in any decision problem there exists a valued function or utility $(U)$, defined by a set of feasible alternatives that the decision-maker seeks (Olson, 1996). MAUT attempts to measure the alternatives which tend to be non quantifiable and assist the decision maker in analysis and evaluation (Iagoudis, et al, 2006). Despite the availability of other methodological tools the Delphi method was applied as it is a method that caters for application in an area where there is no real knowledge or understanding. The Delphi provides a first step basis for the development of new knowledge and methods such as AHP and MAUT would be of greater benefit to the current research question when some basic understandings and knowledge of the potential clustering of the maritime transport sector in the GDR has been identified. AHP and MAUT are primarily decision making tools, while the Delphi Method as a research tool is also an enabler to decision making, it is also a method that caters for forecasting and consensus building. The core of the current research is to gain knowledge on the potential of the clustering of the maritime transport sector in the GDR, from experts within the industry and to build that new knowledge and understanding from consensus through repetitive feedback. 


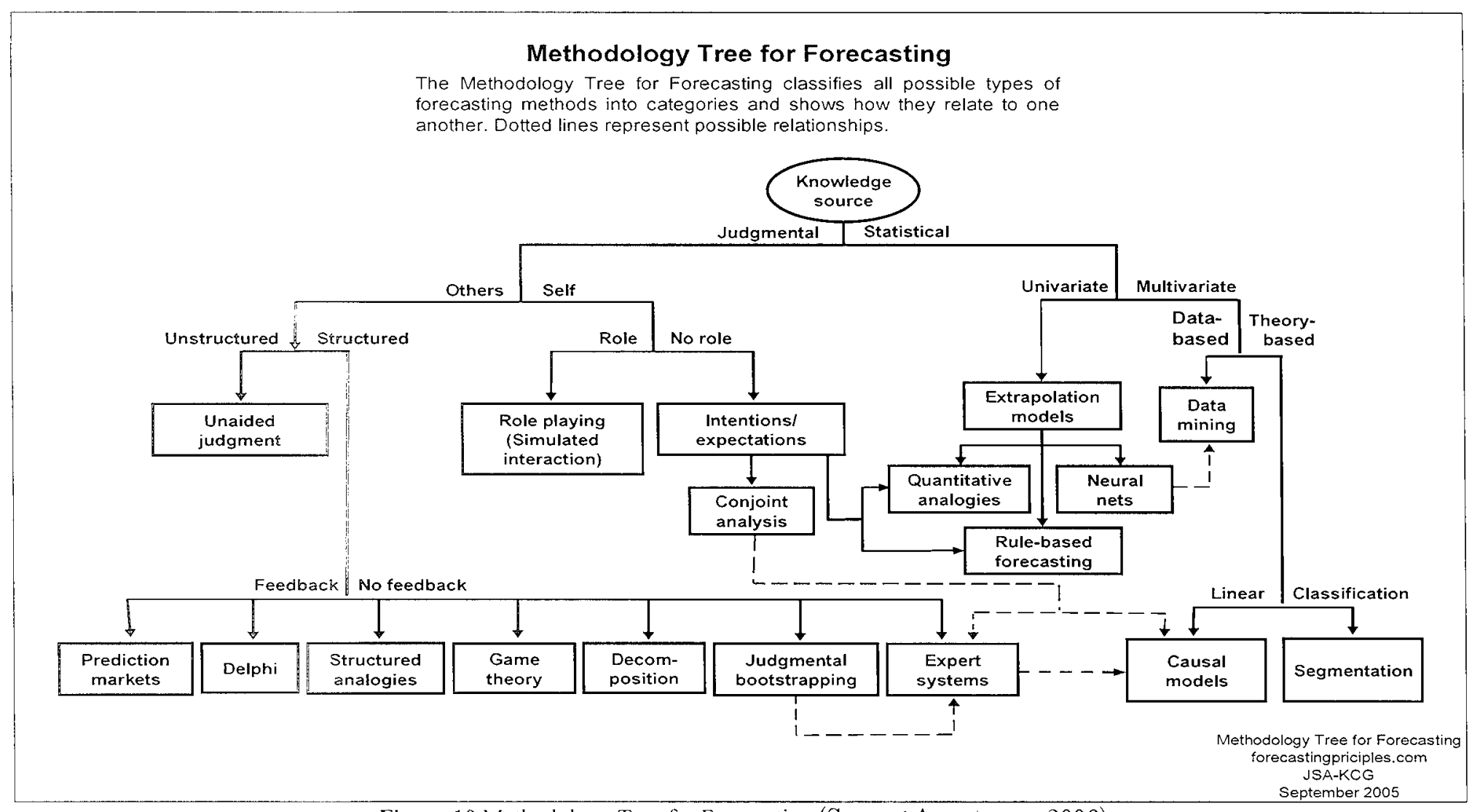

Figure 10 Methodology Tree for Forecasting (Source: Armstrong, 2006) 


\subsection{Delphi Content}

In terms of Delphi questionnaire design and due to the sizeable concept of clusters and clustering the questions put to the Delphi panel require some limitation or structured containment in order to secure the greatest benefit of knowledge creation. The cluster structure and cluster governance framework developed by de Langen (2003) based on the four main schools of economic theory (refer to Chapter 3) help provide a framework to aid the design of the Delphi questionnaire and provide structured examples of questions. In research conducted by de Langen (2003) the cluster structure cluster governance framework was utilised in a case study approach to analyse the clustering performance of seaports in Durban, Rotterdam and the Lower Mississippi.

\subsection{Questions}

Questionnaires are a common method of data collection and Vaus (2004) discusses basic principles to be considered in questionnaire design and execution which include reliability, validity, discrimination, response rate and relevance. Questionnaires are often utilised for data collection when resources are limited. Such limitations may be with respect to academic resources such as the availability of statistics or knowledge on the subject matter concerned or subsequent types of resource limits such as time or money. Questionnaires are also used when it may be necessary to protect the privacy or identity of respondents involved. Wording of the questions is important and the questions must be clear, unambiguous, and understandable, avoid slang or jargon and be void of potential bias. The questionnaire designer must also give consideration to the respondent's knowledge level and apply caution in terms of any level of presumed knowledge (Cooper and Schindler, 2003) and questionnaires are more effective and understandable if the language used is simple and clear and the question itself is as short as possible (Vaus, 2004). In wording questions it is important not to include leading questions that guide a respondent to answer a question in a manner which they may not have if the question had 
been phrased in a more neutral way (Vaus, 2004). There are two main types of questionnaire format, open and closed. A closed questionnaire is one that has provided a number of answers for the respondent to select. An open questionnaire is one in which respondents provide their own answers. The Delphi conducted in the current research could be argued as having elements of both a closed and open questionnaire format; however this may depend on the manner in which a Delphi is conducted as there are different types of Delphi studies and research objectives. In the context of the current research the Delphi respondents must answer either "agree", "disagree" or "unable to comment" which is similar to the closed format by way of providing three options for the answer to the question. However the respondents in the current research must give a reason for their answer and in providing such a format this is reflective of the open format questionnaire which caters for the opinion of the respondent.

\subsubsection{Bias}

The subject of bias is an inherent trait in research practice as it is an "inclination or" a prejudice in favour of a particular person. thing or" viewpoint' (Oxford Dictionary, 2005). A research question or objective is about the attainment of new knowledge, greater understanding, reality and truth upheld in the validity of a research process. However there are initially two major types of bias which are the bias of the researcher and bias in which the research is carried out. There are a range of different types of bias which can also be dependent of the type of format of the research performed. For example halo bias or the halo effect is a systematic bias that is incurred by a general impression. Examples of the halo effect are when an individual agrees with someone because they consider the person to be intelligent or believe a student's written examination will be as good as their previous examination (Cooper and Schindler, 2003). A prestige bias is the tendency for respondents to answer a question in a manner which would make them feel better. A respondent who infers a prestige bias may overrate themselves, for example they may state that they are more intelligent than they are. Or a question that asks a respondent how long it 
may take them to learn a language for example should be approached with caution, as a respondent may claim it would take a shorter time than it actually would. Prestige bias is difficult to avoid. However written mail questionnaires would be less affected by prestige bias when compared to telephone or person to person interviews (Cooper and Schindler, 2003). Mail questionnaires can be biased due to the nature of an individual to read a document first and then go back and answer the question or to skip questions with the intention of referring to them later on (Oppenheim, 1968). In mail questionnaires there is the tendency for the individual to pass on the questionnaire to a subsequent person; however in Delphi it requires the agreement of the person to take part in the questionnaire prior to receiving the questionnaire. The identification of the individual to answer the Delphi is important to the method as it requires the individual to be an expert in their field. However the advantage of a questionnaire compared to an interview method is its cost effectiveness and also a larger sample for data collecting can be obtained. The core time consumed is the individual filling in the questionnaire as opposed to the interviewer travelling to the respondents to gather the data. Analysing gathered data in a questionnaire can be a simpler process than in interviews as mail questionnaires can produce poor response rates and subsequently in Delphi despite participation agreement of respondents prior to despatch of the questionnaire, drop out rates are still visible. The interview method however enables the gathering of a greater level of "rich" information than in a mail questionnaire (Oppenheim, 1968) and the fact that the data was obtained in face-to-face manner may afford the researcher greater security over the reliability of the results despite the risk of bias.

\subsubsection{Reliability, Validity and Practicality}

Reliability and validity refers to the ability to assess the result in terms of research effectiveness in measuring what was intended to be measured. Oppenhemin (1968) discusses the importance of distinguishing the difference between reliability and validity. Reliability infers the consistency to obtain the same result again and again and validity refers to the 
question, and if the question measures what it is intending to measure. Practicality is concerned with a range of features associated with the research such as economy, convenience and reasonableness (Cooper and Schindler, 2003).

There are various concerns surrounding the validity of any research process and content validity addresses the extent to which the measurement effectively and adequately addressees the concept being investigated. Cooper and Schindler (2003) argue that good content validity requires first agreement on the features or elements that will constitute a sample representation of the research interest. As already discussed the questions for the Delphi survey were based on de Langen's (2003) Cluster Structure Cluster Governance Framework. The framework provides a list of the key components of economic theories which can have a positive effect on the clustering of an industry. The framework provided an ideal structure to investigate clustering from an explorative aspect as it catered for the delimitating of the literature on clusters to the core economic features while providing adequate coverage of the subject matter for the research question. Reliability infers different meanings but always affords the ability to produce consistent results. In terms of the collection of opinion, data reliability becomes more difficult as opinions can change. In the questionnaire method in the current research reliability can be assessed as the agreed respondents are asked the same questions repeatedly through three rounds. However the purpose of the Delphi is to reach convergence or consensus on a number of statements and therefore the implementation of feedback in Round 2 and Round 3 is one of the core attributes of the method. However this can raise the question of the reality of opinion in terms of data. The current research is explorative in nature and Newton (1985) argues that reality can be established through an open forum in which ideas and opinions can be thoroughly questioned and evaluated (Newton, 1985). That forum is represented in the process of expert feedback provided for between the rounds within the Delphi. 
In terms of practicality every research question or research project has trade offs in terms of the research objective, the budget or the time allowed in which to conduct the research. For example both the time taken and the cost of travelling to conduct interviews can be greater than carrying out a survey and similarly a telephone questionnaire/interview can be more expensive and time consuming than a mail questionnaire (Cooper and Schindler, 2003). Convenience can also play a part in the decision of the selection of the methodology as the research may have a small team in terms of staff to conduct and analyse the data gathered and therefore the most convenient method in terms of time, feasibility and practicality and general reasonableness needs to be considered.

\subsection{Empirical vs. Philosopher}

From a research question comes the sub question; from where will the data come? As already discussed, the methodology selection is not only affected by reasonableness in terms of gathering data (potential effects and or restraints of time, cost and availability etc) but also by the actual research question. The current research is explorative in nature as it begins to investigate a concept or real world problem i.e. the potential of the clustering of the maritime transport sector in the GDR. Clusters as an area of research is well documented, however clusters specifically for the maritime transport sector in the GDR are not. In the context of explorative research and in the circumstance of the present research, the empirical approach is unrealistic. The empirical scientist is considered methodical and objective and therefore the knowledge created is considered trustworthy in its inherent ability to validate (Cronin, 1999). The empirical process formulates a description which is hypothetical; the description requires explanation in a technical context (by proven theory and or validation), and when verified returns again to provide a proven true description (Cronin, 1999). Cronin argues that all sciences develop from the process of description and explanation and the empirical sciences are always open for revision on the basis of new knowledge founded on re-examination of the 
original basic principles. The philosopher is concerned with questions concerning reasoning, existence, nature and what constitutes genuine knowledge. The philosopher and philosophy is sometimes considered the opposite of science in terms of knowledge learned, perceived by some as unreliable and based on personnel speculation and opinion which lacks the inherent validity afforded by empirical research. However contemporary empirical research has a level of reliance on belief and trust as the empirical researcher must trust and believe already proven theories as factual even though humans inherently fail and make mistakes. For the philosopher the knowledge that the individual has is developed from a variety of learned senses such as experience, understanding and an evolution towards judgement (Cronin, 1999). For the philosopher there is no reliance in terms of trust and belief in someone else's work as the philosopher relies only on immanent experience and understanding (Cronin, 1999) and therefore can be more sure about what they know when compared to what the empirical scientist knows (Cronin, 1999). Not all real world problems can be solved through empirical logic and in the context of explorative research the features of experience, belief and what an individual believes as truth are components to a process of genuine knowledge creation.

\subsubsection{Epistemology}

The objective of all research is new knowledge creation and as discussed the attainment of new knowledge can have its principles based in the empirical or the philosophical mothods. The data for the current research is being sourced from individuals within the GDR maritime transport industry. Therefore the data sourced is their opinion derived from their accumulation of knowledge and experience which derives to a point of judgement. In examining knowledge and what is knowledge leads to the branch of philosophy that is epistemology. Epistemology addresses the validity of knowledge and beliefs and asks questions such as "what is knowledge?", "how is knowledge acquired?" and "what do people know?" 
Ayer (2000) argues that Hume completed a movement of thought instigated by Locke in his 1960 publication Eassy concerning Human Understanding, further developed by George Berkeley's Principles of Human Knowledge in that man has no knowledge of the world but only what is derived from experience (Ayer, 2000). Cronin (1999) also argues that knowledge is an accumulation of experience, understanding and judgement and within experience, understanding and judgement lies beliefs, truth and eventually knowledge.

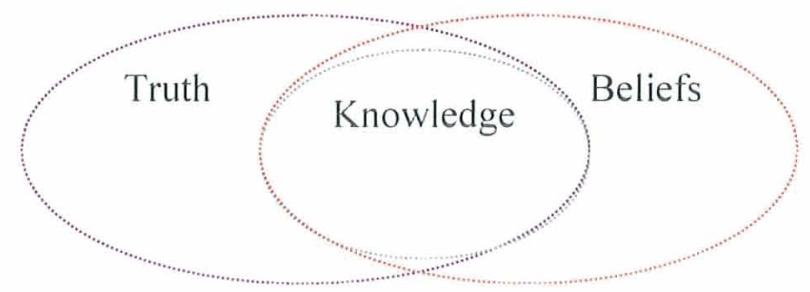

Figure 11 Truth, Knowledge and Beliefs (Source: Cronin, 1999)

The question "what is knowledge", addresses the concepts of truth and beliefs. Lowe (2005) argues in discussing Locke that certain things are known to us intuitively (i.e. a liquid is not a solid) while certain things are know by means of demonstration or from the reasoning provided for by deductive arguments and proof. Lowe (2005) discusses that the requirement of demonstration in the pursuit and acceptance of certain knowledge is a limitation of the human form. False beliefs are not considered knowledge but beliefs are a state in which an individual believes something is true. Beliefs can be devised from experience and understanding and to the believer those beliefs are true, even if they are false. In terms of beliefs the relevant question may be; what is true and what is useful to believe? (Hollis, 1994).

Epistemology helps to address the truth of opinion as a reliable source of knowledge by investigating the validity of opinions and if knowledge reflects reality. In terms of knowledge there is what we know and how we know, although it is argued that the possession of evidence is what makes beliefs justified (Steup, 2005) and that evidence is based in the cognitive experience 
of memory, introspective, perceptual and the intuitional. Memory is the ability to recall knowledge from the past, introspection is the ability to examine inside and decipher the states of tiredness, thirst, sadness or happiness, knowledge through perception is based on the five senses of sight, touch, taste, hearing and smell, and certain knowledge is found intuitively (Steup, 2005). Knowledge derived from beliefs in truth is often addressed from the perspective of a structure of a building block of knowledge in that justified beliefs are the foundation to the building of knowledge (Steup, 2005). Constructivist epistemology supports the concept of the construction of knowledge through social experiences, human perception and the reality in general convention.

\subsection{The Delphi Method}

In the context of the current research the data is sourced from the opinions of experts who work in the maritime transport sector in the GDR. Therefore how valid and reliable are opinions? In the first instance the individual that provides the opinion is carefully selected. The Delphi method requires the utilisation of expert opinion, in that the objective of the information source is not reflective of the consensus of a population. Therefore in terms of the validation of such opinion an appropriate percentage of the population would have to take part in the method in order to produce reliable results. However, Delphi employs experts on the basis that experts when asked questions in their field of expertise, will be usually right when compared to non experts. For Delphi the selection of experts is important and it provides the first point of internal validation, in that the method seeks to apply the best practitioners to the questions asked, in order to achieve reliable results in terms of opinions reinforced through the process of feedback and repetitive rounds to arrive at a general consensus of the total opinion expressed.

In summarising, opinions do hold validity although all opinions may not reflect the truth and reality. There are beliefs which can be built from year's of experience and the members of the Delphi panel do have considerable 
experience in terms of time served in the GDR maritime transport industry. In applying Delphi as a method of collecting opinion further validates the consensus due to the requirement of experts as opposed to any individual with an opinion. As already discussed individual opinion holds truth in individual beliefs although that belief can not conclusively guarantee factual and reliable knowledge. The Delphi method contests this drawback by having a panel of experts and by repeatedly asking the questions through a number of rounds supported by the opinions of the rest of the panel through feedback. Delphi provides a format for the expression of opinion but also for a debate on that opinion which leads to a convergence on consensus. The nature of the research is explorative and the prospect of knowledge creation on the potential clustering of the maritime transport sector extends beyond the constraints of the present research. Therefore it is positive if the research process raises more questions that it can answer as those questions will be more appropriate and relevant in terms of asking the right questions in order to obtain the right answers within a concept of what is useful to know.

The Delphi Method is named after the Greek oracle at Delphi who offered visions of the future (Gupta and Clarke, 1996). The Delphi Method is a technique to utilise and obtain an agreement or consensus on a number of statements, opinions or views. It was developed at the Rand Corporation at the beginning of the cold war to forecast the impact of technology on warfare (Loo, 2002). Since its inception in the 1950's the technique has evolved from research for military intelligence to concentrate on areas such as health, policy, planning and transport. The purpose of this discussion is to investigate the Delphi Method as a methodology with respect to its objectives, characteristics, advantages and disadvantages, effectiveness, reliability, and validity and to illustrate where Delphi has been utilised for transport related research. 


\subsubsection{Definition of the Delphi Method}

The evolution of the Delphi Method over the decades has lead to a selection of definitions containing a similar thread of core terminology. The following definition is provided by Delbecq, Van de Ven and Gustafson (1975) cited in Wiersma and Jurs (2005);

"TThe Delphi Method is] a method for the systematic solicitation and collection of judgments on a particular topic through a set of carefully designed sequential questionnaires" (Wiersma and Jurs, 2005, p281 in Delbecq, Van de Ven and Gustafson, 1975).

A subsequent example of a definition of the Delphi Method is provided by Linstone and Turoff:

"The Delphi Method objective is tol obtain the most reliable consensus of opinion of a group of experts ... by a series of intensive questionnaires interspersed with controlled opinion feedback" (Linstone and Turnoff, 2002, $\mathrm{p} 10)$.

To define what is Delphi seems attainable; to describe the process of Delphi however one would have to take into consideration the evolution of the method from the 1950's. In the early days the method was primarily a methodological tool for forecasting and to obtain consensus, however it has also been used as a means to examine the possible difference of opinion in order to construct alternative scenarios i.e. a policy Delphi (Okoli and Pawlowski, 2004), or as a method for concept development to explore topics and to aid in identifying issues to be developed or clarified in further research. Keeney (et al, 2001) argues that lack of guidance in conducting the method has contributed to the variety of approaches used in different Delphi studies. Therefore the description of the Delphi Method is perhaps best served by terminology associated with the method which includes; forecasting, opinion, statements, elicit judgments, use of experts, controlled feedback, the exploration of issues and their feasibility, consensus, non consensus, sequence of questionnaires, anonymity, discussion, and debate.

\subsubsection{The Objectives of the Delphi Method}

The Delphi method can be used when there is lack of reliable, accurate, feasible and attainable information sources (Linstone and Turoff, 2002), or 
where there is insufficient data on a topic (Tapio, 2002), or utilised as a research method to gather initial preliminary data (Wiersma and Jurs, 1969), or as a method to develop theories and generate scenarios as opposed to a pure classical method of evaluation and validation (Day and Bobeva 2005). Delphi can also be used to look at complicated social systems and to encourage debate or to gather informed expert opinion on a vast range of issues. In its broadest terms the aim of any Delphi is to achieve a consensus on statements, questions, forecasts, opinions or on the analysis of informed judgements of previously identified issues (Saldanha and Gray, 2002). The wording and the application of the term "consensus" basically infers agreement or general agreement (Oxford Dictionary, 2005), however the objective of a Delphi study is a more complicated task than just achieving general agreement as the inherent objective of the method in a contemporary research environment is directly consequential to the context of the subject matter being researched.

\subsubsection{Types of Delphi}

As the method of Delphi has evolved over the decades away from its innovative objective of forecasting, the technique can be broadly classified into three main types of application. The conventional or classical Delphi is usually a paper and pen questionnaire approach, although recent technological developments have seen the medium of the internet (Yao and Liu, Undated) used. The classical Delphi objective is to amalgamate the opinion and views of experts with the aim of convergence or consensus (Wiersma and Jurs, 2005). The second format of the Delphi is the so called policy Delphi, in which the objective is not attainment of consensus but to create a platform for the strongest possible opposing views on major issues of policy (De Loe, 1995). The policy Delphi aims to debate and clarify policy for decision makers in terms of policy effectiveness, resolution, consequences and acceptability (Critcher and Gladstone. 1998). The subsequent Delphi mode is the Decision Delphi in which the consequence of the research question is not to predict, forecast or describe in terms of a reality (Tichy, 2004). The Decision Delphi aligns its objective to that of the approach of soft 
systems such as systems dynamics and hard systems thinking in order to understand real world problems (Jackson, 2003). In categorising Delphi and its possible characteristics Day and Bobeva (2005) complied a taxonomy of Delphi inquiry designs (Table 8). The taxonomy looks at seven key issues of an individual Delphi in terms of the purpose of a particular study, number of rounds, mode of participants, level of anonymity, communication facilitation process, and the concurrency of the rounds.

Table 8 Taxonomy of Delphi Inquiry Designs

\begin{tabular}{|l|l|}
\hline Criteria & Choice \\
\hline Purpose of the study & Building, exploration, testing, evaluation. \\
\hline Number of round & Between 2 and 10. \\
\hline Participants & Homogeneous or heterogeneous. \\
\hline Mode of operation & Face to face or remote. \\
\hline Anonymity of panel & Full or partial. \\
\hline $\begin{array}{l}\text { Communication } \\
\text { media }\end{array}$ & $\begin{array}{l}\text { Paper and pen based, telephone and fax facilitated, } \\
\text { computerised. }\end{array}$ \\
\hline $\begin{array}{l}\text { Concurrency of } \\
\text { rounds }\end{array}$ & $\begin{array}{l}\text { Sequential set of rounds or real time online } \\
\text { conferencing. }\end{array}$ \\
\hline
\end{tabular}
(Source: Day and Bobeva, 2005)

\subsection{Characteristics of the Delphi Method}

In the context of Linstone and Turoff (2002) and subsequent definitions the Delphi Method has certain characteristics. The core underling features and supportive framework of the method which are discussed has its context in the anonymity, experts, controlled feedback, consensus, panel size, and panel genre, level of attrition rates and the number and objective of Delphi rounds.

\subsubsection{Expert Panel}

A core feature of the Delphi Method as a methodology is the use of experts. Historically the classical Delphi utilised the knowledge of informed experts to forecast possible future events as traditional methods of data collection in terms of an individual research question were unsuitable due to constraints of cost, reliability and availability (Linstone and Turoff, 2002). The concept of the use of experts is that, when asked questions within their field of expertise, they will usually be right, when compared to non-experts. The 
method is a proficient way to amalgamate the knowledge of a group of experts (Powell, 2002, citing Lindeman, 1975) or a group of specific subject matter experts (Loo, 2002) for the purpose of knowledge creation. An expert can and is defined in various ways. For example, an expert is an "informed individual, "specialist in their field", "person with knowledge about a specific subject' (Keeney, et al, 2001). The issue of the expert panel in Delphi is an area that tends to incite the controversial side of the method, as the quality of the information and opinion collected is in direct proportion to results achieved. Experts are required for the panel membership and the individual panel member is recruited on the fact that they are an expert. The claim of Delphi to represent expert opinion has been criticized as overstated (Keeney, et al, 2001) and the use of the terminology of "expert" as misleading and citing controversy (Hasson, et al, 2000). However true expertise is difficult to effectively define and Rosenberg (2006) discusses that the true character of an expert and their expertise is the ability of that expert to fully understand all aspects of a problem or situation and to provide "appropriate and specific guidance". De Loe (1995) argues that consensus achieved by expert opinion has a greater chance of proving its accuracy and such assumptions of the use and value of experts is widely accepted by Delphi practitioners.

Usually panel selection requires non-probability sampling techniques (Hasson, et al, 2000, Keeney, et al, 2001). However the Delphi Method does not require the use of random sampling as it employs "experts" (Keeney, et a1, 2001). The experts are selected for the purpose of supplying and to make available their knowledge and expertise of a subject area (Hasson, et al, 2000) as opposed to the requirement of a statistical sample representation of a given population (Okoli and Pawlowski, 2004). Linstone and Turoff (2002) argue that individuals interested in the results could be a source for panel selection, while Jairath and Weinstein (1994) discuss that experts should be impartial to any potential findings. However literature supports the context of panel selection to include both innovators and users. For example Wiersma and Jurs (2005) in the context of curriculum implementation 
suggest that both teachers who will teach a proposed curriculum and curriculum experts should be included in a Delphi study on curriculum.

A diversity of panel members (Powell, 2002) and a diversity of view points sourced from a wider perspective of knowledge and experience related knowledge (Linstone and Turoff, 2002) allows for greater consideration of different perspectives of opinion. Panel diversity can help facilitate and generate interest and involvement as experts drawn from a greater depth of background could provide a greater base of knowledge (Powell, 2002 citing Rowe, 1994). The literature supports the application of a heterogeneous Delphi panel (Wiersma and Jurs, 2005). Research has also been conducted in the area of optimism of rated expert panels (Tichy, 2004) which concluded that there is a higher level of optimism in opinion statements from selfrated experts leading to over-optimistic results. Tichy (2004) therefore argues that Delphi (especially foresight Delphi's) should include top experts but also experts with a more broad range of knowledge.

Data collection focused on opinion and judgement raises the issue of potential bias which requires consideration (Powell, 2002) as Tapio (2004) highlights criticism in the approach used to develop a reliable selection of expert panellists. There can be bias in the selection of experts (Keeney, et al, 2001), if individuals (i.e. the experts) are affected by the possible outcome of the Delphi (Hasson, et al, 2000). Hasson (et al, 2000) discuss the relevance and importance of gate keepers to aid in identifying potential individuals who may have the knowledge associated with the research topic. This is perhaps more prevalent in small and niche areas of research where access to and the availability of informed experts may be lacking.

\subsubsection{Control Opinion Feedback}

Feedback through the Delphi rounds is basically a means to supply the panel members with the opinion and judgements of the total panel, in order for the individual panellist to be informed of the opinion of the group and if necessary to modify his/her original response. Dalkey (1969) acknowledges that Dalkey and Helmer (1964) first introduced the feature of iteration with 
controlled feedback in order to reduce noise in the process and to support the anonymity of the Delphi panel. Feedback in the Delphi provides the medium in which panel members receive opinion and judgements from the total panel and aid the development of the subsequent Delphi round. The feedback between rounds also helps in the development of knowledge and the spread of knowledge to all panel members, which can help to drive and stimulate new ideas or areas of research (Powell, 2002). The process and the facilitation of feedback is outlined in Figure 12. The expert panel receives the Delphi questionnaire from the Delphi moderator or facilitator and conducts the role of the expert as required by the Delphi moderator. The response is returned and summarized by the Delphi moderator. In the update of the process the Delphi moderator summarises the data in a prescribed format for repeating and forwarding again to the expert panel. This process is repeated for the required number rounds (e.g. 3 or 4 ).

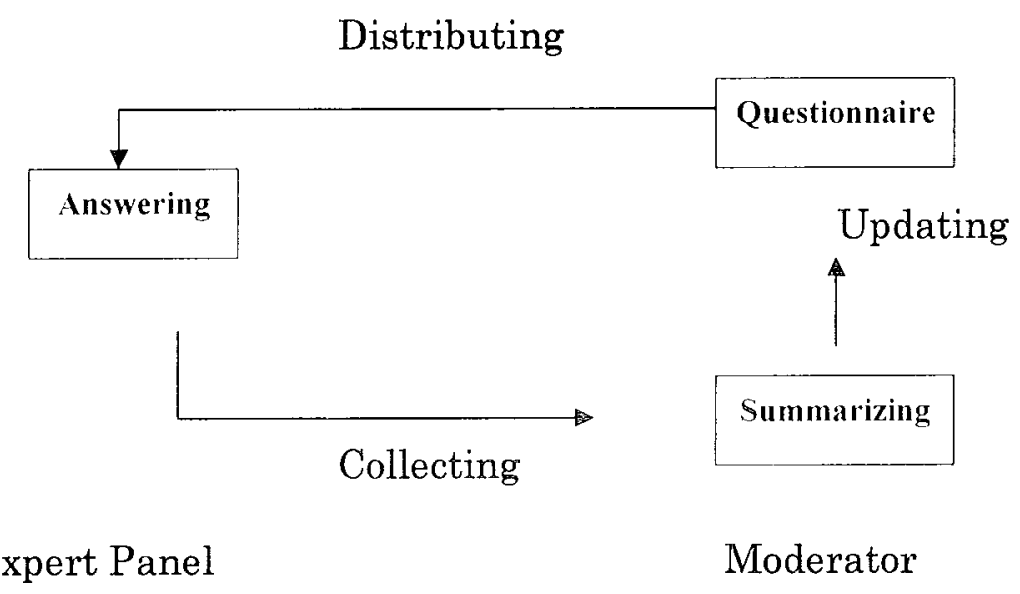

Higure 1\%. Procedure of a Delphi Study

(Source: Yao \& Lio. Undated)

Decisions made in the Delphi process can be strengthened by reasoned arguments (Hasson, et al, 2000) and the process of feedback in Delphi can be displayed in different ways although scarce feedback and summary report type feedback have been criticized (Tapio, 2002). There are generally three types of feedback used in Delphi studies, first iteration (iteration over rounds without feedback from members of the Delphi Panel), second, statistical feedback including mode and median values and lower, medium 
and upper quartile ranges, and thirdly, reasons feedback which includes reasons from the Delphi panel members (Rowe, et al, 2005). In reason feedback panel members are supplied with the results of each question i.e. the majority percentage that either agreed or disagreed with the statement (question, opinion or foresight) and the opinions or reasons of the panel member's judgement. Rowe and Wright (1999) investigated judgement change during rounds and compared different methods of feedback distribution to panel members and compared statistical feedback to reason feedback and discovered that there was a higher improvement in accuracy through the rounds when reason feedback was supplied to panel members. Subsequently when panel members based on reason feedback did change their opinion it was found to be more accurate.

\subsubsection{Anonymity of Panel Members}

In the Delphi technique the panel members are usually completely unknown to each other and only the administrator of the research has knowledge of the full panel membership (Loo, 2000) as the researcher's knowledge and access to the respondents allows for the opportunity for follow up clarifications (Okoli and Pawlowski, 2004). The reason for panel anonymity has it basis in the psychology of human behaviour within group interaction and the tendency for individual participant dominance ( $O^{\prime}$ Loughlin and Kelly, 2004). The design of the Delphi technique took into consideration the issues and problems of gathering panel members together for the purpose of communication and knowledge creation. In an interactive group situation there can be a tendency for a dominant figure within the group that will steer the direction of communication, and persons within the group may be unwilling to provide opinion in fear of reprisal, or fear to modify their view through discussion due to the opinion of the rest of the group (Scapolo and Miles, 2006). The anonymity afford by Delphi helps to reduce the social pressures observed in such interacting groups (Rowe, et al, 2005).

The anonymity of the experts allows for each opinion to be afforded equal importance (Keeney, et al, 2001) and helps to remove potential bias as the 
respondents are not known to each other, although there are Delphi studies where experts have been ranked or self rated (Tichy, 2004). Here a higher weighting is given to experts whose opinion is deemed to be more valuable. In criticism of self rating Powell (2002, in citing Sackman, 1975) suggests that anonymity may lead to a lack of accountability with respect to the opinion provided, or a drop in motivation to complete the study while Tapio (2002), suggests that panellists should be asked to act as a company or organisation representative rather than individual experts in order to secure a greater motivation to complete the study.

\subsubsection{Consensus}

Consensus as a basic concept conveys the meaning of general agreement. One of the aims of using Delphi is to achieve a greater consensus with a reduction in variance through the rounds taken as an indication of greater consensus (Rowe and Wright, 1999). The term and subsequent interpretation of consensus with respect to the Delphi technique as highlighted by Powell (2002) is often omitted in Delphi studies. There seems to be a lack of clarity on what consensus actually means, and there is no clear absolute indication of when a consensus in Delphi is achieved. Powell (2002), on the basis of a review of Delphi studies concluded that there were many ways to infer consensus and the application of a percentage seemed to be the most prominent means of deciding when a Delphi study has reached its final "consensus". Therefore different Delphi studies have attributed different percentages from a range of 100\% to as low as 55\% (Powell, 2002). Consensus is the core of Delphi itself as it is the consensus that provides the final conclusion to the research being conducted. A recent study looked at the possible consensus difference between two methods used to obtain viewpoints and opinions (Kadam, et al, 2006). The two methods applied in the research discussed were Delphi and the Nominal Group Approach. The main difference in the methods is in the fact that the nominal approach helps to create a realistic picture of the true consensus being sought (advantage of face-to-face interaction), while those in favour of Delphi argue that the anonymity of the participant reflects a true representation of the 
individual perspective and a greater accuracy assessment of the individual range in the consensus achieved (Kadam, et al, 2006). The results of the research showed no difference in the consensus obtained by both methods. However Kadam (et al, 2006) emphasizes that there is a need to evaluate the choice of consensus method which could be a possible factor of bias or influence in the results. Keeney (2001) further argues that just because a consensus has been achieved it does not infer that a correct answer has been found, however one of the advantages of the Delphi method is the achievement of consensus in an area of uncertainty (Powell, 2002).

\subsubsection{Panel Size and Panel Grouping}

In Scapolo and Miles (2006) methodological investigation of Delphi, the lack of precise indication of an appropriate panel size was considered a negative attribute of the method. Delphi panels do vary in size and it is argued that there is no ideal optimum panel size (Loo, 2002) however the panel should be representative of the experts in the area being researched (Wiersma and Jurs, 2005). However the literature goes some way to indicate possible sample size of Delphi panels, for example no less than 8 to 10 (Scapolo and Miles, 2006) and Powell (2002, citing Reid, 1988) observed panels ranging from 10 to 1,685 . The biggest Delphi with respect to panel size was conducted in Japan which had a panel size of several thousand (Day and Bobeva, 2005) however De Loe (1995) discusses that a large Delphi panel can result in subsequent questionnaires which can de-motivate panel members to complete the full survey. Parenté and Anderson-Parenté (198\%) suggest a minimum of 10, Delbecq (1975) suggests a range of 25-30 panel members. Kapoor (1987) conducted a Delphi with a panel of 40, Scott \& Green (1993) had a panel of 22, Saldanha and Gray (2002) had a panel of 11 and Islam (2005) had a panel of 12. While there is no established optimal size for a Dclphi panel an increase in the size of a panel will enhance the reliability of the Delphi to a point (Wiersma and Jurs, 2005) and taken in the context of the examples discussed above a typical size range for a Delphi panel would be between 15 and 30 (Loo, 2002). 
The result of a consensus would also be proportioned to some degree to the panel size of the Delphi; Kadam (et al, 2006) makes reference to a study ${ }^{9}$ that considered the effect of sample size on consensus agreement levels. The report concluded that a suggested group with a minimum of six could provide "useful agreement" and maximum level of agreement could be obtained with a group of up to 12. A heterogeneous group can lead to variations in consensus (Kadam, et al, 2006) and Keeney (et al, 2001) argues that panel size and the mode of the panel (homogenous or heterogeneous) can depend on the objective of the individual research project. Powell (2002) citing Delbecq (1975) argues that heterogeneous Delphi groups produce a higher quality of acceptable results than homogenous Delphi groups. Wiersma and Jurs (2005) argues that Delphi panels tend to be homogenous in nature, however opposing views in policy Delphi's benefit from a heterogeneous panel. However key issue in determining the size of a Delphi panel is perhaps a consequence of the subject matter being research in terms of the extent of the research problem being addressed and the availability of experts in the research area as well as concerns centered on resources, duration and finance (Powell, 2002).

\subsubsection{Rounds and Attrition Rates}

The Delphi method is conducted though a series of sequential rounds of which usually there are three to four but some studies have performed a Delphi in excess of four rounds and as short as two rounds (Tapio, 2002). 'The development of the first round of a Delphi is enhanced with a good clear' understanding of the research aims and supportive literature review. Many Delphi studies conduct the first round as an open ended process in which the experts are encouraged to provide their opinion and judgement in their own words to facilitate the generation of ideas (Loo, 2002). Subsequent rounds are therefore used to elaborate and identify specific issues raised in Round 1. The format of Round 1 in Delphi studies have been approached differently and can be structured, semi-structured (Powell, 2002) or

\footnotetext{
${ }^{9}$ Richardson FM. Peer Review of Medical Care. Med Care 1972:10:29-39.
} 
explorative (Wiersma and Jurs, 2005). For example Round 1 can also be used for scenario building in which the Delphi facilitator provides a description of a present state as well as various possible future states. In each round a summary of the results of the previous round is provided although the mode in which the feedback is presented can differ between Delphi studies and utilise both quantitative and qualitative formats (Loo, 2002). The subsequent rounds of a Delphi are basically the analysis of the results from the first round (Keeney, 2001) and generally from Round 2 onwards the form of the Delphi is predominantly a structured questionnaire with a predetermined method of controlled feedback. It is also important to pre-test and redefine the rounds for discrepancy and bias and careful attention must be considered in respect to the structure of sentences and wording (Keeney, 2001).

Delphi studies suffer from high attrition rates and Sackman (1975) discusses strong motivation and a keen interest in the topic area as reasons for panel members completing the set of Delphi rounds required by a particular survey. Scapolo and Miles (2006) discuss that the attrition rates for Delphi can also be attributed to a disagreement with the method or design and content of the questionnaire along with features such as lack of time or the demanding nature of the process. The repetitive nature of the rounds and the questionnaire in general, or the individual expert perceptions of the lack of need to amend earlier opinions are all possible and cited reasons for Delphi drop out rates.

\subsection{The Effectiveness, Reliability and Validity of Delphi}

Rowe and Wright (1999) discuss the Delphi method with respect to its effectiveness as a methodology. Their argument is that Delphi is not a replacement for scientific rigour or a method to challenge statistics or model based procedures. The Delphi method, at its purest is a vehicle for collecting opinion and judgement for the purpose of forecasting, discussion and debate where such statistics or models are unpractical. Rowe and Wright (1999) argue that it is within that context that the informed opinion and judgments 
of experts in their field of expertise through the application of the Delphi technique is a useful methodological tool. Therefore the results of a Delphi study should not be subjected to the reliability and validity of hard science methods (Powell, 2003). The Delphi Method or subsequent forecasting techniques do not strive to create new fact but to create a process to gather data and knowledge, and critics of Delphi should remember that practitioners of the method do not claim that the technique is a replacement for a more rigorous research application. The Delphi method has often been described in the context of the following description;

"The Delphi Method objective is tol obtain the most reliable consensus of opinion of a group of experts ... by a series of intensive questionnaires interspersed with controlled opinion feedback" (Linstone and Turoff, 2002)

However in the evolution of the method and the types of Delphi techniques available Landeta (2006) discuses that a more appropriate contemporary description of Delphi is;

"A social research technique whose aim is to obtain a reliable gxoup opinion using a group of experts" (Landeta, 2006)

The relevance of a change in description is that the importance of achieving consensus in Delphi is not as critical as it once was since the method has adapted to address research issues of social science and real world problems as opposed to a pure methodological tool for forecasting. Landeta (2006) argues further that Delphi provides a platform for structured communication incorporating a group of individuals that can provide reasonable contributions to the resolution of a range of problems. In terms of the use of Delphi as a methodological tool Gupta and Clarke (1996) provided a bibliography (from 1975 to 1994) of research that utilised the method of Delphi, while Landeta (2006) extended the bibliography from 1995 to 2004 (see Table 9). 
Table 9 Frequency of Delphi Studies Published over the Period from 1995 to 2004 (Source: Landeta, 2006)

\begin{tabular}{|l|c|r|}
\hline \multicolumn{1}{|c|}{ Database } & Period & Articles \\
\hline Science Direct & $1995-1999$ & 367 \\
& $2000-2004$ & 571 \\
\hline ABI Inform & $1995-1999$ & 47 \\
& $2000-2004$ & 106 \\
\hline Psycho & $1995-1999$ & 86 \\
& $2000-2004$ & 162 \\
\hline Medline & $1995-1999$ & 361 \\
& $2000-2004$ & 547 \\
\hline
\end{tabular}

In terms of doctoral research the popularity of Delphi reached its height in the 1980's however there is a noteworthy continuation in application of the method which infers Delphi as an accepted technique further supported by the use of Delphi by organisations such as the EU Institute for Prospective Technological Studies ${ }^{10}$ (Landeta, 2006).

It is clear from the literature that Delphi, like all methods has it positives and negatives and a vast majority of Delphi references available concern the application rather than an evaluation of the method. Rowe and Wright (1999) argue that this has led to a widespread conjecture that the method and subsequent results reflect a pure truth. The Delphi method has been criticised for a lack of accountability, reliability and validity, (Critcher and Gladstone, 1998, Keeney, et al, 2001, Hasson, 2000) in that responses provided from different panels to the same question can result in different answers, and at what point to opinions reflect a reality? However, Delphi uses small non-random samples and can be useful in terms of achieving consensus or a decision in potential conflicting issues which does not automatically incur a lack of reliability or induce the study as invalid. A range of scenario options or debate to aid in the identification or prioritization of future and further research issues or theory generation rather than evaluation can be just as desirable a result (Okali and Pawlowski, 2004). The objective of the Delphi panel is not to produce statistical results as the panel sample tends to be small, however the panel

\footnotetext{
${ }^{10}$ The Institute for Prospective Technological Studies (IPTS) is one of the seven scientific institutes of the European Commission's Joint Research Centre (JRC). (http://www.jrc.es/).
} 
provides a synthesis of opinion of a particular group of experts or informed knowledge individuals (Bay and Bobeva, 2005).

The first Delphi study conducted was "expert opinion to the selection, from the point of view of a Soviet strategic planner, of an optimal U.S industrial target system and to the estimation of the number of $A$-bombs required to reduce the munitions output by a prescribed amount" (Linstone and Turoff, 2002). At the time (i.e. 1950's) other methods to address such an issue would have been an extensive and expensive data collection process and such computer programming required was unattainable at that time. Therefore Linstone and Turoff (2002) argue that the original objectives for using Delphi are still relevant today with respect to when accurate information is unavailable, expensive or when the application of statistical models or scientific approaches are unpractical due to the concept of research question.

\subsubsection{Justification for using the Delphi Method}

The Delphi Method as a technique has seen considerable growth in popularity along with an expansion in the application of the method across a wide spectrum of topics and areas of research. Gupta and Clarke (1996) argue that the popularity of the Delphi Method is directly owing to the method's strengths for planning, forecasting and as an aid for decision making, while Landeta (2006) discusses that Delphi provides a platform for structured communication yielding a knowledge contribution. In today's complex world of social and economic systems, governments, managers, decision makers, academics, planners and policy makers are void of the safety and rigour of scientific methods in certain areas of social world research. It is within that context that methods such as Operational Research (OR), Complexity Theory, and Hard and Soft Systems thinking evolved to tackle the increasing complexity of real world problems for real world managers (Jackson, 2003).

As already discussed in terms of the application of Delphi in various areas of research the following discussion addresses specific examples of Delphi in 
transport related research. Sforza and Ortolano (1984) used the method for the forecast of land use, Khan (1989) with respect to the realistic planning of transportation (Delphi used as a secondary source), Ariel (1989) in forecasting issues relating to the dry bulk shipping sector in the year 2000, Fattah (1997) for road freight transportation in Egypt, New and Tomlinson (1994) in the reality of possible supply chain integration, (Delphi used as a secondary source), Vickers (1992) for the use of GDSS to examine the future European automobile industry (Delphi used as a secondary source), Fadda (1997) used the method to investigate Brazilian Coastal Shipping in 2010, Marchau, and Heijden, van der, (1998), on the policy aspects of driver support system implementation, Saldanha and Gray, (2002), investigated the potential for British coastal shipping integrated into a multimodal supply chain, Lirn (et al, 2004, Lirn, et al, 2003) on transhipment selection in a global perspective. Hwang (2004) undertook a comparative study of the logistics services in container liner shipping market in the UK and Islam (2005) investigated international freight transport and multimodal development in developing countries in the context of Bangladesh.

\subsubsection{Comparing Delphi with other Methods}

As already discussed the Delphi method as an application for methodology has evolved over the last few decades and currently there are variations in a Delphi survey approach. The table below compares the Delphi survey to the traditional survey approach and summarising the key areas of the Delphi method addressed in this chapter. In Table 10 devised by Okoli and Pawlowski (2004) compares the issue of sample, sample size, response, validity, anonymity and the richness of data. 
Table 10 Comparison of Delphi with Traditional Surveys

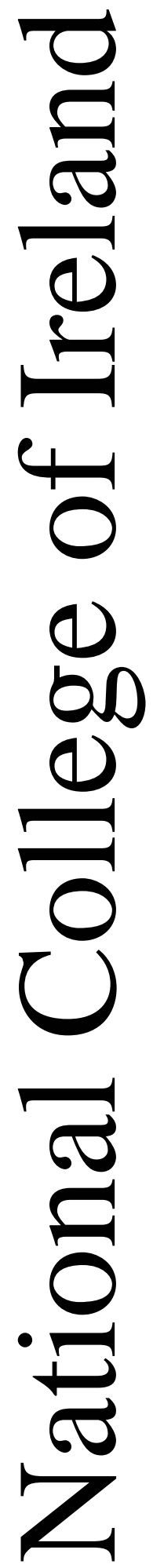

\begin{tabular}{|c|c|c|}
\hline $\begin{array}{c}\text { Evaluation } \\
\text { Criteria }\end{array}$ & Traditional Survey & Delphi Survey \\
\hline Sample & $\begin{array}{l}\text { A random sample representative of } \\
\text { the population is selected using } \\
\text { statistical sampling techniques. }\end{array}$ & $\begin{array}{l}\text { Delphi study investigates high } \\
\text { uncertainty or speculation and therefore } \\
\text { the population selected need to have } \\
\text { sufficient knowledge. A Delphi study is a } \\
\text { virtual panel of experts gathered to } \\
\text { arrive at an answer to a difficult } \\
\text { question. }\end{array}$ \\
\hline $\begin{array}{l}\text { Sample Size for } \\
\text { Statistical } \\
\text { Power and } \\
\text { findings }\end{array}$ & $\begin{array}{l}\text { The goal is to generalize results to a } \\
\text { larger population; the researchers } \\
\text { need to select a sample size that is } \\
\text { large enough to detect statistically } \\
\text { significant effects in the population. } \\
\text { Power analysis is required to } \\
\text { determine an appropriate sample } \\
\text { size. }\end{array}$ & $\begin{array}{l}\text { The Delphi group size docs not depend on } \\
\text { statistical power, but rather on group } \\
\text { dynamics for arriving at consensus } \\
\text { among experts. Thus, the literature } \\
\text { recommends } 10 \cdot 18 \text { experts on a Delphi } \\
\text { Panel. }\end{array}$ \\
\hline $\begin{array}{l}\text { Individual vs. } \\
\text { Group } \\
\text { Response }\end{array}$ & $\begin{array}{l}\text { The researchers average out } \\
\text { individuals responses to determine } \\
\text { the average for the sample which } \\
\text { they generalize to the relevant } \\
\text { population. }\end{array}$ & $\begin{array}{l}\text { Studies have consistently shown that for } \\
\text { questions requiring expert judgement the } \\
\text { average of individual responses is } \\
\text { inferior to the average produced by group } \\
\text { decision processes: research has } \\
\text { explicitly shown that the Delphi method } \\
\text { bears this out. }\end{array}$ \\
\hline $\begin{array}{l}\text { Reliability and } \\
\text { Response } \\
\text { Revision }\end{array}$ & $\begin{array}{l}\text { An important criterion for evaluating } \\
\text { surveys is the reliability of the } \\
\text { measures. Researchers typically } \\
\text { assure this by pre-testing and by } \\
\text { retesting to assure testretest } \\
\text { reliability. }\end{array}$ & $\begin{array}{l}\text { Pre-testing is also important reliability } \\
\text { assurance for the Delphi method. } \\
\text { However, testretest reliability is not } \\
\text { relevant, since researchers expect } \\
\text { respondents to revise their responses. }\end{array}$ \\
\hline $\begin{array}{l}\text { Construct } \\
\text { Validity }\end{array}$ & $\begin{array}{l}\text { Construct validity is assured by } \\
\text { careful survey design and by pre- } \\
\text { testing. }\end{array}$ & $\begin{array}{l}\text { In addition to what is required of a } \\
\text { survey, the Delphi method can employ } \\
\text { further construct validation by asking } \\
\text { cxperts to validate the researcher's } \\
\text { interpretation and categorization of the } \\
\text { variables. The fact that Delphi is not } \\
\text { anonymous (to the researcher) permits } \\
\text { this validation step. }\end{array}$ \\
\hline Anonymity & $\begin{array}{l}\text { Respondents are almost alwars } \\
\text { anonymous to each other. and often } \\
\text { anonymous to the researcher. }\end{array}$ & $\begin{array}{l}\text { Respondents are always anonymous to } \\
\text { each other. but never anonymous to the } \\
\text { researcher. This gives the researchers } \\
\text { more opportunity to follow up } \\
\text { clarifications and further qualitative } \\
\text { data. }\end{array}$ \\
\hline $\begin{array}{l}\text { No Response } \\
\text { Issues }\end{array}$ & $\begin{array}{l}\text { Rescarcher's need to investigate the } \\
\text { possibility of non response bias to } \\
\text { ensure that the sample remains } \\
\text { representative of the population. }\end{array}$ & $\begin{array}{l}\text { Non response is typically very low in } \\
\text { Delphi survers, since most rescarchers } \\
\text { have personaly obtained assurances of } \\
\text { participation. }\end{array}$ \\
\hline $\begin{array}{l}\text { Attrition } \\
\text { Effects }\end{array}$ & $\begin{array}{l}\text { For single survey attrition is a non } \\
\text { issue. For multi-step repeated survey } \\
\text { studies researchers should } \\
\text { investigate attrition to assure that is } \\
\text { it random and non-srstematic. }\end{array}$ & $\begin{array}{l}\text { Similar to nonresponse, attrition tends } \\
\text { to be low in Delphi studies, and } \\
\text { researchers usually can easily ascertain } \\
\text { the cause by talking with dropouts. }\end{array}$ \\
\hline $\begin{array}{l}\text { Richness of } \\
\text { Data }\end{array}$ & $\begin{array}{l}\text { The richness of data depends on the } \\
\text { form and the depth of the questions. } \\
\text { and on the possibility of follow ups. } \\
\text { such as in interviews. Follow up is } \\
\text { often limited when the researchers } \\
\text { are unable to track respondents. }\end{array}$ & $\begin{array}{l}\text { In addition to the richness issues of } \\
\text { traditional survess Delphi studies } \\
\text { inherently provide richer data base } \\
\text { because of the multiple iterations and } \\
\text { their response revision due to feedback } \\
\text { and Delphi participants tend to be open } \\
\text { to follow up interviews. }\end{array}$ \\
\hline
\end{tabular}

(Source: Okoli and Pawlowski, 2004) 
The aim of Delphi is to obtain the most reliable consensus from a group of experts by a series of intensive questionnaires with controlled opinion feedback. The structure of the method takes the positive attributes of interacting groups for the source of knowledge synthesis and employing proactive characteristics to stem the negative influences of peer pressure and social bias (Rowe and Wright, 1999). The next chapter will look at the actual process conducted in the GDR maritime transport Delphi and indicate the result of each Delphi statement concluded over each of the three rounds.

The purpose of next chapter is to discuss in detail the formation process of the greater Dublin region maritime transport Delphi and the progression of the Delphi method through Rounds 1, 2, and 3. 


\section{Chapter 6.GDR Maritime Transport Delphi}

The purpose of this current chapter is to discuss the process of the Delphi through Rounds 1, 2 and 3 and to present the results for each round.

\subsection{Problem Definition}

The current research question is based on the potential of clustering for the GDR maritime transport sector. Ireland is an island nation located on the periphery of Europe and therefore requires maritime transport activities. Within the GDR is the country's principle port facility and the location of the concentration of maritime transport firms, and therefore there is some level of maritime transport clustering. Literature tends to concentrate on the major success stories in clustering, such as maritime clusters like Singapore, Rotterdam and London. However it is arguable that there are far more small potential clusters like Dublin than there are major maritime clusters. Therefore what is the potential for the clustering of the GDR, and at what point does firm agglomeration, derived from the necessity for the transportation of commodities for an island nation, become a maritime transport cluster?

\subsubsection{Framework for Questions}

The nature of the GDR Delphi is explorative and the aim of the research is to look at the potential of the clustering of the GDR maritime transport sector and therefore the process begins from a wide spectrum. The application of the Delphi will help to highlight, indicate and prioritize areas for further research in terms of the potential for the clustering of the maritime transport sector in the GDR. As already discussed in the literature review (refer to Chapter 3) the framework for the structuring of the questionnaires will be based on de Langen's (2003) Cluster Structure Cluster Governance Framework which provides a structured framework for the Delphi. In terms of the current research question, a structured approach is more appropriate given the sizeable nature of the topic of clusters, and a previously applied framework affords greater validity. 


\subsubsection{Panel Selection}

As previously discussed the area of concentration for the research is the GDR which is a geographic boundary defined by the Irish Government's National Spatial Strategy. The research therefore will include firms, business and organisations that are located within the GDR boundary (for discussion on boundary of research, identification of firms and sectors refer to Chapter 4).

The size of a Delphi and the potential experts for the Delphi is in some way determined and delimited by the nature of the research question (e.g. if the research area is very specific there may not be many experts available). The current Delphi concentrates on clustering of the maritime transport sector in the GDR which inherently provides a boundary to the research i.e. firms, businesses and organisations related to the cluster core economic specialisation located within the GDR. The optimum source of potential experts to take part in the study is from the industry and organisations involved and representing the maritime transport sector. Who better to provide opinion on the GDR maritime transport sector than individuals who work and operate within the sector? Through a process of desk and internet research and consultation with industry organisations, a population of 250 maritime transport businesses, organisations and related firms were finally identified. The confidence level in the figure of 250 maritime transport businesses, firms and organisations is high, although it became apparent through the research process that a number of firms had ceased trading and information such as addresses and contact names in some instances were inaccurate. The maritime transport firms were divided into their representative sectors e.g. ports; shippers etc (refer to Chapter 4). The aim of the GDR Delphi is to take the collective approach to the maritime transport sector, however separating firms into their relevant sectors allows for the identification of an individual opinion from a specific sector if necessary, as firms, business and organisations that operate in the maritime transport sector may have similar needs but also may face differing barriers to trade and industry. 


\subsubsection{The Heterogeneous Nature of the GDR Delphi}

A cluster of a particular industry includes all related businesses, firms and associated organisations related to the cluster's core economic specialisation. Therefore the very nature of the current GDR Delphi will be heterogeneous as the research is investigating the collective maritime transport sectors, as opposed to examining one individual sector. Ideally there should be an equal number of panel members from each sector for each round, for example 10 panel members to represent each sector, in order to avoid bias due to possible domination of opinion from one sector. However, the very nature of clusters dictates that this is difficult as it is clear while there may be up to 10 freight forwarders operating within the GDR there is certainly not up to 10 ports, and therefore the ratio of panel members per sector will be irregular. The irregularity of the number of panel members per sector would also be influenced by the level of agreement for potential experts to take part in the study and the attrition rates through the rounds.

The configuration of the GDR Delphi comprised a structured questionnaire for the purpose of exploration, conducted over three rounds based on a heterogeneous panel with remote access in full anonymity with sequential rounds.

Table 11 Taxonomy of GDR Delphi

\begin{tabular}{|l|l|}
\hline Criteria & GDR Delphi \\
\hline Purpose of the study & Exploration \\
\hline Number of round & 3 \\
\hline Participants & Heterogeneous group \\
\hline Mode of operation & Remote \\
\hline Anonymity of panel & Full \\
\hline Communication media & Paper and pen based \\
\hline Concurrency of rounds & Sequential \\
\hline
\end{tabular}

(Source: Day and Bobeva, 2005)

\subsection{Round 1}

The first round of the Delphi survey was sent to a total of 64 agreed panel members. The first round included a letter of appreciation (Appendix 4: Round 1 Appreciation Letter) for their agreed participation. The first round documentation also included the Round 1 Delphi questionnaire (Appendix 5: 
Delphi Round 1 Questionnaire) and a document that requests each panel member to fill in their name, company, current position of employment, brief career history and to indicate (tick the box) which sector of the maritime transport industry their current company represents (Appendix 6: Delphi Panel Member Information Document). The panel members were given clear and precise instructions of how to administer the questionnaire. The panel members were also given full contact details of the Delphi facilitator in case of any problems or concerns that might require clarification.

\subsubsection{Development of Delphi Round 1 Questionnaire}

Prior to the development of the Delphi Round 1 questionnaire, research was conducted on the Delphi technique (refer to Chapter: 5), maritime transport research (refer to Chapter 2) and cluster theory (refer to Chapter 2 and 3). As detailed in the literature review of cluster economic theories in Chapter 3 the first round questions were derived from de Langen's (2003) Cluster Structure Cluster Governance Framework. As detailed in the Delphi Round 1 Model (Figure 13) once the literature review was complete an initial interview exercise was conducted with persons from the maritime transport industry for the purpose of pre-testing the questionnaire to identify any discrepancies, bias or potential misunderstandings (Keeney, et al, 2001, Scapolo and Miles, 2006). 

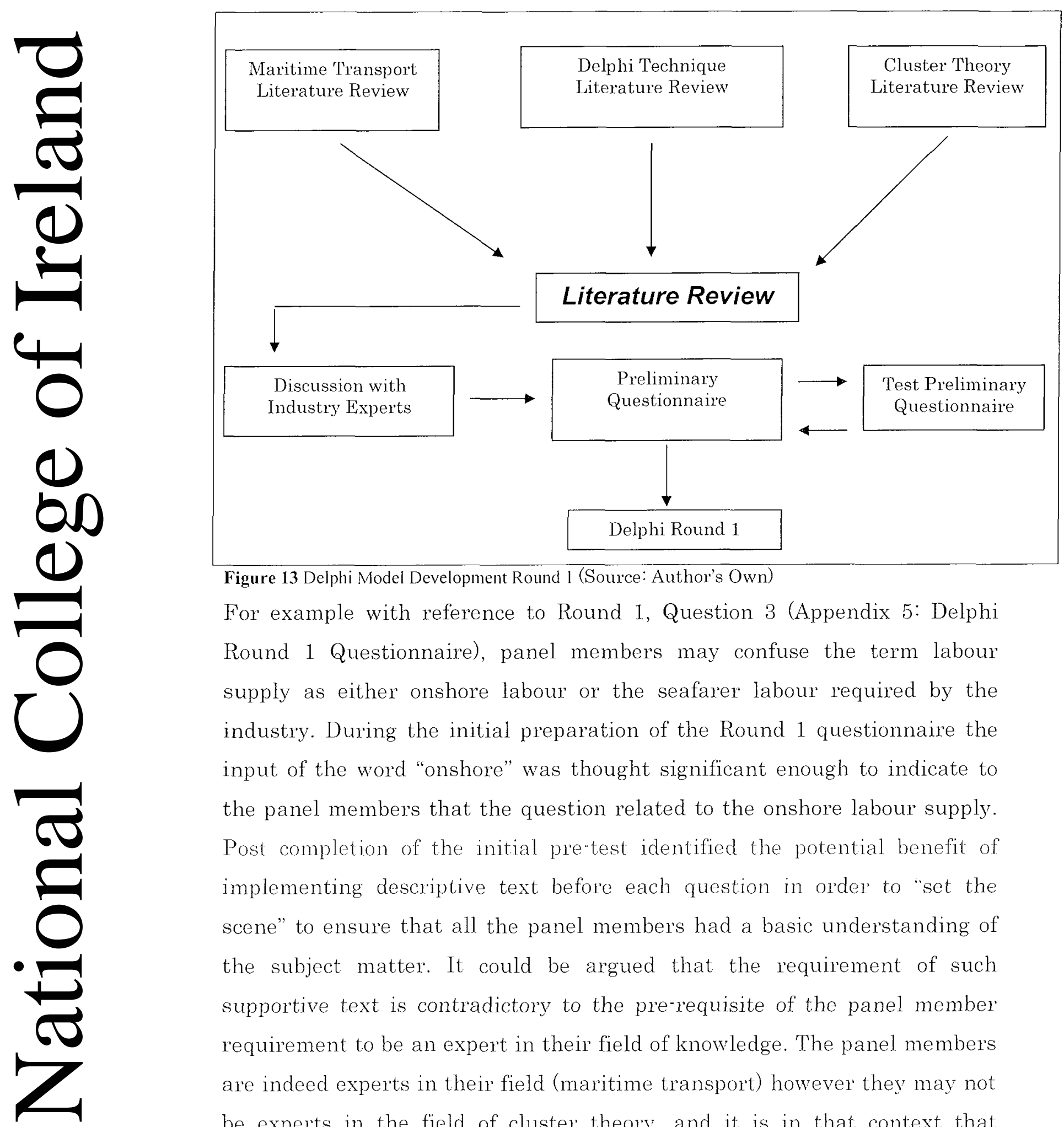

Figure 13 Delphi Model Development Round 1 (Source: Author's Own)

For example with reference to Round 1, Question 3 (Appendix 5: Delphi Round 1 Questionnaire), panel members may confuse the term labour supply as either onshore labour or the seafarer labour required by the industry. During the initial preparation of the Round 1 questionnaire the input of the word "onshore" was thought significant enough to indicate to the panel members that the question related to the onshore labour supply. Post completion of the initial pre"test identified the potential benefit of implementing descriptive text before each question in order to "set the scene" to ensure that all the panel members had a basic understanding of the subject matter. It could be argued that the requirement of such supportive text is contradictory to the prerequisite of the panel member requirement to be an expert in their field of knowledge. The panel members are indeed experts in their field (maritime transport) however they may not be experts in the field of cluster theory, and it is in that context that supplement text is beneficial. For example, with reference to Delphi Round 1, Question 8 (Appendix 5: Delphi Round 1 Questionnaire) with respect to 
barriers of entry to the Dublin maritime sector, there is no doubt that the panel members have considerable knowledge and experience to recognise what might be considered as a barrier of entry or exit. The supportive text is there to explain cluster theory behind each question i.e. the potential positive and negative effects barriers can have on a cluster of industry.

\subsubsection{Breakdown of Delphi Round 1 Questionnaire}

Round 1 of the Delphi had a total of 17 questions which were sub-divided into eight different sections. The following text will illustrate the questions in Round 1 and provide a brief discussion on the relevance of each question.

\subsubsection{Round 1, Section 1}

Round 1, Section 1 of the Delphi survey included two questions that were not representative of the cluster structure cluster governance framework. The questions have relevance in that it is important to establish if the experts consider the GDR as a maritime transport cluster as opposed to assuming that they already consider the GDR as a maritime transport cluster. The Section 1 questions from Round 1 are as follows.

Round 1, Section 1, Question 1

Q1. Do you consider the greater Dublin region maritime transport sector as a maritime cluster?

It is essential to ask the panel members if they first consider the greater Dublin region as a maritime transport cluster. It is important to get a consensus on the statement as it would be ineffective to ask the panel members questions based on cluster theory with respect to the GDR maritime transport sector, if they do not consider the GDR in which they operate a cluster in the first place.

Round 1, Section 1, Question 2

Q2. Do you believe that the greater Dublin region maritime transport sector has the potential to move forward towards a more international recognisable cluster status?

The importance of Round 1, Section 1, Question 2 is to achieve a consensus from the panel member's if they believe that the GDR maritime transport 
sector has any future potential to develop further as a maritime transport cluster.

\subsubsection{Round 1, Section 2}

Round 1, Section 2 of the Delphi survey included three questions related to the labour supply of the GDR and the educational and training opportunities available for that labour supply. The Section 2 questions from Round 1 are as follows,

\section{Round 1, Section 2, Question 3}

Q3. Do you believe there is a lack of sufficient onshore labour supply for any specific maritime transport sector in greater Dublin region?

The labour supply available to firms, business and organisations is important for any cluster and cluster development; therefore it is important to ask panel members if they believe there is sufficient onshore labour supply for the maritime transport sector in the GDR.

Round 1, Section 2, Question 4

Q4. Do you believe the current maritime transport labour supply is sufficient to meet the labour requirements of a growing maritime transport sector?

The purpose of Question 4 irrespective of the final consensus of Round 1, Section 2, Question 3 (i.e. either there is a lack of labour, or the current labour supply is sufficient) is to identify if the Dublin maritime cluster were to develop further would the current level of labour supply be sufficient enough to cope with an increase in demand for maritime transport related labour.

\section{Round 1. Section 2, Question 5.}

Q5. Do you believe there are sufficient educational and training opportunities in Ireland to service the labour, skill and expertise required by various fields in the greater Dublin region maritime transport sector?

Question 5 addresses the issue of training and educational facilities available for the maritime transport sector. Question 5 is in support of the labour related questions as labour requires training and education, and educational institutions and facilities can be the source of that knowledge for a labour pool. 


\subsubsection{Round 1, Section 3}

Round 1, Section 3 of the Delphi survey included two questions related to the importance of the location of a business, firm or organisation and the importance of and access to cluster knowledge. The Section 3 questions from Round 1 are as follows,

\section{Round 1, Section 3, Question 6}

Q6. Do you believe your business, firm or organisation would be at a disadvantage if located somewhere else within the country?

Cluster theory, terminology and definitions superimpose a boundary to any given cluster. It is important to establish the panel's perspective of the importance of their Dublin location and the benefits, if any, of that prominent location.

\section{Round 1, Section 3, Question 7}

Q7. Do you believe that that greater Dublin region location of your firms, business or organisation has the advantage of access to earlier cluster knowledge?

One advantage of locating within a cluster is the advantage of reasonable and early access to cluster knowledge. Question 7 is supportive of Question 6 with respect to the benefit of location, proximity and the access to the clusters creation of cluster knowledge.

\subsubsection{Round 1, Section 4}

Round 1, Section 4 of the Delphi survey included two questions related to the possible entry and exit barriers to the GDR maritime transport cluster. The Section 4 questions from Round 1 are as follows.

\section{Round 1, Section 4, Question 8}

Q8. Do you believe the greater Dublin region maritime transport sector has high barriers of entry?

Ideally individual clusters will want to have high exit barrier's and low entry barriers. The relevance of Question 8 is to achieve initially some debate between the cluster sector's as to what they consider to be high or low barriers. Question 8 should help to reach a consensus on some possible problem areas for firms wishing to enter the sector or what key attributes help keep firms sticky to the Dublin region. 


\section{Round 1, Section 4, Question 9}

Q9. Do you believe that the greater Dublin region maritime transport sector has high exit barriers and that firms, business and organisations in the sector are "sticky" to the Dublin location?

Question 9 is supportive of Question 8 and asks the panel members about the level of stickiness of the cluster (if any) and if the Dublin location has a strong pull to the proximity of the general greater Dublin region.

\subsubsection{Round 1, Section 5}

Round 1, Section 5 of the Delphi survey included two questions related to internal and external competition of the cluster. The Section 5 questions from Round 1 are as follows.

Round 1, Section 5, Question 10

Q10. Do you believe that the greater Dublin region maritime transport sector has a strong level of internal competition?

Section 5, Question 10 asks the panel members about the level of international competition within the GDR maritime transport sector. Good strong levels of domestic competition helps firms become more dynamic, competitive and successful in delivering customer demands.

Round 1, Section 5, Question 11

Q11. Do you believe if the greater Dublin region maritime transport sector were a highly competitive and vibrant environment, Irish business and firms within the sector would be in a better position when competing internationally?

Question 11 is supportive of Question 10 and takes the concept of good internal competition levels to an international perspective. Question 11 could also be important if Question 10 resulted in a disagreement consensus because it could be difficult for firms to compete successfully on an international stage if the domestic market lacked high levels of internal competition.

\subsubsection{Round 1, Section 6}

Round 1, Section 6 of the Delphi survey included three questions related to the diver'sity of the firms present in the Dublin maritime transport sector and their effect on the competition of the cluster and the competition of individual firms. 


\section{Round 1, Section 6, Question 12}

Q12. Do you believe that the greater Dublin region maritime transport sector has a sufficient variety and diversity of maritime transport firms?

Clusters include a range of associated and related firms to the core specialisation and the more firms and diversity of firms a cluster has the stronger the cluster could perform indigenously and internationally.

\section{Round 1, Section 6, Question 13}

Q13. Do you think the greater Dublin region maritime transport sector would perform better if it had a greater variety and mix of maritime transport firms?

The aim of Question 13 is to highlight and identify the panel's opinion on the current Dublin maritime transport sector's possible need (if any) for a greater mix and diversity of firms, and the possibility of the effect of such firms on the competitive working of the cluster.

\section{Round 1, Section 6, Question 14}

Q14. Do you think your business, firm or organisation would benefit from a greater mix and diversity of maritime transport firms?

Question 14 asks individual panel members their opinion on the diversity of the firms in the Dublin maritime transport cluster and how that could possibly specifically affect their sector.

\subsubsection{Round 1, Section 7}

Round 1, Section 7 of the Delphi survey included one question with respect to the level of trust within the cluster.

\section{Round 1. Section 7. Question 15}

Q15. Do you think there is a high level of trust between firms operating within the greater Dublin region maritime transport sector?

Question 15 addresses the behaviour aspect of cluster theory and puts forward to panel members the question of trust and the level of trust, if any, in the Dublin maritime transport sector.

\subsubsection{Round 1, Section 8}

Round 1. Section 8 of the Delphi survey included two questions with respect to leader firms in the cluster and the effect of such leader firms, if any, on the Dublin maritime transport sector. 


\section{Round 1, Section 8, Question 16}

Q16. Do you think there is a lack of leader firms in the greater Dublin region maritime transport sector?

Leader firms are important to a cluster as they act as a recognisable leader for an individual cluster and help to solve cluster problems. Question 16 addresses to the panel members if they think there is a lack of such firms in the Dublin maritime cluster.

\section{Round 1, Section 8, Question 17}

Q17. Do you think a lack of leader firms within the greater Dublin region maritime sector is having a negative affect on the development of the greater Dublin region as a maritime transport cluster?

Question 17 addresses to the panel members if they consider that a possible lack of leader firms is having a negative effect on the development of the greater Dublin region as a maritime transport cluster.

\subsubsection{Round 1 Results}

A total of 64 Delphi surveys were sent out to pre-agreed panel members. A total of 37 were returned in Round 1. It is expected that there will be some level of attrition through the rounds. When the first survey was sent out to the pre-agreed panel member's they were asked to return the survey in three working weeks. The purpose of the deadline is to encourage the panel members to complete the survey within a relative time frame as opposed to leaving the process open ended which could considerably prolong the whole Delphi survey. The re-submission date came and went and the panel members who had not yet returned the survey wore contacted by telephone and provided with extra time to complete and return there response. After a period of six weeks Round 1 of the Delphi was closed and a total of 37 responses had been collected for processing for Round 2.

\subsubsection{Round 1 Analysis}

The analysis of the Round 1 result in the first instance was conducted in three ways. The first process was to note the agreement, disagreement and unable to comment response for each question from each individual 
response (Table 13). The opinion responses provided by each panel member for each question (discussed in Chapter 7) was formulated into a combined feedback document for addressing the questions for Round 2 of the Delphi. In the Delphi a statement achieved consensus when it reached $70 \%$ or more and therefore did not enter the subsequent round. A result of $70 \%-79 \%$ was categorised as a low consensus, consensus between $80-89 \%$ was categorised as a medium consensus and consensus that fall between $90 \%$ and $100 \%$ was categorised as a high consensus.

Table 12 Consensus Ranking

\begin{tabular}{|l|l|}
\hline Low Consensus & $70-79 \%$ \\
\hline Medium Consensus & $80-89 \%$ \\
\hline High Consensus & $90-100 \%$ \\
\hline
\end{tabular}

Each individual question is calculated to obtain a percentage. For example Q1 29/37 $=78.37 \%$. Because Question 1 has majority agreement result, the 29 is then divided by the number of responses i.e. 37. The individual statements and their results for Round 1 are outlined in Table 13. 
Table 13 Total Survey Response Round 1

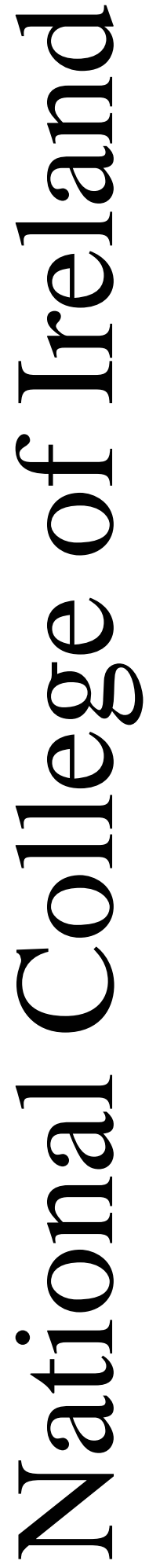

\begin{tabular}{|c|c|c|c|c|c|c|}
\hline No & Delphi Round 1 & $A$ & $D A$ & $U \overline{U C}$ & Total & $\%$ \\
\hline$Q 1$ & $\begin{array}{l}\text { Do you consider the greater Dublin region maritime } \\
\text { transport sector as a maritime cluster? }\end{array}$ & 29 & 7 & 1 & 37 & $78 \%$ \\
\hline$Q \mathcal{Z}$ & $\begin{array}{l}\text { Do you believe the greater Dublin region maritime } \\
\text { transport sector has the potential to move forward } \\
\text { towards a more international recognisable cluster } \\
\text { status? }\end{array}$ & 22 & 10 & 5 & 37 & $59 \%$ \\
\hline$Q 3$ & $\begin{array}{l}\text { Do you believe there is a lack of sufficient onshore } \\
\text { labour supply for any specific maritime transport } \\
\text { sector in the greater Dublin region? }\end{array}$ & 18 & 13 & 6 & 37 & $49 \%$ \\
\hline$Q 4$ & $\begin{array}{l}\text { Do you believe the current maritime transport labour } \\
\text { supply is sufficient to meet the labour requirements of } \\
\text { a growing maritime transport sector? }\end{array}$ & 13 & 18 & 6 & 37 & $49 \%$ \\
\hline$Q 5$ & $\begin{array}{l}\text { Do you believe there are sufficient educational and } \\
\text { training opportunities in Ireland to service the labour, } \\
\text { skill and expertise required by various fields in the } \\
\text { greater Dublin region maritime transport sector? }\end{array}$ & 15 & 17 & 5 & 37 & $46 \%$ \\
\hline$Q 6$ & $\begin{array}{l}\text { Do you believe your business, firm or organisation } \\
\text { would be at a disadvantage if located somewhere else } \\
\text { within the country? }\end{array}$ & 27 & 8 & 2 & 37 & $73 \%$ \\
\hline$Q 7$ & $\begin{array}{l}\text { Do you believe that the greater Dublin region location } \\
\text { of your firm, business or organisation has the } \\
\text { advantage of access to earlier cluster knowledge? }\end{array}$ & 18 & 13 & 6 & 37 & $49 \%$ \\
\hline$Q 8$ & $\begin{array}{l}\text { Do you believe the greater Dublin region maritime } \\
\text { transport sector has high barriers of entry? }\end{array}$ & 14 & 15 & 8 & 37 & $41 \%$ \\
\hline$Q 9$ & $\begin{array}{l}\text { Do you believe that the greater Dublin region maritime } \\
\text { transport sector has high exit barriers and that firms, } \\
\text { business and organisations in the sector are "sticky" to } \\
\text { the Dublin location? }\end{array}$ & 13 & 14 & 10 & 37 & $41 \%$ \\
\hline$Q 10$ & $\begin{array}{l}\text { Do you believe that the greater Dublin region maritime } \\
\text { transport sector has a strong level of internal } \\
\text { competition? }\end{array}$ & 27 & 7 & 3 & 37 & $73 \%$ \\
\hline$Q 11$ & $\begin{array}{l}\text { Do you believe if the greater Dublin region maritime } \\
\text { transport sector were a highly competitive and vibrant } \\
\text { environment, Irish business and firms within the } \\
\text { sector would be in a better position when competing } \\
\text { internationally? }\end{array}$ & 24 & 2 & 11 & 37 & $65 \%$ \\
\hline$Q 12$ & $\begin{array}{l}\text { Do you believe that the greater Dublin region maritime } \\
\text { transport sector has a sufficient variety and diversity } \\
\text { of maritime transport firms? }\end{array}$ & 22 & 13 & 2 & 37 & $59 \%$ \\
\hline Q13 & $\begin{array}{l}\text { Do you think the greater Dublin region maritime } \\
\text { transport sector would perform better if it had a } \\
\text { greater variety and mix of maritime transport firms? }\end{array}$ & 20 & 14 & 3 & $3 \vec{i}$ & $5-1 \%$ \\
\hline$Q 14$ & $\begin{array}{l}\text { Do you think your business, firm or organisation would } \\
\text { benefit from a greater mix and diversity of maritime } \\
\text { transport firms? }\end{array}$ & 16 & 15 & 6 & 37 & $43 \%$ \\
\hline$Q 15$ & $\begin{array}{l}\text { Do you think there is a high level of trust between } \\
\text { firms operating within the greater Dublin region } \\
\text { maritime transport sector? }\end{array}$ & 12 & 15 & 10 & 37 & $41 \%$ \\
\hline$Q 16$ & $\begin{array}{l}\text { Do you think there is a lack of leader firms in the } \\
\text { greater Dublin region maritime transport sector? }\end{array}$ & 20 & 11 & 6 & 37 & $54 \%$ \\
\hline$Q 17$ & $\begin{array}{l}\text { Do you think a lack of leader firms within the greater } \\
\text { Dublin region maritime sector is having a negative } \\
\text { affect on the development of the greater Dublin region } \\
\text { as a maritime transport cluster? }\end{array}$ & 15 & 10 & 12 & 37 & $41 \%$ \\
\hline
\end{tabular}

(n.b. note: $A=$ agree, $D A=$ disagree. $U C=$ unable to comment) 
A graph was designed depicting the response level for each question. The purpose of the graph in Table 14 is to provide an overview of the response rate for each individual question and not a statistical evaluation of the responses.

Table 14 Delphi Round 1 Graph Display Results

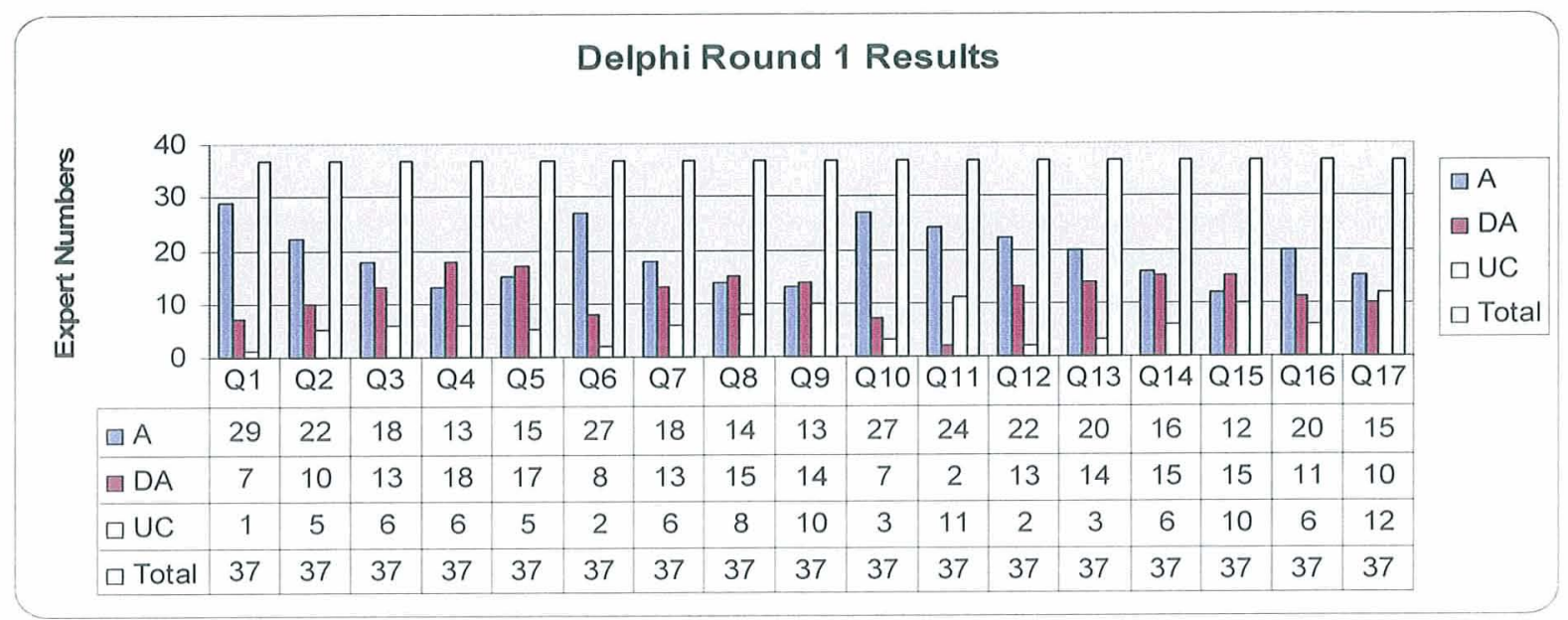

(Source: Author's Own)

The following points from 6.2.2.2 to 6.2.3.9 inclusive detail the result for each section and the subsequent result of each individual question.

\subsubsection{Round 1, Section 1 Result}

Round 1, Section 1, Question 1 had a majority agreement result of $78 \%$. Question 1 has therefore reached a consensus and will not enter the second round.

\begin{tabular}{l|l|l|l|l|l|l|}
\hline 1 & $\begin{array}{l}\text { Do you consider the greater Dublin region maritime transport } \\
\text { sector as a maritime cluster? }\end{array}$ & 29 & 7 & 1 & 37 & $78 \%$ \\
\end{tabular}

Round 1, Section 1, Question 2 had a majority agreement result of $59 \%$. Question 2 will therefore enter Round 2 for further clarification by the Delphi panel along with the supplemented Round 1 feedback document.

Q2 Do you believe the greater Dublin region maritime transport sector has the potential to move forward towards a more international recognisable cluster status?

\subsubsection{Round 1, Section 2 Results}

Round 1, Section 2, Question 3 had a majority agreement result of $49 \%$ and therefore will enter Round 2 for further clarification by the Delphi panel along with the supplemented Round 1 feedback document. 


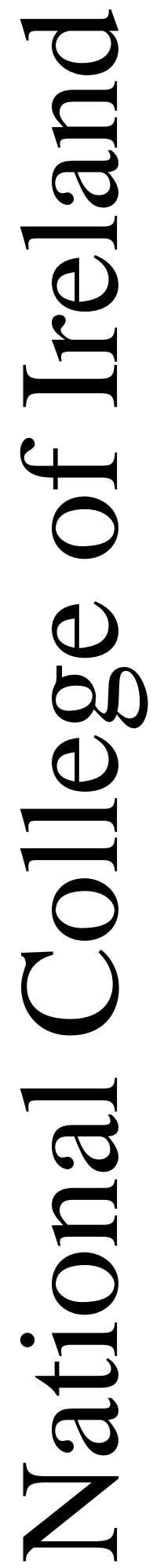

\begin{tabular}{|l|l|l|l|l|l|l|l|}
\hline $\mathbf{Q 3}$ & $\begin{array}{l}\text { Do you believe there is a lack of sufficient onshore labour } \\
\text { supply for any specific maritime transport sector in the } \\
\text { greater Dublin region? }\end{array}$ & 18 & 13 & 6 & 37 & $49 \%$ \\
\hline
\end{tabular}

Round 1, Section 2, Question 4 had a majority disagreement result of $49 \%$ and therefore will enter Round 2 for further clarification by the Delphi panel with the supplemented Round 1 feedback document.

Q4 Do you believe the current maritime transport labour supply is sufficient to meet the labour requirements of a growing maritime transport sector?

\begin{tabular}{|l|l|l|l|l|}
\hline 13 & 18 & 6 & 37 & $49 \%$ \\
\hline
\end{tabular}

Round 1, Section 2, Question 5 had a majority disagreement result of $46 \%$ and therefore will enter Round 2 for further clarification by the Delphi panel with the supplemented Round 1 feedback document

\begin{tabular}{|l|l|l|l|l|l|l|}
\hline Q5 & $\begin{array}{l}\text { Do you believe there are sufficient educational and training } \\
\text { opportunities in Ireland to service the labour, skill and } \\
\text { expertise required by various fields in the greater Dublin } \\
\text { region maritime transport sector? }\end{array}$ & 17 & 5 & 37 & $46 \%$ \\
\hline
\end{tabular}

\subsubsection{Round 1, Section 3 Results}

Round 1, Section 3, Question 6 had a majority agreement result of $73 \%$ and has reached a consensus and therefore will not enter the second round.

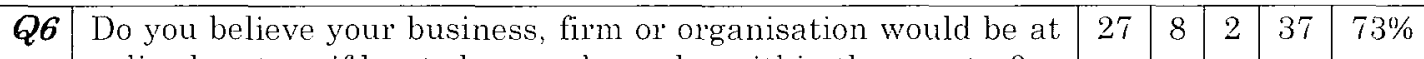
a disadvantage if located somewhere else within the country?

Round 1, Section 3, Question 7 had a majority disagreement result of $49 \%$ and therefore will enter Round 2 for further clarification by the Delphi panel with the supplemented Round 1 feedback document.

\begin{tabular}{|l|l|l|l|l|l|l|}
$Q 7$ & $\begin{array}{l}\text { Do you belicve that the greater Dublin region location of your } \\
\text { firm, business or organisation has the advantage of access to } \\
\text { earlier cluster linowledge? }\end{array}$ & 18 & 13 & 6 & 37 & $19 \%$ \\
\hline
\end{tabular}

\subsubsection{Round 1, Section 4 Results}

Round 1, Section 4, Question 8 had a majority disagreement result of $41 \%$ and therefore will enter Round 2 for further clarification by the Delphi panel with the supplemented Round 1 feedback document.

Q8 $\begin{aligned} & \text { Do you believe the greater Dublin region maritime transport } \\ & \text { sector has high barriers of entry? }\end{aligned}$


Round 1, Section 4, Question 9 had a majority disagreement result of $41 \%$ and therefore will enter Round 2 for further clarification by the Delphi panel with the supplemented Round 1 feedback document.

\begin{tabular}{l|l}
\hline $\boldsymbol{g}$ & $\begin{array}{l}\text { Do you believe that the greater Dublin region maritime } \\
\text { transport sector has high exit barriers and that firms, } \\
\text { business and organisations in the sector are "sticky" to the } \\
\text { Dublin location? }\end{array}$
\end{tabular}

\subsubsection{Round 1, Section 5 Results}

Round 1, Section 5, Question 10 had a majority agreement result of $73 \%$ and has reached a consensus and therefore will not enter the second round.

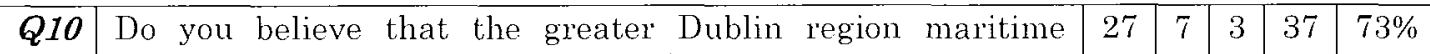
transport sector has a strong level of internal competition?

Round 1, Section 5, Question 11 had a majority agreement result of $65 \%$ and therefore will enter Round 2 for further clarification by the Delphi panel with the supplemented Round 1 feedback document.

\begin{tabular}{l|l|l|l|l|l|l|}
\hline D11 & $\begin{array}{l}\text { Do you believe if the greater Dublin region maritime } \\
\text { transport sector were a highly competitive and vibrant } \\
\text { environment, Irish business and firms within the sector } \\
\text { would be in a better position when competing } \\
\text { internationally? }\end{array}$ & & & & &
\end{tabular}

\subsubsection{Round 1, Section 6 Results}

Round 1, Section 6, Question 12 had a majority agreement result of $59 \%$ and therefore will enter Round 2 for further clarification by the Delphi panel with the supplemented Round 1 feedback document.

\begin{tabular}{|l|l|l|l|l|l|l|l|}
\hline Q12 & $\begin{array}{l}\text { Do you believe that the greater Dublin region maritime } \\
\text { transport sector has a sufficient variety and diversity of } \\
\text { maritime transport firms? }\end{array}$ & 22 & 13 & 2 & 37 & $59 \%$ \\
\hline
\end{tabular}

Round 1, Section 6, Question 13 had a majority agreement result of $54 \%$ and therefore will enter Round 2 for further clarification by the Delphi panel with the supplemented Round 1 feedback document.

\begin{tabular}{|l|l|l|l|l|l|l|}
\hline $\mathbf{Q 1 3}$ & $\begin{array}{l}\text { Do you think the greater Dublin region maritime transport } \\
\text { sector would perform better if it had a greater variety and } \\
\text { mix of maritime transport firms? }\end{array}$ & 20 & 14 & 3 & 37 & $54 \%$ \\
\hline
\end{tabular}

Round 1, Section 6, Question 14 result had a majority agreement result of $43 \%$ and therefore will enter Round 2 for further clarification by the Delphi panel with the supplemented Round 1 feedback document 
$\overline{Q 14}$ Do you think your business, firm or organisation would benefit from a greater mix and diversity of maritime transport firms?

\subsubsection{Round 1, Section 7 Results}

Round 1, Section 7, Question 15 had a majority disagreement result of $41 \%$ and therefore will enter Round 2 for further clarification by the Delphi with the supplemented Round 1 feedback document.

\begin{tabular}{|l|l|l|l|l|l|l|l|}
\hline $\mathbf{Q 1 5}$ & $\begin{array}{l}\text { Do you think there is a high level of trust between firms } \\
\text { operating within the greater Dublin region maritime } \\
\text { transport sector? }\end{array}$ & 12 & 15 & 10 & 37 & $41 \%$ \\
\hline
\end{tabular}

\subsubsection{Round 1, Section 8 Results}

Round 1, Section 8, Question 16 had a majority agreement result of 54\% and therefore will enter Round 2 for further clarification by the Delphi panel with the supplemented Round 1 feedback document.

Do you think there is a lack of leader firms in the greater

Q16 Dublin region maritime transport sector?

Round 1, Section 8, Question 17 had a majority agreement result of 41\% and therefore will enter Round 2 for further clarification by the Delphi panel with the supplemented Round 1 feedback document.

\begin{tabular}{|l|l|l|l|l|l|l|}
\hline Q17 & $\begin{array}{l}\text { Do you think a lack of leader firms within the greater } \\
\text { Dublin region maritime sector is having a negative affect } \\
\text { on the development of the greater Dublin region as a } \\
\text { maritime transport cluster? }\end{array}$ & 15 & 10 & 12 & 37 & $41 \%$ \\
\hline
\end{tabular}

Round 1 of the Delphi survey therefore obtained a total of three consensuses.

\subsection{Round 2}

The second round of the Delphi survey was sent to a total of 37 agreed panel members. The second round documentation included the Round 2 Delphi questionnaire (Appendix 7: Delphi Round 2 Delphi Questionnaire) and a subsequent document which contained the feedback from the Round 1 questionnaire (Appendix 7: Delphi Round 2 Delphi Questionnaire). The panel members were given instructions to first read the feedback from each 
question from Round 1, before answering the subsequent question in Round 2 of the Delphi.

The second round of the Delphi was divided into two separate documents, document 1 included the Round 2 questions, and document 2 included the feedback from the Round 1 questionnaire. During test runs of the second round of the Delphi it became apparent that the nature of the individual document was overwhelming as both the feedback and the Round 2 questionnaire were both contained in a single document. Therefore it was decided the process would be simpler for the panel members if Round 2 of the Delphi were divided into two separate documents. It was also noted from the Round 1 questionnaire where the panel members were asked to tick the relevant box which applied to their sector of industry (i.e. if a panel member was a freight forwarder they should tick the box marked freight forwarder), some panel members ticked more than one box to indicate the sectors they had individually worked in over the years, and not specifically the sector of their current company or organisation. Therefore the process of asking the panel members which sector their company or organisation operated in was repeated for further clarification in Round 2.

\subsubsection{Development of Round 2 Questionnaire}

The Round 2 questionnaire contained the questions from Round 1 that did not reach consensus and the questionnaire kept the original format of 8 sections. Of the 8 sections from the Round 1 questionnaire, Section 2 has had some modifications with the inclusion of two extra questions. In the Round 2 questionnaire there were two questions that were added to Section 2. The two questions are as follows

Q2A. Do you believe that there is lack of management personnel with relative industry experience to be sourced for the onshore labour supply in Ireland?

The importance of this question is to understand if there is problem with the labour supply and if that problem is specific to the level of upper or middle management, or is the issue with low skill worker's. As highlighted in the response of feedback from Round 1, Ireland and specifically the greater 
Dublin region does have the benefit of considerable influx of immigrants to supplement the Irish workforce. The questions strives to identify if there is a problem for companies to obtain management level staff with suitable qualifications and relevant industry experience as apposed to a general labour supply.

The second question is as follows

Q4A. Do you believe that there is a lack of promotion and awareness of the career options available in the maritime transport sector in Ireland?

The purpose of Question $4 \mathrm{~A}$ is to ask the panel members about the promotion and awareness of the industry to the general labour supply in order to ascertain that if there is a lack of promotion and awareness of the industry as could it have a possible affect on attracting labour to the industry.

The development of the Round 2 questionnaire is displayed in the extension of the Delphi model from the Delphi Model Round 1 (Figure 13) to the Delphi Model Development Round 2 (Figure 14). 

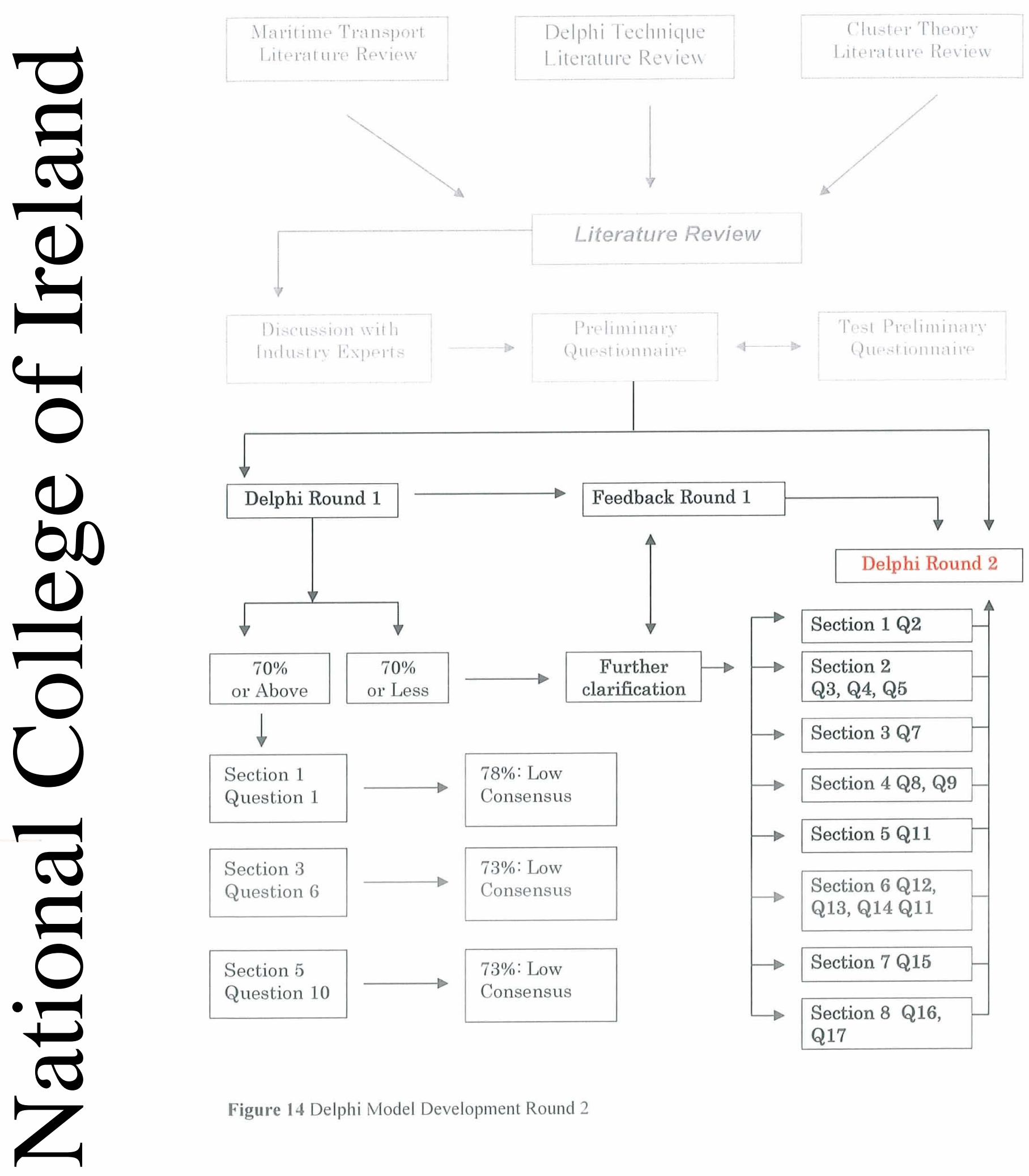

Figure 14 Delphi Model Development Round 2 


\subsubsection{Round 2 Results}

A total of 37 Delphi surveys were sent out to the panel members that returned a Round 1 response. A total of 22 responses were retuned for Round 2 of the Delphi.

\subsubsection{Round 2 Analysis}

The illustration of the Round 2 result as seen in the initial analysis of Round 1 will note the agreement, disagreement and unable to comment response for each question, from each individual response. The opinion responses provided by each panel member for each question was formulated into a combined feedback document for addressing the questions in Round 3 of the Delphi. Finally a graph was designed depicting the response level for each question.

Table 15 Total Response Survey Round 2

\begin{tabular}{|c|c|c|c|c|c|c|}
\hline No & Delphi Round 2 & A & $\mathrm{DA}$ & $\mathrm{UC}$ & Total & $\%$ \\
\hline Q1 & $\begin{array}{l}\text { Do you believe the GDR maritime transport sector has } \\
\text { the potential to move forward towards a more } \\
\text { international recognisable cluster status? }\end{array}$ & 16 & 4 & 2 & 22 & $72 \%$ \\
\hline Q2 & $\begin{array}{l}\text { Do you believe there is a lack of sufficient onshore } \\
\text { labour supply for any specific maritime transport } \\
\text { sector in the greater Dublin region? }\end{array}$ & 9 & 11 & 2 & 22 & $50 \%$ \\
\hline $\mathrm{Q} 2 \mathrm{~A}$ & $\begin{array}{l}\text { Do you believe that there is a lack of personnel } \\
\text { management with relative industry experience } \\
\text { available to be sourced for the onshore labour supply } \\
\text { in Ireland? }\end{array}$ & 10 & 6 & 6 & 22 & $45 \%$ \\
\hline Q3 & $\begin{array}{l}\text { Do you believe the current maritime transport labour } \\
\text { supply is sufficient to meet the labour requirements of } \\
\text { a growing maritime transport sector? }\end{array}$ & 10 & 11 & 1 & 22 & $50 \%$ \\
\hline Q4 & $\begin{array}{l}\text { Do you believe there are sufficient educational and } \\
\text { training opportunities in Ireland to service the labour. } \\
\text { shill and expertise required by various fields in the } \\
\text { greater Dublin region maritime transport sector? }\end{array}$ & 13 & 9 & 0 & 22 & $59 \%$ \\
\hline $\mathrm{Q} 4 \mathrm{~A}$ & $\begin{array}{l}\text { Do you believe that there is a lack of promotion and } \\
\text { awareness of the career options available in the } \\
\text { maritime sector in Ireland? }\end{array}$ & 19 & 1 & 2 & 22 & $86 \%$ \\
\hline Q5 & $\begin{array}{l}\text { Do you believe that the greater Dublin region location } \\
\text { of your firm, business or organisation has the } \\
\text { advantage of access to earlier cluster knowledge? }\end{array}$ & 16 & 5 & 1 & 22 & $72 \%$ \\
\hline$\overline{\mathrm{Q} 6}$ & $\begin{array}{l}\text { Do you believe that the greater Dublin region } \\
\text { maritime transport sector has high barriers of entry? }\end{array}$ & 10 & 9 & 3 & 22 & $45 \%$ \\
\hline Q7 & $\begin{array}{l}\text { Do you believe that the greater Dublin region } \\
\text { maritime transport sector has high exit barriers and } \\
\text { that firms, business and organisations in the sector" } \\
\text { are "sticky" to the Dublin location? }\end{array}$ & 17 & 3 & 2 & 22 & $77 \%$ \\
\hline Q8 & $\begin{array}{l}\text { Do you believe that the GDR maritime transport } \\
\text { sector were a highly competitive and vibrant } \\
\text { environment. Irish businesses and furms within the }\end{array}$ & 17 & 4 & 1 & 22 & $77 \%$ \\
\hline
\end{tabular}




\begin{tabular}{|c|c|c|c|c|c|c|}
\hline & $\begin{array}{l}\text { sector would be in a better position competing } \\
\text { internationally? }\end{array}$ & & & & & \\
\hline Q9 & $\begin{array}{l}\text { Do you believe that the greater Dublin region } \\
\text { maritime transport sector has a sufficient variety and } \\
\text { diversity of maritime transport firms? }\end{array}$ & 16 & 4 & 2 & 22 & $72 \%$ \\
\hline Q10 & $\begin{array}{l}\text { Do you think the greater Dublin region maritime } \\
\text { transport sector would perform better if it had a } \\
\text { greater variety and mix of maritime transport firms? }\end{array}$ & 18 & 4 & 0 & 22 & $81 \%$ \\
\hline Q11 & $\begin{array}{l}\text { Do you think your business, firm or organisation } \\
\text { would benefit from a greater mix and diversity of } \\
\text { maritime transport firms? }\end{array}$ & 15 & 5 & 2 & 22 & $68 \%$ \\
\hline Q12 & $\begin{array}{l}\text { Do you think there is a high level of trust between } \\
\text { firms operating within the greater Dublin region } \\
\text { maritime transport sector? }\end{array}$ & 5 & 13 & 4 & 22 & $59 \%$ \\
\hline Q13 & $\begin{array}{l}\text { Do you think there is a lack of leader firms in the } \\
\text { greater Dublin region maritime transport sector? }\end{array}$ & 12 & 8 & 2 & 22 & $54 \%$ \\
\hline Q14 & $\begin{array}{l}\text { Do you think a lack of leader firms within the greater } \\
\text { Dublin region maritime sector is having a negative } \\
\text { affect on the development of the greater Dublin region } \\
\text { as a maritime transport cluster? }\end{array}$ & 13 & 7 & 2 & 22 & $59 \%$ \\
\hline
\end{tabular}
(n.b. note: $\mathrm{A}=$ agree, $\mathrm{DA}=$ disagree, $\mathrm{UC}=$ unable to comment)

Outlined below in Table 16 is a statistical overview of the results with respect to the agreement, disagreement and unable to comment response from the Delphi panel in Round 2.

Table 16 Delphi Round 2 Graph Display Result

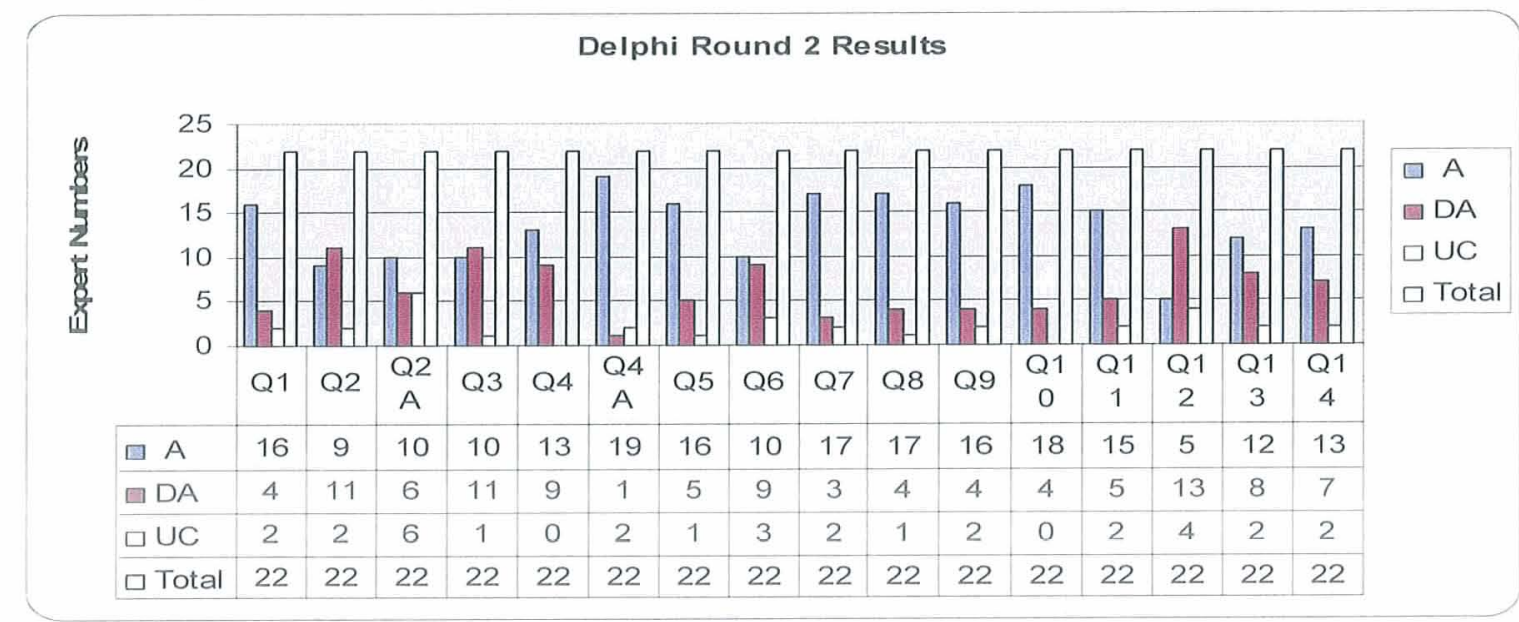

(Source: Author's own)

The following points from 6.3.2.2 to 6.3.2.9 inclusive, detail the results for each section and the subsequent results of each individual question.

\subsubsection{Round 2, Section 1 Result}

Round 2, Section 1, Question 1 had a majority agreement result of $72 \%$.

Question 1 of Round 2 therefore has reached consensus and will not enter

Round 3. 


\subsubsection{Round 2, Section 2 Result}

Round 2, Section 2, Question 2 had a majority disagreement result of $50 \%$. Question 2 will therefore enter Round 3 for further clarification by the Delphi panel with the supplemented Round 2 feedback document.

\begin{tabular}{|l|l|l|l|l|l|l|}
\hline Q2 & Do you believe there is a lack of sufficient onshore labour & 9 & 11 & 2 & 22 & $50 \%$ \\
\hline
\end{tabular} supply for any specific maritime transport sector in the greater Dublin region?

Round 2, Section 2, Question 2A had a majority agreement result of $45 \%$.

Question $2 \mathrm{~A}$ will therefore enter Round 3 for further clarification by the

Delphi panel with the supplemented Round 2 feedback document.

\begin{tabular}{|c|l|l|l|l|l|l|}
\hline Q2A & $\begin{array}{l}\text { Do you believe that there is lack of management personnel } \\
\text { with relative industry experience available to be sourced for } \\
\text { the onshore labour supply in Ireland? }\end{array}$ & 10 & 6 & 6 & 22 & $45 \%$ \\
\hline
\end{tabular}

Round 2, Section 2, Question 3 had a majority disagreement result of $50 \%$.

Question 3 will therefore enter Round 3 for further clarification by the

Delphi panel with the supplemented Round 2 feedback document.

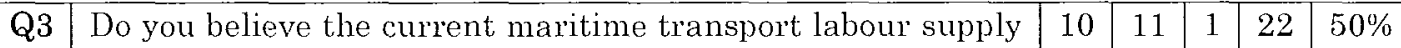
is sufficient to meet the labour requirements of a growing maritime transport sector?

Round 2, Section 2, Question 4 had a majority agreement result of $59 \%$.

Question 4 will therefore enter Round 3 for further clarification by the

Delphi panel with the supplemented Round 2 feedback document.

\begin{tabular}{|l|l|l|l|l|l|l|}
\hline Q4 & $\begin{array}{l}\text { Do you believe there are sufficient educational and training } \\
\text { opportunities in Ireland to service the labour, skill and } \\
\text { expertise required by various fields in the greater Dublin } \\
\text { region maritime transport sector? }\end{array}$ & 9 & 0 & 22 & $59 \%$ \\
\hline
\end{tabular}

Round 2. Section 2. Question 4A had a majority agreement result of $86 \%$.

Question 4A has reached consensus and will not enter the third round.

\begin{tabular}{|l|l|l|l|l|l|l|l|}
\hline Q4A & $\begin{array}{l}\text { Do you believe that there is a lack of promotion and } \\
\text { awareness of the career options available in the maritime } \\
\text { sector in Ireland? }\end{array}$ & 19 & 1 & 2 & 22 & $86 \%$ \\
\hline
\end{tabular}

\subsubsection{Round 2, Section 3 Result}

Round 2, Section 3, Question 5 had a majority agreement result of $72 \%$.

Question 5 has reached consensus and will not enter the third round.

\begin{tabular}{|l|l|l|l|l|l|l|}
\hline Q5 & $\begin{array}{l}\text { Do you believe that the greater Dublin region location of your } \\
\text { firm, business or organisation has the advantage of access to } \\
\text { earlier cluster knowledge? }\end{array}$ & 16 & 5 & 1 & 22 & $72 \%$ \\
\hline
\end{tabular}




\subsubsection{Round 2, Section 4 Result}

Round 2, Section 4, Question 6 had a majority agreement result of $45 \%$. Question 6 will therefore enter Round 3 for further clarification by the Delphi panel with the supplemented Round 2 feedback document.

\begin{tabular}{|l|lll|l|l|l|l|l|}
\hline Q6 & Do you believe that the greater Dublin region maritime & 10 & 9 & 3 & 22 & $45 \%$ \\
\hline
\end{tabular} transport sector has high barriers of entry?

Round 2, Section 4, Question 7 had a majority agreement result of $77 \%$.

Question 7 has reached consensus and will not enter the third round.

\begin{tabular}{|l|ll|l|l|l|l|l|}
\hline Q7 & Do you believe that the greater Dublin region maritime & 17 & 3 & 2 & 22 & $77 \%$
\end{tabular} transport sector has high exit barriers and that firms,

business and organizations in the sector are "sticky" to the Dublin location?

\subsubsection{Round 2, Section 5 Result}

Round 2, Section 5, Question 8 had a majority agreement result of $77 \%$.

Question 8 has reached consensus and will not enter the third round.

\begin{tabular}{|c|c|c|c|c|c|c|}
\hline Q8 & $\begin{array}{l}\text { Do you believe if the greater Dublin region maritime } \\
\text { transport sector were a highly competitive and vibrant } \\
\text { environment, Irish business and firms within the sector } \\
\text { would be in a better position when competing internationally? }\end{array}$ & 17 & 4 & 1 & 22 & $77 \%$ \\
\hline
\end{tabular}

\subsubsection{Round 2, Section 6 Result}

Round 2, Section 6, Question 9 had a majority agreement result of $72 \%$.

Question 9 has reached consensus and will not enter the third round.

\begin{tabular}{|c|c|c|c|c|c|c|c|}
\hline Q9 & $\begin{array}{l}\text { Do you believe that the greater Dublin region maritime } \\
\text { transport sector has a sufficient variety and diversity of } \\
\text { maritime transport firms? }\end{array}$ & \begin{tabular}{l} 
trans \\
\hline
\end{tabular}
\end{tabular}

Round 2, Section 6, Question 10 had a majority agreement result of $81 \%$.

Question 10 has reached consensus and will not enter the third round.

\begin{tabular}{|l|l|l|l|l|l|l|l|}
\hline Q10 & $\begin{array}{l}\text { Do you think the greater Dublin region maritime transport } \\
\text { sector would perform better if it had a greater variety and } \\
\text { mix of maritime transport firms? }\end{array}$ & 18 & -1 & 0 & 22 & $81 \%$ \\
\hline
\end{tabular}

Round 2, Section 6, Question 11 had a majority agreement result of $68 \%$.

Question 11 will enter Round 3 for further clarification by the Delphi panel with the supplemented Round 2 feedback document.

\begin{tabular}{|l|l|l|l|l|l|l|l|}
\hline Q11 & $\begin{array}{l}\text { Do you think your business. firm or organisation would } \\
\text { benefit from a greater mix and diversity of maritime } \\
\text { transport firms? }\end{array}$ & \begin{tabular}{l}
15 \\
\hline
\end{tabular} \\
\hline
\end{tabular}




\subsubsection{Round 2, Section 7 Result}

Round 2, Section 7, Question 12 had a majority disagreement result of $59 \%$. Question 12 will enter the Round 3 for further clarification by the Delphi panel with the supplemented Round 2 feedback document.

\begin{tabular}{|c|l|l|l|l|l|l|l|}
\hline Q12 & $\begin{array}{l}\text { Do you think there is a high level of trust between firms } \\
\text { operating within the greater Dublin region maritime } \\
\text { transport sector? }\end{array}$ & 5 & 13 & 4 & 22 & $59 \%$ \\
\hline
\end{tabular}

\subsubsection{Round 2, Section 8 Result}

Round 2, Section 8, Question 13 had a majority agreement result of 54\%. Question 13 will enter Round 3 for further clarification by the Delphi panel with the supplemented Round 2 feedback document.

\begin{tabular}{|l|l|l|l|l|l|l|l|}
\hline Q13 & $\begin{array}{l}\text { Do you think there is a lack of leader firms in the greater } \\
\text { Dublin region maritime transport sector? }\end{array}$ & 12 & 8 & 2 & 22 & $54 \%$ \\
\hline
\end{tabular}

Round 2, Section 8, Question 14 had a majority agreement result of 59\%. Question 14 will enter Round 3 for further clarification by the Delphi panel with the supplemented Round 2 feedback document.

\begin{tabular}{|l|l|l|l|l|l|l|}
\hline Q14 & $\begin{array}{l}\text { Do you think a lack of leader firms within the greater Dublin } \\
\text { region maritime sector is having a negative affect on the } \\
\text { development of the greater Dublin region as a maritime } \\
\text { transport cluster? }\end{array}$
\end{tabular}

The conclusion with respect to Round 2 of the Delphi survey is that a total of seven consensuses were achieved.

\subsection{Round 3}

The third round of the Delphi survey was sent to a total of 22 agreed panel members. The third round documentation included the Round 3 Delphi questionnaire (Appendix 8: Delphi Round 3 Questionnaire). As in Round 2. the Round 3 documentation kept the same format as Round 2 , with the two separate documents, one document for the feedback from Round 2 and a separate document for the Round 3 questionnaire. The panel members received the same instructions to the questionnaire format as provided for in Round 2.

\subsubsection{Development of Round 3 Questionnaire}

The results from Round 2 of the Delphi concluded seven consensuses and therefore those seven statements will not require further clarification in the 
third round. The development of the Round 3 questionnaire is displayed in the extension of the Delphi model from the Delphi Model Round 1 (Figure 13) to the Delphi Model Development Round 2 (Figure 14) and Delphi Model Development Round 3 (Figure 15) as illustrated. 

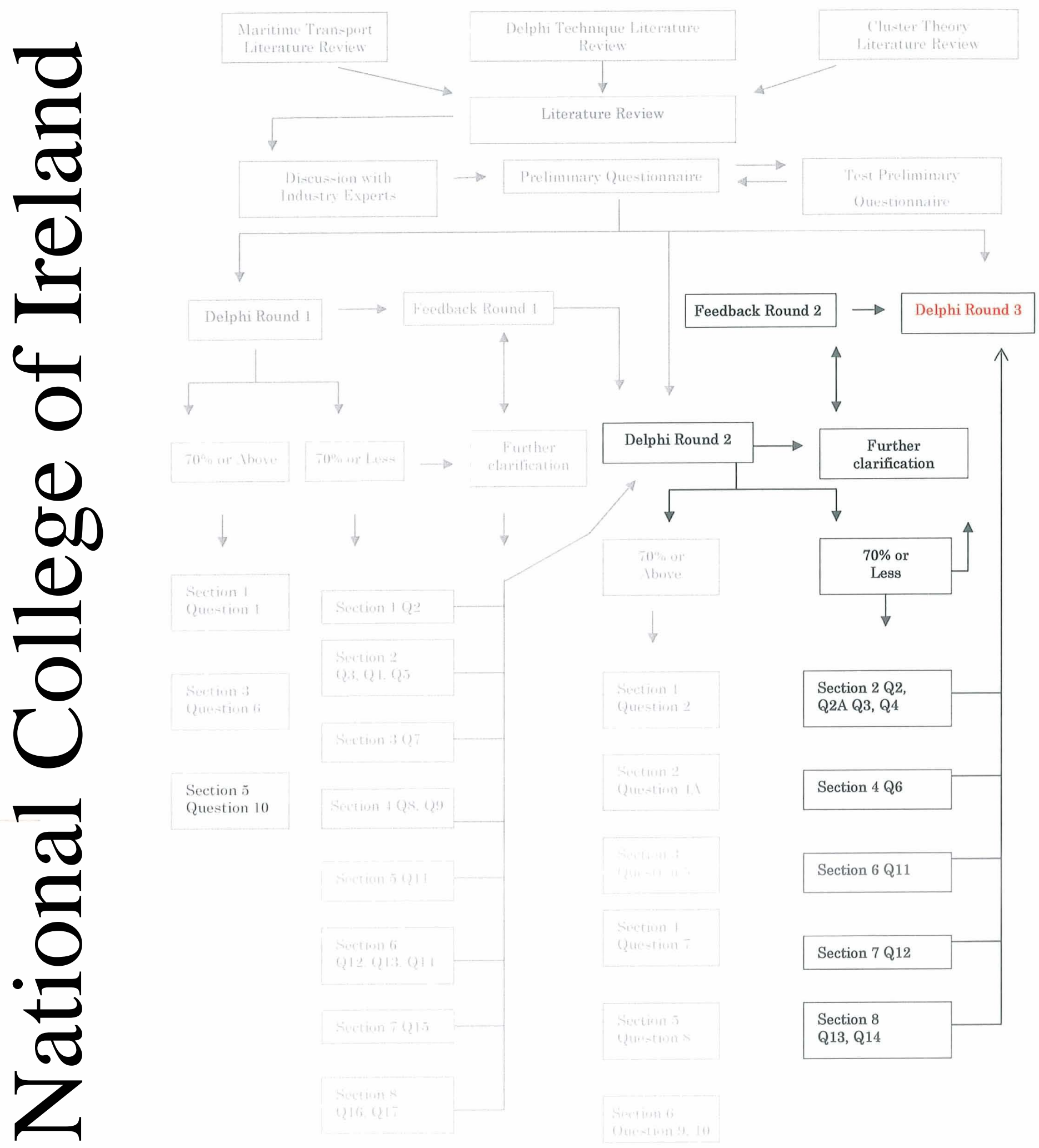

Figure 15 Delphi Model Development Round 3 


\subsubsection{Breakdown of Round 3 Questionnaire}

As in Round 1 and 2, the Round 3 questions have kept the same formatted sections. The numbering of the questions through the consecutive rounds are not matched i.e. Question 5 in Round 1 is not the same as Question 5 in Round 2. The reason for this is to avoid confusion for the Delphi panel. For example, when a panel member is instructed to answer a question as described below;

"Please read the feedback summary in document 2 (page 2), under Round 1, Section 1, Question 2, and answer Question 1 below"

If the same format was held through the three rounds and where the instruction states "answer Question 1 below" is actually representative of Question 2 in Round 1. Panel members might be confused as to the numbering of the questions or may assume it could be a typo. Therefore every questionnaire follows the chronologically numbering format from question 1 question 2, question 3 , question 4 etc.

\subsubsection{Round 3 Results}

A total of 22 Delphi surveys were sent out to the panel members that returned a Round 2 response. A total of 18 responses were retuned for Round 3 of the Delphi.

\subsubsection{Round 3 Analysis}

The analysis of the Round 3 result as seen in the initial analysis of Round 1 and 2 will note the agreement, disagreement and unable to comment response for each question, from each indiridual response.

Table 17 Total Response Survey Round 3

\begin{tabular}{|l|l|l|l|l|l|l|}
\hline No & Delphi Round 3 & A & DA & UC & Total & $\%$ \\
\hline Q1 & $\begin{array}{l}\text { Do you believe there is a lack of sufficient onshore } \\
\text { labour supply for any specific maritime transport sector } \\
\text { in the greater Dublin region? }\end{array}$ & 9 & 6 & 3 & 18 & $50 \%$ \\
\hline $\begin{array}{l}\text { Do you believe that there is lack of personal } \\
\text { management with relative industry experience available } \\
\text { to be sourced for the onshore labour supply in Ireland? }\end{array}$ & $\begin{array}{l}\text { Do you believe the current maritime transport labour } \\
\text { supply is sufficient to meet the labour requirements of a } \\
\text { growing maxitime transport sector? }\end{array}$ & 5 & 8 & 5 & 18 & $14 \%$ \\
\hline Q4 & $\begin{array}{l}\text { Do you believe there are sufficient educational and } \\
\text { training opportunities in Ireland to service the labour. } \\
\text { skill and expertise required by various fields in the } \\
\text { greater Dublin region maritime transport sector? }\end{array}$ & 12 & 5 & 1 & 18 & $66 \%$ \\
\hline
\end{tabular}




\begin{tabular}{|l|l|l|l|l|l|l|}
\hline Q5 & $\begin{array}{l}\text { Do you believe that the greater Dublin region maritime } \\
\text { transport sector has high barriers to entry? }\end{array}$ & 8 & 10 & 0 & 18 & $55 \%$ \\
\hline Q6 & $\begin{array}{l}\text { Do you think your business, firm or organisation would } \\
\text { benefit from a greater mix and diversity of maritime } \\
\text { transport firms? }\end{array}$ & 12 & 4 & 2 & 18 & $66 \%$ \\
\hline Q7 & $\begin{array}{l}\text { Do you think there is a high level of trust between firms } \\
\text { operating within the greater Dublin region maritime } \\
\text { transport sector? }\end{array}$ & 3 & 13 & 2 & 18 & $72 \%$ \\
\hline Q8 & $\begin{array}{l}\text { Do you think there is a lack of leader firms in the } \\
\text { greater Dublin region maritime transport sector? }\end{array}$ & 12 & 4 & 1 & 18 & $66 \%$ \\
\hline Q9 & $\begin{array}{l}\text { Do you think a lack of leader firms within the greater } \\
\text { Dublin region maritime sector is having a negative } \\
\text { affect on the development of the greater Dublin region } \\
\text { as a maritime transport cluster? }\end{array}$ & 11 & 5 & 2 & 18 & $61 \%$ \\
\hline
\end{tabular}

(n.b. note: $\mathrm{A}=$ agree, $\mathrm{DA}=$ disagree, $\mathrm{UC}=$ unable to comment)

Outlined below in Table 18 is a statistical overview of the results with respect to the agreement, disagreement and unable to comment response from the Delphi panel in Round 3.

Table 18 Delphi Round 3 Graph Display Result

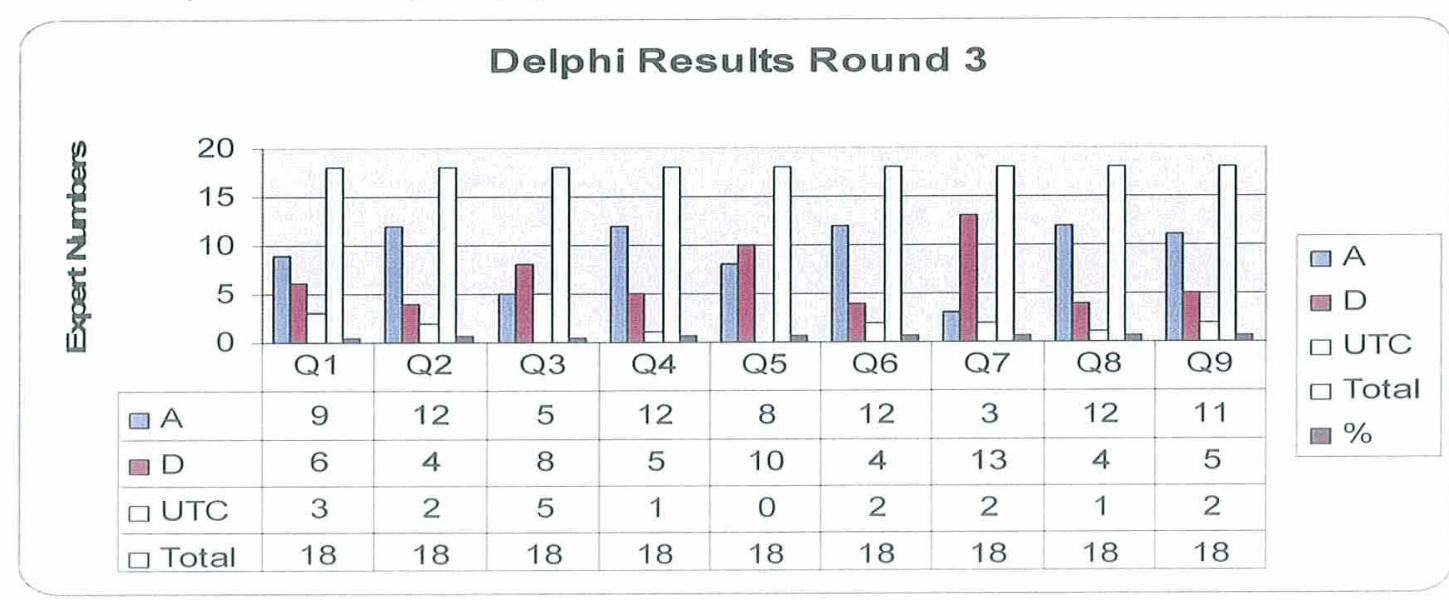

(Source: Author's Own)

The following points from 6.4.2.2 to 6.4.2.6 inclusive, detail the results for each section and the subsequent results of each individual question.

\subsubsection{Round 3, Section 2 Result}

Round 3, Section 2, Question 1 was a majority agreement result of 50\% and therefore the statement has not reached a final consensus.

\begin{tabular}{l|l|l|l|l|l|l|l} 
Q1 & $\begin{array}{l}\text { Do you believe there is a lack of sufficient onshore labour supply } \\
\text { for any specific maritime transport sector in the greater Dublin } \\
\text { region? }\end{array}$ & 9 & 6 & 3 & 18 & $50 \%$ \\
\hline
\end{tabular}

Round 3, Section 2, Question 2 result is a majority agreement result of $66 \%$ and therefore the statement has not reached a final consensus. 
Q2 Do you believe that there is lack of personal management with relative industry experience available to be sourced for the onshore labour supply in Ireland?

\begin{tabular}{|l|l|l|l|l|}
\hline 12 & 4 & 2 & 18 & $66 \%$
\end{tabular}

12

(1)

Round 3, Section 2, Question 3 result is a majority disagreement result of $44 \%$ and therefore the statement has not reached a final consensus.

\begin{tabular}{|l|l|l|l|l|l|l|}
\hline Q3 & $\begin{array}{l}\text { Do you believe that the current maritime transport labour } \\
\text { supply is sufficient to meet the labour requirements of a growing } \\
\text { maritime transport sector? }\end{array}$ & 5 & 8 & 5 & 18 & $44 \%$ \\
\hline
\end{tabular}

Round 3, Section 2, Question 4 result is a majority agreement result of $66 \%$ and therefore the statement has not reached a final consensus.

\begin{tabular}{|l|l|l|l|l|l|l|}
\hline Q4 & $\begin{array}{l}\text { Do you believe there are sufficient educational and training } \\
\text { opportunities in Ireland to service the labour, skill and } \\
\text { expertise required by various fields in the greater Dublin } \\
\text { region maritime transport sector? }\end{array}$
\end{tabular}

\subsubsection{Round 3, Section 4 Result}

Round 3, Section 4, Question 5 is a majority disagreement result of $55 \%$ and therefore the statement has not reached a final consensus.

\begin{tabular}{|l|l|l|l|l|l|l|}
\hline Q5 & $\begin{array}{l}\text { Do you believe that the greater Dublin region maritime } \\
\text { transport sector has high barriers to entry? }\end{array}$ & 8 & 10 & 0 & 18 & $55 \%$ \\
\hline
\end{tabular}

\subsubsection{Round 3, Section 6 Result}

Round 3, Section 6, Question 6 is a majority agreement result of $66 \%$ and therefore the statement has not reached a final consensus.

\begin{tabular}{|c|c|c|c|c|c|c|}
\hline Q6 & $\begin{array}{l}\text { Do you think your business, firm or organisation would benefit } \\
\text { from a greater mix and diversity of maritime transport firms? }\end{array}$ & 12 & 4 & 2 & 18 & $66 \%$ \\
\hline
\end{tabular}

\subsubsection{Round 3, Section 7 Result}

Round 3, Section 7, Question 7 reached a final disagreement consensus of $72 \%$.

\begin{tabular}{|l|l|l|l|l|l|l|}
\hline Q7 & $\begin{array}{l}\text { Do you think there is a high level of trust between firms } \\
\text { operating within the greater Dublin region masitime transport } \\
\text { sector? }\end{array}$ & 3 & 13 & 2 & 18 & $72 \%$ \\
\hline
\end{tabular}

\subsubsection{Round 3, Section 8 Result}

Round 3, Section 8, Question 8 is a majority agreement result of $66 \%$ and therefore the statement has not reached a final consensus.

\begin{tabular}{|l|l|l|l|l|l|l|l|}
\hline Q8 & $\begin{array}{l}\text { Do you think there is a lack of leader firms in the greater } \\
\text { Dublin region maritime transport sector? }\end{array}$ & 12 & 4 & 1 & 18 & $66 \%$ \\
\hline
\end{tabular}

Round 3, Section 8, Question 9 is a majority agreement result of $61 \%$ and therefore the statement has not reached a final consensus.

\begin{tabular}{|l|l|l|l|l|l|l|}
\hline Q9 & $\begin{array}{l}\text { Do you think a lack of leader firms within the greater Dublin } \\
\text { region maritime sector is having a negative affect on the } \\
\text { development of the greater Dublin region as a maritime }\end{array}$ & 11 & 5 & 2 & 18 & $61 \%$ \\
\hline
\end{tabular}


The conclusion in Round 3 of the Delphi survey has obtained a total of one consensus.

\subsection{Delphi Study Summary}

- The Delphi study had a total of 11 consensuses and the following is quick summary of the consensus results.

- The GDR is a maritime transport cluster (agreement of 78\%, Round 1)

- A business, firm or organisation would be at a disadvantage if located elsewhere in the country (agreement of 73\%, Round 1 ).

- The GDR maritime transport sector has strong level of internal competition (agreement of $73 \%$, Round 1).

- The GDR has the potential to move forward toward a more international recognisable cluster status (agreement of $72 \%$, Round 2).

- There is a lack of promotion and awareness of the career option available in the maritime transport sector (agreement of $86 \%$, Round 2).

- Business, firms and organisations located within the GDR have the advantage of access to earlier cluster knowledge (agreement $72 \%$, Round 2).

- If the GDR maritime transport sector was a highly competitive and vibrant environment Irish business and firms within the sector would be in a better position when competing internationally (agreement of $77 \%$, Round 2).

- The GDR maritime transport sector has a sufficient variety and diversity of maritime firms (agreement of $72 \%$, Round 2 ).

- The GDR would perform better if it had a greater mix and variety of maritime transport firms (agreement of 81\%. Round 2).

- The GDR does not have a high level of trust (agreement of $72 \%$, Round 3). 
The next chapter will look in detail at the individual consensus achieved and the opinions retuned for each of the statements.

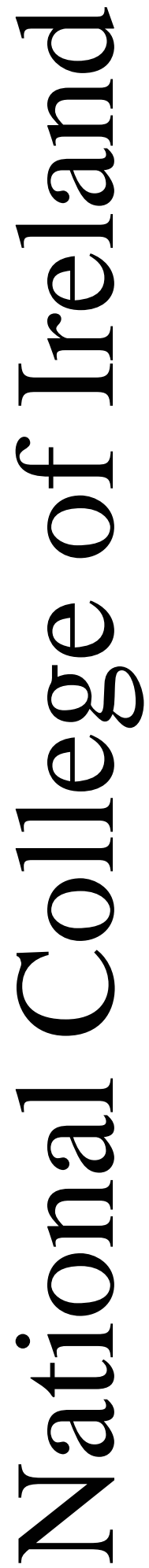




\section{Chapter 7.GDR Maritime Transport Delphi Results}

The purpose of this chapter is to discuss in detail the results of the GDR maritime transport Delphi for each round, to discuss the consensus achieved in each round, the final consensus of the total GDR Delphi and the consequence of the statements that did not achieve a level of consensus. The discussion on the results of the GDR Delphi will also be further supported by examining the data collected from the experts as to their established industry experience.

\subsection{Delphi Panel Members}

The first round of the Delphi was sent to a total of 64 agreed participants and as the nature of the GDR Delphi is heterogeneous, each returned response has been be allocated a category in order to represent an individual sector of the maritime transport industry. Each individual response from a panel member is taken to represent the company/business or organisation that they currently are employed or associated with. The breaking down of a cluster of industry into specific sectors is not as simplified a task as first may appear due to the fact that many businesses or companies may operate in one or more sectors e.g. freight forwarding and agency (refer to Chapter 4 for the discussion on the breakdown of the industry sectors). The Table 19 displays the number of Delphi participants and their representation for each specific industry sector, per round of the Delphi study. The Delphi Method does not require a statistical representative sample of the population of the GDR maritime transport sector in order to collect the data as characteristically it utilises expert opinion. The nature of the current GDR Delphi is heterogeneous and while the GDR may have up to 100 freight forwarders it does not have up to 100 ports located within the GDR boundary. Therefore the uneven panel numbers representing the sectors is perhaps reflective of the nature of the GDR maritime transport sector. For example every sector is represented by a least one business or firm directly except the stevedore sector; however other firms do operate stevedore services. 
Table 19 Delphi Panel Member Representation per Round per Industry Sector

\begin{tabular}{|l|l|l|l|}
\hline Sector & $\begin{array}{l}\text { Round 1 } \\
\text { Agreed }\end{array}$ & $\begin{array}{l}\text { Round 2 } \\
\text { Received }\end{array}$ & $\begin{array}{l}\text { Round 3 } \\
\text { Received }\end{array}$ \\
\hline Port & 2 & 0 & 0 \\
\hline Freight Forwarder/Agency & 21 & 7 & 6 \\
\hline Marine Insurance & 3 & 1 & 0 \\
\hline Marine Finance & 2 & 1 & 1 \\
\hline Maritime Law & 2 & 1 & 1 \\
\hline Stevedore & 0 & 0 & 0 \\
\hline Government & 2 & 1 & 1 \\
\hline Industry Organisation & 7 & 2 & 2 \\
\hline Consultant & 4 & 2 & 2 \\
\hline Academic & 5 & 3 & 2 \\
\hline Ship Management & 1 & 1 & 1 \\
\hline Brokers & 1 & 0 & 0 \\
\hline Shipowner/Operator/Services & 14 & 3 & 2 \\
\hline Other & 1 & 0 & 0 \\
\hline Total & 64 & 22 & 18 \\
\hline
\end{tabular}

(Source: Author's Own)

As Table 19 shows the two highest sectors represented are the freight lagency and the ship owner/operator and shipping services sectors. The freight and agency sector were placed together as many freight forwarders also conduct agency activities and similarly the ship owner/operator and shipping services sector included ship owner and operators, shipping companies and ferry operators. The subsequent sectors such as law, insurance, banking, management and brokering have a small representation in the GDR market and therefore the numbers represented are low when compared to the freight /agency and shipping services sectors. The prevailing number of panel members in the freight lagency and shipping services sectors does bias opinion towards those sectors, although there cannot be equal numbers of panel members for each sector as the GDR sector itself does not have equal number of players for each sector.

In the first round of the Delphi Study each panel member was asked to provide additional information in order to help clarify where opinion was originating. The candidates were asked to provide information on their current position of employment, if they had any industry association membership and to provide a brief summary of their work experience within the industry to date (Appendix 6: Delphi Panel Member Information 
Document). Also in the first round of the Delphi study the panel members were asked to indicate in which specific industry sector they currently work (Appendix 6: Delphi Panel Member Information Document). The purpose of the exercise was to remove any error on the author's part in terms of allocating a company to the wrong industry sector. On more than one occasion in Round 1 of the Delphi, panel respondents ticked more than one or two specific sectors. Many of the panel members have worked in different positions of employment and in different sectors of industry, and this industry experience and expertise development is relevant to the validity of opinions provided by the panel through the Delphi rounds. It also helps to provide an overall more balanced perspective of the opinions provided by the panel members with respect to the number of sectors represented in the Delphi, as it also indicates a level of response from areas which may be considered to have low direct panel member response such as the port sector. In Table 20 six panel members registered ports as an area of previous work experience (the reduction of that number through the rounds represents the drop out rate). Therefore in terms of experience over a period of a career the port sector is represented to a greater degree than illustrated by the individual profession of experts on the Delphi panel. The purpose of displaying the following table is to provide an illustration of the career experience of the Delphi panel in terms of differing sectors of industry. 
Table 20 Delphi Panel Members Sector Representation In Terms of Work Experience

\begin{tabular}{|l|l|l|l|}
\hline & Round 1 & Round 2 & Round 3 \\
\hline Port & 6 & 2 & 1 \\
\hline $\begin{array}{l}\text { Freight } \\
\text { Forwarder/Agency }\end{array}$ & 12 & 6 & \\
\hline Marine Insurance & 2 & 1 & 5 \\
\hline Marine Finance & 1 & 1 & 0 \\
\hline Law & 3 & 2 & 1 \\
\hline Stevedore & 5 & 2 & 1 \\
\hline Government & 3 & 1 & 2 \\
\hline $\begin{array}{l}\text { Industry } \\
\text { Organisation }\end{array}$ & 5 & 4 & 1 \\
\hline Academic & 5 & 4 & 3 \\
\hline Consultant & 7 & 5 & 3 \\
\hline Ship Management & 6 & 3 & 4 \\
\hline $\begin{array}{l}\text { Shipower /Operator/ } \\
\text { Services }\end{array}$ & 7 & 3 & 1 \\
\hline Agency & 12 & 7 & 1 \\
\hline Other* & 2 & 1 & 5 \\
\hline & $*$ Direct road & $*$ Direct road & * Direct road \\
freight & freight \\
\hline
\end{tabular}

(Source: Author's Own)

The process of industry personnel selection for the potential Delphi candidates was aimed at senior management levels as the maritime transport industry can be considered an "older" industry as many of the current upper end management within the industry would have entered into the sector at a young age (i.e. 16 for example) and worked their way up though the ranks and positions and in doing so gained experience in different companies, industry sector's and different positions of employment. Table 21 below provides the information regarding the current position of cach panel member per round. 
Maritime Clusters

Table 21 Delphi Candidates Current Positions of Employment

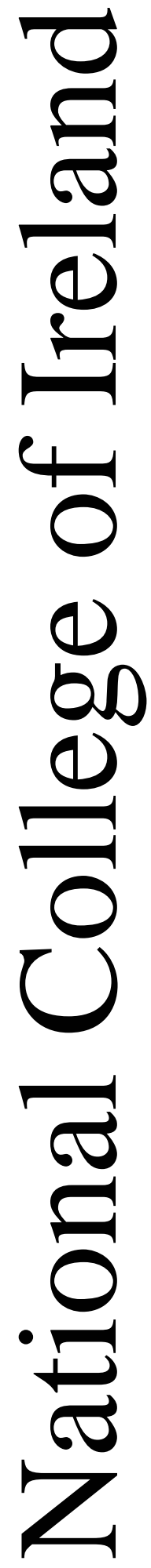

\begin{tabular}{|c|c|c|c|}
\hline No & Position Round 1 & Position Round 2 & Position Round 3 \\
\hline 1 & M.D & 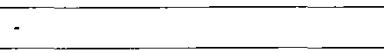 & - \\
\hline 2 & Area Manager & - & $\cdot$ \\
\hline 3 & Group MD & $-\quad+3$ & - \\
\hline 4 & General Manager & General Manager & - \\
\hline 5 & Director & Director & Director \\
\hline 6 & $\mathrm{MD}$ & - & $-\quad+\quad-\quad+$ \\
\hline 7 & Director & - & - \\
\hline$\overline{8}$ & $\mathrm{MD}$ & 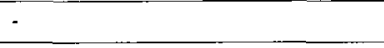 & - \\
\hline 9 & Financial Controller & Financial Controller & Financial Controller \\
\hline 10 & Director of Learning & $-\quad+2+2+3$ & $\cdot+2+\ldots$ \\
\hline 11 & Secretary & - & - \\
\hline 12 & Consultant & Consultant & Consultant \\
\hline 13 & Planning Manager & Planning Manager & Planning Manager \\
\hline 14 & Branch Manager & Branch Manager & Branch Manager \\
\hline 15 & $\mathrm{CEO}$ & CEO & $\mathrm{CEO}$ \\
\hline 16 & Director \& Shareholder & Director \& Shareholder & Director \& Shareholder \\
\hline 17 & Director & - & $-\quad+2+2+1$ \\
\hline 18 & $\mathrm{MD}$ & $\mathrm{MD}$ & - \\
\hline 19 & Owner & Owner & Owner \\
\hline 20 & Managing Director & Managing Director & Managing Director \\
\hline 21 & Partner & 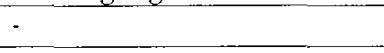 & - \\
\hline 22 & $\mathrm{CEO}$ & $\mathrm{CEO}$ & $\mathrm{CEO}$ \\
\hline 23 & $\begin{array}{l}\text { Chair of Maritime } \\
\text { Logistics \&Policy }\end{array}$ & $\begin{array}{l}\text { Chair of Maritime } \\
\text { Logistics \&Policy }\end{array}$ & $\begin{array}{l}\text { Chair of Maritime } \\
\text { Logistics \&Policy }\end{array}$ \\
\hline 24 & Senior Lecture & Senior Lecture & Senior Lecture \\
\hline 25 & $\begin{array}{l}\text { Head of Maritime } \\
\text { Industries }\end{array}$ & $\begin{array}{l}\text { Head of Maritime } \\
\text { Industries }\end{array}$ & $\begin{array}{l}\text { Head of Maritime } \\
\text { Industries }\end{array}$ \\
\hline 26 & Partner & Partner & Partner \\
\hline 27 & Export Manager & $-\quad$ & $-\quad+2$ \\
\hline 28 & Consultant & - & 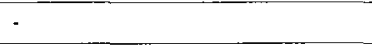 \\
\hline 29 & Principal Officer & Principal Officer & Principal Officer \\
\hline 30 & Professor of Logistics & Professor of Logistics & - \\
\hline 31 & Consultant & - & $-\quad+2+3 .+3$ \\
\hline 32 & Principal Consultant & Principal Consultant & Principal Consultant \\
\hline 33 & Managing Director & Managing Director & Managing Director \\
\hline 34 & Associate Director & $\cdot$ & - \\
\hline 35 & Divisional Manager & 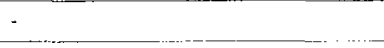 & - \\
\hline 36 & Director & Director & $\therefore$ \\
\hline 37 & $\mathrm{MD}$ & $\mathrm{MD}$ & MD \\
\hline
\end{tabular}

(Source: Author's Own)

The importance of the Delphi Panel member's current position of employment is supported by the fact that they are experts in their field and hold high positions within a range of high management levels. As indicated in Table 20 many of the Delphi candidates hold current positions of Managing Director, Associate Director, Director. Area and General Managers, Professor, Chairs, Partners, CEOs and Consultants. The attainment of such positions requires a considerable amount of industry 
experience, knowledge and qualifications. The candidates were also asked about any industry organisation or association membership. Table 22 provides information on organisation and association membership of the Delphi panel and their representation through each of the rounds.

Table 22 Industry Organisation Membership

\begin{tabular}{|l|l|l|l|}
\hline Industry Organisation & Round 1 & Round 2 & Round 3 \\
\hline Irish Ports Association (IPA) & 1 & 1 & 1 \\
\hline Irish Ship Agents Association (ISAA) & 3 & 2 & 1 \\
\hline Institute of Chartered Shipbrokers (ICS) & 1 & 1 & 1 \\
\hline Institute of Chartered Shipbrokers (Fellow) & 1 & 1 & \\
\hline $\begin{array}{l}\text { Chartered Institute of Logistics \& Transport } \\
\text { (CILT) }\end{array}$ & 7 & 4 & 3 \\
\hline $\begin{array}{l}\text { Chartered Institute of Logistics \& Transport } \\
\text { (Fellow) }\end{array}$ & 5 & 3 & 2 \\
\hline Irish Chamber of Shipping (ICS) & 2 & 2 & \\
\hline Irish Exporters Association (IEA) & 3 & 2 & 2 \\
\hline Irish Freight Forwarders Association (IFFA) & 5 & 1 & 1 \\
\hline Chartered Insurance Board (CIB) & 1 & 1 & 1 \\
\hline Baltic Exchange & 1 & 1 & 0 \\
\hline $\begin{array}{l}\text { European Community Shipowners Association } \\
\text { (ECSA) }\end{array}$ & 1 & 1 & 1 \\
\hline Maritime Law Association (MLA) & 1 & 1 & 0 \\
\hline $\begin{array}{l}\text { British International Freight Association } \\
\text { (BIFA) }\end{array}$ & 1 & 0 & 0 \\
\hline International Air Transport Association (IATA) & 1 & 0 & \\
\hline
\end{tabular}

(Source: Author's Own)

As indicated in Table 22 there is representation of a range of organisations and associations both national and international. Of the panel members there is a high membership association with the Chartered Institute of Transport \& Logistics (CITL) which require individuals to hold either a CITL Advanced Diploma, or an exempting qualification or at least five years experience in logistics and/or transport which includes two years at a senior level position. There are also a number of Fellows (the most senior grade of the institute) of the CITL from the Delphi panel who must hold at least seven years experience in high level positions with experience including management of logistics and or transport (CITL, 2005). Consequently a Fellow of the Institute of Chartered Shipbrokers (ICS) is a member with sufficient seniority within the industry and has engaged in the business of shipbrokeing for six years and therefore is entitled to be called a "Chartered Shipbroker" (ICS, 2007). There is also a panel member with association with 
The Baltic Exchange. The Baltic Exchange is the market place for the arrangement of transportation of bulk commodities and provides daily independent shipping market information and maintains shipbrokeing standards ("Our Word, Our Bond") and helps to resolve disputes (Baltic Exchange, 2007). Industry organisations and associations help to provide a collective voice and forum for members and can act as a lobbying group within industry and government. Industry organisation membership provides contacts and helps to develop business relationships between members and facilitate key networking and access to industry knowledge.

The panel members were finally asked to provide some information on their previous work experience and the duration of time spent working within the industry. The following is an example of the information provided by the Delphi panel members as to their experience within the maritime transport industry.

- Over 10 years working in the sector including areas such as agency, forwarding, haulage and stevedoring.

- Over 14 years working within the industry.

- Experience in retailing, trading in London, Logistics Director for 10 years, owner of shipping and Logistics Company for 12 years.

a Over 36 years of experience within the industry.

- Over 25 years of experience within the industry.

" Over 40 years and have held positions of Deputy Chief Executive and MD.

- Experience in international containers and trailer operations, heavy haulage, ship brokerage, ship agency, ship management, stevedoring, customs clearance, strike insurance, lecturer and consultancy.

- Over 36 years in short sea shipping, 9 year's in deep sea shipping.

- Over 10 years in freight industry.

- All positions involved with domestic and European road freight.

-Over 30 years experience within the industry. 
- Master Mariner, classification surveyor, lecturer, owner representative in shipyards in Poland, East Germany and South Korea.

- Transport consultant and manager UK \& Eire.

- Over 30 years experience, exports/imports, deep sea, short sea, air freight, containers.

- Over 17 years experience and Chief Executive of company

- 20 years in logistics and supply chain management.

- Divisional manager, global maritime risk and investigations consultant, 5 years VP Asia Pacific.

- Over 40 years experience within the industry.

- Over 26 years experience within the industry.

- Over 40 years experience within the industry

- Over 18 years experience, including air transport, government, consultant and academic.

- Over 26 years experience in freight industry.

- Over 17 years in ship finance.

* Former director of operations.

₫ Over 20 years experience in damage claims, risk surveys, loss adjusting for cargoes, and 11 years merchant navy.

Rosenberg (2006) argues that for most of history the mode in which people learned was through apprenticeship and after years of learning the master would decide when competence had been achieved. That concopt has changed somewhat in the modern world where young knowledge seekcrs will enter a skill apprenticeship for a number of short years (3-5) or proceed towards the academic route of degrees, master and in some cases PhDs. In the previous learning mode the learner is older when they enter the "real" experience part of the learning stage. The maritime transport sector is generally considered an older industry and many persons currently working within the sector (and not exclusively to Ireland) would have spent a considerable proportion of their career at sea and then entered the shore side employment of maritime transport, or alternatively entered the 
workforce at a younger age and worked up through the ranks as the academic route was not considered as necessary or as accessible as it is today. Many of the current GDR Delphi panel members went through such an apprentice experience based approach to learning and experiencing the industry effectively though a "learning by doing" process of experience. Rosenberg (2006) argues that expert experience and knowledge are important for dealing with concepts that are not fully resolved such as new research issues, technologies for investigating and improving new knowledge. Thus dealing with experts, their knowledge, experience and opinions can help to move forward towards a solution or possible "correct" answer to a question or problem which in itself is core to the Delphi Method's use of experts to create new knowledge on area that lacks sufficient data or contemporary knowledge.

Through the three rounds of the Delphi the panel members were asked to either agree, disagree or to provide an unable to comment response to the questions provided, the panel members were asked to provide an answer/opinion for each of the statements regardless of which answer option they selected. The purpose of the GDR Delphi is to gather opinion for the purpose of new knowledge and understanding on the potential of the GDR maritime transport cluster. The original panel membership was 64 and it is perhaps more useful and easier for the panel members to review the responses of the subsequent panel members on a paper and pen based format than reading the response from a computer screen. Onc problem with a paper and pen based Delphi is that panel members can miss or forget to fill in the opinion after they have selected their answer. If the Delphi was conducted on a website or through email, a system can be established to prevent the submission of the rounds until all required boxes have been filled in, and in doing so ensures that all panel members include an opinion with their response to each statement. Panel members may fail to provide an opinion because they simply forget or they may indicate that their opinion has not altered from the previous round and do not feel it is necessary to repeat it. 
The Delphi also has the issue of potential bias (see Chapter 5 for discussion on bias) as there is a greater number representing certain sectors over other sectors. This however can be eased by the fact that the opinions are considered as the most important information and the analysis below includes both the agreement and disagreement opinions in the analysis of the statements. The Delphi requires a percentage to confer consensus. As the method deals in opinion the results are taken as an indication as opposed to absolute fact. However the importance of the current research is to increase the understanding and the potential of the sector and to raise questions for further research. Therefore the opinion retuned for statements in disagreement with the final consensus is also important for the development of further understanding of the sector.

\subsection{Delphi Analysis}

The consensuses achieved in the Delphi study have been ranked at three levels; low consensus, medium consensus and high consensus (refer to Table 12 p 127). The most important consensus from the GDR Delphi perspective is from $70-79 \%$ as statements that achieve either an agreement or disagreement consensus of $70 \%$ do not enter the subsequent round. The GDR Delphi could have implemented a clear $70 \%$ cut off mark, however due to the divergent nature of the issue of consensus and the many modes in which a consensus can be inferred a ranking approach post the initial consensus of $70 \%$ was perceived to help apply a level of caution and validity to the result.

Each statement that has achieved a consensus in each of the rounds will be discussed and analysed with the support of both the agreement and disagreement opinion provided for by the panel members. In the Delphi study the questions were divided into eight sections. Through the rounds in some instances responses have been similar and therefore the responses have been devised into threads of opinion in order to facilitate and to enable a reasonable control on the analysis. 


\subsection{Consensus Achieved in Round 1}

In round 1 of the Delphi a total of three consensuses were achieved.

\subsubsection{Round 1, Consensus 1}

The first consensus ranked at 78\% which according to Table 12 is a low consensus agreement. Therefore $78 \%$ of the 37 returned responses for Round 1 consider that the greater Dublin region maritime transport sector as a maritime transport cluster.

\subsubsection{Round 1, Consensus 1 Analysis}

Of the total 37 returned responses, 29 agreed, 7 disagreed and 1 was unable to comment. The importance of the first question in Round 1 of the GDR Delphi is to ascertain if the Delphi candidates consider that they are operating within a maritime transport cluster. If the Delphi panel had returned a disagreement result for the Round 1, Question 1 statement, it may have had a result of altering the perception of what the industry itself perceives as its possible potential. In the first instance the agreement result of this statement indicates that the GDR is a maritime transport cluster. The following text will analyse some of the opinions retuned by the panel members.

Agree Arguments:

Agree Arguments: Thread A

"Beginnings of a cluster" with a broad selection of the necessary business units"

" $[\mathrm{A} /$ cluster, but to a limited degree"

"There are some gaps in the services to support the transport business"

"Small, but in my opinion linked through relationships, a small cluster' of ship manger's, operator's, lawyer's, financier's and insurer's"

Agree Arguments: Thread B

"Proximity to finance and. government"

"Some potential to acquire international recognition as has the IFSC" 
Agree Arguments: Thread C

"Dublin has a major population and industrial centre, and therefore an obvious focal point for many shipping companies and spin offs i.e. warehouse, customs etc"

"I suspect that it has more to do with the demographic problems of the Irish republic where major population centre and major general port facility are co-located"

"Port and airport provide the hub in which the development of the maritime transport sector has progressed"

"As a fraction of the volume of cargo, containerised, Ro/Ro and bulk transiting through the port, all of these activities require a substantial range of support service industries, hence the cluster of services around the port activities"

\section{Agree Argument: Thread D}

"The question is how strong the cluster is and what is a good growth strategy"

Of the opinions returned in agreement with Round 1, Section 1, Question 1 there were four main threads of opinion identified. Of the 37 returned responses, 29 returned in agreement that the GDR is a maritime transport cluster. However opinion appears to incorporate the statement "yes it is a cluster: but!" Therefore the overall result is that the GDR is a maritime transport cluster but with considerations that need to be further examined and acknowledged. It is important to identify those considerations for any further research, future policy recommendations or developmental strategies regarding the GDR maritime transport cluster.

The Thread A opinion was in agreement of the GDR as a cluster but with a noticeable gap in some services for the support of transport, in that it is a cluster but "to a limited degree". There is no clear formula of what minimum number of services or sectors a maritime cluster must have in order for it to be classified as a maritime transport cluster, or to what level and density (i.e. numbers) of sectors should be present. The opinions returned might have been influenced in that the panel members may compare the GDR maritime transport sector to that of major maritime clusters such as London and Rotterdam. As discussed in the literature of cluster theory, relationships have some level of effect on a cluster and their importance was 
mentioned in the opinions provided by panel members; for example, one opinion commented on the issue of relationships due to the small nature of the cluster. Could the smaller nature of a cluster have the benefit of being stronger with a more supportive network of relationships? Therefore perhaps big is not always necessarily better. Such an argument would be supportive in the fact that a cluster is more than just size and density of firms (not disregarding the importance of the number of firms) and that relationships and dynamism are also important drivers of clusters.

Thread B opinion discusses the possibility of developing the finance and banking aspect of the cluster on the back of the IFSC. The IFSC was developed by the Irish government in 1987 in response to rapid growth in the finance sector world wide and the IFSC has been a major Irish success and holds many of the world's leading financial institutions, law firms, accountancy and taxation advisors (IDA, 2007). In $2001 \mathrm{KBC}$ pulled out of the Irish ship finance market (Lloyds List, 2003, A), which helped lead Bank of Ireland to join the ship finance market which in April 2005 confirmed a portfolio of US $\$ 570 \mathrm{~m}$ (Noble, 2005) while other marine finance players located in Ireland include Lombard Global Finance which is 100\% owned by the RBS. The success of the IFSC can perhaps be an encouragement in terms that a financial cluster has been built from scratch within Ireland. Although the IFSC had strong support from government and an exclusive corporation tax regime that required a $10 \%$ rate instead of $40 \%$ rate of company profits (Williams and Shiels. 2002).

The Thread $\mathrm{C}$ arguments take a different approach on the agreement of the GDR as a maritime transport cluster as they highlight the fact that a high proportion of Ireland's population is located within Dublin and the GDR which makes it an "obvious focal point" for business and firms due to the population density. The main argument of Thread B is that yes it is cluster, but perhaps it is a cluster by default due to the location of Dublin port and the demographics of the country and capital city where "capital city and major port facility are colocated'. A port is considered a text book case example of clustering (Fujita and Mori, 1995) and in the GDR maritime 
transport sector the role of Dublin port could perhaps be core to the cluster itself, supported by the demographics of the capital. Thread B arguments could lead to the question of the importance of and the relationship between the port and the country's capital city in the making of the GDR maritime transport cluster, and if that cluster is purely related to the direct activities of the port such as the shipping and agency etc, as opposed to the maritime service sectors of maritime law, insurance, consultancy etc. Basically the opinion in Thread B questions the reality of the Dublin maritime transport sector as a maritime cluster based on factor's such as demographics and the co-location of capital city and major port facility.

The opinion in Thread D raises the question about the strength of the cluster today and its possible potential for the future. This however is a very broad statement of opinion and the overall current research will hopefully go some way to answering or provide guidance for such an issue.

\section{Disagreement Agreements:}

\section{Disagree Arguments: Thread A}

"Not a cluster; only two insurance companies. and banks that deal in the sector are on a domestic basis only, as far as aware no international clients, and international clients would not regard them as experts. companies have a designated person"

"From the point of view of international shipping there is not sufficient activity in Dublin, no specific area in Dublin that is a cluster: except Dublin port"

Disagree Arguments: Thread B

"Does not extend to the GDR, but contained in Dublin port. IFSC, and M25 area"

The disagreement arguments had two main threads of opinion. The opinion in Thread A disagrees that the GDR is a maritime transport cluster due to a lack of presence of certain maritime transport sectors or the international presence of those sectors from within the GDR. The marine finance sector was highlighted in respect of its lack of international status as a major financial player and in terms of activity shipping was also highlighted. The opinion could be based on the panel members comparing a maritime sector in one country to a maritime sector in another. However the disagreement 
opinion adds to the equation the possibility and importance of international presence and critical mass. The exception to the rule (from opinion) in terms of a cluster was that of Dublin port, which again refers to the previous discussed issue in the agreement opinions of the role of the port and its relationship to any possible cluster or cluster development. Further disagreement opinion did highlight the Dublin port region, IFSC and M50 region as the cluster as opposed to the whole of the GDR region. In summarizing, the disagreement opinion was based on the lack of certain activities and internationalisation of those activities from within the GDR maritime transport sector and that the clustering of the sector is primarily based around the location of the Dublin port district.

The result from Round 1, Section 1, Question 1 is an agreement result of $78 \%$, which can be considered as a reasonably confident consensus. In the first instance it can be taken with an appropriate level of confidence that the GDR is a maritime transport cluster from the perspective of the expert panel who work in the industry. The main questions derived from the opinions proved by the panel members for the current statement include;

1. What maritime sectors, if any, does the GDR maritime transport sector lack? Is there an optimum formula for a maritime cluster i.e. number of sectors, type of sectors, and density of sectors?

2. What is the potential to develop the maritime finance and banking aspect of the GDR maritime transport cluster? Can anything be learned from the development of the IFSC cluster?

3. How important is the effect of business relationships on the GDR maritime transport cluster. Does the GDR region benefit more in terms of relationships due to the small size of the sector?

4. How important is the role of the port in the making of the GDR maritime transport cluster (and the role of the city)? How does the country's demographics affect the GDR maritime transport cluster? Is the GDR maritime transport sector a port cluster or the result of agglomeration of people and industry in a specific area? 


\subsubsection{Round 1, Consensus 2}

The second consensus ranked at $73 \%$ which is a low agreement consensus. $73 \%$ of the 37 responses returned for Round 1 Question 6 believe that their business, firm or organisation would be at a disadvantage if located elsewhere in Ireland.

\subsubsection{Round 1, Consensus 2 Analysis}

Of the total 37 returned responses, 27 responded with an agreement opinion, 8 returned a disagreement opinion, and 2 retuned an unable to comment response. The importance of Round 1, Question 6 is in the relevance of a business, firm or organisation's need to be located in and near the concentration of cluster activities. Clusters have some level of geographical boundary and the firms within that boundary have a certain degree of proximity to each other, in which lie the benefits of clustering and economies of scale such as knowledge supply and access to labour pools. The proximity benefits of being positioned where the cluster's knowledge is first developed and having greater access to the cluster's knowledge spillover effect such as up to date market information, innovation diffusion and entrepreneurship created by the market players inside the cluster as well as the benefits of chance meetings and the general "floating" knowledge of the industry and industry players.

\section{Agree Arguments:}

Agree Arguments: Thread A

"Yes, due to nature of our business, i.e. looking after' ships ariving and sailing fiom Dublin port, must be available 24/7, business depends on Dublin port"

"Most of our imports/exports are in this area, pioximity to port and capital and operator's"

"Best planning is conducted if rou are close to the port from a timing point of view for loading/unloading etc, perception of clients of proximity to the port is important, majority of our customers are in the Dublin area, costs may increase, and transit times could get worse if we were in a different part of the city."

"Yes, away from the port, lnowledge costs are high" 
"When government was deciding on its decentralisation policy it decided to keep the Department of Transport in Dublin because of its many functions, the departments Dublin location is convenient for the sector"

"Must be at the point of business, to meet and solve problems, have small offices in other parts of the country to look after clients there"

"City is the hub, and any firm engaged in international trade is aware of its creditability status on the world stage"

"Not to be based in Dublin would look like a blended specialism and not a pure maritime lawyer, access to Dublin ensures access to courts and accessibility to international clients"

Agree Arguments: Thread B

"Can be dependent on the company and type of operation"

Agree Arguments: Thread C

"Yes, for the wrong reasons, too much focus on Dublin port without the infrastructure to match it"

The opinions returned for the current question appear to be influenced to some degree from which sector the opinion stems. Due to the heterogeneous nature of the GDR Delphi there are panel members from different sectors, firms/businesses and organisations which have different needs despite working from within the GDR maritime sector. The agreement opinions have been divided into three threads and the opinions from Thread $\mathrm{A}$ and Thread $B$ make it clear that location is more important for certain sectors than for others. It is apparent that certain sectors within a maritime transport cluster (not just specifically in Dublin) such as the shipping services sector would require greater proximity to the port due to the nature of their: business relationship with port activities when compared to the proximity requirements of insurers and lawyer's to a port. However this adds to the question raised from the analysis discussed in Round 1 , Consensus 1. If city (and or capital) and major port facility are one and the same. which question is the most appropriate?

A) How important is the role of the city in the making of maritime clusters?

$\mathrm{O}^{\prime}$ 
B) How important is the role of the port in the making of cities (and or capital cities)?

Is the GDR solely a maritime transport cluster, or is the GDR purely a port cluster with the beginnings of a maritime cluster, or has the capital city benefited from the historic location of the port, or vice versa. The origins of the answer in the first instance is historic in the context that townships developed around a suitable point of entry and exit for trade, and in the proceeding developmental stage both major port facility and capital city provided a reciprocal level of benefits to each other. However in a modern context the balance of benefits may have shifted in favour of the capital city as opposed to port development incorporating city development, with a revolutionised product being a maritime transport cluster.

Subsequent opinions provided in the response in Thread A also indicate the importance of the perception of firms to their clients and that by not being located within the main industry locality would appear to clients as being "out of the loop". Being absent from the region could suggest a lack of dedication and commitment to the service provided in a sense that the service was fragmented. One opinion did highlight that being located away from the epicentre of activity increases the cost and access to industry knowledge. This comment was made in respect of the port as opposed to the GDR cluster. As discussed in the literature review one of the advantages of being located within a cluster is the earlier access and advantage of cluster knowledge and the benefits from being located near customers and suppliers. Such opinions appear to reaffirm the importance and pull of the capital city to certain sectors within the maritime transport sector. However importance of the pull of the port is perhaps derived by the need for firms to be at the point of business.

The Thread $\mathrm{C}$ argument provided a different approach to the agreement opinion on the importance of the GDR location. However Thread C did indicate that while Dublin was important it was for the wrong reasons as it did not have the necessary infrastructure to match the considerable focus on 
the Dublin and Dublin port area. The opinion did not elaborate further and the question of infrastructure could be related to physical infrastructure for transport in the area, or the infrastructure of possible cluster relationships such as chance meetings and the access to cluster knowledge. The concentration of focus could also be in relation to political focus of Dublin port compared to the rest of the country.

\section{Disagreement Arguments:}

\section{Disagree Argument: Thread A}

"Personnel interaction overrated due to modern communications"

"With modern communications don't see the need for any specific location"

"With agency most work done with email and phone"

\section{Disagree Argument: Thread B}

"Due to the small size of Ireland, the location would have to have very good domestic and international transport access e.g. road, rail and air: Advent of universal broadband will also make the geographical location of some sectors less important"

"Travelling to the locations of our' services is required, the bulk of our" marine services are carried out elsewhere than in the Dublin cluster; this is due to the nature of transport and modern telecommunications"

The disagreement arguments were divided into two threads, Thread A's main opinion was that due to modern telecommunications and the advance in technology, email and general communications has helped to reduce the requirement and benefits of any specific location. However, as seen in the agreement opinion the benefit of location to a certain extent is sector specific.

Despite the possibility that the opinion above came from firms in which their location may not be as crucial to their business when compared to other sectors, it may also be an indication that such firms may experience a lack of interaction with competitors and don't perhaps see or attain any of the benefits generally derived from firms that locate within proximity to each other i.e. business relationships, cluster knowledge etc. However, being located outside the core proximity of the cluster or city will allow for lower costs (i.e. land rents) and less congestion which under agglomeration 
economics are considered dispersers of the agglomeration effect. Perhaps in the ideal situation all firms, business and organisations should want to locate within the cluster for the obvious benefits and economies of scale brought about by the agglomeration of firms in a specific region or industrial district. The lack of identify of a firm to see the benefits of proximity may be the result of the firm type and the service that they provide to their customers and that the cost benefits of locating outside the core city/cluster area are stronger than the benefits gained by locating within the cluster. Is this the result of weak cluster relationships or the push of the importance of location within the capital city for many other industries and not just specifically maritime transport? If cluster relationships were so dynamic and the benefits extremely clear and beneficial would this outweigh the cost of city location? This may be more relevant for firms involved in direct relationship with the port activities as regardless of cost they must be located near Dublin port and thus is located within the heart of Dublin city.

\section{Unable to Comment Arguments}

"As consultants as far" as geography is concerned, being close to the port really helped, but after gaining industry recognition we could have relocated"

"Depends on who and what you are, warehousing etc no, ship operations ports etc yes"

The opinions provided in the unable to comment section again reiterate the importance of location, which can be sector dependent. However the opinion received from the consultant sector is interesting as it states that it was important to have a presence in the city i.e. the perception of taking the job seriously and that after such industry recognition was developed there was perhaps no reason as to why the firm could not have relocated. The interesting concept here is to why the firm did not relocate. It perhaps could be compared to the example of shipbrokers based in London. Due to modern telecommunications and the demise of trading on the Baltic floor there is the argument that shipbrokers do not necessarily need to be located in London to carry out their duties. As long as there is sufficient communications and regional airports, shipbrokers could conduct their 
business from elsewhere i.e. Dublin for example. However, the shipbroker may argue that the explanation for its prominent London location are due to reasons such as, that by being located in London they are in the hub of a maritime transport service cluster and by being removed from the cluster detaches them from access to cluster knowledge and "being in the know". This could be a similar situation for firms whose location within the GDR is perhaps not as essential as other firms. This aspect of proximity could be due to the importance of Dublin as a capital city or the importance of the so called pull of the maritime transport cluster surrounding Dublin port.

The result from Round 1, Question 6 is an agreement of $73 \%$ which can be considered as a reasonably confident agreement consensus. In the first instance it can be taken with an appropriate level of confidence that firms, business and organisations consider that they would be at a disadvantage if located outside the GDR, although to some extent this can be sector specific. The main questions derived from the opinions proved by the panel members for the current statement include;

1. The importance of perception and marketing of a cluster. How does the importance of appearing to be located within the cluster keeps firms located within the GDR. Can you brand a cluster and a city?

2. What is the difference, if any between a port cluster and a maritime transport cluster? How would the difference, if any, effect a firm's choice location inside the GDR?

3. Does the GDR maritime transport sector have an active level of cluster dynamism?

4. Is the importance of being located in the city for all industries having a push out effect of maritime firms that don't have a direct relationship with the port activities and therefore the cost of locating outside the city outweighs the benefit of being in the city and having the proximity to other maritime firms. 


\subsubsection{Round 1, Consensus 3}

The third consensus ranked at 73\% which is a low consensus. $73 \%$ of the 37 responses returned for Round 1 consider that the greater Dublin region maritime transport sector as having a strong level of internal competition.

\subsubsection{Round 1, Consensus 3 Analysis}

Of the total 37 returned responses, 27 agreed, 7 disagreed, and 3 were unable to comment. Round 1, Question 10 is perhaps a difficult question to answer as the panel members may truly feel that they operate in a highly competitive industry and even though the panel members have retuned an agreement response of $73 \%$ that does not however categorically confirm that the GDR maritime transport sector as highly competitive. In the first instance perhaps only certain specific sectors might operate in such a highly competitive environment and their opinion could also be dominated by higher representation in the Delphi survey.

\section{Agree Arguments}

Agree Arguments: Thread A

"Yes strong level, as already operate in a competitive international arena"

"Lot of domestic competition between shipping companies. freight forwarder's, and hauler's because Dublin is small"

"The ferry market (freight) is served by Norkfline, Stena Line, P\&O, Irish Ferries. Celtic Link and all competing for Ro-Ro. of these Norfline. P\&O. Stena. and Irish ferries currently serve Dublin. Celtic Link will from May $2006^{\circ}$

"In the ancillary service sector's res, perhaps less so in the phrsical transport operations"

"Easy access to entry to the profession means lots of compctition and choice for clients, plus competitive rates."

"Obvious by the number of operator's based in Ireland. it also allows by the fact that foreign companies gain entry to the market by the acquisition of locally built firms and strategic ariangements and agreements"

Agree Arguments: Thread B

"Strong level of competition but some abuse of a dominant position" 
"Definitely, but almost destructive competition in some sectors where undercutting fees is creating a pathway and monopolistic tendencies among the advocates of stack them high and sell them cheap"

"Some sector's have a strong levels of competition, but many other's do not, not enough competition in haulage, stevedoring etc, as there is a lack of capacity to higher costs"

Agree Arguments: Thread C

"The strong competition can often result in poor remuneration, which is a problem within some sectors"

"At times the competition is cut throat with margins reduced to ridiculously low levels just to maintain business"

The agreement arguments had three clear threads of opinion and the opinion of Thread A illustrates the agreement that there is a strong level of internal competition in cited sectors such as freight and the shipping services sectors, notably ferries and Ro/Ro trades. The opinions in Thread A indicate that low barriers to access in sectors, and the fact that foreign companies can gain access through acquisition suggests that more market players equals greater levels of competition. From the overall opinion in Thread A it would appear that the GDR does have a strong level of internal competition from the point of view of expert opinion. However from the responses illustrated in Thread B above it would suggest that the GDR is internally competitive, but only in terms of anti-competitive behaviour. The Thread B opinions highlight strong competition, but with the abuse of a dominant position by firms and destructive competition in certain sectors which is encouraging monopolistic behavioux. Such responses indicate an uneven playing field within the GDR sector, but the responses do not give an indication as to which sectors are behaving in such a way. One way to deduce this may be to look at from which sectors such responses originate. However the question asked did refer to the GDR maritime transport sector and did not ask the panel members to comment specifically on their own sector. Despite the opinions on destructive competitive behaviour Thread B opinion did specifically highlight the areas of haulage and stevedoring as lacking in terms of competition. 
The opinions provided from Thread C illustrate that while competition can be a positive aspect of business it can also induce cut throat levels of competition which can drive rates down to low levels which result in poor remuneration. However the opinion does not indicate which sectors experience such cut throat competition levels but it could result in a barrier to entry for the cluster if future firms feel that entering the market would not be economically viable. Overall while panel members are in agreement with the GDR as having a strong level of competition there are opinions that raise concern such as the comment regarding the behaviour of destructive competition and monopolistic tendencies and that such high competition levels in some sectors are placing severe pressure on firms to make sufficient profits.

\section{Disagreement Arguments}

\section{Disagreement Argument: Thread A}

"Irish ports and shipping sector" do not, i.e. the transparency mentioned earlier in prices and rates. For example terminal operator's DFT's parent company is ICG who's parent company of EUCOMN, which gives Eucon preference over competitor's at hey times to the determent of competitor's who have no vested interest in the terminal, similar again MTL whose daughter companies Coastal and $B G$ will get preferential treatment. other cases it's the status quo that has been established for decades giving. grandfather' rights to some companies"

Seven of the panel members had the opinion that the GDR did not have a strong level of internal competition. Unfortunately some of those seven did not provide a reason for their answer. However the agreement argument provided for in Thread $B$ is similar and reflected the opinion in the disagreement argument in Thread $A$ with respect to the strong levels of internal competition having destructive and monopolistic effects.

The result from Round 1, Question 10 produced an agreement result of $73 \%$ which can be considered as a reasonably confident agreement consensus result. In the first instance it can be taken with an appropriate level of confidence that the GDR does have a strong level of internal competition although this may be more relevant for certain sectors. The main questions 
derived from the opinions proved by the panel members for the current statement include;

1. What specific sectors within the GDR are competing under strong levels of internal competition?

2. What sectors are engaging in destructive behaviour, if any? Is there an optimum level between a good level of competition and such strong competition that results in poor remuneration?

\subsection{Consensus Achieved in Round 2}

In round two of the Delphi a total of seven consensuses were achieved.

\subsubsection{Round 2, Consensus 1}

The first consensus ranked at $72 \%$ which is a low consensus. $72 \%$ of the 22 returned responses for Round 2 believe that the greater Dublin region can strengthen its position towards a more international recognisable cluster status.

\subsubsection{Round 2, Consensus 1 Analysis}

Of the 22 returned responses, 16 agreed, 4 disagreed and 2 were retuned unable to comment. In Round 1 the question achieved an agreement consensus of $59 \%$ and through the repetition of the question in Round 2 and the through the provision of feedback from Round 1, the question increased in agreement by $13 \%$ to $72 \%$. The current question being discussed is in support of the Round 1, Question 1 statement which asked the panel if they considered the GDR region as a maritime transport cluster. Therefore the current question develops on the agreement consensus of the GDR as a maritime transport cluster and discusses the clusters potential to develop.

\section{Agreement Arguments}

Agree Arguments: Thread A

"By means of tweaking IFSC regulations to induce shipowners and trader's such as commodity houses to avail of concessionaiy taxation benefits. Genera has obvious parallels"

"It can, but it must concentrate on niche areas in the sector. With a strong IFSC the best way to achieve this is by localizing on finance and associated services" 
"There is already a number of well known and high class organisations in place. Ther'e is a skilled workforce and the IFSC is a potential factor"

"With appropriate fiscal and other incentives to attract and retain maritime companies I believe Dublin can strengthen its current position"

Agree Arguments: Thread B

"Growing population means more buying and selling of services and goods creating a bigger demand"

"Business is growing in several sectors and provided trained staff is available"

\section{Agree Arguments: Thread C}

"Dublin continues to attract, albeit very slowly, the diverse skills required to become a maritime transport cluster. We are a long way behind London/New York in breadth and services e.g. finance insurance, arbitration, sale and purchase. But with continued support from government Dublin's position in maritime affairs will rise in importance. With low end manufacturing dwindling in Ireland and hi end activities including logistics and supply chains have become more component"

"The Dublin region has all the elements to progress to a recognised cluster" status, all shipping modes are handled, and Dublin Port alone is expected to handle around 29 million tonnes in 2006 making it a significant player in European terms, modern IT make our peripheral location no problem. over half the population are located in the area and with new improved land access, growth in the maritime sector is inevitable"

"It has the critical mass to develop as a recognisable maritime cluster. but it will always be of iegional significance only, in a European context"

The agreement arguments have been divided into three threads of opinion. Thread A has again brought up the importance of the IFSC to the GDR and the whole Irish economy. The IFSC argument delivers that "yes" the GDR maritime transport sector could develop on the back of what already is a successful Irish financial cluster. Opinions raised in support of this also address the issue of niche specialisation, which could be maritime finance related or maritime service related i.e. banking and law and Geneva has been mentioned as a parallel that could be further investigated. In 2002 Bank of Ireland (BoI) joined the ship finance industry with had an initial expected portfolio of US\$200m ( $\$ 105 \mathrm{~m})$ of business on its books within 18-24 months with a longer term goal of US\$500m ( $\$ 262 \mathrm{~m}$ ) (Noble, 2005), however the portfolio nearly doubled in 2004 to US\$700m servicing 25-30 customers 
(Lloyds List, 2005). Opinion on appropriate fiscal support and incentives to help develop the cluster for the future pointed out that Ireland like its European counterparts, has the availability of the tonnage tax regime, European funding in terms of Marco Polo and various EU aids to the shipping industry (refer to Chapter 2) and from the domestic perspective Ireland has one of the lowest corporation taxes in Europe (IDA, 2007). The opinion in Thread B highlights that the country's population is growing which means more demand for goods and services involved to support transportation. The population of the GDR is expected to increase by over half a million persons in the period to 2021 and the GDR currently accounts for $32.9 \%$ of the population and projected to account for $40.7 \%$ of a total projection population of 5 million by 2021 (CSO, 2005). The importance of Dublin port was raised again in Thread C and despite Ireland's peripheral location in Europe, opinions did argue that it was a significant player in European terms. Meanwhile disagreement arguments will provide opinion that its importance is regional only and it does not have the presence of European ports and clusters such as Rotterdam and internationally like Singapore and Hong Kong. However there are far more ports and maritime clusters or potential small maritime clusters like Dublin in Europe than there are Rotterdam's. Opinion in Thread C discuss that Dublin as a maxitime cluster is a long away behind the London's/New York's in terms of maritime services. Opinion highlights that while ability to improve is there, Ireland is still of regional significance within a European context.

\section{Disagreement Arguments}

Disagreement Argument: Thread A

"Maritime activity in the Dublin region does not have the scale to be considered a strong cluster in international terms"

"Peripher'al nation, too remote and to small versus competing cluster's like Rotterdam and Singapore"

"Insufficient size due to its geography e.g. not a transhipment centre. lack of resident ship owning and ship management companies" 


\section{Disagreement Argument: Thread B}

"There may be potential but no political drive to make it happen, insufficient qualified people to make the development happen, insufficient education facilities. Too much competition from other recognisable clusters"

The disagreement arguments in Thread A are based on the opinion that the scale of maritime activity in the Dublin region is too small to be considered a cluster within an international sphere. Factors that support this are the remote and peripheral location of the country, lack of transhipment status and the recurring opinion on the lack of residence of ship owing and operating firms within the GDR. Opinion reflects comparison of the GDR cluster to that of major international and recognisable maritime transport clusters which is relevant in the context and importance to know and understand a cluster's major competitors.

The disagreement opinion provided in Thread B brings the issue of the lack of political drive to encourage the maritime transport cluster to grow in terms of future potential and status. While lack of political drive has been mentioned as an issue possibly hindering cluster development, so have insufficient education facilities and qualified people and the fact that there is too much competition from more recognisable international maritime clusters. As regards the opinion raised on education and trained personnel, this area will be discussed later on as the Delphi survey included questions on education and training. The opinion on the lack of political drive is in some way related to the next consensus (Round 2, Q4A) with regard to the promotion and development of the sector. Many industries will express that their government does not recognise "their" industry enough or provide what they consider as sufficient support.

The result from Round 2, Question 1 is an agreement result of $72 \%$ which can be considered as a reasonably confident agreement consensus. The main questions derived from the opinions proved by the panel members for the current statement include; 
1. What is Dublin Ports playing field on a European level? Compare Dublin Port to other European ports, but ports in a similar position to Dublin (i.e. smaller players).

2. What fiscal support and incentives are available to the industry and specifically Ireland? Are the current measures working? How does it compare to the rest of Europe?

\subsubsection{Round 2, Consensus 2}

The second consensus ranked $86 \%$ which is a medium consensus. $86 \%$ of the 22 returned responses for Round 2 believe that there is a lack of promotion and awareness of career options available for the maritime transport sector in Ireland.

\subsubsection{Round 2, Consensus 2 Analysis}

Of the 22 returned responses, 19 agreed, 1 disagreed and 2 were unable to comment. This question is not one of the original 17 questions asked in Round 1 as the question only entered in Round 2. The purpose of inclusion of the statement is two fold; there is a perception within the industry that there is little, if any, awareness of the industry to the general public. The second reason for the question is in accordance with Section 2 of the Delphi survey which addresses the aspect of labour supply for the maritime transport sector and the potential education and training available. It could be relevant to know if panel members agree that there is an issue with the labour supply for the GDR maritime transport cluster, and that perhaps a lack, if any, of the promotion and awareness of the sector may have a knock on effect in terms of available and willing labour supply. In terms of the placement of this question in Section 2 of the survey it supports the exploration of issues of training, labour and industry awareness and educational opportunities to service the requirements of the GDR maritime transport sector.

\section{Agreement Arguments}

Agreement Argument: Thread A

"This is common elsewhere as well: the maritime sector has a very low profile and as such is completely forgotten about. Not aware of any publications promoting careers in maritime transport" 
"There is awareness off jobs at sea but not in the onshore ancillary sectors"

"The maritime sector is not considered an interesting and challenging career" as is not promoted to any great degree nationally. Many people end up working in the sector by accident and not because of any prominence of activity"

"Lack of promotion and awareness of career options, but internet is available and websites such as the IMDO and the website of the Maritime College in Cork. Perhaps more could be done by CILT and IMDO to promote the sector"

"A dedicated website for' the sector would certainly help improve transparency and create healthier market awareness"

\section{Agreement Argument: Thread B}

"I believe the sector' is too disjointed to effectively' promote maritime career's.

"It should also be taken into consideration that the careers in the maritime sector are diverse and thus a unified approach may not be relevant. Why would you promote marine insurance via an emphasis on maritime transport, marine insurer's enter the general insurance market and then specialize"

"Industry organisations in the sector" do little to promote career options as they are more intent on profit margins and consider promotion as a cost with little or' no return - ver'y short-sighted"

Agreement Argument: Thread C

"It doesn't seem to have a significant profile despite the critical importance of ports and shipping to the economy"

"For an island nation with over' 97\% of the trade by sea, the maritime industry does not get a fraction of the promotion it should deserve by right; if a fraction of the 'razzmatazz' being ballyhooed for the Ryder' Cup was directed to an awareness/promotion, the marine industry would reap many folds - short time and in the near future"

Agreement Argument: Thread D

"Schools ignore the prospects of this industry; we are an island nation and government should promote the business in schools. school children are denied knowledge of this business."

"It would appear fiom the feedback that awareness starts at 3rd level which is not early enough"

"Little or no uptake on coul'ses following promotion"

There are a dominant number of agreement opinions for the current question; however panel members who returned a disagreement response and an unable to comment response did not provide statements of opinion. 
The threads of agreement opinion are similar but Thread A discuses the lack of promotion and awareness of the industry to the general public. Opinion indicates that while there is awareness of jobs at sea, the lack of awareness is more associated with shore based jobs within the maritime transport sector. There could also be an issue here with respect to a potential labour force to see a career path in the maritime transport sector beyond the stage of seafarer. Thread B opinion discusses more objectively some of the possible issues of such lack of industry promotion and awareness. Opinions highlights that the term "maritime transport" includes many different sectors and it perhaps would not make good sense to promote a sector such as marine finance or banking under the umbrella of "maritime transport". For areas of law, banking and finance, the individual would have a general interest in the core topic i.e. law and then specialise at a later stage in their career i.e. maritime law, although such specialisation is also directly related and dependent on the opportunities for such specialisation within the market. It is also discussed that many of the current individuals employed within the maritime transport sector "fell into" the sector as opposed to wishing to work in the sector and setting out to qualify and enter the industry. This however can be linked to lack of awareness of the industry and the possible lack of clear third level education process and progression. The industry is perhaps not as an attractive option to potential graduates as other sectors such as business, law and the sciences. In the maritime transport industry in Ircland individuals would have entered and worked thoir way through the ranks; however in contemporary Ireland with almost full employment and free 3 rd level education there are more attractive options for the younger workforce.

Thread D highlights the lack of promotion in schools and that any awareness appears to be established only at third level. However the IMDO have launched the "Follow the Fleet" programme which is a modern hi-tech version of the original scheme developed in the $1970 \mathrm{~s}$ and $80 \mathrm{~s}$ in which school children could follow the progress of the Irish merchant fleet. The aim of the scheme in the 1980s and today is to increase maritime awareness 
and the trading activities of Ireland's merchant shipping among school children (IMDO, 2007). While in the first instance there are many organisation and associations present to represent certain maritime transport sectors (Irish Ports Association, Chartered Institute of Transport \& Logistics, Irish Freight Forwarding Association, IMDO, Irish Exporters Association, Irish Chamber of Shipping etc) as opinion cites a perception of a lack of co-ordinated drive to promote the whole industry. One issue is certain that in context of the significant importance of the ports and shipping to an island nation like Ireland the maritime transport sector appears under-promoted and marketed to the general public and the potential workforce. However any promotion drive must be relevant to the prospect of education and employment opportunities.

The current statement and consensus is that $86 \%$ of the panel membership agreed that there is a lack of promotion and awareness of the industry and this does have an effect in terms of the general perception of the industry and its importance to the Irish economy and as a career option to the general workforce. The current statement was placed in Section 2 in the second round to support the questions on labour supply and education and should be discussed within the results and opinion for those statements. The current question reached consensus in Round 2 and therefore did not enter Round 3. The questions regarding the labour supply and educational opportunities entered the third round for further clarification and therefore will be discussed below.

The result from Round 2, Question $4 \mathrm{~A}$ is an agreement result of $86 \%$ which can be considered as a confident agreement consensus result and the highest consensus achieved in the whole of the Delphi survey. The main questions derived from the opinions proved by the panel members include;

1. What is the best way best to promote the maritime transport industry in Ireland? Should promotion of the industry be based on an individual sector approach, or would a collective maritime transport approach be more effective? 
2. What is the effect or perception of the Irish maritime industries in terms of the economy, importance and employment to the Irish people?

\subsubsection{Round 2 Consensus 3}

The third consensus ranked at $72 \%$ which is a low consensus. $72 \%$ of the 22 returned responses for Round 2 believe that business and firms in the greater Dublin region have the advantage of access to cluster knowledge.

\subsubsection{Round 2, Consensus 3 Analysis}

Off the 22 returned responses, 16 agreed, 5 disagreed and 1 was unable to respond. In Round 1, the question achieved an agreement result of $49 \%$ and through repetition of the question in Round 2 and through the provision of feedback from Round 1 the question increased in agreement by $23 \%$ to $72 \%$. The importance of this question was to identify if the panel members as participants within the GDR maritime sector felt the benefit of access and availability of cluster knowledge. In the first instance the statement reached a consensus of $72 \%$ and therefore can be taken with reasonable confidence that such cluster knowledge does exist as the opinions provided indicate the importance of such knowledge. Literature on clusters (refer to Chapter 2) discusses the importance of, and access to such knowledge in the concept of a cluster. The panel members recognise and identify that such "floating" knowledge is present to some degree within the cluster however they do not address if the access of such knowledge is easily available and accessible to new market entrants. For any future development of the GDR cluster, note should be taken of the importance of cluster knowledge to all players within the market and incorporate strategies that may encourage the amount of, and access to that knowledge base.

\section{Agreement Arguments}

Agreement Argument: Thread A

"The firms in the greater" Dublin area do have an advantage by virtue of the larger number/rolume of services piovided resulting from the disproportionate population in the greater Dublin area compared to the rest of Ireland" 
"Yes, but to a diminishing degree and essentially due to scale of activity in each sub sector"

"Located in the port centre is a good location and from there it is easy to monitor action in the sector"

"Co-location and proximity generate contacts and networks for earlier" communications"

"Better" access to market information and awareness of industry developments"

"Meetings are organised by chance happenings to a greater extent in Dublin. The grapevine is a potent source of information"

"Regular" access through formed and informal channels offer' advantages to those companies that locate in the Dublin region"

"Due to current cluster status - ves. There is a particularly active grapevine and exchange of information. At a casual basis would like to see more formal get togethers and exchange of info, i.e. seminars. Unfortunately commercial pressures usually take precedence."

"Dublin is where it is happening, just look at relevant sectors in the golden pages - most listed as Dublin based. Dublin port has well in excess of twice the throughput of cork and Shannon. In internationally traded goods Dublin handles about $75 \%$ of both containers and ferry freight from the Republic, if you are not in Dublin then growth potential is limited"

"Physically see and hear what happens"

\section{Agreement Argument: Thread B}

"There are advantages in being close to the centre of maritime activity. However modern communications reduce the level of advantage.

"Yes, however the speed of modern communication, including the internet, diminishes the significance of the cluster" in that sense"

The agreement arguments have been divided into two main threads of opinion. Thread A mainly identifies that there is a benefit of access to cluster knowledge due to the co-location of business units within the GDR. However opinion does discuss that this may be due to the disproportionate population and the dominant number of people, customers, suppliers and clients based within the GDR. The port location/region has been used as an example of an advantageous location in which to receive the cluster knowledge and many opinions have highlighted the strong presence of the "grape vine effect". Again similar to that of cluster literature, opinions discuss the advantage of chance meetings, both formal and informal which 
is suggested to happen more regularly within the GDR through the regular access of information channels. The retuned opinions emphasised the importance of Dublin and the GDR region as a whole and it is perhaps difficult from a cluster perspective and from the opinions provided not to underestimate the importance of the region, the port and the city's effect on each other.

However the current question is with respect to cluster knowledge, but the question through the responses provided is drawn back to the importance of the port as one opinion highlights that $75 \%$ of traded goods for the Republic are serviced by Dublin Port. While the demographics of the city may provide an important knowledge base and economic pull for certain maritime transport firms i.e. law and insurance for example, the port has the same effect for certain maritime transport firms i.e. shipping and freight. However opinions have clearly identified that cluster knowledge exists, and players within the industry see a clear benefit of the "grape vine effect" due to co-location and co-proximity as key drivers of networks of communication. However the Thread B agreement arguments are similar to those of the disagreement arguments in Thread $\mathrm{A}$, in that for certain business units the importance of knowledge is reduced by the technology that is available such as the internet, email, fax and phone, and that fundamentally no information or access to information is truly available $24 / 7$.

\section{Disagreement Arguments}

Disagreement Arguments: Thread A

"With email, internet and mobile communication there is no significant advantage to being in Dublin when it comes to obtaining industry knowledge"

"No information is available $24 / 7$ on a website etc. no advantage"

The disagreement opinion will not be elaborated further as it is similar to the agreement opinions in Thread B with respect to modern communications reducing the advantage of being located inside the GDR creating a so called death of distance. However the importance of early access to cluster knowledge may be more important to some sectors than 
others; however there is also an issue of knowledge creation and the diffusion of that knowledge through a cluster.

The result from Round 2, Question 5 is an agreement of $72 \%$ which can be considered as a confident agreement consensus result. The main questions derived from the opinions proved by the panel members include;

1. Address the importance of the pull of the port and the city in terms of the clustering of the GDR maritime transport sector. How does the access and availability of cluster knowledge support this? Is access to cluster knowledge more important to specific sectors?

2. Identify the benefits of cluster knowledge to the GDR. How can the creation of cluster knowledge be improved and diffused more efficiently through the cluster?

\subsubsection{Round 2 Consensus 4}

The fourth consensus ranked at $77 \%$ which is a low consensus. $77 \%$ of the 22 returned responses returned for Round 2 believe that GDR has high exit barriers and firms are "sticky" to the GDR location.

\subsubsection{Round 2 Consensus 4 Analysis}

Of the 22 returned responses, 17 agreed, 3 disagreed and 2 were unable to comment. While other statements have addressed issues such as the access to cluster knowledge and the possible importance of the GDR location, Section 4 of the survey discusses the area of cluster theory related to the possible entry and exit barriers to a cluster. The opinions in some cases may be similar to those of the opinions returned for Round 2, Question 5 which addresses access to cluster knowledge which can be both a cluster entry and exit barrier. Also Round 1, Question 6 discuses the possible advantages of being located within the GDR. The purpose of the questions in Section 4 is to ask the panel if they can identify with any potential barriers to the GDR maritime transport sector. In Round 1 the statement reached a disagreement result of $41 \%$ which reverted to an agreement result of $77 \%$ in the second round. 


\section{Agreement Arguments}

Agreement Argument: Thread A

"The very fact that the presence of the maritime transport firms is still within the greater Dublin area, even with the very high office/real estate, and fuel costs, etc, is a testimony to the fact the firms that are in want to be in to take benefit of geography. However, the sole factor of 'geography' is somewhat diluted with the huge advantages and influences of the improved IT sector/capabilities. The simple fact is that there are huge advantages for the transport sector firms to still have a presence within the greater Dublin region"

"As determined by market forces, i.e. not a choice"

"Economic activity dictates the location where business delivers, the greater" Dublin area is the centre of economic activity in Ireland"

"It is easier to locate in the cluster zone. Dublin is the magnet due to the amount of trade it generates and muster's outwards"

"Dublin is where most of the business in the country is done. It is usual for companies to want to be located where their customers are located. Companies are staying because they have to, not because they like the place. Remote service provider's can and have moved out of the region the "hands on" providers have stayed"

"No one comes near to Dublin's prominence, biggest market: 50\% of the population living within $80 \mathrm{~km}$ of Dublin = demand, to service this market from an alternative cluster/area is uneconomical"

"Sheer" volume of business means that to leave the sector" would mean a decline in work and income. Key players in the Dublin cluster mean a greater stickiness for the smaller operator's"

"Dublin is where the opportunities are, shipping agents who were located up town have now moved into the port estate or environment because traffic was making life difficult for them. Many companies have multiple locations around Irish ports but their main focus remains in Dublin"

Agreement Argument: Thread B

"A combination of staff, business relationships, and tax issues means that firms, business and organisations are sticky to the Dublin location"

"Yes, but not due to the stickiness of the cluster, i.e. the ports and shipping. are based on tradition, it would be as difficult for a Dublin firm to relocate to Cork. and a Cork firm to relocate to Dublin"

"Dublin cluster' is small. however the Dublin region contains key players and their presence in itself constitutes an exit bar'ier' to firms operating a maritime transport business in the state" 
"Sheer population dictates the cluster which is disproportionate to the facilities that exist, a relief/secondary port should exist to compliment the already stretched resources, and it is sticky but illogically"

The core of the opinion in Thread $A$ is with respect to the powerful pull of the city and port despite high costs such as land, rents, fuel and labour, and as one panel member described the benefits of the GDR location as a "huge advantage". Firms still wish to locate inside the GDR boundary despite the benefits of modern technology which may dilute the need. However the GDR location is of principal importance for some sectors (again the similar argument of the pull of the port for sectors which have a direct business relationship with port activities). The opinion provides that market forces dominate the GDR location and firms wish to be in proximity to their customer base, which is especially prevalent when $50 \%$ of the population are located within $80 \mathrm{~km}$ of Dublin city. Therefore opinion raises the question why would you wish to service this market from another location? Dublin can be argued as the trade magnet in terms of capital city and major port facility and opinion highlights that this affords stickiness for smaller players and therefore provides a clustering force. The opinion did point out that remote service providers have moved out of the GDR but the hands-on providers stayed. This could indicate that firms in certain sectors could exit the cluster as barriers for that firm type may not be as high. However for port users there is an exit barrier that cannot be overcome as they require the services of the port. This is a positive aspect for a maritime cluster because the stickiness of port is significant for enticing less port dependent firms to stay located in the city despite high costs. A port is already described as a text book case of clustering; could a port facility be argued as an example of an impervious cluster exit barrier for potential maritime transport clusters?

Thread B opinions are more specific and give examples of barriers as opposed to the dominant opinion in Thread A which addresses the issue of market forces, demographics and the port as agents of cluster stickiness. Opinions illustrate factors that they consider as exit barriers such as labour and access to labour, business relationships (which could also argued as an 
associated factor of the "grapevine effect") and access to cluster knowledge. However the reasons for the stickiness of the GDR region could be different depending on the sector. From the arguments provided in Thread A such as the issue of market forces and the agglomeration of firms, and from previous statements and opinions on the importance of the city, the level of stickiness for certain sectors may be more attributable to the city itself while certain sector stickiness may be more attributable to port activities. One opinion was that the stickiness was not cluster related but port related which adds to the questions already raised about the dichotomy between the importance of the capital city and the importance of the principal port. The importance of Dublin and the GDR is continually recognised among the panel members and opinion discuses that while the pull of the capital city is strong as it holds dominant market players inside its boundary which in itself provides an exit barrier for other firms. Moreover, to be close to larger key market players is an important stickiness factor for smaller firms.

\section{Disagreement Arguments}

\section{Disagreement Arguments: Thread A}

"Don't agree with stickiness, if firms provide an efficient and effective service to the clients/customs, they will retain the customer's if they move"

The disagreement opinion in Thread $A$ argues that if a firm provides a high quality service it will take its customers with the firm, if the firm was to relocate. This of course is true in respect of competition in that the best service will win the customers: however as already discussed certain sectors are sticky to the Dublin location because of the port activities and because of the pull of the city. From the opinion provided from the panel for the current question it is clear that there are other benefits in locating near the city of industry and trade activity.

The result from Round 2, Question 7 gave an agreement result of 77\% which can be considered as a reasonably confident agreement. The main questions derived from the opinions proved by the panel members include; 
1. Identify the GDR maritime transport sectors high exit barriers. Examine their effect on cluster stickiness, specifically the effects of the port, the effects of the city, the effects of demographics and the effect of cluster knowledge and communication.

\subsubsection{Round 2 Consensus 5}

The fifth consensus ranked at 77\% which is a low consensus. $77 \%$ of the 22 returned responses for Round 2 believe that if the GDR were a highly competitive dynamic environment, Irish businesses and firms would be in a better position to compete internationally.

\subsubsection{Round 2 Consensus 5 Analysis}

Of the 22 returned responses, 17 agreed, 4 disagreed and 1 was unable to comment. In Round 1 the statement reached an agreement result of $65 \%$ which has increased by $12 \%$ to an agreement consensus of $77 \%$. This question is part of Section 5 of the Delphi survey. The first question in Section 5 reached a consensus of $73 \%$ (in the first round) that the GDR maritime transport sector has a strong level of internal competition. If the consensus reached had been a disagreement consensus it could suggest that the sector did not have a strong level of internal competition which could also affect a firm's ability to compete sufficiently in the international market place. If an indigenous firm is not competing in a vibrant and highly competitive market domestically then how can a firms be expected to compete against international companies whose home market are vibrant, dynamic and highly competitive?

\section{Agreement Arguments}

Agreement Arguments: Thread A

"Maritime Transport Ireland plc, is at the tail end of a 'supply-chain' of services to mainland Europe; this supply chain passes through the UK which has by geography and history a better position and a better set of supply logistics available to not only exploit the market trends but also in a better' position to offer 'commercial deals' to break even in the 'carrier' inlout journeys"

"Intenational' for Ireland has always meant UK and very lately West Europe (South of Poland). This was historically due to the proximity of 
business, currency of business (Pound sterling) and the lack of market penetration until Haughey/Reynolds forcefully forged links to EEC (EU)"

"Most certainly in the field of agency given the level playing field"

"Rates/ service/provider' have improved dramatically in the last 10 years, so has the use of e-commerce in Ireland"

Agreement Arguments: Thread B

"Our experience would be that the vast majority of maritime transport business and firms have to compete sufficiently in the international market place as shipping is a truly a international business"

"Maritime business is international trade, not to be competing means you will not survive"

"All the main shipping lines in the world either have an office or' an agent in Dublin; international haulers compete on international markets"

The agreement arguments had two main threads of opinion and the opinion in Thread A discusses the disadvantages of Ireland's peripheral location within Europe in that the supply chain passes through the UK and thus the $\mathrm{UK}$ is in a better position to exploit its benefits to the market. Ireland in one sense historically has sat behind Britain in many ways and one opinion highlights that at one stage "international" for Ireland was the trading partner of the UK. The opinions provided in Thread A do not give much insight into this question but it does emphasize the growth and improvement of Ireland in terms of rates, services and provider's. Ireland as a country generally has evolved from being the poor man of Europe to an open and successful economy. The opinion of Thread B incorporates more reality to the discussion in that maritime business is an international trade and therefore requires a presence on international markets.

\section{Disagreement Arguments}

Disagreement Arguments: Thread A

"The Dublin region is not of a scale high enough to be considered to have any effect on the international market place"

"Believe that there is scope for" development in this area but opportunities may be limited partly due to the size of some of the Dublin based business. There must be scope however in banking, insurance and perhaps legal sectors"

"Major' maritime centre in Europe is London and Rotterdam" 


\section{Disagreement Arguments: Thread B}

"In general companies are willing to compete in the international market place. We prefer in the main to stick to what we know in Ireland and not risk the market"

The disagreement arguments have been summarised into two threads of opinion. The opinion of Thread A is that Dublin does not have the scale of activities to have an effect on the market internationally and that major maritime centres from a European perspective are the maritime clusters of London and Rotterdam. Through the analysis of the opinion provided for in various statements it was regularly highlighted in opinions of the lack of residential presence of shipping owner/operating activities. Similar again to re-occurring opinion was the statement of the possible potential for the maritime service sectors of law, finance and insurance. The opinion in Thread $\mathrm{B}$ discusses that while companies may be willing to compete internationally there may be a tendency for firms to stick to the Irish market and limit risk by operating in a market they know. However maritime transport is an international market by its very nature and so firms must in certain instance compete internationally.

The result from Round 2, Question 8 is an agreement result of $77 \%$ which can be considered as a reasonably confident agreement consensus result. The main questions derived from the opinions proved by the panel members include;

1. Evaluate the competitiveness of the Irish maritime transport sector from a collective maritime cluster approach and incorporating individual sector competitive analysis.

\subsubsection{Round 2, Consensus 6}

The sixth consensus ranked at $72 \%$ which is low consensus. $72 \%$ of the 22 returned responses for Round 2 believe that the greater Dublin region has a sufficient variety and diversity of maritime transport firms.

\subsubsection{Round 2, Consensus 6 Analysis}

Of the 22 returned responses, 16 agreed, 4 disagreed and 2 were unable to comment. In Round 1 the statement reached an agreement result of $59 \%$ 
which has increased by $13 \%$ in Round 2 to an agreement consensus of $72 \%$. The current question is part of Section 6 of the Delphi survey which includes three questions regarding the firm structure, density and variety within the maritime transport sector. The set of questions can be related slightly to the questions regarding competition as the more numbers of firms within a sector the greater effect on the levels of competition. Variety of sectors is important for clustering as it affords a level of protection to the cluster as opposed to having a cluster relying on mainly one or two core sectors of industry.

\section{Agreement Arguments}

Agreement Arguments: Thread A

"There is sufficient variety and diversity of maritime transport firms within the greater Dublin region to form the nucleus of a very successful Dublin cluster and still have enough energy to participate as an equal partner with the Belfast and Liverpool cluster" "

"We have sufficient transport firms as there seems to be plenty of firms available to compete and no reports of any deficiencies, if there were gaps they would have been already filled"

"Competition in all areas is fierce and service levels must be up to scratch to keep customer's on board"

"Greater" diversity in the market than most people think"

Agreement Arguments: Thread B

"For now: the trend is bigger" is better' and amalgamation and takeovers will tend to reduce the variety as time goes by"

"Short ter'm only; the consolidation process of rationalising for scale economies is steadily reducing the number' and diversity of specialise firms within the sector; this coupled with the age profile of those with hands on experience is likely to alter the current balance within the next 5 -10 years"

Agreement Arguments: Thread C

"Business opportunities in the maritime sector ensure that sufficient competition exists. just look at the trade directories and you can see that there are plenty of options in all disciplines. Believe that this will continue however' ship owners would be an exception"

The agreement consensus has been divided into three main threads of opinion. The opinion contained in Thread A is that the GDR has a sufficient 
number of firms and that the diversity of the firms present is perhaps greater than what it is actually perceived. The opinions in Thread A are perhaps reflective of economic theory in regards to markets and the supply and demand of services, and therefore if there are gaps it is logical that they would be filled by market forces. Round 1, Question 6 returned an agreement consensus of $72 \%$ that the GDR has a strong level of competition and this is supported in opinion provided in Thread A, as responses have indicated that competition is fierce and firms have to fight hard to keep their customers. However as the survey involved panel members from different maritime transport sectors, the degree of competitiveness may differ between sectors.

Thread B opinion addresses the issue of diversity of firms from a different perspective in that while there may be sufficient diversity of firms at present, the process of amalgamation and consolidation due to of economies of scale is having an impact on the variety and specialisation of firms. Opinion did highlight that the consolidation process and combined with the age profile of current experienced industry personnel could alter the balance of such diversity. The comment on the age profile is linked to the fact that many senior members of the industry entered at a young age and worked their way up through the ranks and when such senior personnel retire there will be a gap in expertise. The Thread $\mathrm{C}$ opinion is very similar to that of Thread $A$ in that it recognises that there are sufficient business opportunities and sufficient firms to take advantage of business opportunities that are available. However the justification for placing this response in an individual thread is due to the opinion that while the panel member considers that there is sufficient diversity of firms and plenty of business options in different disciplines in maritime transport the exception are with respect to shipowners. 


\section{Disagreement Arguments}

\section{Disagreement Argument: Thread A}

"Only sufficient to meet current domestic demand, if the sector' were to expand internationally then certain disciplines would need to be addressed e.g. chartering, ship sale and purchase"

"Areas such as finance and insurance are under represented"

"Not sufficient major" international firms involved"

\section{Disagreement Argument: Thread B}

"Weakness in the variety of specialized maritime sectors. currently companies have to rely on expertise outside the country i.e. $3^{\text {rd }}$ level education, finance, leasing; surveror's, security, hydrographical expertise, port planning"

"Not enough diver'se participants, the amount of available business does not warrant that many firms operate profitably"

Disagreement Argument: Thread C

\section{"Little or" no international shipping expertise"}

"To have a maritime industry you need ship owner's to be located in Ireland. the same with operator's/manager's"

The disagreement arguments have been separated into three threads, Thread A disagrees that there are a sufficient variety and diversity of firms within the context that it is only currently sufficient to meet the demand due to market forces, and if the cluster was to expand, certain areas would have to be developed. The issue of under representation in terms of finance and insurance was again raised. Opinion in Thread B argues that there is a weakness in terms of the variety of specialized maritime sectors and that the drive for such diversity is not there due to the lack of business opportunities to make a viable return in niche sectors. Opinion argues that a lack of niche sectors have forced industry to pull in expertise from outside the republic and when addressed in such a context, perhaps the GDR does not have sufficient diversity and variety in certain sectors when firms have to look outside a cluster for business solutions. Thread C disagreement opinion reverts again to the similar opinion in the agreement arguments seen in Thread $\mathrm{C}$ in respect of the need for more shipowners and operators 
to be located in Ireland as opinions provided indicate that there is little international shipping expertise.

The result from Round 2, Question 9 is an agreement result of $72 \%$ which can be considered as a reasonably confident agreement consensus result. The main questions derived from the opinions proved by the panel members include;

1. Are there gaps in the market, does market forces dictate that there are any gaps? Are the gaps related to the port cluster or the potential of a maritime transport service cluster?

2. Identify niche areas in the maritime transport sector which could be developed. Could the maritime services of finance, law and insurance be further developed? Would developing such areas be realistic in terms of the close location of Dublin to the London maritime service cluster?

\subsubsection{Round 2, Consensus 7}

The seventh consensus ranked at $81 \%$ which is a medium consensus. $81 \%$ of the 22 returned responses for Round 2 believe that the maritime transport sector in the greater Dublin region would perform better if had a greater mix and diversity of maritime transport firms.

\subsubsection{Round 2 Consensus 7 Analysis}

Of the 22 returned responses, 18 agreed, 4 disagreed and 0 were an unable to comment. In Round 1 the statement reached an agreement result of $54 \%$ which has increased by $27 \%$ to an agreement consensus of $81 \%$. The current consensus and the previous discussed consensus (consensus, Round 2 , number 6) are part of Section 6 which is related to the context of a clusters mix, weight and density of firms. Round 2, Question 9, consensus has already concluded that that the GDR has a sufficient variety and diversity of firms at $72 \%$, however the current consensus agreement at $81 \%$ that the GDR would perform better if there were a greater diversity of firms. 


\section{Agreement Arguments}

Agreement Arguments: Thread A

"There is more than sufficient numbers to form a good healthy greater" Dublin maritime cluster, unless again the numbers issue is a criterion"

"The more competition on the sector" the more activity there should be"

"Gr'eater" competition would bring greater efficiency and leaner prices"

"That is true of everywhere there is always greater" variety to be had"

"Greater mix and variety will inevitable lead to greater competition and therefore better performance to gain competitive advantage"

Agreement Arguments: Thread B

"Only in terms of diluting the existing monopolies that have capital resources to restrict access to limited public facilities at the port and thereby create common user conditions"

"Additional companies provide greater' competition whether' it is important that there are not too many companies or they will collapse due to lack of barriers"

"Competition is always good and the quality service provider inevitable rises to the top, this ensures that the best survive, however if the number of service provider's increases to a level where the market is fragmented then the performance of service levels will fall"

Agreement Arguments: Thread C

"There are sufficient firms in many sectors, but the shortage of road haulage for the ever increasing LO/LO business via Dublin is worrying. The road infrastructure on the region needs to be urgently upgraded to allow for new entrants for' the haulage sector' who might see an economic future"

"Attracting more international companies is critical to development of the maritime cluster"

"But the mix will not change unless shipowners and operators are attracted to the region"

The agreement arguments have been divided into three key threads and again some opinions will be similar to those of the previous consensus as both statements are included in Section 6 of the Delphi survey. The synopsis of opinion in Thread $A$ is a positive one in terms of more players within the market will lead to greater competition, leaner prices and greatcr efficiency and ideally encourage firms to perform better. Opinion in Thread A expresses that while a greater mix would be better for all concerned there 
currently is sufficient firms for a maritime transport cluster. However the opinion does make reference to the issue of the size of the cluster with respect to numbers of firms and raises the question again, is there an optimum size of firms for a cluster? Opinion also highlighted that greater diversity of firms is something that all sectors wish to have, although the reality may be subject to variables of competition, access and the potential for viable economic returns. The opinion in Thread B is in agreement that a greater diversity and variety of firms would be better for the GDR, however the opinion is perhaps a more cautious one. A cluster having low entry barriers is positive as it enables firms to enter the market, increase diversity and competition; however the opinion from the panel has raised the point that too much competition induced by low barriers of entry can also have a negative effect on the firms already competing within the cluster. Strong competition will ensure that the best service providers will survive the competitive market, however if barriers are too low allowing increased access and entry of firms into the market could lead to a fragmented service and a fall in the quality of the overall service provided. Thread $\mathrm{B}$ also brought back the response about existing monopolies and that more firms could have the effect of diluting such monopolistic tendencies by breaking up the precedence supposedly held by certain firms. This opinion is held in context to the port and the restricted access to certain facilities. Thread $\mathrm{C}$ agreement opinions discuss that there are sufficient firms in many of the maritime transport sectors but recognises a shortage in road haulage for the increasing Lo/Lo trade with specific reference to Dublin. The quality of the physical infrastructure has also been discussed as a possible entry barrier for haulage firms entering the market in that the physical infrastructure would have to be greatly improved to entice such firms into the sector.

Thread $\mathrm{C}$ remarks again that attracting more international firms is "critical' from a cluster developmental perspective and an interesting opinion provided is that the current mix and weight of firms within the GDR will not alter unless more shipowners and operators are attracted to the 
GDR. This could imply that a rise in shipowners and operators would have a positive knock on effect for other services and create greater demand. The interesting aspect of this comment is that it could be a supportive argument of the GDR as a port cluster with the beginnings of a maritime transport cluster. Basically if there were an increase in shipowners and operators would this have a direct effect of increasing the business potential of maritime lawyers, insurance and financiers? Are certain sectors of the maritime transport cluster directly related to the critical mass of core operations, such as shipping services? Is the relationships between such proposed dependent sectors (i.e. law, banking etc) linked to the requirement of shipowners and operators and their direct operational relationship with the port activities, which in effect creates a chain of dependent relationships, i.e. port opens, shipowners and operator need port and need to be located near port, rise in number of core port users helps develop a market for services such as law and banking. Therefore perhaps it could be investigated that a way to develop a maritime transport cluster is to increase critical mass of port dependent users. This argument could be true in a traditional sense with modern communications abilities and the fact that a maritime service cluster like London can exist without core port activities. However it should be noted that the London service cluster historically developed on the back of a well established and traditional maritime activities.

\section{Disagreement Arguments}

Disagreement Arguments: Thread A

"There is sufficient presence of operator's with enough competition to ensure fair market rates in nearly all instances. More operators may create problems if they "buy" business in certain areas and below cost levels"

"It is difficult to judge the saturation level in any market. Greater variety of" the sector does not mean an increase in qualitr of service: it certainly increases the cost of competition"

"There will not be adequate space to cater" for increased competition in the terminal handling sector in Dublin port, the advent of Bremore port would be a positive development for the country in general" 
Disagreement opinions argue that there are a sufficient number of firms with sufficient competition with the result of fair rates for the players concerned and while many panel members will agree that more players in the market will benefit the GDR cluster, disagreement opinions are cautious in that at some stage there is an optimum level of market saturation in that too many players can have a negative effect. Opinion highlights specifically that terminal handling is an area that cannot cater for increased competition in Dublin port and recognises the potential port development at Bremore as a potential benefit to the country.

The result from Round 2, Question 10 is an agreement result of $81 \%$ which can be considered as a reasonably confident agreement consensus result. The main questions derived from the opinions proved by the panel members include;

1. Identify entry barriers to the GDR maritime transport cluster. Evaluate how lowering entry barriers to the GDR maritime transport cluster could both positively and potential negatively effect the GDR maritime transport cluster.

2. Investigate further the opinions on the monopolistic behaviour in certain sectors of the GDR maritime transport sector.

3. Investigate if certain sectors (i.e. shipping services and ports) provide a greater clustering force in terms of maritime clusters when compared to other maritime transport sectors.

\subsection{Consensus Achieved Round 3}

In round 3 of the Delphi one consensus was achieved.

\subsubsection{Round 3, Consensus 1}

The consensus in Round 3 ranked at $72 \%$ which is a low consensus. $72 \%$ of the 18 returned responses for Round 3, Question 7 do not believe that the GDR maritime transport sector has a high level of trust.

\subsubsection{Round 3, Consensus 1 Analysis}

Of the 18 returned responses, 3 agreed, 13 disagreed and 2 were unable to comment. In Round 1 the statement reached a disagreement result of $41 \%$, in Round 2 the statement reached a disagreement result of $59 \%$ and finally 
the statement increased by $13 \%$ to reach a final agreement consensus of $72 \%$

\section{Agreement Arguments}

\section{Agreement Arguments: Thread A}

"It is difficult to be definite here; high levels of trust exist between haulers/freight forwarders/ shipping lines and their agents. All have a part to play in shipping goods and need to be able to trust each other. However other elements such as ferry services and shipping lines operate in a highly competitive business. On a personal level co-operation exists between them especially on the transfer of innocent information"

Our sector indicates that there is a high level of trust between firms.

The agreement arguments for the present consensus have been summarised in one thread which indicates that the issue of trust or mistrust within the sector could be dependant on the individual sectors. The opinion highlights that certain sectors are trustful due to the nature of their work and the necessity of their interaction in order to transport goods. In effect certain sectors need each other to some degree with helps to foster levels of trust due to their obligatory business relationships. Alternatively firms in highly competitive markets who perhaps do not require obligatory business relationships to conduct their role within the market may be more mistrustful. The agreement opinion discusses that high trust exists between hauliers, freight forwarders and shipping lines; however the ferry sector was mentioned as a very highly competitive sector and although co-operation exists for the collective purpose of general innocent information. However it is not difficult to conceive that firms in a highly competitive sector may be mistrustful to each other.

\section{Disagreement Arguments}

Disagreement Arguments: Thread A

"Evidence from previous responses would indicate a lack of trust, particularly with the bigger companies in the market"

Disagreement Arguments: Thread B

"Competitor's are generally distrustful of one another" and in a limited market this is even more acute. 
"Cut throat competition does not empower trust; however there are exceptions to the rule"

"No, too much competition for business"

"It is a competitive environment and companies cannot affor'd to trust competitors. Information is often too important to be shared"

"Quite the opposite - mistrust is prevalent but cloaked as heavily competitive scepticism"

\section{Disagreement Arguments: Thread C}

"The sector is very competitive, good faith yes, but tr'ust with any internal information amongst competitors would dilute the business advantage and our edge in an increasingly tight market."

"No trust between competing companies. Companies connected up and down stream in the supply chain must have trust on the basis of there survival"

"No. trust only extends to companies who are not competing, or are not perceived as future competitors"

The disagreement opinion were summarised into three main threads of opinion. Opinion in Thread A refers to the presence of mistrust due to responses retuned from panel members through Round 1 and Round 2 and specifically refers to the mistrust with bigger companies. The opinion in Thread B primarily discuses low trust levels associated with high levels of internal competition and that a limited market can reduce trust to even lower levels. The opinion from the panel is that a highly competitive market does not encourage trustful relationships and that such trustful actions are not generally a courtesy directly competing companies can afford. However one opinion did highlight that such mistrust as illustrated by many of the opinions cited is just a face for competitive scepticism. This does lead to the question of the right level of trust and what that level should be and in terms of co-competition firms should be able to protect their business but also support clustering characteristics such as good trustful business relationships.

In Thread $\mathrm{C}$ the opinion is that yes there are low levels or no trust within the sector, however the opinion elaborates in terms that such low trust levels is with respect to competing companies and as cited in the agreement opinion. There is trust with firms that are linked and connected up and 
down the supply chain who need each other for their survival and companies that are not directly competing with each other do not have such trustful relationships. Opinions discuss that while trust is poor there is a positive element of good faith and argues that trust with respect to internal information between competitors could possibly affect a company's market edge which is increasingly important with firms that operate in a cut throat market. This again would refer to the question on an optimum trust level in which firms can protect business but aid clustering by behaving and engaging in a trustful manner.

The result from Round 3, Question 7 is an agreement result of $72 \%$ which can be considered as a reasonably confident agreement consensus result. The main questions derived from the opinions proved by the panel members include;

1. Is the optimum level of trust for a cluster/sector? How can a trust level within a sector be measured? What can be done to encourage trust?

\subsection{Non Consensus Statements}

The Delphi survey achieved a final total of 11 consensuses with a further 8 statements that did not achieve any level of consensus agreement. The purpose of the current Delphi is one of exploration with regard to GDR maritime transport sectors clustering potential and therefore even though eight questions did not reach any level of consensus, the opinion provided through the rounds can provide some information on the subject matter for future research and clarification. The following analysis will provide a brief discussion of the questions that failed to reach agreement consensus and will be discussed in context of their relevant sections within the survey.

\subsubsection{Section 2}

In Section 2 the panel were asked if they believed there was a lack of sufficient onshore labour supply for the maritime transport sector in the GDR. The statement had a majority agreement result of $49 \%$ in the first 
round, a majority disagreement of $50 \%$ in the second round and majority agreement result of $50 \%$ in the final round.

\section{Agreement Arguments}

\section{Agreement Arguments: Thread A}

"Sufficient, but not attractive to graduates, most people "fell" into the industry and worked up the ranks"

"In recent years positions within the liner agency, road transport, port worker's sectors etc have been filled by worker's from Eastern Europe. Irish workers tend to look for opportunities in other industries. This may well be a major trend long term and the maritime sector may well become increasingly dependent on overseas workers. As the eastern European economies develop we may face severe shortages in the future"

\section{Agreement Arguments: Thread B}

"There is a deficiency to fill positions in midrange i.e. 2 to 4 years experience in mid management level. Plenty of foreign nationals looking for low level work despite their qualification. Language difficulties pose a problem when customer's service positions need to be filled"

"Lack of suitable qualified people in ship management and operations and international shipping consultants and in ship finance personnel due to the infancy of this sector in the Dublin region and Ireland as a whole"

"Great difficulty in recruiting competent and trained personnel for accident claims and investigation, surveying and loss adjusting. Many people. but with poor and insufficient training, knowledge and expertise"

"I think that finding adequate personnel in even day to day agency vacancies is difficult, pay is generally poor compared to other sector's of industry and conditions are unsocial and becoming even more so with $24 / 7$ working the normal scenario"

\section{Disagreement Arguments}

\section{Disagreement Arguments: Thread A}

"Not enough, but increase in the profile of the cluster' would encourage entry" of labour from indigenous sources and attract foreign nationals with appropriate skill and experience"

"Reliant on immigrant workers with little or no skills and port labour' continues to be a high cost"

"Difficult to recruit trained staff within certain disciplines"

"I do believe that there is no lack in the onshore labour' supply" 
"No evidence of unfilled vacancies and if there were a shortage of skilled onshore labour the wage rate would be driven upward and the labour' would be forthcoming"

\section{Disagreement Arguments: Thread B}

"Adequate number's of people but inadequate numbers of trained people, no cohesive drive in the area to promote carcers, insufficient courses and training except within some developed companies and those recently established by the National College of Ireland"

'Labour' supply inhibited by poor paying career' prospects, the services sector' has developed software system dependency, system operations largely shun necessary training for management in problem solving and opportunity development roles, few entrepreneurs are coming through the indigenous ranks"

\section{Unable to Comment}

"No experience in the matter, but a hunch, that it cant be easy to get a competent qualified labour' supply with unemployment at very low levels and strong competition from more attractive industries to young graduates"

The indication of opinion through the rounds is that there is a lack of sufficient onshore labour supply. Opinion discusses that the sector is not attractive to graduates as many of the potential Irish workforce tend to work in other industries. Positions are filled by immigrant workers from Eastern Europe and if this develops as a long term trend the sector could develop a high dependency on foreign workers. This leads to the question, from where such labour could be sourced in the future when Eastern European economies develop and how to attract a viable workforce for the future. Some of the areas that have been referred to as lacking in labour supply are suitable personnel for mid management level with two to four years experience, areas of ship management and operations, international shipping consultants, marine finance (although it is in its infancy), accident claims and loss adjusting and general people with skill and knowledge of the industry. Disagreement opinion argues that there is no shortage and no unfilled vacancies and if there were the wage price would be driven upward which would draw labour out to the market. It is also argued that there are adequate numbers of people but an inadequate number of trained personnel and insufficient training courses available. 
The next survey question asked the panel if they believe that there is a lack of management personnel with relative industry experience available to be sourced as a labour supply for the GDR maritime transport sector. The statement reached an agreement consensus of $45 \%$ in Round 2 and increased to an agreement result of $66 \%$ in Round 3 . The relevance of this statement was to define if there is an issue of labour supply is it associated with general labour or specifically related to management positions.

\section{Agreement Arguments}

\section{Agreement Arguments: Thread A}

"There has been a trend over recent year's where the Irish maritime sector" has not been an attractive career for people entering the job market, this has lead to a shortage of qualified people in the sector. who may have been given a management role without proper training and experience"

"Various sectors of the industry are either small scale or in their infancy which means there is a shortage of experience management"

"Experience levels in middle management appear to be lacking with little willingness to develop skills/expertise in this area. A lot of foreign owned companies also have foreign nationals in middle/senior management positions on a mid term basis before being repatriated without succession and planning taking place with existing permanent staff"

\section{"Lack of understanding within the trade is woeful"}

"Based on feedback discussions with industry participants there appears to be a shared belief that foreign nationals will not fill the gap"

"The pool of resources in this specific sector" is final, the sector' is specialized and under developed and does not attract interest from outside the sector. In general. promotion is from within with little or no training to assist new management to succeed"

"There is a lack of experienced management personnel although this may be rectifiable by attracting people with relevant experience to relocate or to return to Ireland"

\section{Disagreement Arguments}

Disagreement Arguments: Thread A

"Human lecourses exist at present but the age profile is a cause for' concern. The education and training ethic among management in general tends to be weak at a time of high staff turnover - as at present"

"There is no evidence of a lack of per'sonnel management" 
"Many of the skills involved are not marine specific, e.g. financial/HR/ maintenance etc. At the present we seem to have a good supply of these. There are big numbers of Irish and EU nationals at sea. Many of theses would welcome a return to a shore based job. Their experience as a ship master or officer would be invaluable in ports, e.g. pilots/tugs etc. In other freight sectors young people are always coming through the ranks gaining experience all the time"

"No evidence of shortage"

"My experience plenty of managers available with plenty of experience"

The opinion discusses that the sector is not attractive to graduates or the general potential labour supply which opinion further argues has lead to a shortage of qualified people who may have obtained management positions without the relevant training and industry experience. Opinions also argue and as highlighted from the feedback that the industry also feel that the influx of immigrant workers is perhaps insufficient to fill any labour gaps. One panel member did strongly describe that the understanding of the industry from within the industry is "woeful". However the disagreement opinions argue that there is no such shortage although one opinion does raise concern over the age profile and the lack of training for potential managers in a time cited has having a high turnover of staff. It is also discussed that many positions are generic such as $\mathrm{HR}$, accounts and finance and can be filled quite easily due to the young age of the Irish workforce and the uptake of general third level courses in business and associated disciplines.

The next question in Section 2 asked the panel if they believed that the current maritime transport labour supply is sufficient to meet the labour requirements of a growing maritime transport sector. The statement had a majority disagreement of $49 \%$ in Round 1, a majority disagreement of $50 \%$ in Round 2, and finally a majority disagreement of $44 \%$ in Round 3.

\section{Agreement Arguments}

Agreement Arguments: Thread A

"More tasks are now being mechanised and the numbers employed are not growing at the same rate as cargo throughput. overseas labour has met the demand in this area. Many Irish have withdrawn from certain tasks such as 
truck driving. Most driver's of Irish trucks on the continent are foreign nationals. The local and overseas labour will be able to meet the demands. The more labour intensive industries (e.g. construction) have found this to be the case and the maritime sector will be no exception"

"There is more than sufficient labour. within the Dublin region, if there were not we would immediately see an increase of supply from the UK or middle Europe to satisfy the demand"

"The current supply is sufficient to meet the need of the market and any further' needs can be provided from the growing labour' pool"

"Increased use of computers and by biinging in foreign nationals will probably cover the problem, the move away from traditional shipping; documentation to "line" booking notes will assist"

\section{Disagreement Arguments}

\section{Disagreement Arguments: Thread A}

"In most sector's, but gaps in positions in finance and law"

"There are currently many shortages of labour in various sectors of the maritime industry and it is very difficult to source suitable personnel. There is many non-national people entering the sector and although there work is very good the language is a problem and can be a negative factor particularly in operational areas"

\section{Disagreement Arguments: Thread B}

"Lack of educational infrastructure effects the growth of the sector. The sector needs labour input at all levels"

"At present there are insufficient numbers of personnel to allow the maritime transport sector to grow although this may be rectified by making the employment opportunities more attractive with better training and remuneration"

"The seed pool includes 3rd level educated new EU nationals - however" supply will dependent upon cducation and training"

The agreement opinion addresses again the divergence of the Irish population away from transport related labour and cites the construction industry as an example of where jobs have been taken up by an immigrant workforce. The influx of immigrant workers and EU nationals are seen as an increasing available labour source although the barrier of the English language is seen as a problem. More jobs are being mechanised and the increase in technology has also reduced labour requirements. Again the disagreement arguments cite shortages in areas of infancy such as finance 
and the ability to source suitable labour. Education has been raised as an issue that needs to be addressed and a factor that may help solve certain sectors problems with finding suitable labour.

The final question in Section 2 asked the panel about sufficient training and education opportunities available for the labour supply. The statement reached a majority disagreement consensus of $46 \%$ in the first round, and majority agreement of $59 \%$ in Round 2, and finally a majority agreement of $66 \%$ in Round 3.

\section{Agreement Arguments}

\section{Agreement Arguments: Thread A}

"The cour'ses that are available need to be co-coordinated between the ITs, the universities and CILT, etc. A training analysis also needs to be undertaken to identity gaps in training and update course content."

"There are educational opportunities, but they need to be highlighted and marketed"

\section{Agreement Arguments: Thread B}

"There have never' been more educational opportunities. The Nautical College in Cork, Universities. ITs and other's such as Irish Exporter's Association and Chartered Institute of Transport offer specialized courses, more and more entrants to the industry come with a relevant $3^{\text {rd }}$ level qualification"

"There are several institutions offering training at different levels for the transport sector; and again if the market demand for higher trained/experienced personnel is required ther can be hired from elsewhere."

"Good third level and companics can provide on the job training to make people skills specific to maintain the sector."

Agreement Arguments: Thread C

"50/50 on this subject, ther'e are courses available, but are they suitable to the needs of the industry. Is there a "body" taking an overview to determine the gaps in the education system? Having fully qualified shipbroker's is a positive but if the industry needs docks and warehouse workers, then the gaps will remain"

"I have no doubt that the training facilities in Ireland are sufficiently" adequate and address the needs of the sector" 
"It is not huge market and probably the balance between supply and demand is about right"

\section{Disagreement Arguments}

\section{Disagreement Arguments: Thread A}

"Not enough, very few academic cour'ses especially at advanced level."

"There is no co-coordinated approach to the problem of labour shortage. There are some special training programmes but we need to have training. for port workers, hauler's, liner agency etc to ensure we have sufficient labour in the future"

"I believe that although there are sufficient educational and training opportunities in certain sectors (Maritime Management through NCI, Seagoing personnel through Maritime College, Cork and Shipbrokeing through ICS) others are lacking such as insurance and ship finance"

"The ingredients are available for the recipe but the mix is incomplete"

In review of the opinions returned Ireland is identified has having a good third level education system in general. However opinion did suggest that specific third level courses in transport are lacking. Opinion also argues that in terms of education their present situation is a reflection of a balance in supply and demand. Further discussion highlights the need for a more unified approach to education and courses across the spectrum of transport related bodies and that a training and skills analysis would be beneficial in order to identify any gaps in training and education.

\subsubsection{Section 2: Further Research}

At present the previous discussed statements did not reach a level of agreement consensus. However there are some opinions that can help to structure further research questions to aid in identifying a research proposal that can help resolve if there is a lack of labour supply for the maritime transport sector in the GDR. In one instance the fact that the statements did not reach consensus could be an indication that there is a real disagreement between the different industry sector's. The question would have to be addressed sector by sector as opposed to an entire cluster as certain sectors may have different levels of staffing requirements. Supportive literature and statistics from other sources can also be useful such as the FAS Skill bulletin. However such statistics generally 
incorporate maritime transport with other transport services such as air transportation. The research would also have to address specific job gaps, for example low skilled gaps or more management type labour gaps. If labour gaps are identified or the issue of an over reliance on immigrant workers would also need to be addressed and the training and education available for future labour supplies. Section 2 of the Delphi did however achieve a consensus in that the panel consider in agreement of $86 \%$ that there is a lack of promotion and awareness of the career options available in the industry.

\subsubsection{Section 4}

Section 4 had a total of two questions of which only one did not manage to obtain any level of consensus agreement. In Round 1 there was a majority disagreement of $41 \%$ that the GDR maritime transport sector has high barriers of entry, in Round 2 the statement reached a majority agreement of $45 \%$ and in Round 3 reached a majority disagreement of $55 \%$.

\section{Agreement Arguments}

Agreement Arguments: Thread A

"The area is highly regulated anti- competitive. unionized and closed. especially stevedoring and all ports. Ports and shipping sector is secretive and based on family ties, outsiders treated with suspicion. Financial transparency in relation to vessels, ports and freight rates are inaccessible which makes getting info to make the decision about entering the business not available, because of the legal set up in terminals makes it impossible for new companies to cnter the market"

"I have to qualify this by saying it depends on the particular sector. Port terminals, handling equipment etc are all very expensive. Land and building costs all over Dublin are prohibitive to some new entrants. Other areas such as haulage, freight forwarding etc present less serious entry problems, you also have to look at the profit levels and at whether some sector's are over' supplied"

"Barrier' is to many operators, tight margins and no money to be made and the way of operations of the larger dominate companies creating difficulties for' new entrants"

"The limited opportunities and high level of existing competition mean that opportunities in certain areas such as shipping routes, stevedoring; and 
Maritime Clusters

terminal operations are limited. However the growth in traffic can make the market attractive"

Agreement Arguments: Thread B

"High costs, rent, rates, labour, tolls, poor road access, lower productivity on delivery/collection vehicles, lots of competition from multinationals in the sector"

"Lack of skills and knowledge is a major obstacle to overcome, by importing and training increases the cost of relocating"

"Not because of too much competition but due to the fact that the market is limited, the growth going forward will not be sufficient to attract more entrants, the economics of entering at this stage are questionable as the potential returns would not be acceptable"

"A lack of cluster, it's a closed shop, a lack of expertise"

\section{Disagreement Arguments}

\section{Disagreement Arguments: Thread A}

"Only real barrier to entry is the size of the overall business cluster' and the consequent level of business opportunities available"

"No quality requirements to enter/access the Dublin region other than bread and butter issues i.e. fuel, driver's etc"

"However some areas of intense competition do create barriers as the perception is that no money can be made"

"New operators such as Irish Sea Express and Celtic and the set up of the new port operations"

"There is a space issue and also maybe a skills one when compared to the UK for' example. But overall ther'e seems to be few"

"No more than other regions or cities"

"Can only comment on own sector' where the barier' to entry ar'e low. In most sectors there is rery little not to prevent a new plarer from entering the market place"

"Entry is not a problem; getting your hands on some business is where the problems start. Very often we have seen new agencies start up based on personnel dragging business with them. That doesn't do very much for development of a cluster, it just creates more competition for the came sized cake"

The second question of Section 4 reached an agreement consensus of $77 \%$ that the GDR maritime transport sector has high exit barrier and firms are sticky to the Dublin location. Therefore it can be established with reasonable confidence from the Delphi that GDR location is sticky and this 
can also be further supported by the pull of the city and the port as discussed previously. The opinions in agreement to the question on barriers to entry make reference to barriers such as the limited market, tight margins and the dominant position of certain companies. However there has also been strong opinion on the closed nature of certain sectors such as ports, stevedoring and terminal operations. Knowledge has also been cited as a barrier as transparency in information is weak which can make it more difficult for a new entrant to decide whether to risk the market or not. However it is also argued that the barriers of entry can be sector dependent and some sectors such as freight forwarding are easier to enter than other sectors. Generally barriers have been noted as high costs such as land and rent (noted in agglomeration economics as dispersion factors for clustering), a general lack of skills and knowledge, a lack of growth potential and an overall lack of cluster and expertise. Disagreement opinion also highlighted that due to the high level of cut throat competition there is a perception that money cannot be made, which in itself creates a perception barrier to the cluster i.e. a lot of hard work fighting for business without necessarily a viable economic return. The ferry sector has been used time and time again as an example of a sector functioning under high levels of internal competition and the sector has been used as an example of one which has low barriers of entry due to the examples of firms that have actually entered the market.

\subsubsection{Section 4: Further Research}

For further research into the aspect of cluster barriers specific to the GDR maritime transport sector it would beneficial to develop a research question that would address barriers to the cluster from both a cluster barrier perspective and a individual maritime transport sector perspective. The cluster barrier aspect could address issues like labour supply, land rents, congestion and barriers to knowledge access and diffusion of knowledge across the cluster. It would also be informative to look at barriers to individual sectors such as infrastructure, policy, and issues of competition and trust. The research would also have to address any potential side effects 
of having barriers to entry that are too low and may fragment business and lower quality of services.

\subsubsection{Section 6}

Section 6 had a total of three statements of which two reached a final consensus. The question in Section 6 that did not reach a consensus asked the panel if they think that their business, firm or organisation would benefit from a greater mix and diversity of maritime transport firms. The statement had a majority agreement in Round 1 of $43 \%$, in Round 2 it had a majority agreement of $68 \%$ and in Round 3 had a majority agreement of $66 \%$.

\section{Agreement Arguments}

Agreement Arguments: Thread A

"Enlarged sector' with greater" mix and diversity of transport firms will be good for the whole sector including the finance business"

"All maritime transport firms would greatly benefit and this would create a favourable synergy to the maritime industry - ports, ships, transport, and education units - academic and professional etc"

"Greater' mix I feel would drive rates down and would give my firm greater" possibilities to earn more provided we could retain the business against increased competition caused by the greater mix of transport firms. The larger the market the more work available. The greater the diversity the more we must adapt and grow to service that diversity and the needs of different organisations. It would be healthy"

Agreement Arguments: Thread B

"Some cartels and vested interest groups mav be broken up and the market may bonefit as a result"

"Consideration within the industry has restrictive practise in some areas that inhibits competition. More and varied competition would be welcome if it encouraged the dismantling of such artificial competition"

Agreement Arguments: Thread C

"On the basis that the volume of business would increase, I think my business would benefit in the long term, in the short term increased competition from a greater mix would be painful until the new business opportunities kicked in"

"I am surprised that all did not agree with this, the problem is not with a greater mix and diversity but with a danger of orersupply leading to market fragmentation and perhaps service suppliers going to the wall. this would not be good on the long r'un" 


\section{Disagreement Arguments}

Disagreement Arguments: Thread A

"The business does not warrant too much diversity"

"Plenty of transport firms what's lacking is port facilities"

"There is a sufficient mix of firms in most areas with notable exception of the availability of container haulage"

Disagreement Arguments: Thread B

"We are adequately catered for in terms of suppliers and associates, further competition would be demand driven"

"Further competition would force down rates to non" sustainable levels"

"We cover' a niche market; whether" we would benefit from more firms competing for' a small slice of the cake is debatable"

Disagreement Arguments: Thread C

"I think Dublin is fairly well serviced in terms of diversity. The main problem is Dublin has a lack of space and very often the more diverse traffic is turned away"

The opinion provided in the agreement arguments is that a greater mix of firms would be of benefit to the panel member's firms as a larger market means more work and greater possibility of business. The possibility of a greater mix and weight of firms is taken in the context that while new competition would increase efficiency and drive down rates it is a positive aspect as long as firms can maintain business against increased competition. Greater competition and an increase in firms operating within the scctor is also seen by panel members as a means to reduce the power of certain firms with what some panel members describe as monopolistic behaviour and restrictive practise. One opinion did highlight the fact that not all panel members agreed that a greater mix of firms would be of benefit to their own individual firm. The opinion does recognise that such adjustment would be tough in the short term but overall in the long term it would be of greater benefit; however opinion stresses that there is a danger of oversupply which could lead to market fragmentation. The disagreement opinion argues that there are plenty of maritime transport firms; however exceptions are noted in container haulage and port facilities. Opinions are 
concerned that an increase in firm diversity would drive rates down to unsustainable levels which could be especially true for firms operating in niche markets. Again one similar thread that has been raised in many opinions for different statements is the lack of space in Dublin and in the port facilities and infrastructure as one opinion highlights that diverse traffic has to be turned away.

\subsubsection{Section 6: Further Research}

In terms of Section 6 further research could investigate specifically the individual sectors of the GDR maritime transport cluster to determine if any gaps exist in the market and the potential to establish and further develop niche sectors.

\subsubsection{Section 8}

Section 8 had a total of two questions which asked the panel members about the presence of leader firms, if any, in the GDR maritime transport sector. The first question in Section 8 asked the panel if they thought there was a lack of leader firms in the GDR maritime transport sector. The response returned in Round 1 was a majority agreement of 54\%, in Round 2 a majority agreement of $54 \%$ and finally in Round 3 a majority agreement of $66 \%$.The following discussion will look at the responses returned.

\section{Agreement Arguments:}

Agreement Arguments: Thread A

"Lack of leader firms and instead a number of monopoly companies. In relation to teiminals an oligopoly exists rather than leader companies. No Irish maritime company could be clearly defined as a leader on an international scale"

"Lack of leader" firms in the shipowningloperating area"

"The investment in superstructure limits the chance of too many leader" firms in the industry and leads towards the monopoly".

"Market share spilt within the ferry sector' shows Norflkine as a leader; this is on an all Ireland network: analysis of individual routes however shows the Dublin corridor without a clear leader". 
Agreement Arguments: Thread B

"No leader' firms, the centre here would not been seen as a centre of excellence, leadership must come from government".

"Lack of leader' firms reflects the volatility of the market. Few companies in my sector last more than a generation which indicates that they are purely profit driven rather than quality and service driven, get in, make money and sell off"

"No firm in Ireland is an international leader. A leader" firm would have to have a special competitive advantage. Bank of Ireland is a sector providing hope for the development of a financial cluster".

"We do not seem to have any Irish owned world leaders. World leaders such as Maersk and Stena do not have the same profile in Ireland as they have in other countries. We obviously have leader firms in Ireland but not necessarily significant internationally"

"No obvious leader firm that stands out or has a particular profile that suggests that it will become a leader, the size of the market and number add value and may be a reason for this"

\section{Disagreement Arguments}

\section{Disagreement Arguments Thread A}

"Most if not all transport companies are now present in Ireland having bought smaller indigenous companies with existing business or having started from scratch"

"Clear evidence of leader firms in most areas i.e. ferry companies, stevedores, lawrers, ship agents etc"

"Some world mega operator's have there own offices here e.g. Maersk, MSC, and on Irish Sea or European there are large operators e.g. Stena, Irish Ferries, P\&O. Norflkine"

Disagreement Arguments Thread B

"It is difficult to visualise the premise within the Dublin context, most firms activities fall within the service sector, if a flag ship principal were to operate internationally from Dublin that could change the outsider's perception"

"I disagree, as I do believe that there are several 'leader' firms' in the greater" Dublin maritime transport sector to form a strong fundamental base for' a thriving maritime "Dublin cluster".

"Ther'e are some firms who are a leader' in their" particular' sector' i.e. ferries on Ireland UK. LolLo operator's between Ireland and Europe. However in an international contert there are no leader firms" 
"For market size Dublin has a good number of leader firms perhaps people who think the reverse are thinking purely of Irish companies. Plenty there but more would be preferable"

"There is a strong representation of multinational transport and logistics companies offering air/sea/road and logistics solutions"

The agreement opinion overall is that there is no clear defined leader firms in Ireland with a international status however there seems to be some debate in that as some panel members argue that there are leader firms within Ireland, but not in a international context. Is there an importance difference, if any, between a leader firm within Ireland which does not have international significance? Does the domestic cluster still benefit, and to what extent? Generally the opinion indicates the perception that there is no clear leader firm with particular reference to shipowners and operators. However certain firms are mentioned and considered by some panel members as leader firms, notably Bank of Ireland, Stena, and Irish Ferries. However opinions also support that certain firms as mentioned as leader firms are mainly foreign companies and that those companies do not appear to have the same profile in Ireland as they do in other countries. The size, profile, infrastructure and market potential have also been mentioned as possible reasons for a lack of such firms together with a lack of suitable leadership from government. Opinion also argued that the possible lack of leader firms within the Irish market is an indication of volatility in the market, as few companies within certain sectors only last more than a generation and the opinion argues that this is a result of profit driven goals as opposed to service driven goals. The disagreement opinion argues that there is no lack of leader firms within the GDR and discusses the fact that all transport modes are represented by many of the major European companies which have an Irish office and presence and opinion suggests that there is clear evidence of leader firms in operational areas such as ferries, stevedores, lawyers and ship agents. It was also commented that more leader firms would be beneficial as such firms would have a greater international significance and could be of benefit to Ireland and improve the perception of the industry based in Ireland. 
Maritime Clusters

The second question in Section 8 asked the panel that if they did consider that there is a lack of leader firms, is such a lack having a negative effect on the development of the GDR as a maritime transport cluster. In Round 1 the statement had a majority agreement of $41 \%$, in Round 2 the statement increases to a majority agreement of 59\%, and finally in Round 3 the statement reached a majority agreement of $61 \%$.

\section{Agreement Arguments}

\section{Agreement Argument: Thread A}

"Yes it would draw in competitor's and related companies' due to the fact that there are no maritime leaders here will not rank Ireland or Dublin as a maritime location. Just as GPAaircraft leasing attracted some of the worlds leading players in aviation to Dublin, similarly in the medical products, Ireland has 8 of the 10 healthcare companies located here and the trend was started by one leader firm locating here"

"Leader firms could drive the sector towards excellence and a coherence which would facilitate the development of a maritime transport cluster."

"Without leader firms of shipowners and operator's being attracted to the region it is also unlikely ancillary business will be attracted also"

"Leader firms indicate stability and long term profit; if leader firms did exist the maritime sector would grow"

Agreement Argument: Thread B

"Mersyside has 600 companies employing 6000, combined turnover" $\mathfrak{L 1 . 3 m}$ from a report commissioned by Merseyside maritime, a private sector led initiative set up last year to re-establish the area as a recognized centre of maritime excellence with a priority on marketing, education, training and skills"

"Sector" needs a strong defined growth plan for the infrastructure of the region, capacity restraints is not taken seriously by government. In this climate the regular companies in the cluster do not have confidence to expand, develop, look for new opportunities and the sector is in danger of stagnating"

"To be a leader' firm means you a doing it right, if we had a leader' firm it would give participants a standard to aim for thus improving the overall service, it would provide a lift for the image of the sector. It would provide an image for the region from a maritime cluster point of view with inevitable beneficial effects"

"Perception is everything: If investors and business people take the vier" that Dublin has a lack of leader firms then they are unlikely to want to 
invest and develop in the cluster. This would have a detrimental affect on the development of the sector"

\section{Disagreement Arguments}

\section{Disagreement Arguments: Thread A}

"I disagree to the statement that there is a lack of leader' firms in the greater Dublin region and this lack of leader firms is having a negative effect on the development of the greater Dublin maritime cluster. However. what is lacking is the will and consensual acceptance that for the common good, the big single firms may have to compromise a part of their perceived territorial claims. It is this failure to acknowledge, lack of trust and the lack of imagination that has held back maritime industry in the greater. Dublin region"

"There are sufficient firms operating in the maritime sector to cater for the Irish market and it does not really matter that there are leader firms or not" "The leader firms are not having a negative effect. The cluster' does not have to be large. A good small cluster is better than a large sprawling one"

"The greater Dublin region can develop to a limited extent as a maritime cluster, but this does not depend on whether we have leader firms or not"

Reviewing the agreement opinion for the current question, the location of such leader firms within the GDR would encourage confidence and possible growth in the market and help to facilitate any future cluster development. The opinion did give the example of the location of GPAircraft and the positive effect it has had on aircraft leasing market within Ireland. The location of a leader firm within a country can help to create a greater and healthier business perception of the sector to the international industry and help to internationalise the sector or cluster. From a maritime perspective Mersey Maritime was mentioned as an example of a similar maritime cluster that has taken on a marketing drive lead by a private sector initiative to market and promote the Mersey cluster. In conjunction with the unresolved issue of leader firms and the lack therefore, if any, opinions have discussed the need for an action plan for sector development with specific reference to infrastructure and capacity restraints which is argued that government is not taking seriously, and thus the opinion reflects the lack of confidence of market players to invest and expand. Perception is again discussed as an important element in business and the proposed lack of 
visible leaders firms infers long term instability and is argued as having a serious negative effect on the development of the cluster as the presence of such firms helps to gauge a standard of service, which would improve the overall service provided by the cluster and the overall perception internationally of the Irish maritime transport sector. Opinions disagreeing with the statement that a lack, if any, is having a negative effect on the development of the GDR maritime transport cluster discuss that the GDR has some potential to develop but that this is not necessarily hindered by a lack of leader firms and that there are sufficient firms operating within the Irish market. Opinion argues that it is not necessarily the lack of leader firms that may hinder cluster development than a lack of trust, imagination and drive to develop the sector towards are recognisable cluster status.

\subsubsection{Section 8: Further Research}

Further research in terms of Section 8 and the questions addressing leader firms would benefit from a concise understanding of what actually constitutes as a leader firm in the Irish market. Also is there a difference between the benefits of domestic leader firms and that of an international leader firms that locate and operate from within the GDR. Further research could help appropriately identify leader firms in the maritime sector in Ireland. Also an examination of leader firms in Ireland which are not specifically marine or maritime based would also be useful in terms of compare and contrast and to identify measures which could attract leader firms to the Irish market. or to identify ways in which current firms could be encouraged to behave more like leader firms for their individual industry sectors.

\subsection{Summary of Delphi Results}

The following will provide a brief summary of the Delphi results in terms of the consensus reached in each of the three rounds as displayed in Table 23 supported by a concise summary of consensus achieved in terms of the original sections of the Delphi questionnaire. A total of 11 consensuses were 
achieved with 9 achieving a low grade consensus, 2 achieving a medium grade consensus and 0 statements achieving a high consensus.

Table 23 Low, Medium and High Ranking in Round 1, 2 and 3

\begin{tabular}{|l|l|l|l|l|}
\hline & Round 1 & Round 2 & Round 3 & Total \\
\hline Low: $70-79 \%$ & 3 & 5 & 1 & 9 \\
\hline Medium: $80-89 \%$ & 0 & 2 & 0 & 2 \\
\hline High: $90 \cdot 100 \%$ & 0 & 0 & 0 & 0 \\
\hline Total & 3 & 7 & 1 & 11 \\
\hline
\end{tabular}

(Source: Author's Own)

\subsubsection{Analysis of Delphi Consensus per Section}

The consensus achieved in the Delphi has been discussed sequentially in terms of when each statement reached consensus through each of the rounds. The purpose of the following discussion analysis is with respect to the fact that the questions within the Delphi Survey were divided into eight different sections, as in each individual section the questions were supportive of each other in that they represented a particular segment of cluster theory.

\subsubsection{Section 1}

Section 1 had two questions which were not based on cluster theory however it was important to establish if the panel as active players within the GDR maritime transport sector consider if the industry is a maritime transport cluster and if that cluster has any future potential. The first statement achieved a 78\% agreement consensus in Round 1 that the GDR is a maritime transport cluster. The second statement achieved an agrcement consensus of $72 \%$ in Round 2 in that the GDR maritime transport cluster has the potential to develop in the future.

\subsubsection{Section 3}

Section 3 had two questions which was based on cluster theory in relation to the benefits of locating within a cluster and the potential access to cluster knowledge. The first question relating to the benefit of locating within the GDR reached an agreement consensus of 73\% in Round 1. The second statement on the availability and access to cluster knowledge reached an agreement consensus of $72 \%$ in Round 2 . The Delphi panel agree that there 
are benefits in locating within the GDR and identifies that there is active cluster knowledge within the GDR.

\subsubsection{Section 6}

Section 6 had three questions which were based on the mix, variety and diversity of firms within the GDR cluster. In Round 2, 72\% of the panel agreed that the GDR maritime transport sector had a sufficient variety and diversity of maritime transport firms, $81 \%$ agreed that the region would perform better if it had a greater mix and weight of transport firms and $68 \%$ agreed that their specific firm would benefit from a greater mix and diversity of firms.

\subsubsection{Section 7}

Section 7 had only one question relating to the level of trust within the GDR maritime transport sector. The Section 7 question reached a disagreement consensus of $72 \%$ in Round 3 in that the panel members disagreed that there was a high level of trust between firms operating within the GDR maritime transport sector.

\subsubsection{Concluding Remarks}

The manner in which the results have been displayed within this chapter was dictated by the fact that the core data derived from the Delphi is opinions. Opinions can be a difficult subject matter to present, however in the current discussion the Delphi results were examined by formulating the retuned opinion into a number of similar threads. The discussion focused on the statements that achieved a level of consensus however and the discussion also incorporated opinions that went against the final agreed consensus. No statement reached $100 \%$, therefore even if the final result was an agreement of $75 \%$ for example, there are still opinions that disagreed with the majority of the panel and therefore by not disregarding opinion simply because it does agree with the majority opinion helps to provide a balance in terms of developing future research agendas. In criticism of the Delphi applied in the present research the extraction of the 
data from the opinions would have benefited from the application of a likert scale. The application of a likert scale or a similar mode of scaling would have catered for the subtraction of a richer understanding of data drawn from the opinions provided for by the Delphi panel. The nature of the research is explorative and the Delphi has produced many further research questions as displayed in Table 24 . 
Table 24 Further Research Questions Derived tron the Opinions Returned in the GDR Delphi

\section{Section 1}

\begin{tabular}{|c|c|c|c|}
\hline Question & Consensus & Opinion Thread & Future Research \\
\hline $\begin{array}{l}\text { Do you consider the } \\
\text { greater Dublin } \\
\text { region maritime } \\
\text { transport sector as } \\
\text { a maritime cluster? }\end{array}$ & $\begin{array}{l}\text { Agreement of } \\
78 \%\end{array}$ & $\begin{array}{l}\text { (1). Beginnings but limited, some gaps } \\
\text { in services. } \\
\text { (2). Proximity to finance and } \\
\text { government. } \\
\text { (3). Issues of demographics in terms of } \\
\text { population, industry and cargo. }\end{array}$ & $\begin{array}{l}\text { (1). What maritime sectors, if any, does the GDR } \\
\text { maritime transport sector lack? Is there an optimum } \\
\text { formula for a maritime cluster i.e. number of sectors, } \\
\text { type of sectors, and density of sectors? } \\
\text { (2). What is the potential to develop the maritime } \\
\text { finance and banking aspect of the GDR maritime } \\
\text { transport cluster? Can anything be learned from the } \\
\text { development of the IFSC cluster? } \\
\text { (3). How important is the role of the port in the } \\
\text { making of the GDR maritime transport cluster (and } \\
\text { the role of the city)? How does the country's } \\
\text { demogxaphics affect the GDR maritime transport } \\
\text { cluster? Is the GDR maritime transport sector a port } \\
\text { cluster or the result of agglomeration of people and } \\
\text { industry in a specific area? }\end{array}$ \\
\hline $\begin{array}{l}\text { Do you believe the } \\
\text { GDR maritime } \\
\text { transport sector has } \\
\text { the potential to } \\
\text { move forward } \\
\text { towards a more } \\
\text { international } \\
\text { recognisable cluster } \\
\text { status? }\end{array}$ & $\begin{array}{l}\text { Agreement of } \\
72 \%\end{array}$ & $\begin{array}{l}\text { (1). Policy and fiscal incentives } \\
\text { developed of the back of IFSC success } \\
\text { and niche areas. } \\
\text { (2). Growing population and port } \\
\text { (Dublin), although port of regional } \\
\text { significance. } \\
\text { (3). Cluster and port are remote, } \\
\text { regional, and insufficient in size and } \\
\text { against competing clusters. Potential } \\
\text { but no political drive. }\end{array}$ & $\begin{array}{l}\text { (1). What fiscal support and incentives are available } \\
\text { to the industry and specifically Ireland? Are the } \\
\text { current measures working? How does it compare to } \\
\text { the rest of Europe. } \\
\text { (2) \& (3). What is Dublin port playing field on a } \\
\text { European level? Compare Dublin to other European } \\
\text { ports, not necessary Rotterdam and Singapore, but } \\
\text { ports in a similar position to Dublin (i.e. smaller } \\
\text { players) }\end{array}$ \\
\hline
\end{tabular}




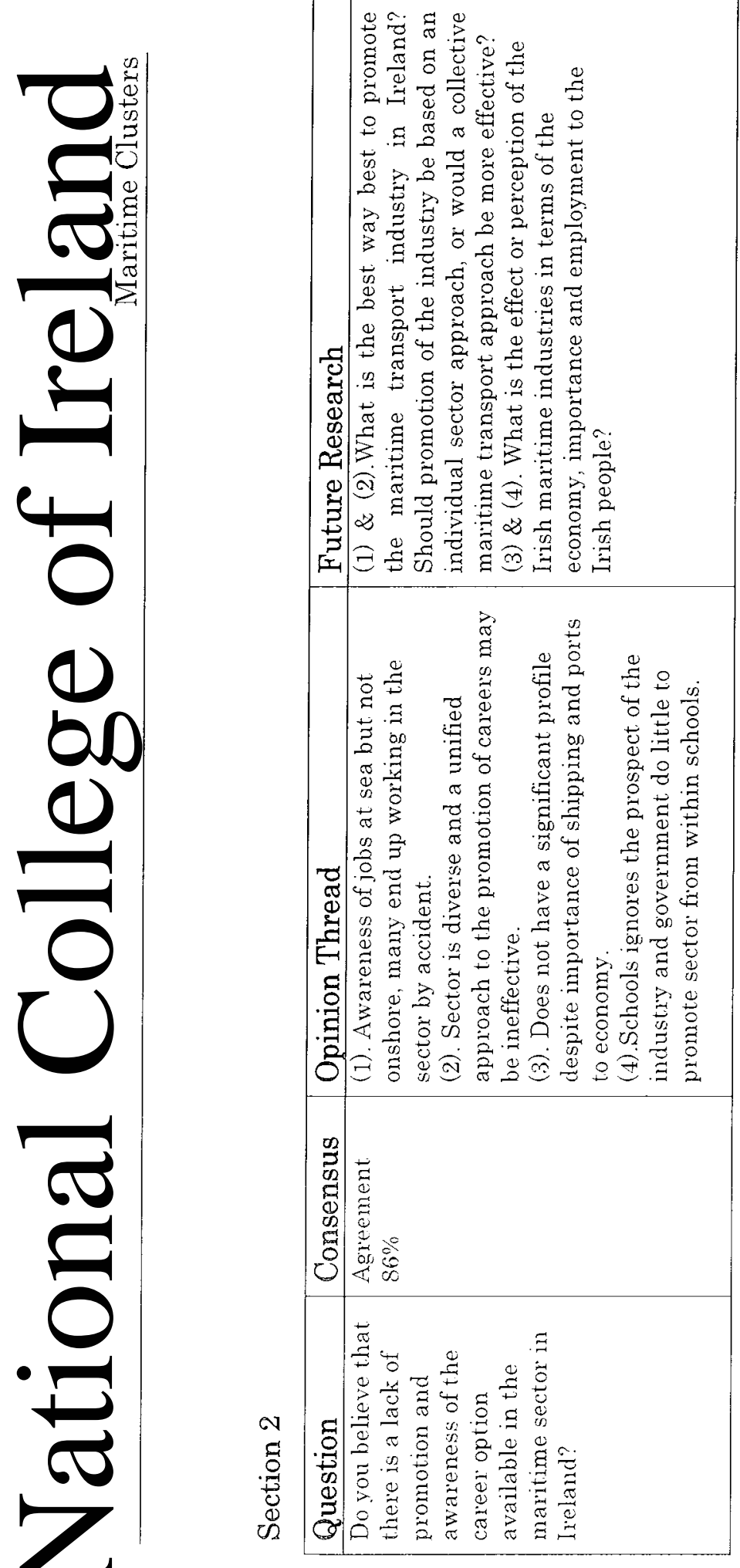



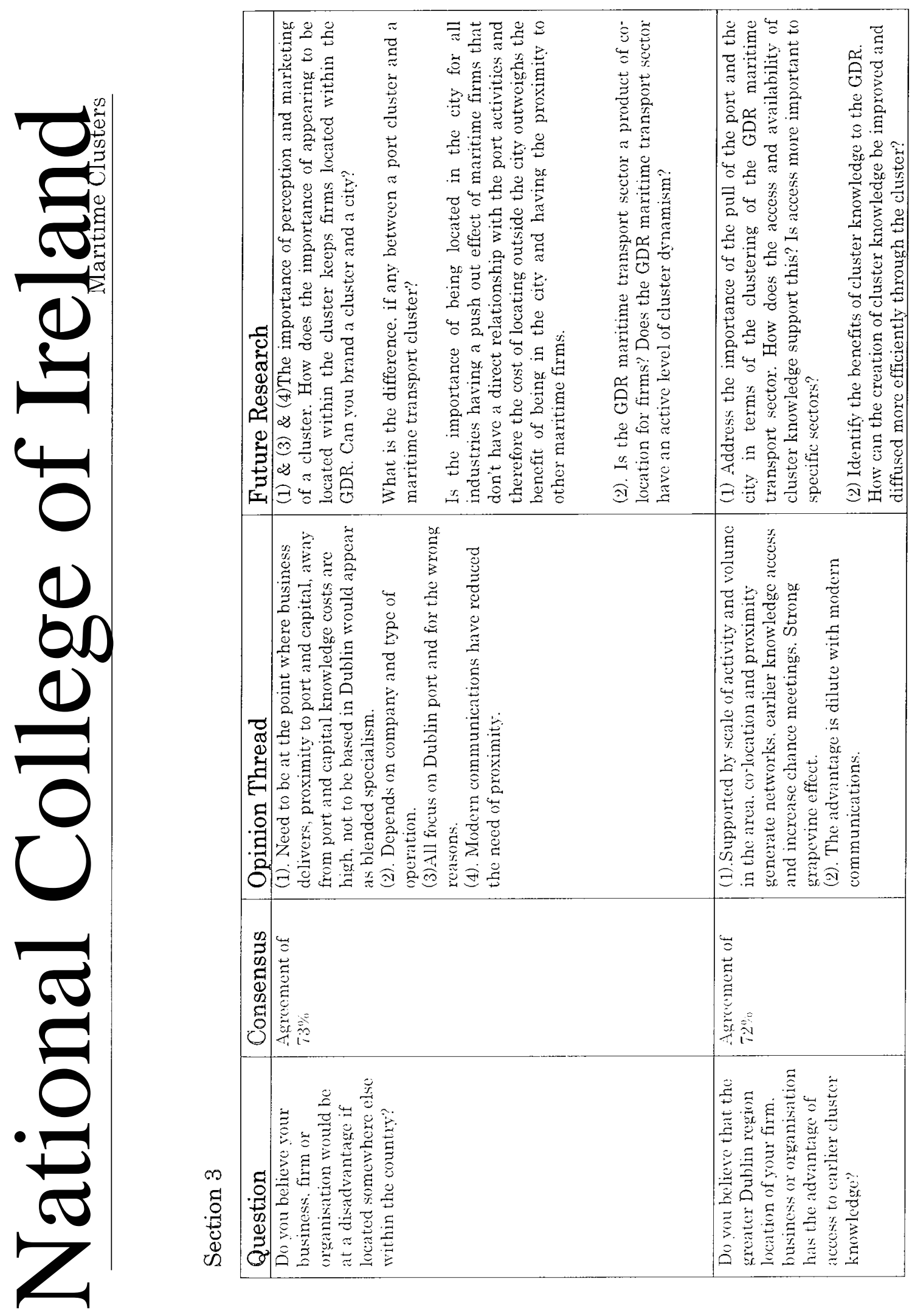
Section 4

\begin{tabular}{|c|c|c|c|}
\hline Question & Consensus & Opinion Thread & Future Research \\
\hline $\begin{array}{l}\text { Do you believe that the greater } \\
\text { Dublin region maritime transport } \\
\text { sector has high exit barriers and that } \\
\text { firms. business and organizations in } \\
\text { the sector are "sticky" to the Dublin } \\
\text { location? }\end{array}$ & Agreement of $77 \%$ & $\begin{array}{l}\text { (1).Determined by market forces as } \\
\text { economic activity dictates. Dublin is } \\
\text { where business is done companies } \\
\text { locate because they have too despite } \\
\text { high costs of land and rents. Dublin is } \\
\text { the biggest market and key players } \\
\text { create stickiness. Although dilute with } \\
\text { modern I.T and communications. } \\
\text { (2). Combination of tax and business } \\
\text { relationships. Location and presence of } \\
\text { key players creates an exit barrier. } \\
\text { Sheer population dictates the cluster } \\
\text { which is disproportion to the facilities } \\
\text { that exist, sticky but illogically. } \\
\text { (3). If firms provide efficient service } \\
\text { clients and customers will follow. }\end{array}$ & $\begin{array}{l}\text { (1)\& (2) \& (3) Identify the } \\
\text { GDR maritime transport } \\
\text { sectors high exit barriers and } \\
\text { their effect on cluster } \\
\text { stickiness, specifically the } \\
\text { effects of the port, the effects } \\
\text { of the city, the effects of } \\
\text { demographics and the effect of } \\
\text { cluster knowledge and } \\
\text { communication. }\end{array}$ \\
\hline
\end{tabular}


Section 5

\begin{tabular}{|c|c|c|c|}
\hline Question & Consensus & Opinion Thread & Future Research \\
\hline $\begin{array}{l}\text { Do you believe that } \\
\text { the greater Dublin } \\
\text { region maritime } \\
\text { transport sector has a } \\
\text { strong level of } \\
\text { internal competition? }\end{array}$ & Agreement of $73 \%$ & $\begin{array}{l}\text { (1).Lots of domestic competition especially in ferry } \\
\text { (freight) market. Entry into profession means lots of } \\
\text { competition and choice. Foreign companies enter the } \\
\text { market by acquisition of locally built firms. } \\
\text { (2).Strong, but some abuse of a dominant position. } \\
\text { Destructive competition and monopolistic tendencies. } \\
\text { Some sectors have strong competition, some sector do } \\
\text { not have enough competition. } \\
\text { (3). Strong, can result in poor remuneration, at times } \\
\text { competition so cut throat margins are reduced to very } \\
\text { low levels. } \\
\text { (4). No transparency in rates and prices and } \\
\text { preferential treatment and "grandfather rights" }\end{array}$ & $\begin{array}{l}\text { (1) \& (2) \& (3) \& (4) What } \\
\text { specific sectors within the } \\
\text { GDR are competing under } \\
\text { strong levels of internal } \\
\text { competition? What sectors are } \\
\text { engaging in such destructive } \\
\text { behaviour, if any? Is there an } \\
\text { optimum level between a good } \\
\text { level of competition and such } \\
\text { strong competition that } \\
\text { results in poor remuneration? }\end{array}$ \\
\hline $\begin{array}{l}\text { Do you believe that } \\
\text { the GDR maritime } \\
\text { transport sector were } \\
\text { a highly competitive } \\
\text { and vibrant } \\
\text { environment, Irish } \\
\text { businesses and firms } \\
\text { within the sector } \\
\text { would be in a better } \\
\text { position competing } \\
\text { internationally? }\end{array}$ & Agreement of $77 \%$ & $\begin{array}{l}\text { (1). International for Ireland has historically been the } \\
\text { UK. Rates/service and providers have improved } \\
\text { dramatically in the last } 10 \text { years. } \\
\text { (2). Must compete internationally because it is truly an } \\
\text { international business. All main shipping lines in the } \\
\text { world have an office or agent located in Dublin. } \\
\text { (3). Not on a scale to affect international market place. } \\
\text { Ireland is the end of a UK supply chain which due to } \\
\text { geographic and historical factors is in a better position } \\
\text { commercially and strategically. } \\
\text { (4).Willingness to compete, prefer to stick to what we } \\
\text { know in Ireland and not risk the market. }\end{array}$ & $\begin{array}{l}\text { (1) \& (2) \& (3) \& (4) Evaluate } \\
\text { the competitiveness of the } \\
\text { Irish maritime transport } \\
\text { sector from a collective } \\
\text { maritime cluster approach } \\
\text { and incorporating individual } \\
\text { sector competitive analysis. }\end{array}$ \\
\hline
\end{tabular}



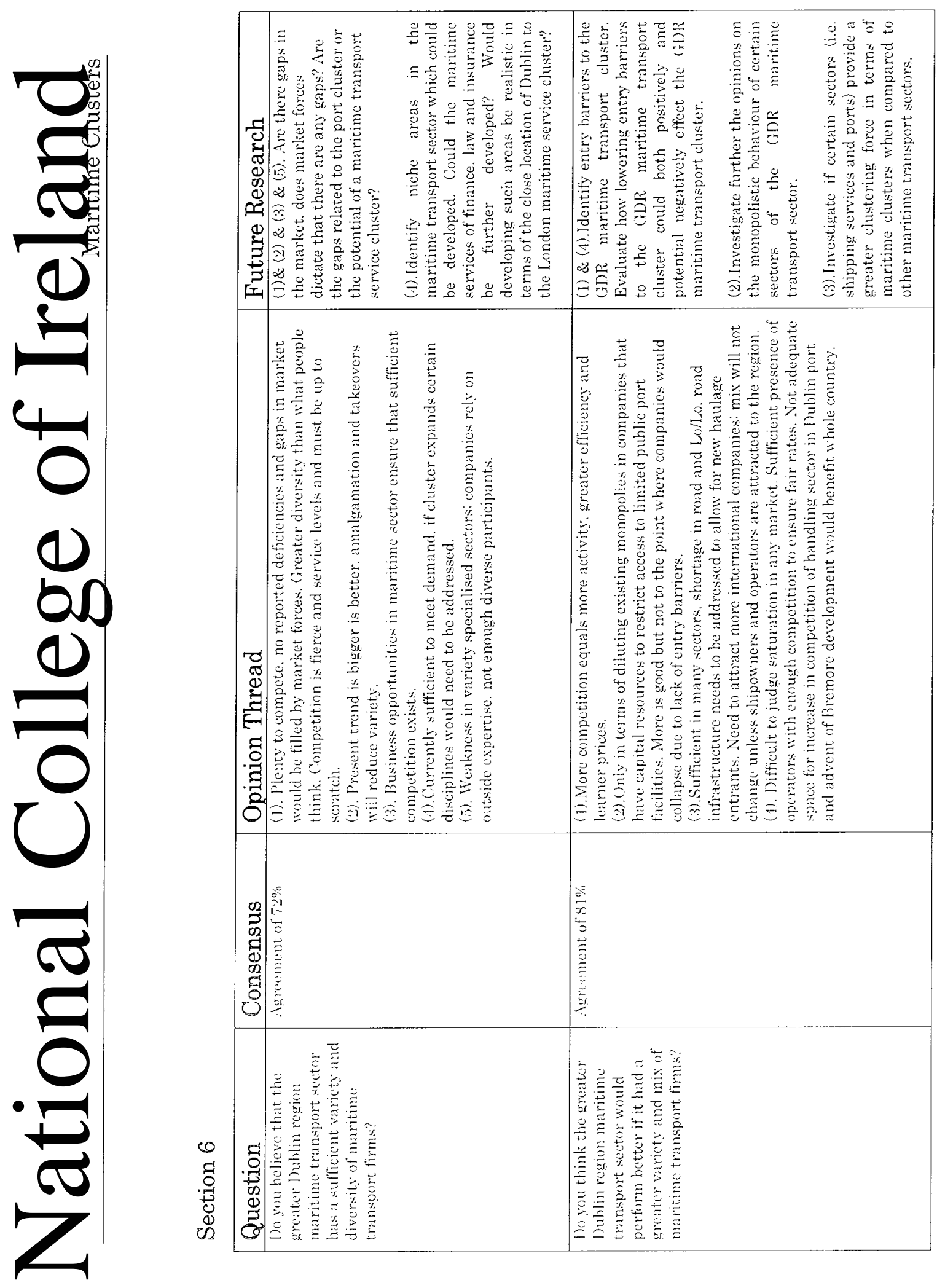

$\stackrel{0}{d}$ 
Section 7

\begin{tabular}{|c|c|c|c|}
\hline Question & Consensus & Opinion Thread & Future Research \\
\hline $\begin{array}{l}\text { Do you think there is } \\
\text { a high level of trust } \\
\text { between firms } \\
\text { operating within the } \\
\text { greater Dublin region } \\
\text { maritime transport } \\
\text { sector? }\end{array}$ & $\begin{array}{l}\text { Disagreement of } \\
72^{n !},\end{array}$ & $\begin{array}{l}\text { (1). High trust exists between haulers/ } \\
\text { freight/shipping lines/ agents. A personnel level of } \text { co- }^{-} \\
\text {operation exists for the transfer of innocent } \\
\text { information. } \\
\text { (2). In a limited market, mistrust prevails. Can't } \\
\text { afford trust as information is too important to be } \\
\text { shared. Mistrust is prevalent and cloaked as heavily } \\
\text { competitive scepticism. } \\
\text { (3). Very Competitive, good faith yes, trust with } \\
\text { internal information would dilute business } \\
\text { advantage. For companies connected up and down } \\
\text { the supply chain must have trust on the basis of } \\
\text { survival. No trust between competing companies only } \\
\text { extends to companies not competing or not perceived } \\
\text { as future competitors. }\end{array}$ & $\begin{array}{l}\text { (1) \& (2) \& (3). Is the optimum } \\
\text { level of trust for a } \\
\text { cluster/sector? How can a } \\
\text { trust level within a sector be } \\
\text { measured? What can be done } \\
\text { to encourage trust? }\end{array}$ \\
\hline
\end{tabular}




\section{Chapter 8. A Maritime Cluster or a Consequence of Co-location of Capital City and Principle Port}

The question addressed within this chapter will begin to investigate the reality of the GDR as a maritime transport cluster. The question is as follows; "is the GDR a maritime transport cluster, or is it the result of major port facility and capital city being one and the same". The discussion will not be able to produce a conclusive answer; however it will provide an initial insight into the question. The issue of deciding which question to address has its basis in the initial research objective - to understand the potential clustering of the GDR maritime transport sector, and if the GDR maritime transport cluster is exclusively a port cluster, or a port cluster with the capability of supporting fledging developments of maritime transport services through the influence of the country's capital city. It is therefore important to understand the nature of the maritime transport sector. The sector may appear visibly as a maritime transport cluster but there is also a possibility of the sector being based on firm agglomeration in which major port facility and capital city are one and the same. The understanding of the concept is important for policy maker's who may easily visualise the GDR as a maritime transport cluster, of which could be the result of co-location of capital city and major port facility and an issue of distorted demographics. The purpose is to ensure that any future policy recommendations are targeted towards generating positive returns for the sector.

\subsection{Question Deconstruction}

The question of the functionality of the GDR in terms of major port facility and capital city being one and the same is approached by breaking down the problem into three sub-questions.

- Is there is a difference between a seaport cluster and a maritime transport cluster.

- The argument for and against the GDR maritime transport sector as a maritime transport cluster. 
- If the GDR maritime transport sector is a seaport cluster with capital city supporting fledging maritime services.

For the purpose of illustration a cluster is often recognised as an economic prize. A cluster could be viewed similar to that of a horizontal line with three core points, $\mathrm{A}, \mathrm{B}$ and $\mathrm{C}$. The point that denotes $\mathrm{C}$ is the optimum economic cluster or the major successful cluster, the point that denotes $\mathrm{A}$ is the beginning of clustering in terms of early signs of firm agglomeration. In the context of the current research the GDR maritime transport sector is somewhere between point $\mathrm{A}$ and $\mathrm{C}$, in that while it is not a major maritime cluster it is also more than early firm agglomeration. Therefore the GDR maritime transport sector and potential maritime cluster is at the point which denotes B, which is somewhere between point $\mathrm{A}$ and point $\mathrm{C}$. However the exact point of $B$ is unknown. What is known is, that somewhere on the horizontal scale from A to $\mathrm{C}$ lies the clustering of the maritime transport sector. The second question strives to provide a balance to the research concept and addresses the evidence for and against the GDR maritime transport sector as a maritime cluster. It is important to consider both sides of the argument as opposed to concentrating on just trying to prove or disprove the concept. The final section of the question approaches the concept of the GDR maritime transport sector as a cluster with capital city supporting fledging maritime clustering. The importance of the final sub-section question is to take into consideration the surrounding environment in which the maritime transport sector functions.

\subsection{The Difference between a Seaport and a Maritime Transport Cluster}

In approaching the difference between a seaport cluster and a maritime transport cluster the definition of a cluster in general provides an initial insight into the characteristics associated with both types of potential maritime clusters. In the current context of clusters, definitions from Porter (1990) and de Langen (2003) are those that implicitly indicate the way things should be (Roberts, 2005), i.e. a programmatic definition. The first definition is from Porter (1990) who defines a cluster as a; 
"A spatially concentrated groups of firms in the same or related industries that are linked through vertical and horizontal relationships"

(Porter; 1990, P149)

The second from de Langen (2003) who defines a cluster as;

A population of geography concentrated and mutually related business units, associates and public/private organisations centred around a distinctive economic specialization"

(de Langen, 2003, P10)

The two examples indicate that a general cluster has three main, albeit broad characteristics. A cluster has an economic specialisation which is the core or primary sector of industry. The definition also suggests that the cluster has some level of spatial consideration or cluster boundary. Finally the units of the cluster are the related firms, businesses and organizations linked through vertical and horizontal relationships attributed to the core economic specialisation and located within some degree of co-proximity. Therefore in investigating an individual cluster the programmatic definition instruction can help to identify the initial basic features of a cluster, which are;

1. Economic specialisation

2. Spatial concentration

3. Mutually related firms

The following discussion will address the concept of the difference, if any, between a seaport cluster and a maritime transport cluster in terms of the economic specialisation, spatial consideration and mutually related firms. The author acknowledges that there may well be more differences between a seaport cluster and a maritime transport cluster; however limitations in the research process will confine the discussion.

\subsubsection{Economic Specialisation}

The context of the current research is the potential for the clustering of the GDR maritime transport sector and therefore the economic specialisation is maritime transport and the associated units involved in the transport of 
commodities. For clarification in the discussion the term port cluster or seaport cluster will be used.

\subsubsection{Seaport Economic Specialisation}

The economic specialisation of a seaport is the economic consequence of transporting commodities through a port and the logistical interface mode in which ships and commodities arrive and depart. A port as an entity is considered a text book example of clustering due to the lock-in effect a port can produce in the requirement of shipping companies to be at the point of business and for it to facilitate and transcend the cargo from ship through port, to shore (Fujita and Mori, 2006). Despite the discussion of a seaport as an example of a clustering process, ports have not often been approached from a cluster research perspective (de Langen, $2003^{11}$ ).

A port is multifaceted in terms of a wide range of characteristics including geography, depth, cargo handled and ship type serviced. A seaport is a complex system and ports are dissimilar in terms of their assets, the role of a port to a region, the domestic economy and in terms of port activities and services performed (Bichou and Gray, 2005). A port as a physical entity is organised or regulated by a port authority or a higher authoritative body (i.e. local council) and therefore the indigenous government can be represented within a port to varying degrees of influence, control and presence (Meersmann, et el, 2005). Government holds the interest of the public in terms of public policy and a port can illustrate the economy of a region in terms of an engine of, and indicator for economic growth. and the level and potential of socio-economic growth in a region and domestic economy (Bichou and Gray, 2005). A port and a cluster cannot easily be compared to other ports or clusters due to the fact that they are dissimilar in nature. The Port of Dublin is different form the Port of Cork, and the London cluster is different from the Singapore cluster.

The current research has incorporated the relevance of cluster definitions, albeit from a general cluster perspective. De Langen (2003) cites

1 With exception: Antwerp"s port cluster by the Bank of Belgium. 
Haezendonck (2001) as the first scholar to use the term "port cluster" and derives a definition of a port cluster from cluster theories and defines a port cluster as a;

"a set of independent firms engaged in port related activities, located within the same port region and possibly with similar strategies leading to competitive advantage and characterized by a joint competitive position via$\dot{a}$-vis the environment external to the cluster"

The business units and firms associated with the activities of the port can be divided into two core groups, first the port users and second the service providers. The port user group generally consists of shipping companies and shippers while the service provider group which is heterogeneous includes pilots, towage services, forwarders, ship repairers, bunkers, agency, waste reception facilities and stevedores ${ }^{12}$. The clustering of a seaport area/region or district is also related to the critical mass of players in the area, which is directly related to the demand for port activities and the capacity of the port to facilitate that demand. This is further supplemented by the access to the port in terms of deep water facilities, transhipment port status and the availability of land in and near the port area for storage.

\subsubsection{Maritime Transport Cluster Economic Specialisation}

The economic specialisation of a maritime transport cluster is maritime transport, and this incorporates all activities and associated services that facilitate the transport of commodities. Due to the variety and range of services associated with the transport of commodities there are different types of maritime transport clusters which differ in terms of maritime activities, size, and scope. Literature on maritime clusters illustrates how individual cluster's perceive themselves, and the importance placed on certain sectors and sub-sector activities by an individual maritime cluster. As already discussed, clusters generally are not the same and therefore are difficult to compare (Benneworth, 2002).

\footnotetext{
12 Meersman (et al. 2005) notes that stevedores are a special case has they are evolving towards terminal operating companies as they provide a paid service.
} 
Maritime clusters include sectors such as shipbuilding, finance, law, ports and shipping companies etc. It can be argued that a maritime transport cluster should have representation from all possible maritime transport sectors in order to be classified as a maritime transport cluster. However the London maritime cluster for example does not have a shipbuilding sector and the lack of such a service does not render the London maritime service cluster an area of firm agglomeration as opposed to an international successful cluster. A maritime transport cluster would infer that the cluster has a critical mass in terms of physical transport activities as opposed to just services, or a combination of both physical logistical transportation and supportive services.

Maritime transport cluster's economic specialisation is maritime transport. The economic strength of the specialisation may be dictated by a specific sector e.g. port focused cluster, logistics focused or service focused. Also many contemporary maritime clusters will have been heavily influenced by geographic and historical economic occurrences. The London cluster is known as a maritime service cluster due to its critical mass of world market players and proliferation of maritime services such as banking, law, consultancy, media, risk, arbitration, and insurance. Historically, the UK had a significant merchant fleet and London held a prominent position in terms of a major world maritime power. However as the merchant fleet flagged out and trading moved east, and London in terms of port activities no longer really exists, the city of London has managed to maintain its prominence by evolving from a major maritime trading nation to a major maritime service cluster. This could be argued as a successful combination in historical and economic terms of the strength and growing prominence of the city of London and declining presence of the UK flagged fleet and general position of the UK as a major maritime power. Basically the UK maritime industry was successful in evolving and maintaining its maritime success in terms of critical mass, economics and perception of world class service to evolve from major trading maritime nation to major world class maritime service cluster. 
In comparison, the economic specialisation of Dublin's maritime cluster is directly related to port activities, shipping services and freight forwarding. The concentration of the clustering of firms is based on the physical distribution of goods with a small representation of maritime transport support services. As described in Figure 16, the country's principle port drives the demand for firms and businesses to facilitate the trade of cargoes through the port. However Dublin port lies within proximity to Dublin, the countries capital city which inherently creates synergies between the city and the port and the establishment of some level of maritime transport service clustering.

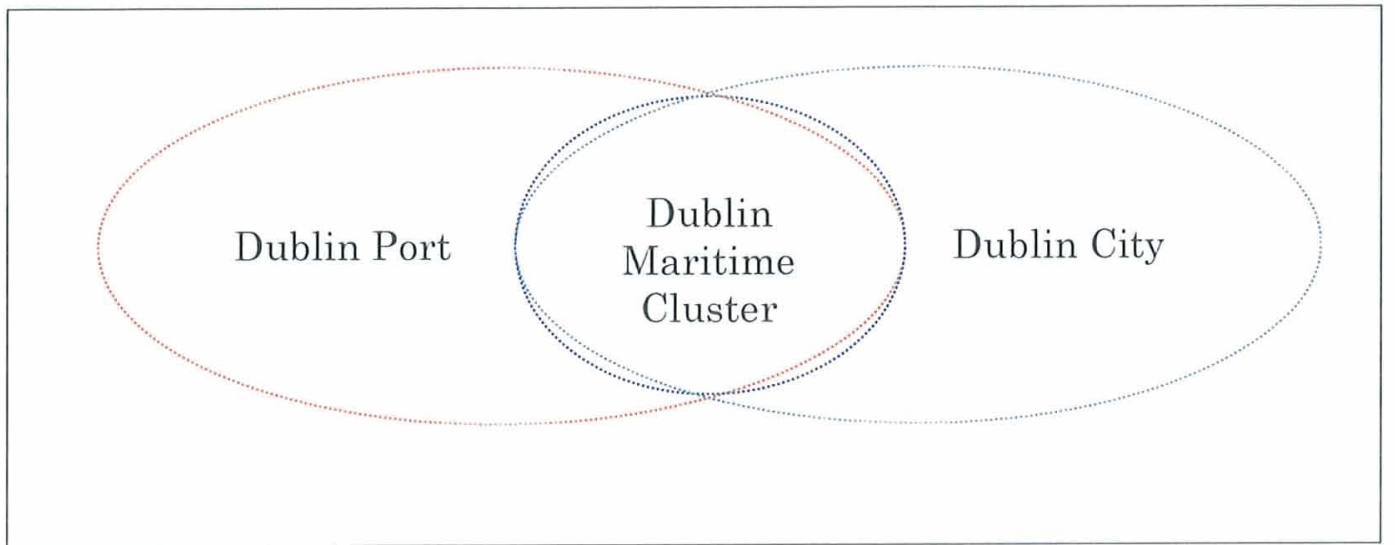

Figure 16 Interrelationship in the Dublin Maritime Cluster (Source: Author's Own)

In summarising the importance of Dublin port as a seaport cluster which is key to the drive in developing a maritime transport service sector supportive of Dublin as a capital city. Therefore any future clustering and industry expansion development would logically benefit from the growth in services in Dublin port. Dublin port is situated on the east coast of Ireland and Table 25 displays the value of trade handled in some of Ireland's ports in 2006 in which Dublin exceeds by far. 
Table 25 Estimated Value of Trade Handled by State Commercial Seaports $(€)$

\begin{tabular}{|l|r|r|r|}
\hline \multicolumn{1}{|c|}{ Port } & High $^{* 13}$ & \multicolumn{1}{c|}{ Low $^{*}$} & \multicolumn{1}{c|}{ Mean } \\
\hline Dublin & 46,805 & 28,038 & 37,444 \\
\hline Cork & 16,311 & 9,787 & 13,049 \\
\hline Rosslare & 9,631 & 5,779 & 7,705 \\
\hline
\end{tabular}

(Source: Irish Port Association, Indecon Analysis, 2006)

Dublin port in terms of Ro/Ro trade handled over 693,000 freight units and this accounts for $55 \%$ of the total throughput (Dublin Port, 2007). In terms of Lo/Lo Dublin is also the main handler which in 2006 handled over 675,000 TEU's (Dublin Port, 2007). The port also caters for liquid bulk, dry bulk and cruise liners. Ireland being an island nation the country's domestic ports handle $99.5 \%$ of Irish foreign trade in terms of volume, $90 \%$ of Ireland's GDP is exported, of which $42 \%$ is serviced through Dublin port. Between $40 \%$ and $50 \%$ of goods entering Dublin port are destined for areas within the M50, which increases to $75 \%$ when the area is extended to $80 \mathrm{~km}$ radius of the city (Dublin Port Co, 2006).

The economic specialisation of a maritime transport cluster is influenced by the geographic location of the cluster. For example major clusters like Rotterdam and Singapore have the benefit of critical mass due to their status as transhipment ports for Europe and Asia respectively. The main concept of a maritime transport cluster is the clustering of maritime transport firms as opposed to a port cluster in which firms are located in or near the port facility due to their direct operational role and lock in effect with the port facility.

\subsubsection{Spatial Concentration}

Spatial consideration in terms of clusters relates to an issue of cluster boundaries or the delimiting of a cluster zone. Basically the spatial consideration is an aim to determine the geography of an individual cluster and therefore the geographical extent of its positive effects. However literature on clusters will support the theory that clusters do not have a boundary and the positive attributes associated with the clustering effect

$13 *$ High and Low estimates presented are based on a range of - $25 \%$ around the mean estimates shown. 
cannot be confined to the spatial consideration of artificial boundaries implemented by government. The onslaught of globalisation and technological development has truly created a death of distance in world markets; however there is still a recognised benefit of being located within a cluster and therefore there is consideration to the reality of a cluster boundary. The difficult question is with respect to the extent of diffusion of the positive effects of a cluster and the extent of spatial consideration.

\subsubsection{Spatial Consideration of a Seaport Cluster}

The spatial consideration of a port or the relevant port region consists of the interface of land and sea in the transport of commodities and the immediate surrounding area. The size of a port and the availability of the surrounding area to support port activities vary from port to port. The area of a port can be divided into two, first the primary port area which is directly proportional to the size, structure, depth and capacity of the port to handle cargo and includes the physical structure of quays and terminals. Beyond the initial primary port area is the business district of the port which incorporates offices and firms.

The spatial consideration of a port area is determined by a firm's activity and the need to be located within the port area or relevant port region to service the point of business. In the context of Dublin port the physical area is 270 hectares (IMDO, 2007) and the port area and relevant region holds the country's second biggest industrial estate in terms of employment of 4,000 personnel of which Dublin Port Company specifically employs $2 \% 0$ (Port Policy Statement, 2005). Proximity in terms of the port is enforced by the need of port users to be located near the point where business delivers. The terms of the spread of the relevant port region is determined by the growth in volume of goods transiting through the port and the available space the port has to utilise for future capacity demand. Currently Dublin Port has plans to reclaim and develop 21 hectares of its foreshore (Oram. 2006) for future expected demand for port capacity. 
As discussed, the relevant port region is determined by many physical factors and therefore when compared to the spatial concentration of a maritime transport cluster, a seaport cluster physical area can be a lot smaller. This could also provide clustering benefits for direct port related firms. The knowledge spillover effect would not have a greater distance to diffuse and the smaller concentration of players may allow for faster diffusion of existing knowledge and quick access to new knowledge in cluster developments. The smaller nature of the cluster may help to foster stronger relationships of trust as the potential negative effects of a firm acting in a mistrustful manner may be more serious due to closer proximity of firms. The relative closeness of proximity may also help to fuel faster cluster relationships as port regions tend to be detached and isolated by the very nature of the port being an industrial district. Basically other firm types and different industries will not locate in the port region; they would locate in the city or general business area as only port related firms and transport firms would logically locate within the port zone.

\subsubsection{Spatial Consideration of Clusters}

The spatial consideration of Dublin's potential maritime transport cluster is centred on Dublin city and Dublin port. The current research required a definition of a boundary or potential cluster zone and the justification is two fold. First, from cluster definitions, a cluster has some concept of a boundary and second the potential cluster being researched required a boundary in order to place some control on the research process. In terms of thinking of a potential maritime cluster, Dublin is essentially a port city which is self explanatory; port and city are co-located and derive from historical consequence of the need to trade. In terms of spatial consideration in a contemporary framework the city and the port are in reasonable close proximity. For the purpose of the current research the obvious boundary is that of the city limits and the city centre. However the government NSS (2002-2020) discusses that much of Ireland's recent prosperity has been generated in an area defined as the GDR which refers to the area including 
Dublin city and all the Counties of Dun Loaghaire/Rathdown, Fingal, Kildare, Meath, South Meath, South Dublin and Wicklow.

Unlike the enforced spatial consideration of a seaport cluster, a maritime transport cluster's spatial consideration in a contemporary setting is based in history while its future and potential have as yet to be realised. The boundary of a cluster can be determined geographically, spatially in terms of the physical space actually available, economically in terms of its potential and the ability to succeed in international markets. The spatial consideration of a maritime transport cluster is a combination of the geographic breadth and depth of the city and the ability of that city to be successful in an international business sphere. The city does not hold a lockin effect as strong as a port, although depending on the cluster and its international success, the city can have a strong location pull. The City of London's international competitive advantage as a maritime transport service cluster has an inherent strength and lock-in effect in terms of world prominence, clustering, and market knowledge which keeps maritime service firms focused on the importance of their London location.

There are differences and similarities of a seaport and a maritime transport cluster, as already discussed. However clusters cannot be easily compared (Benneworth, 2002) and similarly ports cannot be easily compared. Is a seaport cluster just a smaller set or a sub-set of a maritime transport cluster? There is little doubt that the two are linked and interact, benefit and influence each other. Although it could be reasonable to argue that a port cluster originally would have had a greater influence on the development of a maritime transport cluster as opposed to a maritime transport cluster influencing the development of a port cluster. The Fishers Associate (2004) report investigated the future of the London maritime service cluster, and $59 \%$ of the respondents did not believe that the London cluster will not be what it is today in ten to twenty year's time. This would raise the question of the significance of considerable port activities for major and future maritime cluster development. For example, Singapore, Hong Kong and Rotterdam are three of the world's major maritime clusters and 
all three hold critical mass in terms of port activities. Perhaps a maritime cluster can be built without considerable port activities; however the activities of the port are a core feature in the development of a maritime transport cluster, especially in a historical context. The important question in terms of countries like Ireland, where the port in question is not a major port or transhipment facility, is the ability to develop further a maritime transport cluster supported by only some level of limited port activities.

In terms of spatial consideration there is a difference between a seaport cluster and a maritime transport cluster. A seaport cluster is limited by space and capacity and geographic facilities such as depth. A maritime transport cluster is potentially limited by a city boundary, however the world is its market and thus its success it determined by the firms and the clusters ability to succeed in international markets.

\subsubsection{Mutually Related Firms}

Within a cluster, firms are mutually related to each other and determined by the cluster's core economic specialisation. The discussion on mutually related firms is similar to that of the economic specialisation in terms of the type of firm, business or organisation within a cluster.

\subsubsection{Mutually Related Seaport Cluster Firms}

Firms associated with a seaport cluster are mutually related and determined by the requirement of the port and the port's facilities. The firms are also linked by the conomic specialisation of maritime transport. As already discussed in the context of the port there are port user's and service provider's. What links firms to a port cluster is the direct relationship with the activities of the port as port users and the need for certain port services to accommodate the service an individual firm provides. The basic mutual relationship of firms in a seaport cluster is their purpose to be in the port in the first place. This may appear as a curious statement; however it has relevance when one considers the mutual relationship of firms in a seaport cluster to that of the mutual relationship of firms in a maritime transport cluster. 


\subsubsection{Mutually Related Maritime Transport Cluster Firms}

A maritime cluster has a wider scope of business than that of a port cluster. Maritime cluster's provide the services to support trade such as banking, law, consultancy, media, insurance, academia and research and development. As discussed in the literature review many maritime clusters have an array of maritime sectors and not every individual maritime cluster has all potential maritime sectors. A maritime cluster's firm purpose is to provide a service and therefore can basically locate in any country or in any maritime cluster. Within a maritime and seaport cluster firms have direct relationships, but a maritime transport cluster would also have a greater density of indirect relationships owing to the varying nature of services and sectors potentially provided for. While the direct relationships in the port and maritime transport cluster are based on business necessities with each other, the maritime transports indirect relationships may be more common due to association with the core economic specialisation of maritime transport. The difference between a seaport cluster and a maritime cluster depends on the individual cluster, as the type of and levels of maritime operations differ. There is also a historical and evolutionary perspective to maritime clusters and maritime industries, as clusters of industries must evolve and adapt to maintain their competitive advantage. Other decision factors could be the role of government, the location of the region in terms of the host country and the strategic location of the country and the general perception and importance of the maritime industry nationally. Definitions of clusters describe the concept of mutually related firms in order to aid in identifying what type of firm is associated with a specific cluster. Clusters of industries are complex and have many different sectors and potential subsectors as illustrated in Figure 5 in the shipbuilding sector relationship with the potential sub-sectors of construction, ICT, the environment and energy. As illustrated in the literature review different cluster will class sectors differently and hold more importance of some sectors over others. The relevance of mutually related firms is in context to the core economic 
specialisation and the possible direct and indirect relationships firms have to the clusters core economic specialisation and to each other.

The comprehension of the difference between a seaport cluster and a maritime transport cluster is relevant for the process of policy design. In the first instance a cluster infers that there is a level of critical mass. With a seaport cluster that critical mass is enforced and defined by firms who have and require a direct relationship with a specific port, for the port itself the critical mass can be determined by its geographical location and it ability to facilitate cargo now and in the future. The port itself can be looked upon as negative in terms of effects on the environment, impact of local communities, and increasing levels of noise, pollution and traffic and therefore port development can be affected by local community groups, councils and governments. In terms of a maritime transport cluster the critical mass is a benefit, more players increase the level of cluster competition, firm variety and potential cluster stickiness. In terms of a maritime transport cluster its potential market is determined by the world markets and is not as critically restricted by factors of space and geographical location and its potential market is determined by the individual cluster's ability to win customers and maintain a competitive advantage.

\subsection{The Evidence/Argument For and Against that the GDR Maritime Transport Sector as a Maritime Transport Cluster}

The next stage of the discussion is to investigate the arguments for and against the GDR maritime transport sector as a maritime transport cluster. It is important to argue both cases in ordex to provide an appropriately unbiased and balanced view. However it is an easier task to argue reasonably that the GDR is a maritime transport cluster than to argue against it. In a similar way it is easier to prove competitive advantage using Porter's 5 Forces model than to disprove a competitive advantage. 


\subsubsection{The Argument for the GDR as a Maritime Transport Cluster}

The importance of the research question for the maritime sector in Ireland and specifically in the Dublin region is that Ireland is an island nation located on the periphery of Europe, and therefore requires commercial activities that facilitate the transportation of commodities. Due to the geographical requirement for the transportation of goods and the fact that within the GDR lies the country's principle port and the critical mass of maritime firms, there is some level of clustering in the maritime transport sector in the GDR.

In summary, the GDR appears to have a maritime transport cluster for the simple reason that it has to. The reality of the question is, is the sector of industry displaying clustering characteristics or is it just basic maritime transport firm agglomeration. The cluster itself is to some extent visible because within the GDR lies the country's principle port and the critical mass of maritime transport and related firms. The maritime transport sector within Ireland and specifically within the GDR therefore can be classified as being a cluster, although it simply does not compare in terms of critical mass and economic return to major maritime clusters of London, Rotterdam and Singapore. There are no appropriate guidelines although there are some indications that infer when a cluster has been achieved. The maritime transport sector in the GDR looks like a small maritime transport cluster.

\subsubsection{Evidence from the Delphi Study}

As the results from the Delphi study have already been discussed in detail this discussion will not elaborate further. However the discussion will focus on consensus and opinions that support the argument of the GDR maritime sector as a maritime cluster. The first question in the Delphi asked the panel members if they consider the GDR maritime transport sector as a maritime cluster. The question achieved an agreement consensus of $78 \%$ in the first round and therefore $78 \%$ of the panel consider the GDR as a maritime transport cluster. The consensus had four main threads of opinion 
which had two core discussion points. First the GDR maritime transport sector is a maritime cluster, although it is a small cluster in that it is limited and there are gaps in certain services. However opinion did make the distinct correlation of the importance of relationships in clusters and although the Dublin maritime industry is small and has a small number of players in contrast to major maritime clusters, the smallness of the industry is supported in the benefit of relationships the industry players have by supporting co-proximity. The second core of opinion addresses Dublin city and the surrounding area as a focal point in terms of both population density and industrial centre and therefore an obvious focal point for business location. As already discussed $40 \%$ to $50 \%$ of goods entering Dublin port are destined for areas within the M50, which increases to $75 \%$ when the area is extended to an $80 \mathrm{~km}$ radius of Dublin City (Dublin Port Co, 2006). There are three key strong factors here, first the distortional population demographics near and around the GDR, the location of the countries principle port in the GDR and the location of the countries capital and primate city in the GDR. In combination and co-location the three factors discussed are a strong and considerable clustering force for the GDR, or for any industry. However it may be that such forces are the clustering power for the GDR maritime transport sector as opposed to the industry being the defining clustering force. Clusters of industries, like economies are not stationary, they evolve, develop, grow and fail and their future success is linked to their future potential.

The second question in the Delphi addressed the future potential clustering of the GDR maritime transport, which reached a consensus agreement of $72 \%$ in Round 2 that the GDR maritime transport sector had potential to move forward to a more recognisable cluster status. Returned opinions for the question concentrate on the need of tweaking regulations, incentives and implementing attractive policy and developing niche areas of maritime industry. The importance of Dublin port was again addressed in terms of the trade volumes it services and therefore the future potential trade volumes and growing projected population statistics are important. 
Population statistics will be discussed in the following section and in terms of cargo throughput statistics (Appendix 1) outlined the trade flows for the Ports of Drogheda and Dublin. The advent of the new Bremore port development has already been discussed and will not be further elaborated upon within this discussion. However in conclusion there is an expected increase in the population of Ireland and trade flows continue to increase in the short to medium term period and therefore the demand for goods and the volume of goods will increase.

\subsubsection{Cluster Statistics}

In looking at clusters generally and more specific maritime clusters we can gain an understanding of the concepts involved. While the common dominator of a cluster may not be solely one of critical mass, it in no way diminishes the advantages and identified benefits of mass players within coproximity. Major successful clusters are first easily identifiable due to their size alone but not all clusters are "major clusters" and this leads to the question of a general cluster formula; does a cluster require a certain number of firms before it can be classed as a cluster? Is there an optimum firm level that encourages the fostering of relationships? The story of clusters is not always about the major successful clusters as it could be reasonably argued that there are far more smaller and medium sized clusters as regional clustering can be identified in almost all advanced economies and developing economies (Enright, 2003). In order to go some way to address such questions, a meta-study of clusters was devised from both developed and developing nations and the author Linde (2003) concluded that the study is the largest and most representative basic data on cluster description.

\subsection{Location}

In terms of location the results from the study show that $41.8 \%$ of clusters (a total of 705 clusters) were located within the boundaries of a city, $18.9 \%$ within a metropolitan area and 19.9\% within part of a state (Linde, 2003). Cluster's by their very nature are geographic concentrations. However the 
context of a cluster life cycle and its relationship with the evolution of a city would be an interesting research area as it can be reasonable argued that cities do provide some level of host for a cluster. This supports the metastudy when almost half of the clusters of the study are located within cities boundaries and a further $18.9 \%$ within a metropolitan area. The maritime transport sector in the GDR is located within Dublin city boundaries.

\subsection{Size}

As already discussed clusters vary in size and scope, however in terms of the study with respect to cluster size, an average cluster has 150 companies. The study had data with respect to size from 382 clusters of which $41.6 \%$ had less than 100 firms, $13.9 \%$ had between $100-200$ firms and $9.4 \%$ had between 200-300 firms and therefore smaller clusters tend to be the norm. In line with cluster definition and in terms of what type of firms, business and organisations are included in a cluster, the GDR had 250 units. Therefore it could be proposed that the GDR maritime transport sector has a reasonable cluster count. However a large proportion of that count would be firms associated with direct port services such a freight forwarders as opposed to maritime service areas of law, banking and brokering. The current cluster count for the GDR include government and industry organisations and it is unclear if the study also considered such activities within the study cluster count.

\subsection{Employment}

The cluster size is also directional proportional to cluster employment statistics with smaller cluster size of less than 15,000 employees again representing the norm. Of the cluster data available (457 clusters) 38.1\% had less than 5,000, 12.3\% had between 5,000 and 10,000, and 8.8\% had between 10,000 and 15,000. In contrast the largest workforce was 1 million from the Silicon Valley and the smallest was 50 employees in a French musical instrument cluster (Linde, 2003). In terms of employment numbers, direct statistics can be difficult to obtain as there is a tendency for governments to include maritime transport into a general transport 
category which can include road, rail and air. Also in terms of maritime, statistics can include areas of marine science and sectors such as aquaculture which result in a distortion of precise figures. In terms of statistics of the GDR there are no definite employment statistics however the Ports Policy Statement (2005) cited the Dublin Port district employing 4,000 personnel with 270 being employed by Dublin port alone. The GDR statistics while not conclusive, places the maritime transport sector and predominately the port district near the less than 5,000 employees bracket which represents $38.1 \%$ of the employment figures in the cluster meta study.

Linde (2003) cites one of the largest clusters as that of the textile cluster in Prato (Italy) which has over 9,000 firms; however one of smallest clusters is the Swiss hearing aid cluster and the ion implanting equipment cluster in Boston (USA) which have only three core companies. Linde (2003) discusses further how successful clusters can be overlooked in statistics as in the previous discussed Boston cluster has only three companies which hold $90 \%$ of the world market supporting hundreds of employees, and world leading research. In conclusion on the argument of the GDR as a maritime transport cluster, first it looks like a cluster, the industry that function within the cluster in terms of consensus consider that it is a cluster and in context of Linde (2003) meta study on clusters further supports the fact that in terms of location, size and employment the maritime transport sector is of a reasonable clustering size.

\subsubsection{The Argument against the GDR as a Maritime Transport Cluster}

For the purpose of providing a balanced argument it is reasonable to hypothesise why the GDR is not a maritime transport cluster in light of the fact that it is difficult to acutely define when an individual industry as achieved a clustering status. As already discussed it is easier to devise arguments for the GDR as maritime transport cluster than to develop arguments that disprove the concept. In light of the arguments discussed for the GDR as a maritime transport cluster the main source of disagreement 
arguments come from the Delphi study and therefore the following discussion will concentrate on opinions returned that support the concept that the GDR is not a maritime transport cluster.

\subsubsection{Evidence from the Delphi Study}

In the first round of the Delphi a consensus agreement was achieved in that $78 \%$ of the Delphi panel considered that the GDR maritime transport sector is a maritime cluster. Therefore $22 \%$ of the panel disagreed that the GDR is a maritime transport cluster and the opinion returned had two main threads. First there is the opinion that in the context of international shipping there is not sufficient activity in Dublin and this opinion can be repeatedly seen throughout the three rounds of the Delphi. Depending on the context of the Delphi question many of the panel stated that there is a real need for more shipowners and operators to be located in the Dublin maritime transport sector, either for the purpose to classify the sector as a cluster or in the context of improving and strengthening the clustering of the industry. The dominant number of firms with working relationships based on port activities, either directly or indirectly supports the argument of the GDR being currently based on the importance of port activities and therefore it can be reasonably argued that an increase in shipowners and operators will increase demand for maritime services. However opinion did also discuss that there is no specific area in Dublin that is a cluster except that of Dublin port and as already discussed in terms of employment figures, the Dublin port area is perhaps one of the largest concentrations of industry in a specific geographic region within Ireland. Further opinion retuned in disagreement discusses the maritime service sector specifically citing insurance and banking in that there are only one or two firms facilitating such a service and the service is for domestic trade only, in that international clients would not consider such firm's experts. It was also discussed that many service orientated firms would only have a designated person that would deal with maritime interests. 
In Round 2 the Delphi panel returned an agreement consensus of $72 \%$ that the GDR maritime sector has the potential of developing further its maritime cluster. Therefore $28 \%$ of the panel disagreed with the consensus and the opinion returned in disagreement had two threads of opinion. The opinion returned further argued that the GDR was not a cluster or had future cluster potential due to the region's lack of scale to be considered a strong cluster in international terms. The core arguments against the GDR being considered a maritime transport cluster appear to have its basis in size and critical mass as opinion discusses the peripheral location of Ireland and it remoteness in contrast to competing clusters of London, Rotterdam and Singapore. The lack of resident shipowning and operators was again raised and the fact that there is no port in Ireland with transhipment port status. The supporting thread of opinion discusses that while there may be potential there is a lack of political drive to make it happen and discusses further a lack of qualified labour supply and training and education while the issue of size and critical mass along with residential shipowners appear to be the main arguments in dispute of the GDR as a maritime transport cluster.

In concluding the argument against the GDR as a maritime transport cluster the Delphi panel did provide valid examples and discussions from there opinion in disputing the sector of industry as a cluster which also provides indications to the weakness of potential industry clustering. It could be argued that the real relevance of the GDR maritime transport industry not actually being a cluster is in terms of a point of policy intervention to developing any policy or strategy to encourage clustering behaviour. The following discussion develops further on the reality and concept of the GDR maritime sector as a maritime cluster or the proposed concept of port cluster and capital city supporting fledging maritime services. 


\subsection{The GDR Maritime Sector as a Port Cluster with Capital City Supporting Fledging Maritime Services}

It has been highlighted throughout that the maritime sector in the GDR is dominated by port activities in that the critical mass of firms are associated with direct transportation as opposed to maritime based services such as law or banking etc. This section will investigate the role of the city as the host for maritime transport industries and its potential support in developing the clustering of a maritime transport sector.

\subsubsection{The Importance of Cities and Dublin City}

Fujita and Mori (1996) describe the concentration of economic activities in terms of cities as perhaps one of the most noteworthy features of contemporary economic geography. Many of the world's major cities developed at a site of good water access and the optimum geographical point for the trading of commodities. Historically, many cities developed from the importance of initial port activities and the importance of a logistical mode interface for land and sea trading, even though currently some cities do not require the ongoing role of port activities to hold prominence of a cities status such as in the case of Paris, Chicago and London.

Dublin is the capital city of Ireland which is an island nation located on the northwest periphery of Europe. The city was originally founded in the late 19 th century by Viking settler's and later the city developed into a port and urban settlement by the Anglo Normans (Williams and Redmond, 2006). The Republic of Treland in the $1980^{\circ} \mathrm{s}$ suffered a repression and considerable job losses as unemployment peaked in the 1980's at 18\% (Williams and Redmond, 2006), however together with a shift from a manufacturing and agriculture based economy to a service based economy and the closure of tariff protected industries (Williams and Shiels, 2002, A) the country experienced rapid economic growth which facilitated a strong "Celtic Tiger" effect on the Irish economy in the 1990's. From a historical and contemporary perspective the Irish economy can be evaluated in three distinct phases, first the basic manufacturing stage and considerably 
agricultural based economy, second phase sees the economy develop rapidly with the help of foreign direct investment and successful inward investment and finally the economy is progressing towards an innovative and knowledge based economy. Ireland's attainment for a knowledge based economy is perhaps driven by an over reliance on foreign direct investment and the result of poor infrastructural facilities to cope with the recent rapid development of the economy seen over the last decade (Williams and Redmond, 2006).

Dublin is the dominant city in Ireland and is therefore classed as a primate city (examples of primate cities include, London, Paris, Tokyo and Mexico City) which infers that Dublin city is the significant city in terms of financial, political and population for the country and its status is not rivalled by any other city within the country. The law of primate cities was developed by the geographer Mark Jefferson in order to understand the phenomenon of large cities which hold a substantial proportion of a country's population (Rosenberg, 2006). In terms of the continued prominence of Dublin city within Ireland's regional population, projections for the period 2006 to 2021 inclusive for the greater Dublin area (i.e. Dublin, Kildare, Meath and Wicklow) is expected to increase by over half a million persons. In line with the Central Statistics Office MIF2 scenario the scenario assumes a continuation of recent demographics trends) the greater Dublin area which currently possess $39.2 \%$ of the population of the state is projected to increase to $40.7 \%$ of the total projected population of 5 million in 2007 (CSO, 2005). Table 26 depicts the breakdown of the population statistics in terms of Dublin city and the surrounding areas that constitute the GDR.

Table 26 Population in Province. County or City

\begin{tabular}{|l|r|}
\hline Province, County or City & Total \\
\hline Dublin & $1,187,176$ \\
\hline Of which & \\
\hline Dublin City & 506,211 \\
\hline Dun Laoghaire / Rathdown & 194,038 \\
\hline Fingal & 239,992 \\
\hline South Dublin & 246,935 \\
\hline
\end{tabular}




\begin{tabular}{|l|r|}
\hline Meath & 162,831 \\
\hline Wicklow & 126,194 \\
\hline State & $4,239,848$ \\
\hline
\end{tabular}

(Source: CSO, 2007, A)

The breakdown of the age profile of the population as depicted in Table 27 and shows that the largest set of the population is the $35-44$ age group which is the main source of labour supply.

Table 27 Population by Age in 2006

\begin{tabular}{|l|l|}
\hline Age Group & Total \\
\hline $0-14$ & 864,449 \\
\hline $15-24$ & 632,732 \\
\hline $25-44$ & $1,345,873$ \\
\hline $45-64$ & 928,868 \\
\hline 65 and over & 467,926 \\
\hline Total & $4,239,848$ \\
\hline \multicolumn{2}{|c|}{ (Source: CSO $2007, \mathrm{~B})$} \\
\hline
\end{tabular}

The presence of a primate city tends to indicate an unbalance in development which is reflected in Ireland generally in terms of the Government's National Spatial Plan and the desire to relocate government offices to external GDR locations. Dublin is the commercial, political, financial, administrative and cultural centre of Ireland and holds $40 \%$ of the population along with $80 \%$ of government offices and $70 \%$ of headquarters of major Dublin and private firms locate within Dublin city (Williams and Shiels, 2002).

\subsubsection{The Role of the Port in the Making of Major Cities and Clusters}

Many of the world's prevailing cities historically developed at the site of good access and many country's dominant cities have developed at port sites (e.g. Rotterdam and Singapore). There are also leading cities which are not based on port activities (Chicago and Paris) although it is argued that their original growth is founded on their historical necessity to access water (Fujita and Thisse, 1996). The question of original port development can be of interest to many different scholars. From a historical and geographic perspective the port is the optimum point for the activities of trade however 
Fujita (et al, 1996) argues that for the economist the question of ports is not clear. The struggle of the economist in the concept of the interrelationship of ports and cities may have its relevance in a contemporary framework as opposed to just historical precedence. The neoclassical port city model is based on the trade theory of comparative advantages, however history has lead to the identification of the limitation of such a model as many port cites have continued to develop long after the initial advantages the port location offered i.e. access to cheap water and transportation. Fujita (et al, 1996) argues that in terms of the neoclassical model of port cities, such cities should have declined once the feature of cheap access become redundant. As discussed ports have been important for city development historically but other influences have aided city development as an individual economy broadens and produces additional services along with social structural enhancement (Gleave, 1997). Therefore it can be reasonably recognised that there is a level of interrelationship between city and port and terms of maritime transport there is some instance of co-evolution towards a maritime transport cluster.

In examining a cluster the first natural step is to investigate a successful cluster. The process can be described as; Country A has a successful cluster in developing a certain type of drug (e.g. drug is being used as an analogy of an industry cluster) and has gained a competitive advantage. Country B has identified Country A's success and also wants a competitive advantage. Countrys $B$ first process is to identify the ingredients of that drug with the basic believe that if Country $B$ identifies and acquires those ingredients, Country B will also gain a competitive advantage. Country B's acquires such ingredients but still it fails to achieve the cluster success of Country A. By just acquiring the ingredients will not guarantee any clustering success as while the ingredients are the main components, Country A's ingredients would have been distilled, and produced in different ways i.e. the formula, the manner in which the ingredients are mixed, the different quantity of ingredients added. The formula process is what makes a cluster a successful cluster, and it is something that occurs over a period of time (years, decades 
etc) with historic consequence and moments of governance, policy and economic serendipity and supports the temporal dimensions of clusters. Clusters in there simplicity are just complicated, and by mimicking a successful cluster will not guarantee the same positive economic consequence. Individual investigating successful clusters should approach the concept as knowledge exploration and not as a formula for economic success.

The City of London and the London maritime service cluster provides a good example of how a city can continue and evolve to support a maritime cluster. If the City of London did not hold an international prominence in services such as banking, law and finance it would be reasonable to conjecture that the London maritime service cluster would not be the formidable cluster it is today. Historically the city of London like many cites developed from the appropriate point for access to trade supported by the United Kingdom's dominance as a world superpower and major maritime trading nation. The subsequent decline of the merchant fleet, flagging out and the fact that the city presently does not the hold the relevance of port activities it once had has contributed to the decline of the physical elements of the maritime cluster. However as London declined in terms of port activities and the location of shipowners and operators the City of London was continually developing as one of the world's major cities and foremost financial clusters. The maritime industry like all industries requires the services of banking and law and associated support services and the City of London helped evolve a major maritime trading nation into a world class city which hosts a distinct competitive advantage in terms of a maritime service cluster, supported by the City of London's prominence as a financial cluster. Therefore it can be argued that a natural or organic maritime cluster develops from the location of a port first which inherently creates some level of port clustering. From the port cluster comes the port users and at some point the city begins to support and facilitate the services for the port users and the original port cluster can evolve towards a maritime transport cluster. 


\subsubsection{The Relationship between Cities, Ports and Maritime Clusters}

From the review of literature it is accepted that clusters can aid in the development and successful competitive performance of regional economies (Leibovitz, 2004). Although difficult to fully conceptualise there are mutual benefits in terms of the co-location harvested between cities, ports and maritime clusters. The relevant question in the current discussion is to begin to understand that concept for Dublin City, Dublin Port and the potential clustering of the maritime transport sector in the GDR i.e. the Dublin maritime cluster. The full extent of the concept would require detailed examination and thus is beyond the scope of the current discussion; however the current debate can begin to appropriately structure the concepts involved for further research. As already discussed, Dublin City is a primate city and currently holds significant mass in terms of employment, population, and industry. The country's principle port and mass of maritime transport firms are also co-located in the GDR and particularly within Dublin City. In the first instance due to the consequence of co-location there appears a visible albeit small in global standards maritime transport cluster.

\subsubsection{Importance of Understanding Port, City and Cluster}

The importance of understanding the interrelationship and flow of benefits between port, city and cluster has its relevance in why the current question (is the GDR a maritime transport cluster, or is it the result of major port facility and capital city being one and the same) was selected over the other research questions derived from the Delphi. Many of the further research questions at some level assume or indicate that a cluster already exists. If there is even a slight indication or viable query that questions the reality of the GDR and its cluster, that question must first be addressed. It is important to know and understand first the extent and reality of the concept of the Dublin maritime cluster.

The discussion has considered the argument that the GDR maritime transport cluster may be predominately port based with the strength of 
Ireland's capital city supporting fledging maritime services and thus producing a visible maritime transport cluster. For the Irish maritime transport industry in terms of clustering it could be argued that the colocation of principle port and capital city as been an industry clustering serendipity. However the true reality and nature of the clusters foundations is still important. It is significant for policy intervention and potential urban branding to truly understand the foundations of the cluster. If the industry is a cluster and behaves like a cluster, then if at some point in the future government or a relative industry organisation decides to devise a strategy or policy to fuel industry clustering based on knowledge obtain from research and clustering theories, there is a possibility that such a strategy or policy may derive some benefit. However, if the industry appears to look like a cluster, but the reality is basic firm agglomeration, then the implementation of cluster driven polices may well fail as the policy would be based on theories that enhance industry clustering. If the industry is not a cluster then clusters driven policy will fail. Therefore in terms of the GDR maritime transport sector areas of research and understanding that concentrate on city development and evolution, knowledge management and urban or city branding may be much more appropriate and more useful. In such an instance the maritime cluster could still market itself as cluster however it is important to know and understand the reality for the point of policy intervention and to aid any process which looks at enhancing the sector of industry. As Ireland is an island nation it must have the industry of maritime transport and therefore it would appear logical and reasonable that government, industry, policy makers and academics would have a continuing interest in the ongoing development of Ireland's and specifically the GDR maritime transport sector. Leibovitz (2004) argues the element of the role of the public sector and public policy can have an important influence of the relationship between cities and cluster development. Leibovitz (2004) discusses that universities, research institutions facilitate a significant role in terms of providing a potential knowledge and labour base for a cluster. Therefore it can be argued that the city could adapt or tweak 
certain infrastructures to positively encourage the conditions of clustering for a particular industry.

The next chapter will draw on the final conclusions of the research. 


\section{Chapter 9. Conclusions}

In discussion of the conclusions for the research the original basis for the research question must be briefly revisited. Ireland is an island nation located on the periphery of Europe and therefore requires by necessity the ability to import and export commodities. Specifically located within the GDR lies the country's principle port and the critical mass of maritime transport and related maritime firms. Therefore as an island nation there is some level of maritime transport activity and exclusively within the GDR due to co-location of principle port, capital city and critical mass of maritime transport firms, there is some level of maritime transport clustering. In concluding the necessity for maritime transport and the proposed clustering of maritime transport activities within the GDR; what is the potential for the clustering of the maritime transport sector in the GDR? In terms of the research objective and the specific research question there are three key words which arguably are the foundation blocks of the research and direct the formulation of the research process. Those three key words are explorative, clustering and potential.

The basis of the research is explorative in the sense that while there is established examination in maritime research, cluster's and maritime clusters, there is no research concept that has investigated clusters in the maritime transport sector in Ireland and specifically within the GDR. The hypothesis of the research question addresses the maritime transport sector from a cluster perspective which therefore includes business, firms and organisations related to activities of maritime transport. The inherent nature of the research question dictates that all maritime transport related sectors must be involved in the research process. In considering the clustering of the GDR maritime transport sector requires the research process to begin from a point of greater perspective of potential maritime clustering, as opposed to investigating the clustering of one individual maritime transport sector - for example the port sector. In terms of clusters of industry they are complex systems with a variety of features and 
characteristics to consider. Therefore this leads to the question of what is the most appropriate point to investigate a proposed cluster or clustering process. It is logical in explorative research that progression through the research and the results will help identify future research questions, in order to achieve the most appropriate answers required, and also to discover what is useful to know. In terms of any research process the research question is important, and that the answers obtained, answer the question that was originally asked. In understanding a cluster and a clustering process identifying those specific questions is important not only for further research but to concentrate knowledge attainment on the reality of potential clustering of the maritime transport industry in the GDR and also what is useful to know to help develop a sophisticated understanding of the industry that currently functions within the GDR.

The research question enquires about the potential clustering of the maritime transport sector in the GDR. The use of the term "potential" is directly linked to the use of the terminology of clustering and both terms are expressed in constructing the research question. Potential infers that there is a capacity to develop in the future or there are certain qualities that may be shaped to lead to future success. As already discussed there is some level of maritime transport activity in the GDR and there is some level of maritime transport clustering. Is it unrealistic in the light of the development of knowledge on clusters and the clustering process to assume that the GDR maritime transport sector cannot improve? In a historical framework clusters can be established owing to a natural asset, a resource or due to the strategic location of a region. In a contemporary context governments will often investigate or fiscally support the development of industry and industry clustering. Clusters to some degree can be man made, although a man made cluster does not guarantee economic success or the attainment of a distinct competitive advantage. The maritime transport sector in the GDR is an industry that has to function in the context of market forces, the demand for commodities and to facilitate trade. If a 
particular industry is required out of necessity then it is logical to strive to understand that industry and its potential to improve and develop further.

In terms of looking at clustering, an analogy of a horizontal line can be used. The line has three denoted points of $\mathrm{A}, \mathrm{B}$ and $\mathrm{C}$. Point $\mathrm{C}$ is a well established maritime cluster with a distinct competitive advantage such as the maritime clusters of London, Rotterdam and Singapore. Point A of the scale denotes basic firm agglomeration in that there are a number of similar and related firms located in co-proximity. Point B denotes a process of clustering which is neither $\mathrm{A}$ or $\mathrm{C}$ but lies somewhere between the two points. Point B describes an economic condition of an industry which is more than just basic firm agglomeration, but less than a considerable cluster with a distinctive international competitive advantage. In terms of the maritime transport sector in the GDR it is arguable to identify that the sector of industry is more than just a basic firm agglomeration and equally arguable not a major maritime cluster. But the maritime transport sector in the GDR does reflect clustering and therefore the proposed cluster is denoted at point B. What is the potential of this cluster? A cluster is always in a process of clustering as it is not a fixed economic state and can evolve towards greater clustering in terms of economic returns or decline and loss of competitive advantage. Therefore the basis of the research was to investigate a particular industry that is required out of the necessity to facilitate trade for an island nation. The industry is concentrated in a particular region which also holds colocation and co"proximity for firms related to the particular industry being researched. Therefore specifically within the GDR, the maritime transport industry exhibits some level of industrial clustering and has potential which indicates a capacity to develop and strengthen clustering ability to enhance the economic condition of a industry.

The following section discusses conclusions with respect to the methodology process and conclusions concerning the research question. 


\section{Develop an effective and explorative research process}

In terms of a methodological hypothesis the first objective was to devise and develop an effective explorative research process. As already discussed three key words of terminology that describe the foundation of the research are; explorative, clustering and potential. Clusters as an area of research is extensive owing to the complicated nature of the subject matter and the varying characteristics associated with an industry cluster and a clustering process. For the purpose of the current research the concept of clusters had to be contained in order to provide order and control. There are many ways in which to approach research on clusters. The current research was explorative in that no pervious work had been undertaken on the clustering of the maritime transport sector in the GDR. Many cluster scholars, governments or organisations in investigating a cluster from a more qualitative perspective will utilise an economic theory such as Porter's five forces model. It is arguable that all economic models or theories have their weaknesses and such models are derived from an exploration of an economic occurrence. However in devising that economic model there is no guarantee that the same economic occurrence will be reflected in the GDR maritime transport sector. The combination of four of the main economic theories associated with the clustering process allows for the creation of a checklist of potential clustering features that can positively enhance the clustering effect as opposed to concentrating the research on just one model. If the research concentrated on one cconomic model this might it have delimited the research area and also run the risk of disregarding features that affect clustering just because they are not represented in the chosen model. While the current research investigates clustering in the GDR, Porter's model investigates competitive advantage in many industries and thus it may be logical that certain clustering characteristics relevant to the GDR may be lacking due to the different objectives of the current research question and original objective of Porter's model. Combining four of the main theories provides a broader base from which to investigate an explorative cluster research process. As the research was addressing the potential clustering of 
the maritime transport sector in the GDR it required to use of industry experts and the four theories provided a checklist of features that were used as a base for the questions in the Delphi. The Delphi method facilitated the explorative nature of research process as the research question dictated the necessary involvement of all maritime transport and related sectors acting within the GDR. The Delphi method acted as a platform for discussion for the industry experts as the Delphi panel was asked the questions repeatedly through three rounds in order to achieve some degree of consensus. Due to the explorative nature of the research the Delphi method was a more appropriate methodological process as opposed to using a survey or a one shot questionnaire.

2. The utilisation of Delphi in explorative research; a process to identify the right questions to ask in order to gain the right answers

In effectively examining any research concept the full potential of the subject matter is restricted by the limitations and scope of the $\mathrm{PhD}$ process. The current research was considerable in size due the nature of the research process and due to the fact that in order to examine the potential of the clustering of the maritime transport sector in the GDR requires the inclusion of all maritime transport and related maritime sectors. The research fundamentally is explorative, in that the research question starts as a process of discovery and knowledge creation in terms of building an understanding of the clustering of an industry. The research undertakes a first step in the process of understanding clustering in the maritime sector and does provide for the creation of new knowledge in terms of the concepts being researched. Fundamentally however the research through the utilization of the Delphi method, also affords a process that creates the formulization of validated questions for further research. Clusters as an area of research is extremely wide and it is difficult to validate the decision process of making up research questions which are appropriate and relevant. As a result the original Delphi statements were delimited by four economic theories from which eleven final consensuses were achieved. In the context of further research the consensus achieved and the opinion provided 
are a reliable and a useful framework in which to develop and investigate further the potential of clustering of the maritime transport sector in the GDR. Each statement that achieved consensus as displayed in Chapter 7 had key threads of opinion and from those opinions a number of further research questions were devised in order to help investigate the full potential and expanded context of the subject matter being examined. In criticism of the applied Delphi, it would have benefited from the application of a likert scale in order to subtract a greater understanding and value from the opinions provided for by the Delphi panel. The consensus result achieved indicates a level of agreement or disagreement; however it is the opinions returned both for and against, that provide a balanced perspective to develop further research objectives. The opinion from the expert panel concentrates future research towards what is relevant and what is useful to know and structures efficiently the development of a potential framework of research. The current research process has been successful in obtaining new knowledge and developing an understanding of the potential clustering of the maritime transport sector in the GDR but also catered for defining and validating a subject concept for further and future research.

3. Taking established theories to see how useful they are to provide a structure for explorative analysis

As already discussed the volume of literature available for clusters and clustering is large owing to the complex nature in which clusters of industry function. There are many hypotheses as to why clusters exist, how they are formed, explanations for their evolution and ongoing success and understanding their decline. However due to the inherent complexity of clusters one aspect of the cluster concept is clear; there is no one model or theory that can evaluate or measure the full impact of a cluster and its potential clustering effect. Clusters as an economic entity has grown in significance for all cluster participants such as the firms that act within the industry, the region and local council in which the cluster of industry is located, the government along with policy makers, academics and related and associated organisations. Historically, research on industrial clustering 
was driven by the need to understand why some countries are rich and why some are poor, why do certain countries have a distinct natural competitive advantage in a particular industry that is so robust it affords a level of global dominance. There is no theory called the "cluster theory" but there are those that look at different features such as competitive advantage, population of an industry, why industries cluster or converge in particular regions or countries. Such features are interrelated and it is the term cluster that combines all the concerns of industry, competition and global competitive advantage into one concept; the concept of clusters and the process of clustering. The theories that investigate clusters and clustering approach the concept from different perspectives which obliviously overlap at certain points. While it may appear that theories do not approach clusters directly the concept examined in the theories investigates and eventually theorize the fundamental characteristic of an industry cluster. Many scholars in examining a cluster will take the perspective of one theory such as Porter's five forces model which may be appropriate if the context is to examine an industry from a competitive advantage. A cluster is wider in terms of an economic occurrence and therefore by combining four of the main theories establishes a more appropriate framework for explorative analysis. However individual theories have their weakness and can fail to take into consideration what people do and it is argued that the practicability of examining a cluster should take into consideration many philosophies such as economics, sociology and knowledge management. The cluster structure cluster governance framework devised by de I angen based on the theories of agglomeration economics, competitive advantage, population ecology and the industrial district theory is utilised for initial research or exploration of a potential cluster and does not test the validity of the individual economic model, but rather adapts the core characteristics of each theory to formulate a cluster ingredients list or cluster. SWOT analysis. Such a process caters for explorative research and aids in delimiting a large concept into an appropriate format in order to devise an effective and realistic research question. 


\section{Is the GDR a maritime transport cluster?}

In terms of a cluster it is difficult to prove when a cluster of industry has been achieved. At what point is an industry a cluster? At what point does a process of industry clustering achieve a cluster status. Major clusters are easily identifiable due to their distinct international competitive advantage, there visible size, critical mass of industry players, the creation of new cluster knowledge, a centre of excellence, and number of firms and employees. Identifying when a cluster exists is difficult and in terms of a point of policy or intervention it is important to strive to understand if the industry is in fact a cluster or just the product of firm agglomeration. The first question of the Delphi asked the panel if they considered the GDR maritime transport sector as a maritime transport cluster. The question reached an agreement consensus in round 1 of $78 \%$. The Delphi panel who operate within the GDR maritime transport sector considered that it is a maritime transport cluster. In further support the panel also reached an agreement consensus of $72 \%$ that the GDR maritime transport sector has the potential to move forward and develop further. Appropriate statistics where available can be used to support the argument that the GDR cluster exists. Statistics can also provide some level of proof that a cluster exists in terms of contribution to balance of payments and the domestic economy. However there is not an agreed defined level in terms of economic statistics or number of firms that suggest when a cluster of industry has been achieved. A cluster is more than just the hard economics associated with money and numbers; cluster's are fundamentally the basis of business and economic relationships and interaction therein. An individual cluster may hold a thousand firms but a cluster may also have ten firms which hold $90 \%$ of a world market. Is the cluster with ten firms not a cluster? Evaluating clusters in terms of statistics and numbers can be useful. In comparing the Dublin and London cluster the result obtained would indicate the difference in size, number of firms and economic contribution etc. The result would provide details that clarify the difference between the two clusters, however if the Dublin cluster were to achieve a par with that of the London cluster in 
terms of those economic statistics that would not necessarily infer that the Dublin cluster has achieved a maritime cluster in terms of the success and international competitive advantage of London. It is already known that the London cluster is larger than the Dublin cluster (in terms of economic contribution, employment and firm statistics) and although useful to know it only provides a numerical and statistical difference. In does not provide insight or understanding on how to enhance the clustering of the maritime transport sector in the GDR. One of the original objectives was to establish if the GDR was a maritime transport cluster as opposed to relying on an assumption that the industry was clustering within the GDR. In conclusion the representatives from the GDR maritime transport industry, in consensus though the Delphi process showed that the GDR maritime transport sector is a maritime transport cluster.

5. Develop guidance for the development of the GDR maritime transport cluster

The objective of the research is to expand the understanding and knowledge of the maritime transport sector in the GDR. The drive behind the objective is in the logic that if we know and understand the industry, we can help and encourage further development of the sector through clustering. The first aspect of guidance is concerning the results of the Delphi and the initial guidelines derived from the Delphi consensuses for further research. A total of eleven consensuses were achieved and the consensuses provide the first direction in terms of the reality of the clustering of the GDR. In the consensuses that were achieved a number of further research questions were formulated. The objective of the further research questions is to investigate further the validity of the consensuses and to determine the full reality of the potential clustering of the GDR. While not an original objective of the research, Round 1 opinion highlighted the possibility that even though the GDR may appear to be a maritime transport cluster, there is also the possibility that the cluster is the result of a major port facility and capital city being one and the same. The concept was discussed in chapter 8 and won't be summarised further in these conclusions. However two points 
can be repeated. First, the capacity of the Delphi panel to raise important considerations for discussion on the potential clustering of the maritime transport sector in the GDR and secondly it reaffirms the complex nature of clusters and the process of clustering. The research has identified that clusters are a process that continuously evolve and therefore must be approached as a long term strategy as opposed to a one off cluster policy or initiative. Therefore it is logical that the first step for guidance in the developing further the maritime transport industry requires the establishment of an Irish maritime transport cluster organisation. The format of such an organisation is debateable in terms of the construction of the organisation from government, industry, industry organisations, academics and public and private companies. Resources to financially support such an organisation are also an issue which could also possibly affect the organisation's format. However the really important fact is that any cluster organisation, objective or government policy should take into consideration the breadth and complex nature of a cluster.

6. Developing an understanding of the temporal dimensions of clusters and the developmental evolution of a maritime cluster

An economy, sector of industry and the individual firm is often measured in terms of success as an economic or statistical value and is a result that infers quantifiable measurement which is a fixed process and a fixed result. That fixed numerical value within the greater perspective of world markets and the passing of time provides a snap shot of the value of the economy, industry or firm being measured. The passing of time is a similar process to that of the evolution of clusters, in that a cluster is a process of clustering as opposed to a fixed state which describes a fixed economic condition. Therefore the term cluster is perhaps misleading and the term clustering which illustrates some level of movement is perhaps a more appropriate economic description of an industry in co-location and co-proximity. Due to the explorative nature of the research there was no original objective to measure the potential GDR cluster as basically it was unsure if a cluster existed in the first place and the difficult nature of the clustering concept 
raised questions such as, how do you know when a cluster of industry has been achieved? The qualitative nature of the current research has reaffirmed the importance of understanding a cluster from the temporal dimension and that they evolve over time in an industrial clustering process. The evolution of clusters of industry can be depicted effectively by examining a cluster from a historical context. In examining a cluster such as the maritime transport sector in the GDR it can be useful to observe other major international maritime clusters. The effect of time on clusters can be witnessed in the fact that clusters can die due to many different reasons such as the effects of change in international markets or the decline of a natural resource. However what more common is that a cluster can grow, adapt maintain its international competitive advantage as seen in the case of the London maritime service cluster. In the evolution of clusters, the history of how a cluster is established in international markets can help in the understanding of contemporary clustering by the acknowledgement of where and how it was originally established. In the current research the GDR maritime transport cluster is arguably a cluster due to co-location of principle port, capital city and critical mass of maritime transport firms. Therefore the GDR maritime transport sector is a maritime cluster based on industrial descriptions of clusters and in comparison to other maritime clusters (albeit smaller). However it is the evolution of the GDR cluster that raises the question of the reality of the cluster of industry, in that what may appear to be in fact a cluster. is in fact a consequence of economic history, geographic location and the development of the capital city. The GDR maritime transport industry may be approached from a cluster perspective but also from that of city development and future city evolution, branding and city and industry knowledge management.

\section{Further Research}

In the context for further research there are certain areas that should be highlighted. First, the issue of typology of clusters in that maritime clusters tend to be mainly port focused, logistics focused or service focused, or some degree of combination of one or more of the above mentioned sectors. 
Exploring maritime clusters from this perspective would be of benefit in further understanding the complexity that is industrial clustering in the context of maritime industries. Also approaching clusters from a typology concept would cater for greater understanding of potential sub and sub-sub sectors of a maritime transport cluster.

The Delphi provided a format for data collection and the production of new knowledge. However, the methodology also provided many further research questions outlined in Table 24 (p221). The initial research question discussed the potential of the clustering of the maritime transport sector in the GDR. From the Delphi method there was significant knowledge extracted from the expert panel which was formed into threads of opinion and formulated into further research questions. The research questions outlined in Table 24 have already been presented and will not be further discussed here. Due to limitations of the current research there are many further research questions drawn from the Delphi that can be utilized for further knowledge creation and understanding on the GDR maritime transport cluster.

The context of the current research was maritime clusters from smaller maritime nations, in that there must be more maritime clusters like Dublin that there are Rotterdam's, Singapore's or Hong Kong's. The methodological approach catered for the investigation of the cluster from a broad perspective in order to start to attain a true understanding and potential of the cluster and the clustering process. It would be of benefit to see the methodological process carried out in the current research repeated in another small potential maritime cluster in order to further validate the approach, and to identify if the methodological approach can be of benefit for the purpose of knowledge creation and understanding in other maritime clusters.

Another area highlighted in the research that would benefit from further research is the issue of the temporal dimensions of clusters. Clusters of 
industry move and evolve of periods of time as clusters are not a fixed economic state. Developing knowledge and understanding on temporal dimensions would help to identify why certain clusters are major maritime clusters and to investigate to evolution of clusters over a period of time, in order to understand why certain maritime industries and clusters have declined and how some clusters successfully evolved and maintained there international competitive advantage. Investigating temporal dimensions would also involve investigating other factors that effect clusters over a period of time, such as the effect of cities on maritime clusters.

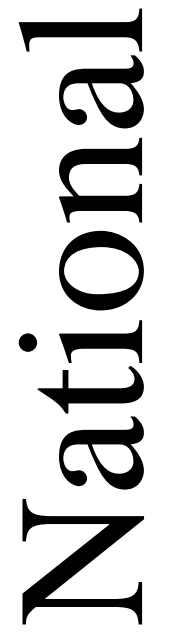


References

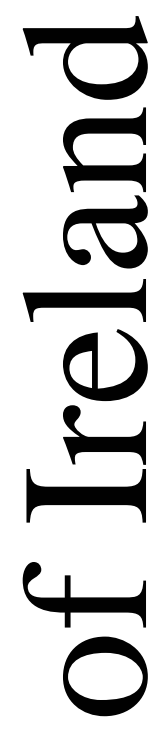

(1)

bo

(1)

o

ส

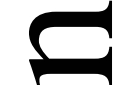

○

.

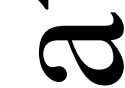

Z 
Adamowitsch, W. G. (2006). The German Maritime Cluster. In: Wijnolst, N. eds. Dynamic European Maritime Cluster's. Netherlands: Delft University Press.

Ariel, A. (1989). Delphi Forecast of the Dry Bulk Shipping Industry in the Year 2000. Maritime Policy \& Management, vol. 16, no (4), pp.305-336.

Armstrong, J. (2006). Selection Tree. [Online] Available At:

http://www.forecastingprinciples.com/selection tree.html . Accessed Date: 15.12.2006.

Audretsch, D. (2003). Globalization, Innovation and the Strategic Management of Places. In: Johannes Brocker, Dirk Dohse, and Rudiger Soltwedel, eds, Innovation Clusters and Interregional Competition (Berlin: Springer, 2003), pp.11-27.

Audretsch, D. and Feldman, M. (2003). Knowledge Spillovers \& Geography of Innovation. Indiana University for Economic Policy. University of Toronto. [Online] Available At: http://1.1.1.1/427308108/263839520T070911111919.txt.binXMysModapplica tion/pdfXsysModhttp://www.core.ucl.ac.be/staff/thisseHandbook/audretsch:f eldman.pdf. [Accessed Date: 02.08.06]

Ayer, J. A. (2000). Hume: A Very Short Introduction. United Kingdom: Oxford University Press.

Baltic Exchange. (2007). Our' Word Our Bond. [Online] Available At: http://www.balticexchange.com/default.asp?action=article\&ID =2 .Accessed Date: 03.03.07.

Baptista, R. (2003). Productivity and the Density of Local Clusters. In: Johannes Brocker, Dirk Dohse, and Rudiger Soltwedel, eds, Innovation Clusters and Interregional Competition (Berlin: Springer, 2003), pp.163181.

Baptista, R. (2001). Geographical Cluster's and Innovation Diffusion. Technological Forecasting and Social Change, vol. 66, pp31-46.

Bathelt, H., Malmberg, A., and Maskell, P. (2004). Clusters and Knowledge: Local Buzz, Global Pipelines and the Process of Knowledge Creation. Progress in Human Geography, vol.28, no (1), pp. 31-56.

Bech, S, M. (2006). The Danish Maritime Cluster, in Wijnolst, N (Ed) Dynamic European Maritime Cluster's. In: Wijnolst, N. eds. Dynamic European Maritime Clusters. Netherlands: Delft University Press.

Benito, G. (2000). Den Maritime Sektor I norge Sett I et Klyngeperspektiv. Sandvika, BI-rapport nr 8. 
Benneworth, P. (2002). Creating new Industries and Service Clusters on Tyneside. Local Economy, vol. 17, no (4). pp.313-327.

Bichou, K. and Gray, R. (2005). A Critical Review of Conventional Terminology for Classifying Seaport. Transportation Research Part A, vol 39 , pp.75-92.

Brooks, M, R. and Button, K, J. (1992). Shipping within a Framework of a Single European Market. Transport Reviews, vol 12, no (3), pp.105-117

Brown, R. (2000).Clusters, Supply chains and Local Embeddedness in Fyrstad. European Urban and Regional Studies, vol 7, no (4), pp.291-305.

Brownrigg, M. (2006) The United Kingdom's Maritime Cluster. In: Wijnolst, N. eds. Dynamic European Maritime Clusters. Netherlands: Delft University Press.

Brownrigg, M., Dawe, G., Mann, Weston, P. (2001). Development in UK Shipping: The Tonnage Tax. Maritime Policy \& Management, vol 28. no (3), pp.213-223.

Cairncross, F. (1995). The Death of Distance. The Economist. vol, 336, Issue 7934, pp.5.

Central Statistics Office. (2007). Total Population 1901 - 2006. Population [Online] Available At: http://www.cso.ie/statistics/Population1901-2006.htm . Accessed Date. 02.05.06.

Central Statistics Office. (2007, A). Population of each Province, County and City, 2006. Population. [Online] Available At: http://www.cso.ie/statistics/popofeachprovcountycity2006.htm . Accessed Date. 02.05 .07 .

Central Statistics Office. (200\%, B). Population by Age. Population. [Online] Available At: http://www.cso.ie/statistics/popnbyage2006.htm . Accessed Date: 02.05.07.

Central Statistics Office. (2005). Regional Population Projection 2006 2021. Regional Population Projections. [Online] Available At: http://www.cso.ie/releasespublications/reg_pop_projections.htm . Accessed Date. 03.05.07.

Chartered Institute of Logistics and Transport. (2005). Membership. [Online] Available At: http://www cilt.ie/membership.shtml. Accessed Date. 03.11 .06 . 
Coleman, S. (2005). PD's Plan to Relocate Dublin Port to Balbriggan. The Sunday Tribune, August $14^{\text {th }}$.

Conçalves, E, M. (2006). Risk and the Governance of Innovation in Europe: An Introduction. Technological Forecasting \& Social Change, vol 73, pp. 112 .

Commission of European Communities (2007) Communication from the Commission to the European Parliament, the Council, the European Economic and Social Committee and the Committee of the Regions. An Integrated Maritime Policy for the European Union. The European Union. Brussels 10.10.2007, COM(2007)574 Final.

Cooke, P. (2002). Knowledge Economies: Cluster's, Learning \& Co-operative Advantage. Studies in International Business \& the World Economy. London, Routledge.

Cooper, D. and Schindler, P. (2003). Business Research Methods. $8^{\text {th }}$ Edition. US: McGraw-Hill Higher Education.

Critcher, C. and Gladstone, B. (1998). Utilizing the Delphi Technique in Policy Discussion: A Case Study of a Privatized Utility in Britain. Public Administration, vol 76, Autumn, pp. 431-449.

Cronin, B. (1999). Foundations of Philosophy: Lonergan's Cognitional Theory and Epistemology. 10 th Edition. Nairobi: Consolata Institute of Philosophy,

Conference of Peripheral Maritime Regions of Europe (2006) Europe of the Sea Project. 2nd Interim Report. February, 2006. Rennes. [Online] www.crpm.org.

Dalkey, C. N. (1969). The Delphi Method: An Experimental Study on Group Opinion. United States Air Force Project RAND. Santa Monica.

Dalkey, N. and Helmer, O, Report on a Long Range Forecasting Study, The RAND Corporation, p-2982 (CDDC No. AD607777), September 1964.

Day, J, and Bobeva, M. (2005). A Generic Toolkit for the Successful Management of Delphi Studies. The Electronic Journal of Business Research Methodology, vol. 3, Issue. (2), pp 103-116. [Online] Available At: www.ejbrm.com.

Dayasindhu, N. (2002). Embeddedness, Knowledge Transfer, Industry Clusters and Global Competitiveness: A Case Study of the Indian Software Industry. Technovation, vol 22, pp.551-560. 
Delbecq, A. L., Van de Ven, A. H., and Gustafson, D. H. (1975). Grouping Techniques for Program Planning: A Guide to Nominal Group and Delphi Process. Glenview, IL: Scott Foresman.

De Loe, C, R. (1995). Exploring Complex Policy Questions Using the Policy Delphi. Applied Geography, vol. 15, pp. 53-68.

Department of Communication Natural Resource and the Marine (2005). Ports Policy Statement. Department of Communication Natural Resource and the Marine. May 2005.

Dickery, A. (1997). Dutch Dream Team Wide Awake: A New Organisation has been established in the Netherlands to Stimulate the Cross-Pollination of Ideas, Policies and Strategies between a Diverse group of Business Interests. Lloyds List. Tuesday, December $09^{\text {th }}$.

Dijk, M, P, V. and Sverrisson, À. (2003). Enterprise Clusters in Developing Countries: Mechanisms of Transition and Stagnation. Entrepreneurship \& Regional Development, 15 (July-September), pp.183-206.

Drogheda Port Company (2006). Leading the Way in Port Logistics. [Online] Available At: http://www.droghedaport.ie/index home.html . Accessed Date: 15.04.07.

Dosi, G. (1987). Sources, Procedures and Micro-Economic Effects of Innovation, Journal of Economic Literature, vol. 26, pp.1120-1152.

Dubai Maritime City. (2006). Dubai Maritime City. [Online\} Available At: http://www.dubaimaritimecity.ae/. Accessed Date: 25.07.06

Dublin Port. (2007). Roll On Roll Off. [Online] Available At: http://www.dublinport.ie/business/rorol. Accessed Date: 16.07.07.

Dublin Port. (2007). Lift On Lift Off. [Online] Available At: http://www dublinport.ie/business/lolo/. Accessed Date: 16.0\%.0\%

Dublin Port Co. (2006). Dublin Port Co: Growing, Sustaining: Developing. Dublin Port Co Year Book 2006.

Dutch Maritime Forum (2004). Leader Firms in the Dutch Maritime Cluster: [Online] Available At: http://forum.dutch-maritimenetwork.nl/forum/nml/dispatch.cgi/f.nmlseriepub/showFile/100033/d2004031 8104357/No/Summarv\%2022\%20-\%20Leader\%20Firms.pdf . Accessed Date: 28/07.06.

Dutch Maritime Network Foundation. (2005). Welcome to the Site of Dutch Maritime Network Foundation. [Online] Available At: http://www.dutch: maritime-network.nl/english.html. Accessed Date: 08.10.05. 
Ecotec Research \& Consultancy. (Undated). A Practical Guide to Cluster Development. Report to the Department of Trade and Industry. England's Regional Development Agencies. [Online] Available At: http://1.1.1.1/712847428/435040376T070924143126.txt.binXMysModapplica tion/pdfXsysMOdhttp://www.dti.gov.uk/files/file14008.pdf . Accessed Date: 08.04.06.

EU Enterprise \& Industry. (2004). Economic Impact of Maritime Industries in Europe. Policy Research Corporation and Institute of Shipping Economics and Logistics. [Online] Available At: http://ec.europa.eu/enterprise/maritime/maritime industrial/economic impa ct study.htm. Accessed Date: 23.11.05.

EuroActive. (2004). Lisbon Agenda. [Online] Available At: http://www.euractiv.com/en/future-eu/lisbon-agenda/article-117510. Tuesday 17th August. Accessed Date: 29.07.06

Europa. (2006). Lisbon Strategy for Growth and Jobs: Commission's Annual Progress Report. Press Release, 25.01.06 The European Union. [Online] Available At: http://europa.eu/rapid/pressReleasesAction.do?reference=MEMO/06/23\&for

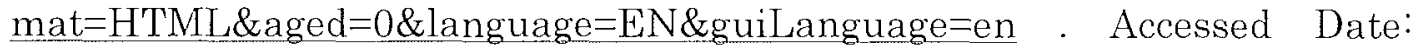
18.11.06.

European Commission. (2007). The MARCO Polo II Programme (20072013). The European Union. [Online] Available At: http://ec.europa.eu/transport/marcopolo/index en.htm . Accessed Date: 20.09 .07 .

European Commission Green Paper. (2006). Towards a Future Maritime Policy for the Union: A European Vision for the Oceans and Seas. The European Union, 07.06.2006, COM (2006) 275 Final.

European Commission. (2006). Trans European Networks. The Trans. European Transpon't Networks "Ten-T". "The European Union. [Online] Available At: http://ec.europa.eu/ten/transport/guidelines/index en.htm. Accessed Date. 15.10.06.

European Commission. (2001). White Paper: European Transport Policy for 2010: A Time to Decide. The European Union. [Online] Available At: http:/lec.europa.eu/transport/white paper/index_en.htm . Accessed Date: 03.12 .05 .

European Commission. (1996). Torards a New Maritime Strategy. Communication from the Commission to the Council, the European Parliament, the Economic and Social Committee and the Committee of the Regions. COM (96) 81 Final. 13.03.1996. 
European Commission. (2004). Liberalisation of Port Services. The European Union, COM (2004) 654 Final. [Online] Available At: http://eurlex.europa.eu/smartapi/cgi/sga doc?smartapi!celexplus!prod!DocNumber\&lg $=$ en\&type doc $=$ COMfinal\&an doc $=2004 \&$ nu doc $=654$. Accessed Date: 12.02 .05 .

European Council \& Parliament. (2004). The Adoption of Article 12a TEN-T Guidelines, 30.04.2004. COM (2004) 0884.

ENMC Newsletter. (2006). European Maritime Network Clusters. Official Creation of the French Maritime Cluster. European Maritime Network Clusters Newsletter. February 2002, Issue 2.

Enright, J, M. (2003). Regional Clusters: What we know and what we Should Know. In: Johannes Brocker, Dirk Dohse, and Rudiger Soltwedel, eds, Innovation Clusters and Interregional Competition (Berlin: Springer, 2003), pp. 99-129.

Fadda, E. (1997). Brazilian Coastal Shipping in 2010: Qualitative Scenarios through the Application of Delphi and Scenario Writing Methods, Unpublished Thesis for PhD, Department of Maritime Studies and International Transport, University of Wales College, Cardiff.

Fairplay. (2005, A). Norwegian Cluster Fading Fast. Fairplay. February $11^{\text {th }}$.

Fairplay. (2005, B). Norwegian Tax Levels Crucial. Fairplay. June $7^{\text {th }}$.

Farrel, S. (2001). If it Ain't Bust, Don't Fix It: The Proposed EU Directive on Market Access to Port Services. Maritime Policy and Management. vol 28, no (3), pp 307-313.

Fattah, A. (1997). Road Freight Privatisation in Egypt A Comparative Analysis with Great Britain and Hungry. Unpublished Thesis for PhD. University of Plymouth, UK.

Fesser, E. J. (1988) .Old and New Theories of Industry Clusters. In: M. Steiner (eds) Clusters and Regional Specialisation, pp. 18-40. London: Pion Limited

Fisher Associates. (2004). The Future of London's Maritime Serrice cluster: A Call for Action. London; The Corporation of London. [Online] Available At: http://1.1.1.1/712847428/264830856T070909164519.txt.binXMysModapplica tion/pdfXsysModhttp:/www fisherassoc.co.uk/dbimgs/Maritime\%20Services \%20London\%20Final\%20v2.pdf . Accessed Date 10.02.05. 
Fist Marine International. (2005). Dutch Maritime: Research, Development and Innovation Expenditure. vol, 28. Netherlands: Delft University Press.

Forsman, M, Solitander, N. (2003) Knowledge Transfer in Clusters - An Interdisciplinary Conceptual Analysis. Journal of International Business Studies. [Online] Available At:www.jibs.net. Accessed Date: 06.07.06

Frank, J. (2004). Buongiorno! D'Amico gives Irish Maritime Hopes a Boost: Italian Shipping Group to Base its Financial and Management Support Services in Dublin. Lloyds List. Thursday, April 22nd.

Fritisch, M. (2003). How and Why Does the Efficiency of Regional Innovation Systems Differ? In: Johannes Brocker, Dirk Dohse, and Rudiger Soltwedel, eds, Innovation Cluster's and Interregional Competition (Berlin: Springer, 2003), pp. 99-129.

Fujita, M., Krugman, P., and Venables, A. (2001). The Spatial Economy: Cities, Regions and International Trade. Cambridge: MIT Press.

Fujita, M., and Mori, T. (1995). The Role of Ports in the Making of Major Cities: Self Agglomeration \& Hub Effect. Joumal of Derelopment Economics, vol 49, pp. 93-120

Gardner, B., Naim, M., Rojas, O. B., Pettit, S. (2001). Maintaining The Maritime Skills Base: Does The Government Have A Realistic Strategy. Maritime Policy and Management. vol 28, no (4), pp. 347-360.

Gelauff, G and Lejour, A. (2006). The New Lisbon Strategy. An Estimation of the Economic Impact of Reaching 5 Lisbon Targets. Jan 2006.

Gleave, M, B. (1997). Port Activities and the Spatial Structure of Cities: The Case of Freetown, Sierra Leone. Journal of Transport Geography; vol 5, No (4), pp.257-275.

Gleeson, M. A.. Rune, F., and Sutherland, J. (2005). Promoting Industrial Cluster: Evidence from Treland. No. 89. October. IIIS Discussion Paper. [Online] Available At: http://1.1.1.1/438784068/475422784T070913145306.txt.binXMysModapplica tion/pdfXsysM0dhttp://www.tcd.ie/iiis/documents/discussion/pdfs/iiisdp89.pd f. Accessed Date: 07.07.06.

Gordon, I., and McCann, P. (2005). Clusters, Innovation and Regional Development: An Analysis of Current Theories and Evidence, in Karlsson, C. Johansson, B. Stough, R, R. (eds), Industrial Clusters and Inter-firm Networks, UK, Edward Elgar. 
Goss, R. O. (1993). The Decline of British Shipping: A Case for Action? A Comment on the Decline of the UK Merchant Fleet: An Assessment of Government Policies in Recent Years. Maritime Policy and Management, vol 20. Issue 2, pp.93-100.

Government Offices. (2002). National Spatial Strategy for Ireland 20022020, People, Places and Potential. Dublin. [Online] Available At: http://www.irishspatialstrategy.ie/. [Accessed Date. 05/07/2003.]

Goswami, D., and Karmeshu. (2004). Study of Population Heterogeneity In Innovation Diffusion Model: Estimation Based on Simulated Annealing. Technological Forecasting \& Social Change, vol. 71, pp. 705-722.

Green, R. (2000). Irish ICT Clustei: OCED Cluster Focus Group Workshop. Utrecht, May 8-9.

Gupta, U, G., and Clarke, R. E. (1996). Theory and Applications of the Delphi Technique: A Bibliography (1975-1994). Technological Forecasting \& Social Change, 53, pp. 1885211.

Gupta and Clarke. (1996) .citing: Sforza, C, V., and Ortolano, L. (1984) Delphi Forecasts of Land Use: Transportation Interactions. Journal of Transportation Engineering; vol. 110, pp. 324-339.

Gupta and Clarke. (1996). citing: Khan, A, M. (1989) Realistic Planning for Transportation - A Flexible Approach. Long Range Planning; October, pp.128-327.

Gupta and Clarke. (1996). citing: New, S., and Tomlinson, G. (1994) Supply Chain Integration: Hype or Reality? Logistic Focus, vol. 2, Issue 4.

Gupta and Clarke. (1996). citing: Vickers, B, (1992) Using GMDSS to Examine the Future European Automobile Industry, Futures, vol. 2, Issue. (4), pp. $789 \cdot 812$.

Haezendock. F. (2001). Essays on Strategy Analysis for Seaports. Leuven, Garant.

Hamburg School of Logistics. (2003). Excellent further Education in Logistics. Hamburg School of Logistics. [Online] Available At: http://www.hslog.de/ hslwww/cgi-bin/en index_v6.php. Accessed Date: 22.07 .06 .

Hasson, F., Keeney, S., and McKenna, H. (2000). Research Guidelines for Delphi Survey Technique. Journal of Advanced Nursing; 32, pp.1008-1015. 
Harrigan, R., and Porter, E. (1991). End Game Strategies for Declining Industries. Michael E. Porter on Competition and Strategy. Harvard Business Review.

High Level Review. (2004). High Level Review of the State Commercial Ports operating under the Harbour's Acts 1996 and 2000. Raymond Burke Consulting

Hollis, M. (1994) The Philosophy of Social Science: An Introduction. UK: Cambridge University Press.

Hwang, K. S. (2004). A Comparative Study of Logistics Services in the Container Liner Shipping Market in the UK and South Korea, Unpublished Thesis for PhD, Plymouth Business School, University of Plymouth.

ICG. (2007) Welcome to the ICG Website. [Online] Available At: http://www.icg.ie/. Accessed Date: 1.10.07

IDA. (2007, A). Industry Profile - International Financial Services. [Online] Available At: $\quad$ http://www.idaireland.com/home/index.aspx?id=58 . Accessed Date: 12/02/2007.

IDA. (2007). Tax in Ireland. [Online] Available At: http://www.idaireland.com/home/index.aspx?id=659. Accessed Date. 03.04.07.

IDA. (2006). Ireland Innowledge Is In Our Nature: Vital Statistics. IDA, September 2006.

International Financial Services London. (IFSL) (2003). City Business Series 2003: Maritime Services. London: IFSL

Institute of Chartered Shipbrokers. (2007). Professional Membership. [Online] Available At: http://www.ics.org.uk/profmembership.htm. Accessed Date: 03.03.07.

IMDO. (2007). Dublin Port. IMDO [Online] Available At: http://www.imdo.ie/dublin-port.htm . Accessed Date: 15.10.07

IMDO. (2006). Our Office. [Online] Available At: http://www.imdo.ie/main.htm . Accessed Date: 23.011.06.

IMDO. (2003). An Exceptional Tax Environment. February 2003, Issue 5.

Ireland.com. (2007). Dublin Port Sees 36\% surge in Profit. Ireland.com. [Online] http:/www ireland.com/newspaper/breaking/2007/0910/breaking44.htm. Accessed Date: 10.09 .07 . 
Irish Ports Association. (2006). Economic Impact of State commercial Seaports on the Ixish Economy. Indecon International Economic Consultants.

Islam, D., M., Z. (2005). International Freight Transport Multimodal development in Developing Countries: the Case of Bangladesh, Unpublished Thesis for PhD, Plymouth Business School, University of Plymouth.

Jackson, C., M. (2003). Systems Thinking: Creative Holism for Managers. UK: John Wiley \& Sons.

Jaffe, A., Trajtenberg, M., Henderson, R. (1993). Geographic Localization of Knowledge Spillovers as Evidenced by Patent Citations. The Quarterly Journal of Economics. August, 1993.

Jairath, N. and Weinstein, J. (1994). The Delphi Methodology: A Useful Administrative Approach. Canadian Joumal of Nursing Administration, vol. 7 , pp. 29-42.

Janssens, H. (2006). The Dutch Maritime Cluster, in Wijnolst, N. (Eds) Dynamic European Maritime Clusters. Delft University Press, Netherlands.

Janssen, H. (2005.) Maritime Industries Forum. Bremen Jan $26^{\text {th }} 2005$. [Online] Available

At: http://1.1.1.1/418588868/260812808T061102131410.txt.binXMysMOdapplica tion/pdfXsysM0dhttp://www.fisherassoc.co.uk/dbimgs/Dutch\%20Maritime $\% 2$ oCluster.pdf. Accessed Date:

Jasimuddin, S, M. (2001.). Analysing the Competitive Advantage of Saudi Arabia with Porter's Model. Journal of Business \& Industrial Relations, vol. 16, no. (1), pp. 59-68.

Kadam, U., Jordan, K.. Croft, P. (2006). A Comparison of two Consensus Methods for Classifying Morbidities in a Single Professional Group Showed the same Outcomes. Journal of Clinical Epidemiology; vol. 59, pp.1169-1173

Kapoor, P. A. (1987). System Approach to Documentary Maritime Fraud, Unpublished Thesis for PhD, University of Plymouth, UK.

Karlsen, A. (2005). The Dynamics of Regional Specialization and Cluster Formation: Dividing Trajectories of Maritime Industries in Two Norwegian Regions. Entropreneur'ship \& Regional Derelopment, vol. 17, September, pp. 313-338.

Kenney, S, Hasson, F.. McKenna, H. (2001). A Critical Review of the Delphi Technique as a Research Methodology for Nursing. International Journal of Nursing Studies, vol, 38, pp.195-200. 
Kristian, K. (2005) The Norwegian Maritime Cluster - Synergy Breeds Excellence. The Official Norwegian Trade Portal. [Online] Available At: http://www.nortrade.com/index?cmd=show_article\&id=168. Accessed Date: 10.02 .06 .

Krugman, P. (1995). Development Geography and Economic Theory. US: MIT Press.

Krugman, P. (1993). First Nature, Second Nature, and Metropolitan Location. Journal of Regional Science, vol.33, no. (2), pp.129-144.

Krugman, P. (1991). Increasing Returns and Economic Geography. Journal of Political Economy, vol. 99, no. 3, pp. 483-499.

De Langen, W, P. (2005). Collective Action Regimes In Seaport Clusters: The Case Of The Lower Mississippi Port Cluster. Journal Of Transport Geography. Vol. 13, 173-186.

De Langen, W, P. (2004) Governance in Seaport Clusters. Maritime Economics and Logistics, Vol. 6 pp. 141-156.

De Langen, W, P. (2003). The Performance of Seaport Clusters; A Framework to Analyse cluster Performance and an application to the Seaport Clusters in Durban, Rotterdam and the Lower Mississippi. Unpublished PhD thesis. Erasmus University, Rotterdam.

Iagoudis, I, Lalwani, C and Naim, M, M. (2006) Ranking of Factors Contributing to Higher Performance in the Ocean Transportation Industry: A Multi Attribute Utility Theory Approach. Maritime Policy and Management, Vol. 33, No. 4, pp. 345-369.

Landeta, J. (2006). Current Validity of the Delphi Method in Social Science. Technological Forecasting and Social Change, vol. 73, pp. 467-482.

LeGuin, U. (1969). The Left. Hand of Darkness. London: MacDonald \& Co.

Leggate, H. (2004.). The future Shortage of Seafarers. Maritime Policy and Management, vol 31, no 1, pp3-13

Leibovitz, J. (2004). "Embryonic" Knowledge-Based Clusters and Cities: The Case of Biotechnology in Scotland. Urban Studies, vol 41, No5/6, pp. 11331155, May.

Linde V, D, C. (2003) The Demography of Clusters - Findings from the Cluster Meta- Study. In: Johannes Brocker, Dirk Dohse, and Rudiger Soltwedel, eds, Innovation Clusters and Interregional Competition (Berlin: Springer, 2003), pp.132-149. 
Lindeman, C. (1975). Delphi Survey of Priorities in Clinical Nursing Research. Nursing Research, vol .24, pp. 434-441.

Linstone, H. A., Turoff, M. (eds) (2002). The Delphi Method: Techniques and Applications. [On]ine] Available At: http://1.1.1.1/412188868/382198824T070616110524.txt.binXMysM0dapplica tion/pdfXsysM0dhttp://is.njit.edu/pubs/delphibook/delphibook.pdf. Accessed Date: 17.08 .05 .

Lirn, T.C, Thanopoulou, H, A. and Beynon, M.J. and Beresford, A, K, C. (2004). An Application of AHP on Transhipment Port Selection: A Global Perspective. Maritime Economics and Logistics, vol. 6 (1), pp.70-91.

Lirn, T.C, Thanopoulou, H, A. and Beresford, A, K, C. (2003). Transhipment Port Selection and Decision-Making Behaviour: Analysing the Taiwanese Case. International Journal of Logistics: Research and Applications, vol.6, no (4), pp.229-244.

Lloyds List. (2005). Ship Finance Booming as Bank Moves into New Line of Business. Lloyds List. July, Friday 22nd

Lloyds List. (2003). Bank of Ireland Establishes Green Shoots in Maritime Scene. Lloyds List, Wednesday, April $9^{\text {th }}$.

Lloyds List. (2001). Irish Continental Group Calls for Tonnage Tax as Disease Hits Profits. Lloyds List. June 29th

Lloyds List. (2000). Dutch Maritime Network Strives to Raise Profile. Lloyds List. Tuesday Sept $26^{\text {th }}$.

Loo, R. (2002). The Delphi Method: A Powerful Tool for Strategic Management. Policing. An International Journal of Police Strategies \& Management. vol. 25, no. 4, pp 762-769.

Lowe, E, J. (2005) Locke. UK: Routledge.

MacSwneey, T. (2003, A). Irish Vessel Registration Faces major Overhaul. Lloyds list, Wednesday, July $20^{\text {th }}$.

MacSwneey, T. (2003, B). Flag of Convenience Fear's over Irish Registry. Lloyds List. Wednesday, December $5^{\text {th }}$

Mangan, e \& Associates (2004). Drogheda Port Derelopment: The Strategic Necessity for New Port Development. John Mangan and Associates. Sept 2004. 
Marchau, A, W, J, and Heijden, van der, R, E, C, M. (1998). Policy Aspects of Driver Support Systems Implementation: Results of an International Delphi Study. Transport Policy, vol. 5, pp. 249-258.

Marine Institute. (2007). Follow the Fleet Scheme Reborn in Cyberspace.

[Online] Available At:

http://www.marine.ie/home/aboutus/newsroom/pressreleases/Follow + the $+\mathrm{Fl}$ eet+Launch.htm.Accessed Date: 26/03.07.

Maritime Development Centre of Europe. (2007) The Association of Maritime Development Centre of Europe. [Online] Available At: http://www.maritimecenter.dk/inenglish/theboard/articles/. Accessed Date: 25.09 .07$.

MIF (2007) About MIF [Online] Available At: http://www.mif-eu.org/ . Accessed Date.13.02.07.

Maritime London. (2006) Maritime London's Aims Are. [Online] Available At: www.maritimelondon.com/about/index.shtml. [Accessed Date: 06.03.07]

Marshall, S. (1890). Principles of Economics. $8^{\text {th }}$ Edition. London: MacMillan

Maunsell Consultants. (2003). Study to Strengthen Hong Kong's Role as an International Maritime Centre. Hong Kong Port and Maritime Board. January 2003.

Meersman, H, Van de Voorde, E and Vanelslander. (2005). Ports as Hubs in the Logistic Chain: International Maritime Transport Perspectives. Leggate, H, McConville, Morvillo, A. Routledge, London.

Mersey Maritime. (2007). About Mersey Maritime: A Brilliant Future. [Online] Available At: http://www.merseymaritime.co.uk/displayPage.asp?page_key=2 . Accessed Date: 25.09.07.

Morosini, P. (2002). Industrial Clusters, Knowledge Integration and Performance. World Development, vol. 32, no.4, pp.305-326.

Maritime \& Port Authority Singapore. (2002). Manpower Development Maritime Cluster Fund. MPA Singapore [Online] Available At: http://www.mpa.gov.sg/manpowerdevelopment/mcf/mcf.htm . Accessed Date: 06.07 .2005 .

Nautical Enterprise Centre Ltd. (2001). Ireland's Position within The Atlantic Arc. Maritime Transport \& Development Consultants. October 2001. 
National Development Plan. (2007). Your Plan - Your Future. National Development Plan. [Online] Available At:

http://www.ndp.ie/viewdoc.asp?fn=\%2Fdocuments $\% 2 \mathrm{Fhomepage.asp.}$

Accessed Date: 12.03.07.

National spatial Strategy (2002) National Spatial Strategy for Ireland 20022020. People, Places and Potential. Dublin: Irish Government Publications

Newton, B, F. (1985). Promise or Mirage: A Summary. Journal of Counselling and Development, vol. 64, November, pp.216-217

Nijdam, M and de Langen, P. (2003). Leader Firms in the Dutch Maritime Cluster: Paper present at ERSA 2003 Congress, Erasmus University. Rotterdam.

Noble, H. (2005). The Maritime Cluster: Recent Developments in the Irish Shipping Industry. Mason Hayes \& Curren. [Online] Available At: http://www.mhc.ie/news-t-events/legal-articles/149/. Accessed Date. 05.08 .05

Nonaka, I. (1991). The Knowledge Creating Company. Harvard business Review, vol 69, Issue 6, pp. 96-104.

Okoli, C, Pawlowski, D, S. (2004). The Delphi Method as Research Tool: An Example, Design Considerations and Applications. Information and Management, vol. 42, pp 15-29.

Olson, D.L. (1996) Decision Aids for Selection Problems, Springer, New York

Oram, H. (2006). Ports Make Plans for Future. The Irish Times. Wednesday, November $15^{\text {th }}$, p 25 .

Origin. (2002). Irelands Software Cluster: Innovation - The Fuel for International Success. A report on the Indigenous Software Sector in the Republic of Ireland and Northern Ireland

Osler, D. (2006) RMT Renews Attack on British Owners. Lloyds List. Thursday April 27th.

O' Loughlin, R., and Kelly, A. (2004). Equity in Resource Allocation in the Irish Health Service. A Policy Delphi Study. Health Policy. Vol 64, pp.271. 280.

O' Malley, E. Egeraat V. C. (2000). Industry Clusters and Irish Indigenous Manufacturing: Limits of the Porter View. The Economic and Social Review: Vol. 31, no. 1, January, pp. 55-79. 
Oppenheim, A, N. (1968). Questionnaire Design and Attitude Measurement. UK: Gower.

Oxford Dictionary. (2005). Oxford Dictionary of English. Oxford: Oxford University Press.

Paixao, A. and Marlow, P (2001). A Review of the European Union Shipping Policy. Maxitime Policy and Management, Vol. 28, 2, pp.187-198.

Parenté, F, J., and Anderson-Parenté, J. (1987). Delphi Inquiry systems. In G. Wright and P. Ayton (Eds), Judgmental Forecasting (pp.129-156). New York: Willey.

Peeter, C, and Webers, H. (2006). European Maritime Clusters: Solving the Definition and Data Puzzle In: Wijnolst, N. eds. Dynamic European Maritime Cluster's. Netherlands: Delft University Press.

Powell, C. (2002). The Delphi Technique: Myths \& Realities. Methodological Issues in Nursing Research. Blackwell Publishing.

Port of Rotterdam (2004) ABC of the Port of Rotterdam. [Online] Available At:http://www.portofrotterdam.com/mmfiles/ABC vd Rotterdamse haven $\mathrm{E}$ N 2004 tcm26-10152.pdf. Accessed Date 20 May, 2008.

Porter, M, E. (1998). On Competition: New Agendas for Companies, Government and Institutions. United States: Harvard Business Press. Chapter pp. 197-289.

Porter, M, E. (1991). Michael E. Porter on Competition \& Strategy. Harvard Business Review. United States: Univer'sity of Harvard.

Porter, M, E. (1990). The competitive Advantage of Nations. London: Macmillian.

Progressive Democrats. (2006) A New Heart for Dublin, Making it Happen: The Future of Dublin, Its Bay and the City's Economic Growth. Proceedings from the Progressive Democrats 2006 Conference, Dublin Castle, October $20^{\text {th }} 2006$.

Psaraftis, H, N. (2005). EU Ports Policy: Where Do We Go From Here? Maritime Economics and Logistics, vol 7, pp.73-82.

Reid, N. (1988). The Delphi Technique: Its contribution to the Evaluation of Professional Practice. In Professional Competence and Quality Assurance in the Caring Professions (Ellis R. eds.). Chapman \& Hall, London 
Roberts, P. (2005). A Framework for Analysing Definitions of Literacy. Educational Studies, vol. 31, no 1, March 2005, pp.29-38.

Rosenberg, M, J. (2006). Beyond e-Learning: Approaches \& Technologies to Enhance Organizational Knowledge, Learning \& Performance. San Francisco: John Wiley \& Sons.

Rosenberg, M. (2006). Primate Cities. About Geography [Online] Available At:

http://geography.about.com/od/urbaneconomicgeography/a/primatecities.htm . Accessed Date: 02.05.07.

Rowe, G, Wright, G, McColl. (2005). Judgement Change During Delphi Like Procedures: The Role of Majority Influence, Expertise and Confidence. Technological Forecasting \& Social Change, vol. 72, pp. 377-399.

Rowe, E. (1994). Enhancing Judgement and Decision Making; A Critical and Empirical Investigation of the Delphi Technique. Unpublished PhD Thesis, University of Western England, Bristol

Rowe, G and Wright, G. (1999). The Delphi Technique as a Forecasting Tool: Issues and Analysis. International journal of Forecasting; vol. 15, pp. 353375.

Saber, U. (1996). Accounting for Variation in the Performance of Industrial Districts: The Case of Baden-Württemberg. International Journal of Urban and Regional Research, vol. 20, no. 2, pp.299-310.

Sackman, H. (1975). Delphi Critique. Boston: Lexington Books.

Saldanha, J. and Gray, R. (2002). The Potential British Shipping in a Multimodal Chain. Maritime Policy and Management, vol. 29, no. 1, p77-92.

Scapolo, F and Miles, I. (2006) Eliciting Experts Knowledge: A Comparison of two Methods. Technological Forecasting \& Social Change. vol. 73, pp. 679704.

Scott, J., and Green, D, J. (1993). US Experts Perceptions on International Business Communication Action Statements. Journal of Education for Business, vol. 68, Issue. 5, May/June, pp. 1-13.

Sea and Water. (2007). Sea and Water short Sea and Water'ways Solutions. [Online] Available At: http://www.seaandwater.org/index.php. Accessed Date: 13.07 .07 .

Sea Vision UK. (2007). Take a Fresh Look at the Sea. [Online] Available At: http://www.seavisionuk.org/index.htm . Accessed Date: 12.03.07. 
Sea Vision UK (2006). Sea Visions Core Message. [Online] Available At: http://www.seavisionuk.org/core messages.htm. Accessed Date: 01/09.06.

Selkou, E and Roe, M. (2002) UK Tonnage Tax: Special Case OR Subsidy? Maritime Policy and Management. vol 29, No 4, pp. 393-404.

Selkou, E, and Roe, M. (2004). Globalisation, Policy and Shipping. Transport Economics, Management \& Policy. UK: Edward Eglar.

Singapore Maritime Foundation. (2007). Singapore Maritime Foundation: Welcome. [Online] Available At: http://www.sgmf.com.sg/. Accessed Date: 06.04.07.

Singapore Maritime Portal. (2002). Maritime Technology Cluster Development Roadmap. Singapore Maritime Portal. [Online] Available At: http://www.singaporemaritimeportal.com/mtc/htm/fundings_roadmap.htm . Accessed Date: 06.09.05.

Smith, N. (2004). A Tale of Eight Port Cities. Lloyds List. Friday August $27^{\text {th. }}$

Society of Maritime Industries. (2007). The Voice of the UK Maritime Business Sector: [Online] Available At: http://www.maritimeindustries.org/ . Accessed Date: 25.09.07.

Spurrier, A. (2006). French Cluster Plan goes Ahead. Lloyds List. Thursday $5^{\text {th }}$, January 2006.

Stares, J. (2006). How Ports Directive Fiasco Made History. Lloyds List. Monday, March 20th.

Stares, J. (2005, A). EU Ports Bill Tackles Wrong Issue. Lloyds List.

Tuesday $13^{\text {th }}$ September.

Stares. J. (2005. B). Five Good Reasons to Ditch the New FU Port Service Directive. Llords List. Friday $12^{\text {th }}$ August.

Steup, M. (2005). Epistemologr. Stanford Encyclopaedia of Philosophy. [Online] Available At: http://plato.stanford.edu/entries/epistemology/. Accessed Date: 24/08/07.

Tapio, P. (2002). Disaggregate Policy Delphi Using Cluster Analysis as a Tool for Systematic Scenario Formation. Technological Forecasting \& Social Change, vol. 70, pp. 83-101.

The National Institute for Transport and Logistics. (2004). Irish Supply Chain Management Services Directory 2001/2005: Incorporating the Who s 
Who directory to the Irish Fright \& Logistics Industry. Dublin: Malahide Promotions.

Transport21. (2006). The Ten-Year Transport Investment Framework.

Transport21. [Online] Available At:

http://www.transport21.ie/WHAT IS TRANSPORT 21/TRANSPORT 21/Th e Ten-Year Transport Investment Framework.html. Accessed Date:

\subsubsection{7.}

Tichy, G. (2004). The Over-Optimism Among Experts in Assessment and Foresight. Technological Forecasting \& Social Change, vol. 71, pp 341-363.

UNCTAD. (2004). Review of Maritime Transport 2004. Report by The UNCTAD Secretariat. United Nations, New York/ Geneva.

Urrutia, B. (2006). The EU Regulatory Action in the Shipping Sector: A Historical Perspective. Maritime Economics \& Logistics, vol 8, pp.202-221.

Vaus, D. (1985). Surveys in Social Research. $5^{\text {th }}$ Edition. Australia: Allen and Unwin.

Viitanen, M., Karvonen, T., Vaiste, J., and Hernesniemi, H. (2003). The Finnish Maritime Cluster. Technology Review: National Technology Agency, 124/2003.

Wallis, K. (2003, A). Hong Kong Unveils Strategy for Unified Maritime Centre. Lloyds List. Friday July $18^{\text {th }}$.

Wallis, K. (2003, B). Hong Kong Shipowners Tell Government: Prepare To Go Dutch. Llovds List. Tuesday March $18^{\text {th }}$.

Wang, J., and Slack, B. (2004). Regional Governance of Port Development in China: A Study of Shanghai International Shipping Centre. Maritime Policy and Management, vol. 31, no.4, pp.357-373.

Wiersma, W. and Jurs, S. G. (2005). Rescarch Methods in Eiducation. $8^{\text {th }}$ Edition. USA: Pearson Education Inc.

Wijnolst, N. (Eds) (2006). Dynamic European Maritime Cluster's. Delft University Press, Netherlands.

Winjnolst, N. , Jennessen, I, J., Sødal, S. (2003). European Maritime Cluster's: Global Trends: Theoretical Framework: The Case of Norway and The Netherlands. Dutch Maritime Network, Netherlands.

Williams, B. and Redmond, D. (2006). Ideopolis: Linowledge City Region. Dublin Case Study. The Work Foundation. 
Williams, B. and Shiels, P. (2002, A). The Socio-Economic Profile of Dublin. Dublin Institute of Technology. Cahiers De L'iaurif $\mathrm{N}^{\circ} 135$.

Williams, B. and Shiels, P. (2002). Economic Performance of the European Regions. [Online] Available At:

http://1.1.1.1/380829764/257038952T070322144337.txt.binXMysModapplica tion/pdfXsysMOdhttp://www.iaurif.org/en/doc/studies/cahiers/cahier 135/pdf/ 161-168.pdf. Accessed Date: 22/03/07.

Yao, J, T. and Liu, W, N. (Undated) Web-Based Dynamic Delphi: A New Survey Instrument. [Online] Available At: http://www2.cs.uregina.ca/ jtyao/Papers/Delphi Cam.pdf . Accessed Date: 15.07.07.

Zander, I. (2004). The Microfoundation of Cluster Stickiness - Walking in the Shoes of the Entrepreneur. Journal of International Management, vol, 10 , pp. 151-175. 


\section{Appendices}

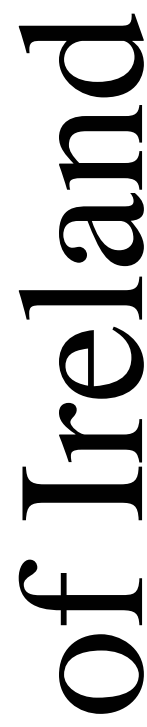

(1)

bo

(1)

r.

0

U

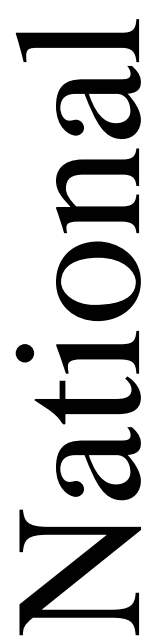




\section{Appendix 1: Dublin Port and Drogheda Port Statistics}

\section{Dublin Port}

Dublin Port is the premier port in Ireland in terms of cargo handled, economic impact, freight and passengers services and Dublin Port Company is responsible under statute for the management, control, operation and development of its harbour (IMDO, 2007). Throughput at Dublin port is expected to exceed 30 million tonnes in 2007 which is an increase of $8.7 \%$ from 2005 (Ireland.com, 2007).

Dublin Port Cargo Statistics

\begin{tabular}{|l|l|l|}
\hline & \multicolumn{1}{|c|}{2006} & \multicolumn{1}{c|}{2005} \\
\hline Total Tonnage & $29 \mathrm{~m}$ tonnes & $27 \mathrm{~m}$ tonnes \\
\hline Imports & $19 \mathrm{~m}$ tonnes & $17.5 \mathrm{~m}$ tonnes \\
\hline Exports & $10 \mathrm{~m}$ tonnes & $9.5 \mathrm{~m}$ tonnes \\
\hline Ro-Ro & 693,000 units & 630,000 units \\
\hline Lo-Lo & 675,000 TEU's & 590,000 TEU's \\
\hline Liquid Bulk & $4.2 \mathrm{~m}$ tonnes & $4.0 \mathrm{~m}$ tonnes \\
\hline Dry Bulk & $2.3 \mathrm{~m}$ tonnes & $2.1 \mathrm{~m}$ tonnes \\
\hline Break Bulk & 80,000 tonnes & 90,000 tonnes \\
\hline Trade Cars & 120,000 & 137,000 \\
\hline Passenger No's & $1.1 \mathrm{~m}$ & $1.2 \mathrm{~m}$ \\
\hline Tourist Cars & 245,000 & 285,000 \\
\hline
\end{tabular}




\section{Drogheda Port}

Drogheda Port is one of Ireland's premier multi modal ports and facilitates a wide range of commodities including paper, containers, LPG, petroleum, grains, timber and steel (IMDO 2007).

Drogheda Port Cargo Statistics (tonnes)

\begin{tabular}{|l|r|r|r|r|r|}
\hline & \multicolumn{1}{|c|}{2005} & \multicolumn{1}{c|}{2004} & \multicolumn{1}{c|}{2003} & \multicolumn{1}{c|}{2002} & \multicolumn{1}{c|}{2001} \\
\hline Total Import & $1,104,820$ & 964,425 & $1,003,002$ & $1,092,711$ & $1,025,123$ \\
\hline TEU & 23,939 & 23,425 & 29,899 & 31,307 & 21,880 \\
\hline Total Export & 296,735 & 303,972 & 252,071 & 279,752 & 304,647 \\
\hline TEU & 24,834 & 24,948 & 31,494 & 31,872 & 22,873 \\
\hline Throughput & $1,401,555$ & $1,268,405$ & $1,255,076$ & $1,372,463$ & $1,329,970$ \\
\hline No. of Vessels & 592 & 570 & 640 & 743 & 668 \\
\hline
\end{tabular}

(Source: Drogheda Port Company, 2006) 


\section{Appendix 2: Bremore Deepwater Port Development}

The map shows the location of the Bremore site in relation to Dublin port and the direct access that Bremore site would have to the logistical infrastructure of the M1 and the M50.

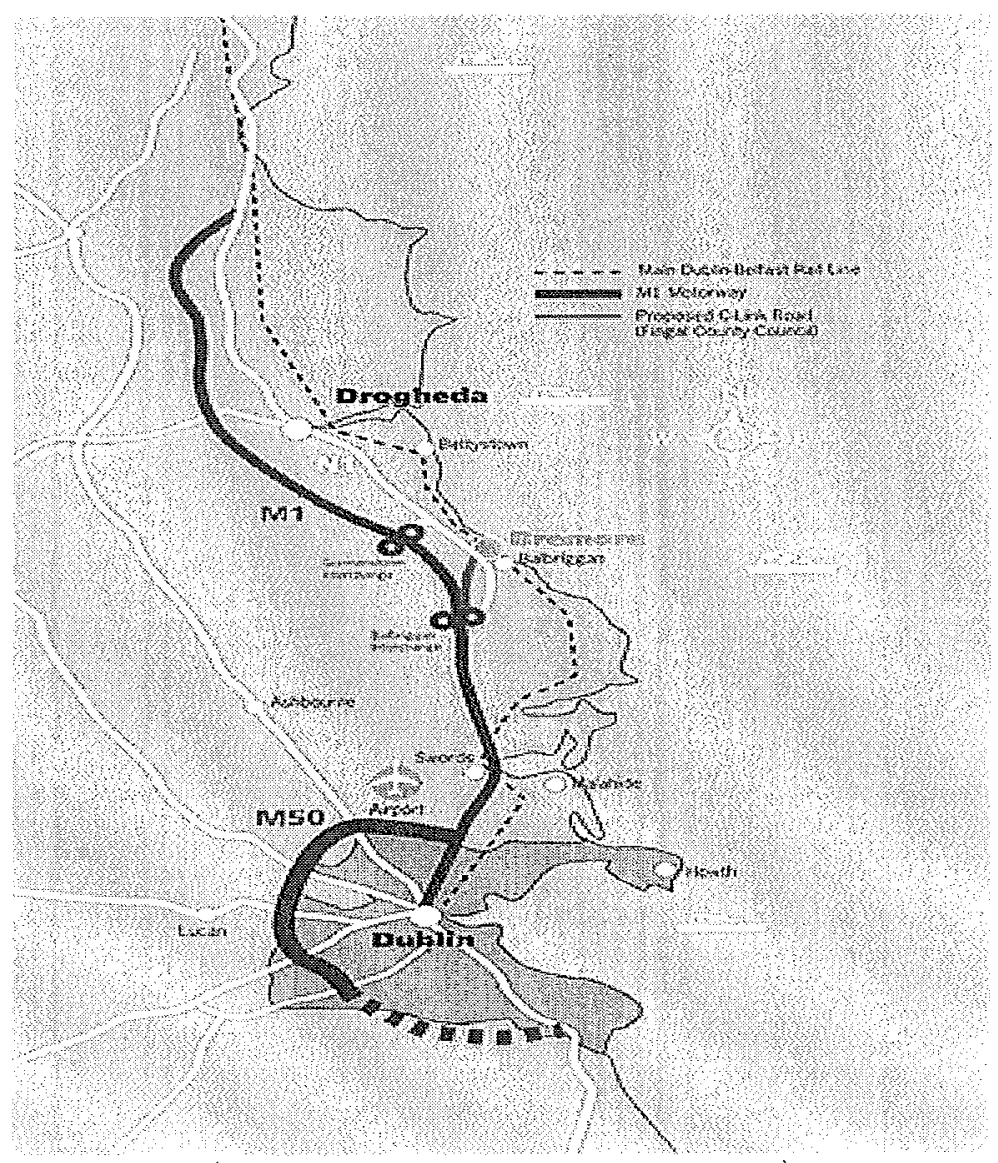

(John Mangan Associates, 2004) 


\section{Appendix 3: NACE Classification}

There are a number of formats for the classification of industries in order to formulate and organise the collection of statistical data on economic activities such as the SIC (Standard Industrial Classification) and Europe's NACE (Nomenclature génerale des Activités économiques dans les Communautés Européennes). The following NACE sector classification devised by Peeters and Webers (2006) establishes a starting point in terms of maritime sector classification for maritime industries.

\section{$\underline{\mathrm{NACE}}$}

Shipping: Merchant shipping and ship management, short sea shipping, cruise and ferry services, ocean towage.

NACE 61.10 Sea and Coastal water transport.

Shipbuilding: New buildings (merchant ships, fishing boats, tugs, workboats, supply ships, floating sections, barges, dry docks, inland vessels, yachts, naval vessels).

Repair and conversion of vessels.

Ship Scrapping.

NACE 35.11 Building and repairing of ships.

NACE 35.12 Building and repairing of pleasure and sporting boats.

Marine Equipment: Manufacturing and wholesale in maritime equipment NACE 29.11, 51.14, 51.65, 63.22 (partly).

Offshore (supply): Construction, installation and conversion of platforms, storage vessels and equipment, drilling and support services.

NACE 28.11 Manufacture of metal structures (party).

NACE 63.22 Other supporting water transport activities.

Dredging: Dredging, river works, construction of dykes, sand transport, nautical cable and pipeline works for offshore.

NACE 45.24 Construction of water projects.

NACE 61.20 inland water transport (partly: sand and transport).

Inland Shipping: Inland shipping (dry cargo, liquid bulk, containers, special transport), river and harbour towage, freighting, inland cruises and ferries) NACE 61.20 Inland navigation. 
(Sea)ports: Cargo handling, shipping related storage, agency, maritime logistics and forwarding, port authorities, pilotage.

NACE 63.11 Cargo handling (partly).

NACE 63.22 Other supporting water transport activities (partly).

Fishing: Maritime fishing, professional inland fishing, shellfish production.

NACE 05.01 Fishing.

NACE 05.02 Fish Farming.

Water Recreation: Yacht construction (sporting, sailing and rowing boats, canoes, inflatable boats, floating sections).

Repair.

Yacht renting and catering.

NACE 35.12 shipbuilding pleasure boats (partly).

NACE 71.22 Renting of water transport equipment.

Maritime Services: bunkering, ship supply, rescue, diving, research and development, nautical training and education, maritime associations, maritime associations, maritime government services.

NACE 63.22 other' supporting water transport activities (partly).

Navy: (operations, maintenance, staff and administration, education and research).

NACE 75.22 Defence activities (partly). 


\section{Appendix 4: Round 1 Appreciation Letter}

\section{Dear $* * * * *$}

First, I would like to take this opportunity to thank you for agreeing to participate in the Delphi study survey on the Greater Dublin Region maritime transport sector. You're agreed participation and involvement is vital to the overall success of the research project.

As described in the first letter, the Delphi Study is a survey that is conducted over three rounds of questionnaires. The candidates are asked to try and finish the questionnaire and return it by post within three working weeks. I do realise that this may not always be possible for candidates. however if the responses are received in good time the whole Delphi process can be fulfilled quickly. Once all the responses have been returned. I as the Delphi facilitator can process the responses and formulate the second round questionnaire.

If at any time you have any concerns about the Delphi questionnaire or any questions about the research process please don't hesitate to contact me.

Thank you for your time and co-operation and looking forward to your response.

Kind Regards

Valerie Brett

National college of Ireland.

Mayor Street. IFSC.

Dublin 1.

014498547

vbrett@ncirl.ie 
Appendix 5: Delphi Round 1 Questionnaire

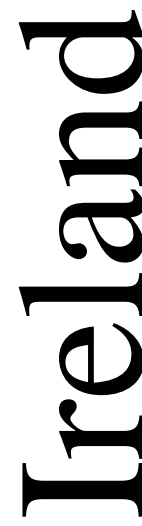

0

(1)

ob

(1)

파

0

(

 


\section{Delphi Questionnaire - Round 1}

\section{ALL ANSWERS MUST REFER TO THE IRISH TRANSPORT SECTOR ALL ANSWERS MUST PROVIDE AN EXPLANATION}

The purpose of the following questionnaire is to discuss the maritime transport sector in Ireland and more specifically the current clustering of the maritime transport sector in the greater Dublin region ${ }^{14}$. The term "cluster" or "clustering" is used in respect to the concentration of certain industry activities in a particular region or area.

A cluster can be defined as,

Spatially concentrated groups of firms in the same or related industries that are linked through vertical and horizontal relationships".

A maritime cluster for example can be defined as,

"A population of geography concentrated and mutually related business units, associates and public/pivate organisations centred on a distinctive economic specialization".

A maritime transport cluster is a population of related business units such as ship managers, shipbrokers, ship agency, stevedores, freight forwarders, chartering, shippers, ship operators, port authorities. consultants, maritime lawyers, ship financiers, marine insurers, government. maritime education and training along with associations and related public and private organisations.

it Refers to the area including Dublin city and all of the Counties of Dun Laoghaire/Rathdown. Fingal. Kildare. Meath. South Dublin and Wicklow as defined by the National Spatial Strategy (NSS) 2002 2020 . 


\section{Section 1}

Q1. Do you consider the greater Dublin region maritime transport sector as a maritime cluster?

Do you,

Agree

Disagree

Unable to comment

Please give an explanation for your answer

Q2. Do you believe the greater Dublin region maritime transport sector has the potential to move forward towards a more international recognisable cluster status?

Do you,

Agree Disagree Unable to comment

Please give an explanation for your answer

\section{Section 2}

Clusters occur for many reasons such as the primary availability of a particular resource (i.e. oil, metals, minerals or a specific labour supply) or the strategic location of a region (i.e. the port of Singapore). There are certain factors or criteria that can help to fuel the growth of a cluster, and the feature of access to an efficient and skilled labour force is just one of those features that can help or enhance cluster development. 
In the maritime transport sector there are two main types of maritime labour requirements, first the seafaring labour required to physically man and operate ships, and second the labour supply working in the maritime transport sector and related transport areas. Question 3 and 4 addresses the question of access to, and the quality of the onshore labour in the Irish maritime transport sector. Question 5 concerns the area of education and training of that labour for the maritime transport sector.

Q3. Do you believe there is a lack of sufficient onshore labour supply for any specific maritime transport sector in the greater Dublin region?

Do you,

Agree Disagree Unable to comment

Please give an explanation for your answer

Q4. Do you believe the current maritime transport labour supply is sufficient to meet the labour requirements of a growing maritime transport sector?

Do you,

Agree Disagree? Unable to comment

Please give an explanation for your answer 
Q5. Do you believe there are sufficient educational and training opportunities in Ireland to service the labour, skill and expertise required by various fields in the greater Dublin region maritime transport sector? Do you,

Agree

Disagree

Unable to comment

Please give an explanation for your answer

\section{Section 3}

An important part of cluster theory is the feature of location and the advantages of locating and operating inside a cluster and in co-proximity with other related firms.

Q6. Do you believe your business, firm or organisation would be at a disadvantage if located somewhere else within the country?

Do you,

Agree

Disagree

Unable to comment

Please give an explanation for your answer

Business and firms that locate within a cluster region have the benefit of being located where the cluster's knowledge is first developed and have greater access to the knowledge spillover affect. Therefore businesses, firms and organisations located in the relevant cluster region have earlier access to cluster knowledge as it flows easily locally, along with the benefit of being in close proximity to individual firm's competitor's and customers. The term cluster knowledge includes up to date market information, innovation and 
entrepreneurship created by the market player's inside the cluster as well as the benefits of chance meetings and the general knowledge created by the industry and the industry players. Question 7 addresses if the candidates consider that the greater Dublin region location provides advantages with respect to access to cluster knowledge.

Q7. Do you believe that the greater Dublin region location of your firm, business or organisation has the advantage of access to earlier cluster knowledge?

Do you,

Agree

Disagree

Unable to comment

\section{Please give an explanation for your answer}

\section{Section 4}

Clusters have both barriers to entry and barriers to exit. A cluster will want to have high exit barriers so that the cluster's infrastructure will make it hard for firms or business to leave and operate in competing clusters. A cluster will want to be "sticky" and aim to provide firms and business with resources that they would find hard to source elsewhere. Clusters will also want to have low barriers to entry as opposed to high barriers to entry (e.g. infrastructure, access the cluster knowledge and generally barriers that make it difficult for firms, business or organisations to relocate to the area), as low entry barrier's would make it easier for firms, business and organisations to relocate into a new cluster. 
Q8. Do you believe the greater Dublin region maritime transport sector has high barriers to entry?

Do you,

Agree

Disagree

Unable to comment

Please give an explanation for your answer

Q9. Do you believe that the greater Dublin region maritime transport sector has high exit barriers and that firms, business and organisations in the sector are "sticky" to the Dublin location?

Do you,

Agree

Disagree

Unable to comment

Please give an explanation for your answer

\section{Section 5}

The level of internal and external competition in a country and an individual sector is important to fuel a ribrant and competitive environment. If a firm within a cluster does not operate in a highly competitive and vibrant market place domestically, then firms can be at a disadvantage when competing with firms in an international market place who do operate in an active, vibrant and competitive workplace. 
Q10. Do you believe that the greater Dublin region maritime transport sector has a strong level of internal competition?

Do you,

Agree

Disagree

Unable to comment

Please give an explanation for your answer

Q11. Do you believe if the greater Dublin region maritime transport sector were a highly competitive and vibrant environment, Irish business and firms within the sector would be in a better position when competing internationally?

Do you,

Agree

Disagree

Unable to comment

Please give an explanation for your answer

\section{Section 6}

The mix and weight (different size) of firms operating and conducting business from within a cluster is an important agent in internationalising and strengthening a cluster from external shocks in a market place. As the earlier cluster definition described clusters combine "mutually related business units" and a maritime transport cluster includes industry sectors such as ship managers, ship brokers, ship agency, stevedores, freight forwarders, charters, shippers, ship operators, maritime lawyers and banking, marine consultants and insurers, industry and government organisation, ports and the port authorities. Therefore a good mix and 
weight and variety of firms operating within a cluster adds to the overall performance of a cluster and helps to internationalize a cluster.

Q12. Do you believe that the greater Dublin region maritime transport sector has a sufficient variety and diversity of maritime transport firms? Do you,

Agree Disagree Unable to comment

Please give an explanation for your answer

Q13. Do you think the greater Dublin region maritime transport sector would perform better if it had a greater variety and mix of maritime transport firms?

Do you,

Agree

Disagree

Unable to comment

Please give an explanation for your answer

Q14. Do you think your business, firm or organisation would benefit from a greater $\mathrm{mix}$ and diversity of maritime transport firms?

Do you,

Agree

Disagree

Unable to comment

Please give an explanation for your answer 


\section{Section 7}

Numerous amounts of firms operate within a cluster and each individual firm is operating within a competitive environment within the cluster i.e. regionally, nationally and internationally. It is important for firms to keep their competitive base but to also have a level of trust, interaction and $\mathrm{co}^{-}$ operation with the contemporary firms that operate within the cluster. Ideally a level of co-competition is required where firms maintain their competitiveness and co-operate on a level that benefits the whole cluster while still supporting their individual competitive needs. In order for $\mathrm{co}^{-}$ competition to develop there is the requirement of a good level of trust between the industry players.

Q15. Do you think there is a high level of trust between firms operating within the greater Dublin region maritime transport sector?

Do you,

$\begin{array}{lll}\text { Agree } & \text { Disagree Unable to comment }\end{array}$

\section{Please give an explanation for your answer}

\section{Section 8}

Clusters are internationally recognisable centres of excellence and one factor that helps in the process of internationalising a cluster is the residence of leader firms within a cluster. A firm in a cluster that functions as a leader firm is so called due the firms size and the firms strong market position within the domestic cluster and internationally. 
Q16. Do you think there is a lack of leader firms in the greater Dublin maritime transport sector?

Do you,

Agree

Disagree

Unable to comment

Please give an explanation for your answer

Q17. Do you think a lack of leader firms within the greater Dublin maritime sector is having a negative affect on the development of the greater Dublin region as a maritime transport cluster?

Do you,

Agree Disagree Unable to comment

Please give an explanation for your answer 
Appendix 6: Delphi Panel Member Information Document

The following information is kindly requested with respect to the current Delphi survey.

Background knowledge of individual participants can help to understand where possible answers are sourced.

- Name:

- Company:

- Current Position:

- Membership of Transport or Associated Organisations:

- Brief Summary of Transport Work Experience:

Which of the following activities does your business, firm or organisation belong to? (You can tick more than one box if applicable. If you tick other please describe the reason for your answer).

\section{Sector Definition}

Port

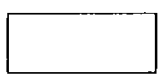

Freight Forwarder

Marine Finance

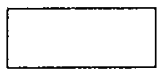

Marine Insurance
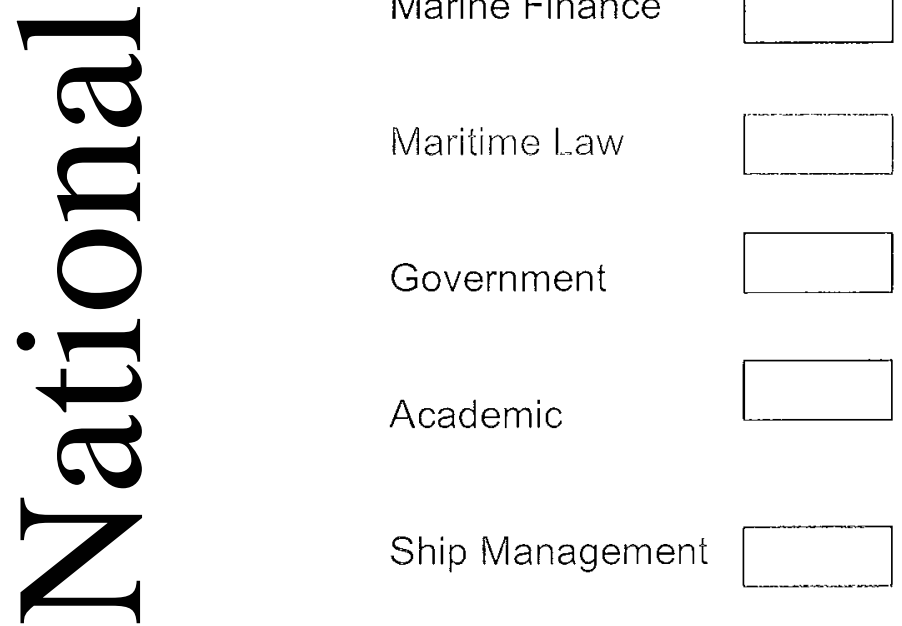

Stevedore

Maritime Law

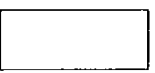

Industry Organisation

Government

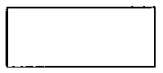

Consultant

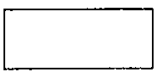

Academic

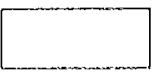

Shipowner / Operator

Ship Management

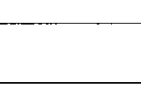

Other
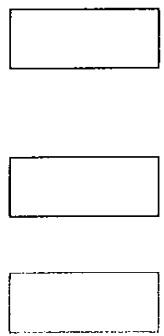

Agency 
If ticked the "other" box please provide an explanation

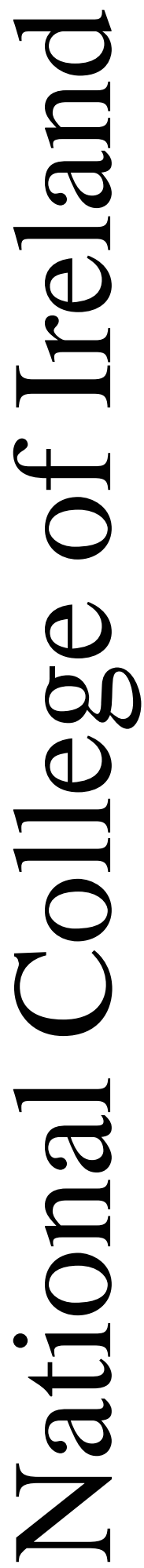




\section{Appendix 7: Delphi Round 2 Questionnaire}
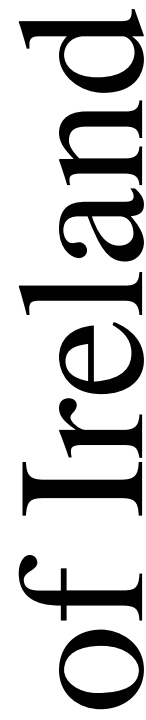

(1)

of

(1)

r

0

(

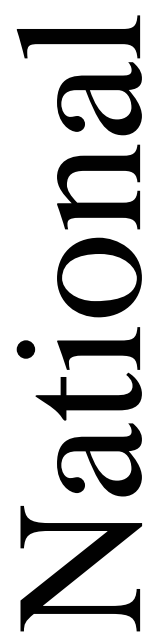


PLEASE NOTE THE NAMES OF THE PARTICPANTS IN THIS DELPHI SURVEY ARE CONFIDENTIAL AND WILL NOT BE MADE AVAILABLE OR PUBLISHED AT ANY TIME.

\section{Name:}

\section{Company:}

\section{PLEASE NOTE THE FOLLOWING:}

- There are a total of 14 questions in Round 2 of the Delphi Study Survey.

- Question that achieved a result consensus of over 70\% (from Round 1) are not included in the second round.

- Candidates are asked to read the feedback provided from Delphi Round 1 statements (in document 2) before proceeding to answer the Delphi Round 2 statements.

- Candidates are asked to read the feedback provided and to answer the questions.

Thank you very much on your co-operation......... 


\section{Section 1}

In Section 1 of the Delphi Round 1 Survey, respondents were asked if they considered that the greater Dublin region maritime transport sector had the potential to move towards a more international recognisable cluster status.

\section{The Response from Round 1, Section 1, Question 2}

The majority of the response for Round 1, Section 1, Question 2 shows an agreement result of $59 \%$.

Result: Agreement Consensus of 59\%

\begin{tabular}{|l|l|l|l|l|l|l|}
\hline No & Delphi Statement Round 1 & Agree & Disagree & $\begin{array}{l}\text { Unable to } \\
\text { Comment }\end{array}$ & Total & $\%$ \\
\hline Q2 & $\begin{array}{l}\text { Do you believe the greater } \\
\text { Dublin region maritime transport } \\
\text { sector has the potential to move } \\
\text { forward towards a more } \\
\text { international recognisable cluster } \\
\text { status? }\end{array}$ & 10 & 5 & 37 & $59 \%$ \\
\hline
\end{tabular}

Please read the feedback summary in document 2 (page 2 ), under Round 1, Section 1, Question 2, and answer Question 1 below.

\section{DELPHI ROUND 2}

Q1. Do you believe the greater Dublin region maritime transport sector has the potential to move forward towards a more international recognisable cluster status?

Do you?
Agree
Disagree
Unable to Comment

\section{Please give an explanation for your answer}

\section{Section 2}

Section 2 of the Delphi Round 1 Survey addressed the area of the onshore labour supply for the greater Dublin region and the education and training available for that specific labour pool. 


\section{The Response from Round 1, Section 2, Question 3}

The majority of the response for Round 1. Section 2, Question 3 shows an agreement result of $49 \%$.

Result: Agreement Consensus of 49\%

\begin{tabular}{|l|l|l|l|l|l|l|}
\hline No & Delphi Statement Round 1 & Agree & Disagree & $\begin{array}{l}\text { Unable to } \\
\text { Comment }\end{array}$ & Total & $\%$ \\
\hline Q3 & $\begin{array}{l}\text { Do you believe that there is a lack of } \\
\text { sufficient onshore labour supply for any } \\
\text { specific maritime transport sector in the } \\
\text { greater Dublin region? }\end{array}$ & 18 & 6 & 37 & $49 \%$ \\
\hline
\end{tabular}

Please read the feedback summary in document 2 (page 3 ), under Round 1, Section 1, Question 3, and answer Question 2 and $2 \mathrm{~A}$ below.

\section{DELPHI ROUND 2}

Q2. Do you believe that there is a lack of sufficient onshore labour supply for any specific maritime transport sector in the greater Dublin region?

Do you?
Agree
Disagree
Unable to Comment

\section{Please give an explanation for your answer}

Q2A. Do you believe that there is lack of management personnel with relative industry experience available to be sourced for the onshore labour supply in Ireland?

Do you.
Agree
Disagree
Unable to Comment

\section{Please give an explanation for your answer}




\section{The Response from Round 1, Section 2, Question 4}

The majority of the response for Round 1, Section 2, Question 4 shows a disagreement result of $49 \%$.

Result: Disagreement Consensus of $49 \%$

\begin{tabular}{|l|l|l|l|l|l|l|}
\hline No & Delphi Statement Round 1 & Agree & Disagree & $\begin{array}{l}\text { Unable to } \\
\text { Comment }\end{array}$ & Total & $\%$ \\
\hline Q4 & $\begin{array}{l}\text { Do you believe the current maritime } \\
\text { transport labour supply is sufficient to } \\
\text { meet the labour requirements of a } \\
\text { growing maritime transport sector? }\end{array}$ & 13 & 18 & 6 & 37 & $49 \%$ \\
\hline
\end{tabular}

Please read the feedback summary in document 2(page 5), under Round 1, Section 2, Question 4, and answer Question 3 below.

\section{DELPHI ROUND 2}

Q3. Do you believe that the current maritime transport labour supply is sufficient to meet the labour requirements of a growing maritime transport sector?

Do you.
Agree
Disagree
Unable to Comment

Please give an explanation for your answer

\section{The Response from Round 1, Section 2, Question 5}

The majority of the response for Round 1. Section 2. Question 5 shows a disagreement result of $46 \%$.

Result: Disagreement Consensus of $46 \%$

\begin{tabular}{|l|l|l|l|l|l|l|}
\hline No & Delphi Statement Round 1 & Agree & Disagree & $\begin{array}{l}\text { Unable to } \\
\text { Comment }\end{array}$ & Total & $\%$ \\
\hline Q5 & $\begin{array}{l}\text { Do you believe there are sufficient } \\
\text { educational and training opportunities } \\
\text { in Ireland to service the labour. skill } \\
\text { and expertise required by various fields } \\
\text { in greater Dublin region maritime } \\
\text { transport sector? }\end{array}$ & 15 & 5 & 34 & $46 \%$ \\
\hline
\end{tabular}


Please read the feedback summary in document 2 (page 5), under Round 1, Section 2, Question 5, and answer Question 4 and question 4A below.

\section{DELPHI ROUND 2}

Q.4. Do you believe there are sufficient educational and training opportunities in Ireland to service the labour, skill and expertise required by various fields in the greater Dublin region maritime transport sector?

Do you,
Agree
Disagree
Unable to Comment

\section{Please give an explanation for your answer}

Q4A. Do you believe that there is a lack of promotion and awareness of the career options available in the maritime transport sector in Ireland?

Do you,
Agree
Disagree
Unable to Comment

Please give an explanation for your answer 


\section{Section 3}

Section 3 of the Round 1 Delphi Survey addressed the possible advantage of a business, firm or organisation location within the greater Dublin region and the possible advantage and availability of industry knowledge inside the greater Dublin region.

\section{The Response from Round 1, Section 3, Question 7}

The majority of the response for Round 1, Section 3, Question 6 shows an agreement result of 49\%. Result: Agreement Consensus of 49\%

\begin{tabular}{|l|l|l|l|l|l|l|}
\hline No & Delphi Statement Round 1 & Agree & Disagree & $\begin{array}{l}\text { Unable to } \\
\text { Comment }\end{array}$ & Total & $\%$ \\
\hline Q7 & $\begin{array}{l}\text { Do you believe that the greater } \\
\text { Dublin region location of your } \\
\text { firm, business or organisation } \\
\text { has the advantage of access to } \\
\text { earlier cluster knowledge? }\end{array}$ & 18 & 13 & 6 & 37 & $49 \%$ \\
\hline
\end{tabular}

Please read the feedback summary in document 2 (page 7), under Round 1, Section 3, Question 7, and answer Question 5 below.

\section{DELPHI ROUND 2}

Q5. Do you believe that firms, businesses or organisations located in the greater Dublin region have the advantage of access to earlier industry knowledge?

Do you.
Agree
Disagree
Unable to Comment

\section{Please give an explanation for your answer}

\section{Section 4}

Section 4 of the Delphi Round 1 Survey addressed the issue of the barriers to entry and exit of a cluster and the level of stickiness firms might have to the greater Dublin region location. 


\section{The Response from Round 1, Section 4, Question 8}

The majority of the response for Round 1, Section 4, Question 8 shows a disagreement result of $41 \%$.

\section{Result: Disagreement Consensus of $41 \%$}

\begin{tabular}{|c|c|c|c|c|c|c|}
\hline No & Delphi Statement Round 1 & Agree & Disagree & $\begin{array}{l}\text { Unable to } \\
\text { Comment }\end{array}$ & Total & $\%$ \\
\hline$\overline{Q 8}$ & $\begin{array}{l}\text { Do you believe the greater } \\
\text { Dublin region maritime } \\
\text { transport sector has high } \\
\text { barriers to entry? }\end{array}$ & 14 & 15 & 8 & 37 & $41 \%$ \\
\hline
\end{tabular}

Please read the feedback summary in document 2(page 8), under Round 1, Section 4, Question 8, and answer Question 6 below.

\section{DELPHI ROUND 2}

Q6. Do you believe the greater Dublin region maritime transport sector has high barriers to entry?

Do you,
Agree
Disagree
Unable to Comment

\section{Please give an explanation for your answer}

\section{The Response from Round 1, Section 4, Question 9}

The majority of the response for Round 1. Section 4. Question 9 shows a disagreement result of $41 \%$.

Result: Disagreement Consensus of $41 \%$

\begin{tabular}{|l|l|l|l|l|l|l|}
\hline No & Delphi Statement Round 1 & Agree & Disagree & $\begin{array}{l}\text { Unable to } \\
\text { Comment }\end{array}$ & Total & $\%$ \\
\hline Q9 & $\begin{array}{l}\text { Do you believe that the greater } \\
\text { Dublin region maritime transport } \\
\text { sector has high exit barriers and } \\
\text { that firms business and } \\
\text { organisations in the sector are } \\
\text { "sticky" to the Dublin location? }\end{array}$ & 13 & 14 & 10 & 37 & $41 \%$ \\
\hline
\end{tabular}


Please read the feedback summary in document 2(page 9), under Round 1, Section 4, Question 9, and answer Question 7 below.

\section{DELPHI ROUND 2}

Q7. Do you believe that the greater Dublin region maritime transport sector has high exit barriers and that firms, businesses and organisations in the sector are "sticky" to the Dublin location?

Do you,
Agree
Disagree
Unable to Comment

\section{Please give an explanation for your answer}

\section{Section 5}

Section 5 of Round 1 of the Delphi survey addressed the issue of the level and application of internal competition.

\section{The Response from Round 1, Section 5, Question 11}

The majority of the response for Round 1. Section 5. Question 11 shows an agreement result of $65 \%$

\section{Result: Agreement Consensus of $65 \%$}

\begin{tabular}{|l|l|l|l|l|l|l|}
\hline No & Delphi Statement Round 1 & Agree & Disagree & $\begin{array}{l}\text { Unable to } \\
\text { Comment }\end{array}$ & Total & $\%$ \\
\hline $\begin{array}{l}\text { Q11 } \\
\text { Doblin region maritime gransport } \\
\text { sector were a highly competitive } \\
\text { and vibrant environment. Irish } \\
\text { business and firms within the } \\
\text { sector would be in a better } \\
\text { position when competing } \\
\text { internationally? }\end{array}$ & 24 & 2 & 11 & 37 & $65 \%$ \\
\hline
\end{tabular}

Please read the feedback summary in document 2 (page 10 ), under

Round $\mathbb{1}$, Section 5 , Question $\mathbb{1 1}$, and answer Question 8 below. 


\section{DELPHI ROUND 2}

Q8. Do you believe if the greater Dublin region maritime transport sector were a highly competitive and vibrant environment, Irish business and firms within the sector would be in a better position when competing internationally?

Do you,
Agree
Disagree
Unable to Comment

\section{Please give an explanation for your answer}

\section{Section 6}

Section 6 of the Round 1 Delphi Survey addressed the issue of the mix and variety of firms available and currently operating in the greater Dublin region maritime transport sector.

\section{The Response from Round 1, Section 6, Question 12}

The majority of the response for Round 1, Section 6. Question 12 shows an agreement result of $59 \%$.

Result: Agreement Consensus of 59\%

\begin{tabular}{|l|l|l|l|l|l|l|}
\hline No & Delphi Statement Round 1 & Agree & Disagree & $\begin{array}{l}\text { Unable to } \\
\text { Comment }\end{array}$ & Total & $\%$ \\
\hline Q12 & $\begin{array}{l}\text { Do you believe that the greater } \\
\text { Dublin region maritime } \\
\text { transport sector has a sufficient } \\
\text { variety and diversity of } \\
\text { maritime transport firms? }\end{array}$ & 22 & 13 & 2 & 37 & $59 \%$ \\
\hline
\end{tabular}

Please read the feedback summary in document 2 (page $\mathbb{1} 1$ ), under Round 1, Section 6, Question 12, and answer Question 9 below.

\section{DELPHI ROUND 2}

Q9. Do you believe that the greater Dublin region maritime transport sector has a sufficient variety and diversity of maritime transport firms?

Do you.

Agree

Disagree

\section{Please give an explanation for your answer}




\section{The Response from Round 1, Section 6, Question 13}

The majority of the response for Round 1, Section 6, Question 13 shows an agreement result of $54 \%$.

\section{Result: Agreement Consensus of 54\%}

\begin{tabular}{|l|l|l|l|l|l|l|}
\hline No & Delphi Statement Round 1 & Agree & Disagree & $\begin{array}{l}\text { Unable to } \\
\text { Comment }\end{array}$ & Total & $\%$ \\
\hline Q13 & $\begin{array}{l}\text { Do you think the greater Dublin } \\
\text { region maritime transport sector } \\
\text { would perform better if it had a } \\
\text { greater variety and mix of } \\
\text { maritime transport firms? }\end{array}$ & 20 & 14 & 3 & 37 & $54 \%$ \\
\hline
\end{tabular}

Please read the feedback summary in document 2 (page 12), under Round 1, Section 6, Question 13 and answer Question 10 below.

\section{DELPHI ROUND 2}

Q10. Do you think the greater Dublin region maritime transport sector would perform better if it had a greater variety and mix of maritime transport firms?

Do you.
Agree
Disagree
Unable to Comment

Please give an explanation for your answer

\section{The Response from Round 1, Section 6, Question 14}

The majority of the response for Round 1. Section 6. Question 13 shows a disagreement result of $43 \%$.

Result: Disagreement Consensus of $43 \%$

\begin{tabular}{|c|c|c|c|c|c|c|}
\hline $\mathbb{N}_{0}$ & Delphi Statement Round 1 & Agree & Disagree & $\begin{array}{l}\text { Unable to } \\
\text { Comment }\end{array}$ & Total & $\%$ \\
\hline $\mathbb{Q} 14$ & $\begin{array}{l}\text { Do you think your business. } \\
\text { firm or organisation would }\end{array}$ & 16 & 15 & 6 & 37 & $43 \%$ \\
\hline
\end{tabular}




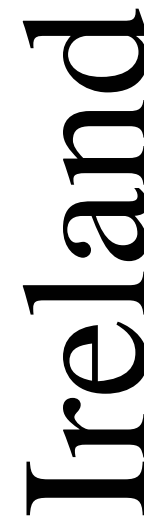

\begin{tabular}{|l|l|l|l|l|l|}
\hline $\begin{array}{l}\text { benefit from a greater mix and } \\
\text { diversity of maritime transport } \\
\text { firms? }\end{array}$ & & & & & \\
\hline
\end{tabular}

Please read the feedback summary in document 2 (page 13), under Round 1, Section 6, Question 14, and answer Question 11 below.

\section{DELPHI ROUND 2}

Q11. Do you think your business, firm or organisation would benefit from a greater mix and diversity of maritime transport firms?

Do you,
Agree
Disagree
Unable to Comment

Please give an explanation for your answer

\section{Section 7}

Section 7 of the Round 1 Delphi Survey addressed the issue of trust greater Dublin region maritime transport sector.

\section{The Response from Round 1, Section 7, Question 15}

The majority of the response for Round 1. Section 7. Question 15 shows a disagreement result of $41 \%$.

Result: Disagreement Consensus of $41 \%$

\begin{tabular}{|l|l|l|l|l|l|l|}
\hline No & Delphi Statement Round 1 & Agree & Disagree & $\begin{array}{l}\text { Unable to } \\
\text { Comment }\end{array}$ & Total & $\%$ \\
\hline Q15 & $\begin{array}{l}\text { Do you think there is a high } \\
\text { level of trust between firms } \\
\text { operating within the greater } \\
\text { Dublin region maritime } \\
\text { transport sector? }\end{array}$ & 12 & 10 & 37 & $41 \%$ \\
\hline
\end{tabular}

Please read the feedback summary in document 2 (page 14), under Round 1, Section 7, Question 15, and answer Question 12 below. 


\section{DELPHI ROUND 2}

Q12. Do you think there is a high level of trust between firms operating within the greater Dublin region maritime transport sector?

Do you.
Agree
Disagree
Unable to Comment

Please give an explanation for your answer

\section{Section 8}

Section 8 of the Round I Delphi Survey addressed the topic of leader firms.

\section{The Response from Round 1, Section 8, Question 16}

The majority of the response for Round 1, Section 7, Question 16 shows an agreement result of $54 \%$.

Result: Agree Consensus of 54\%

\begin{tabular}{|l|l|l|l|l|l|l|}
\hline No & Delphi Statement Round 1 & Agree & Disagree & $\begin{array}{l}\text { Unable to } \\
\text { Comment }\end{array}$ & Total & $\%$ \\
\hline Q16 & $\begin{array}{l}\text { Do you think there is a lack of } \\
\text { leader firms in the greater } \\
\text { Dublin maritime transport } \\
\text { sector? }\end{array}$ & 20 & 11 & 6 & 37 & $54 \%$ \\
\hline
\end{tabular}

Please read the feedback summary in document 2 (page 15), under Round 11 , Section 8 , Question 16, and answer Question 13 below.

DELPHI ROUND 2

Q13. Do you think there is a lack of leader firms in the greater Dublin maritime transport sector?

Do you.
Agree
Disagree
Unable to Comment

Please give an explanation for your answer 


\section{The Response from Round 1, Section 8, Question 17}

The majority of the response for Round 1, Section 8, Question 17 shows an agreement result of $41 \%$

\section{Result: Agree Consensus of $41 \%$}

\begin{tabular}{|l|l|l|l|l|l|l|}
\hline No & Delphi Statement Round 1 & Agree & Disagree & $\begin{array}{l}\text { Unable to } \\
\text { Comment }\end{array}$ & Total & $\%$ \\
\hline Q17 & $\begin{array}{l}\text { Do you think a lack of leader } \\
\text { firms within the greater Dublin } \\
\text { maritime sector is having a } \\
\text { negative affect on the } \\
\text { development of the greater } \\
\text { Dublin region as a maritime } \\
\text { transport cluster? }\end{array}$ & 10 & 12 & 37 & $41 \%$ \\
\hline
\end{tabular}

Please read the feedback summary in document 2 (page16), under Round 1, Section 8, Question 17 and, answer Question 14 below.

\section{DELPHI ROUND 2}

Q14. Do you think a lack of leader firms within the greater Dublin maritime sector is having a negative affect on the development of the greater Dublin region as a maritime transport cluster?

Do you.
Agree
Disagree
Unable to Comment

\section{Please give an explanation for your answer}


Appendix 8: Delphi Round 3 Questionnaire

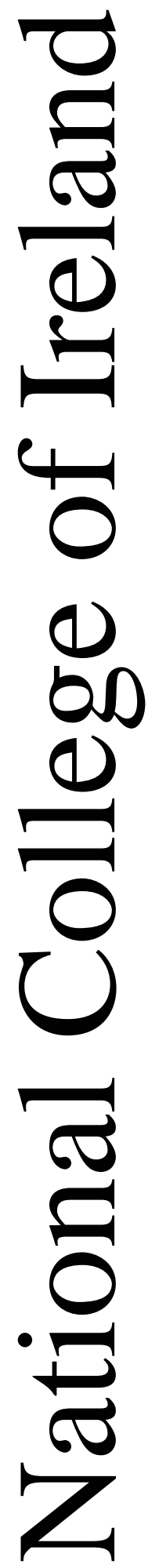




\section{Document 1: Delphi Round 3 Questionnaire}

PLEASE NOTE THE NAMES OF THE PARTICPANTS IN THIS DELPHI SURVEY ARE CONFIDENTIAL AND WILL NOT BE MADE AVAILABLE OR PUBLISHED AT ANY TIME.

Name:

Company:

PLEASE NOTE THE FOLLOWING:

- This is the final round of the Delphi and the last questionnaire you will receive.

- Questions that achieved a result consensus of over 70\% (from Round 2) are not included in the third round.

- Candidates are asked to read the feedback provided from Delphi Round 2 statements (in document 2) before proceeding to answer the Delphi Round 3 questions contain in this document (document 1).

- Candidates are asked to read the feedback provided and to answer the questions.

a There are a total of 9 questions in round 3.

Thank you very much on your' co-operation.......... 


\section{Section 1}

All questions in Section 1 reached a consensus of over $70 \%$ and therefore there are no questions in Round 3, Section I.

\section{Section 2}

Section 2 of the Delphi Round 2 Survey addressed the area of the onshore labour supply for the greater Dublin region and the education and training available for that specific labour pool.

\section{The Response from Round 2, Section 2, Question 2}

The majority of the response for Round 2, Section 2, Question 2 shows a disagreement result of $50 \%$.

Result: Disagreement Consensus of 50\%

\begin{tabular}{|l|l|l|l|l|l|l|}
\hline No & Delphi Statement Round 2 & Agree & Disagree & $\begin{array}{l}\text { Unable to } \\
\text { Comment }\end{array}$ & Total & $\%$ \\
\hline Q2 & $\begin{array}{l}\text { Do you believe that there is a lack of } \\
\text { sufficient onshore labour supply for any } \\
\text { specific maritime transport sector in the } \\
\text { greater Dublin region? }\end{array}$ & 9 & 11 & 2 & 22 & $50 \%$ \\
\hline
\end{tabular}

Please read the feedback summary in document 2 under Round $\mathbf{2}$, Section 2, Question 2 (page 2) and answer Question 1 below.

\section{DELPHI ROUND 3}

Q1. Do you believe that there is a lack of sufficient onshore labour supply for any specific maritime transport sector in the greater Dublin region?

Do you.
Agree
Disagree
Unable to Comment

\section{Please give an explanation for your answer}

\section{The Response from Round 2, Section 2, Question 2A}

The majority of the response for Round 2. Section 2. Question 2A shows an agreement result of $45 \%$. 
Result: Agreement Consensus of 45\%
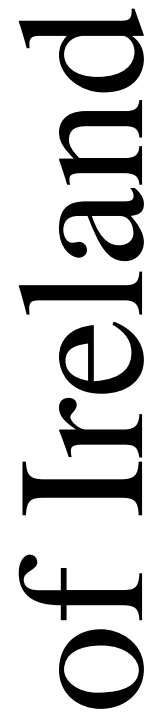

(1)

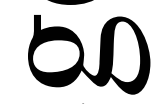

(1)
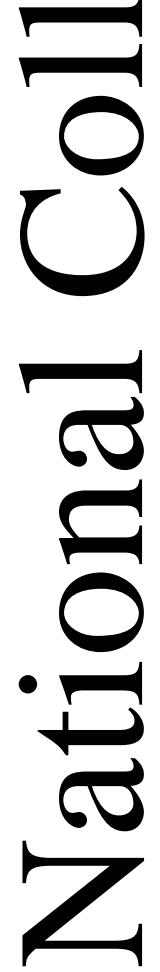

\begin{tabular}{|l|l|l|l|l|l|l|}
\hline No & Delphi Statement Round 2 & Agree & Disagree & $\begin{array}{l}\text { Unable to } \\
\text { Comment }\end{array}$ & Total & $\%$ \\
\hline Q2A & $\begin{array}{l}\text { Do you believe that there is lack of } \\
\text { management personnel with relative } \\
\text { industry experience available to be } \\
\text { sourced for the onshore labour supply in } \\
\text { Ireland? }\end{array}$ & 6 & 6 & 22 & $45 \%$ \\
\hline
\end{tabular}

Please read the feedback summary in document 2 under Round 2, Section 2, Question 2A (page 3), and answer Question 2 below.

\section{DELPHI ROUND 3}

Q2. Do you believe that there is lack of management personnel with relative industry experience available to be sourced for the onshore labour supply in Ireland?

Do you,
Agree
Disagree
Unable to Comment

\section{Please give an explanation for your answer}

\section{The Response from Round 2, Section 2, Question 3}

The majority of the response for Round 2. Section 2. Question 5 shows a disagreement result of $50 \%$.

Result: Disagreement Consensus of $50 \%$

\begin{tabular}{|c|c|c|c|c|c|c|}
\hline No & Delphi Statement $\mathbb{R o u n d} 2$ & Agree & Disagree & $\begin{array}{l}\text { Unable to } \\
\text { Comment }\end{array}$ & Total & $\%$ \\
\hline $\mathbb{Q} 3$ & $\begin{array}{l}\text { Do you believe that the current maritime } \\
\text { transport labour supply is sufficient to } \\
\text { meet the labour requirements of a growing } \\
\text { maritime transport sector? }\end{array}$ & 10 & 11 & 1 & 22 & $50 \%$ \\
\hline
\end{tabular}

Please read the feedback summary in document $\mathbb{1}$ under $\mathbb{R}$ ound 2 , Section 2, Question 3 (page 5), and answer Question 3 below. 


\section{DELPHI ROUND 3}

Q3. Do you believe that the current maritime transport labour supply is sufficient to meet the labour requirements of a growing maritime transport sector?

Do you,
Agree
Disagree
Unable to Comment

\section{Please give an explanation for your answer}

\section{The Response from Round 2, Section 2, Question 4}

The majority of the response for Round 2, Section 2, Question 4 shows an agreement result of $59 \%$.

Result: Agreement Consensus of 59\%

\begin{tabular}{|l|l|l|l|l|l|l|}
\hline No & Delphi Statement Round 2 & Agree & Disagree & $\begin{array}{l}\text { Unable to } \\
\text { Comment }\end{array}$ & Total & \% \\
\hline Q4 & $\begin{array}{l}\text { Do you believe there are sufficient } \\
\text { educational and training opportunities in }\end{array}$ & 13 & 9 & 0 & 22 & $59 \%$ \\
$\begin{array}{l}\text { Ireland to service the labour, skill and } \\
\text { expertise required by various fields in the } \\
\text { greater Dublin region maritime transport } \\
\text { sector? }\end{array}$ & & & & & & \\
\hline
\end{tabular}

Please read the feedback summary in document 1 under $\mathbb{R}$ ound 2 , Section 2, Question 4 (page 6), and answer Question 4 below. 


\section{DELPHI ROUND 3}

Q4. Do you believe there are sufficient educational and training opportunities in Ireland to service the labour, skill and expertise required by various fields in the greater Dublin region maritime transport sector?

Do you,
Agree
Disagree
Unable to Comment

\section{Please give an explanation for your answer}

\section{Section 3}

All questions in Section 3 reached a consensus of over $70 \%$ and therefore there are no questions in Round 3 Section 3.

\section{Section 4}

Section 4 of the Delphi Round 2 Survey addressed the issue of the barriers to entry and exit of a cluster and the level of stickiness firms might have to the greater Dublin region location.

\section{The Response from Round 2, Section 4, Question 6}

The majority of the response for Round 2. Section 2. Question 6 shows an agreement result of $45 \%$.

Result: Agreement Consensus of 45\%

\begin{tabular}{|l|l|l|l|l|l|l|}
\hline No & Delphi Statement Round 2 & Agree & Disagrec & $\begin{array}{l}\text { Unable to } \\
\text { Comment }\end{array}$ & Total & $\%$ \\
\hline Q6 & $\begin{array}{l}\text { Do you believe that the greater Dublin } \\
\text { region maritime transport sector has high } \\
\text { barriers of entry? }\end{array}$ & 10 & 9 & 3 & 22 & $45 \%$ \\
\hline
\end{tabular}

Please read the feedback summary in document 1 under $\mathbb{R}$ ound 2 , Section 4, Question 6 (page 8), and answer Question 5 below. 


\section{DELPHI ROUND 3}

Q5. Do you believe that the greater Dublin region maritime transport sector has high barriers of entry?

Do you,
Agree
Disagree
Unable to Comment

\section{Please give an explanation for your answer}

\section{Section 5}

All questions in Section 5 reached a consensus of over $70 \%$ and therefore there are no questions in Round 3, Section 5.

\section{Section 6}

Section 6 of the Round 2 Delphi Survey addressed the issue of the mix and variety of firms available and currently operating in the greater Dublin region maritime transport sector.

\section{The Response from Round 2, Section 6, Question 11}

The majority of the response for Round 2. Section 6 Question 11 shows an agreement result of $68 \%$.

Result: Agreement Consensus of $68 \%$

\begin{tabular}{|l|l|l|l|l|l|l|}
\hline No & Delphi Statement Round 2 & Agree & Disagrce & $\begin{array}{l}\text { Unable ro } \\
\text { Comment }\end{array}$ & Total & $\%$ \\
\hline Q11 & $\begin{array}{l}\text { Do you think your business. firm or } \\
\text { organisation would benefit from a } \\
\text { greater mix and diversity of maritime } \\
\text { transport firms? }\end{array}$ & 5 & 2 & 22 & $68 \%$ \\
\hline
\end{tabular}

Please read the feedback summary in document $\mathbb{1}$ under $\mathbb{R}$ ound 2 , Section 6, Question 11 (page 9), and answer Question 6 below. 


\section{DELPHI ROUND 3}

Q6. Do you think your business, firm or organisation would benefit from a greater mix and diversity of maritime transport firms?

Do you,

Agree

Disagree

Unable to Comment

\section{Please give an explanation for your answer}

\section{Section 7}

Section 7 of the Round 2 Delphi Survey addressed the issue of trust greater Dublin region maritime transport sector.

\section{The Response from Round 2, Section 7, Question 12}

The majority of the response for Round 2. Section 7, Question 12 shows a disagreement result of $59 \%$.

Result: Disagreement Consensus of 59\%

\begin{tabular}{|l|l|l|l|l|l|l|}
\hline No & Delphi Statement Round 2 & Agree & Disagree & $\begin{array}{l}\text { Unable to } \\
\text { Comment }\end{array}$ & Total & $\%$ \\
\hline Q12 & $\begin{array}{l}\text { Do you think there is a high level of } \\
\text { trust between firms operating within the } \\
\text { greater Dublin region maritime transport } \\
\text { sector? }\end{array}$ & 5 & 13 & 4 & 22 & $59 \%$ \\
\hline
\end{tabular}

Please read the feedback summany in document 1 under Round 2 , Section 7, Question 12 (page 11), and answer Question 7 bellow.

\section{DELPHI ROUND 3}

Q7. Do you think there is a high level of trust between firms operating within the greater Dublin region maritime transport sector?

Do you.
Agree
Disagree
Unable to Comment

\section{Please give an explanation for your answer}




\section{Section 8}

Section 8 of the Round 2 Delphi Survey addressed the topic of leader firms.

\section{The Response from Round 2, Section 8, Question 13}

The majority of the response for Round 2. Section 8, Question 13 shows an agreement result of $54 \%$.

Result: Agreement Consensus of 54\%

\begin{tabular}{|l|l|l|l|l|l|l|}
\hline No & Delphi Statement Round 2 & Agree & Disagree & $\begin{array}{l}\text { Unable to } \\
\text { Comment }\end{array}$ & Total & \% \\
\hline Q13 & $\begin{array}{l}\text { Do you think there is a lack of leader } \\
\text { firms in the greater Dublin maritime } \\
\text { transport sector? }\end{array}$ & 12 & 8 & 2 & 22 & $54 \%$ \\
\hline
\end{tabular}

Please read the feedback summary in document 1 under Round 2 , Section 8, Question 13(page 12), and answer Question 8 below.

\section{DELPHI ROUND 3}

Q8. Do you think there is a lack of leader firms in the greater Dublin maritime transport sector?

Do you.
Agree
Disagree
Unable to Comment

\section{Please give an explanation for your answer}

\section{The Response from Round 2, Section 8, Question 14}

The majority of the response for Round 2. Section 8. Question 14 shows an agreement result of $59 \%$.

Result: Agreement Consensus of $59 \%$

\begin{tabular}{|l|l|l|l|l|l|l|}
\hline No & Delphi Statement Round 2 & Agree & Disagree & $\begin{array}{l}\text { Unable to } \\
\text { Comment }\end{array}$ & Total & $\%$ \\
\hline
\end{tabular}




\begin{tabular}{|l|l|l|l|l|l|l|}
\hline Q14 & $\begin{array}{l}\text { Do you think a lack of leader firms } \\
\text { within the greater Dublin maritime } \\
\text { sector is having a negative affect on } \\
\text { the development of the greater Dublin } \\
\text { region as a maritime transport } \\
\text { cluster? }\end{array}$
\end{tabular}

Please read the feedback summary in document 1 under Round 2, Section 8, Question 14(page 14), and answer Question 9 below.

\section{DELPHI ROUND 3}

Q9. Do you think a lack of leader firms within the greater Dublin maritime sector is having a negative affect on the development of the greater Dublin region as a maritime transport cluster?

Do you,

Agree

Disagree

Unable to Comment

\section{Please give an explanation for your answer}

